\title{
Scientific Research and Experimental Development (SR\&ED) Engagement and Management by Small Canadian-Controlled Private Corporations (CCPCs)
}

by

\section{Lucille Perreault}

A thesis submitted to the Faculty of Graduate and Postdoctoral Affairs in partial fulfillment of the requirements for the degree of

Doctor of Philosophy

in

Management

Carleton University

Ottawa, Ontario

(C) 2020

Lucille Perreault 


\begin{abstract}
Innovation plays a vital role in the growth of an economy. Spending on research and development (R\&D) is an important determinant of the innovation process. Engaging in R\&D can be considered risky for firms as there is no guarantee that there will be a positive return and concerns of competitors imitating a successful innovation. As a result, firms may be reluctant to engage in R\&D. These challenges may be especially acute for small Canadiancontrolled private corporations (CCPCs), who may not have the same access to resources and expertise as larger firms. Given the importance of innovation for growth, governments seek to intervene to fix the R\&D under-investment issue through grants, loans, or tax incentives.
\end{abstract}

Since 1944, the Canadian government has used the Income Tax Act and R\&D tax incentives to stimulate scientific research activity. The incentives have evolved, and since 1985, the primary mechanism used in Canada to encourage R\&D is the Scientific Research and Experimental Development (SR\&ED) program. The SR\&ED program comprises tax deductions and an investment tax credit with differing rates for smaller CCPCs, individuals, and larger corporations.

Traditional research in $R \& D$ and tax incentives has evaluated whether the incentives displace private R\&D activities (crowding-out) or induce increased R\&D expenditures and projects (additionality). There was little understanding of why CCPCs engage in R\&D and how they manage their R\&D practices. In order to better understand the motivation to engage in R\&D 
and how small CCPCs manage their R\&D practices in the context of the SR\&ED program, the research design includes semi-structured interviews with 18 small CCPCs.

This study finds that firms that engage in R\&D are more likely to have an internal context that has values and a strategic orientation to develop innovation. The decision to engage in $R \& D$ is also influenced by the product lifecycle, resources, systems, and processes constraints. In contrast, the R\&D management practices are influenced by the external environment. The findings of this study provide insight into the motivation to apply for the SR\&ED program and the influence the program has on $R \& D$ behaviour within a small CCPC. 


\section{ACKNOWLEDGEMENTS}

I would like to express my gratitude to my research supervisor, Francois Brouard, for his support, guidance, and encouragement throughout my Ph.D. journey. Francois was instrumental in defining the path of my research, and I appreciate all the feedback provided throughout the process.

I would like to thank the other members of my thesis committee, Merridee Bujaki, Gerald Grant, Margaret Dalziel, and Frances Woolley. I would also like to thank the economic development organizations, associations, firms, and their leadership; their assistance was invaluable to this study. I appreciate the interview participants' enthusiasm for this subject and giving me time from their busy days for an interview.

Finally, I would like to express my deepest gratitude to my husband Larry and my children Alexandre, Julia, Brianna, Philippe, and Domonique. Without their love, patience, encouragement, and support, this thesis would not have been possible. 


\section{TABLE OF CONTENTS}

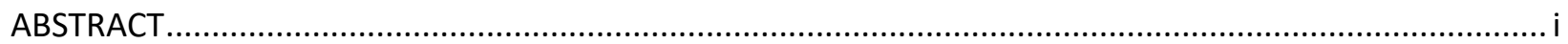

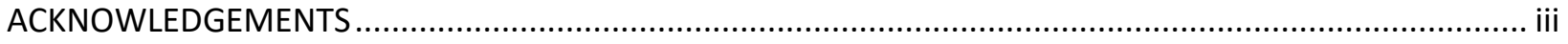

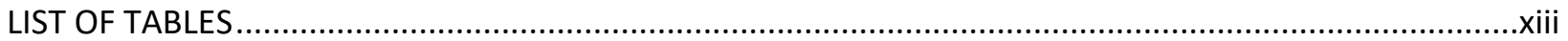

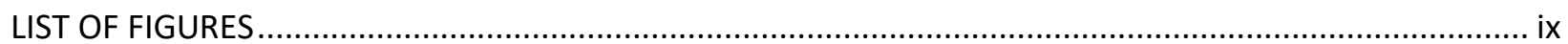

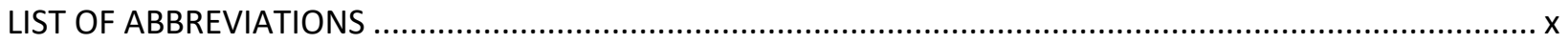

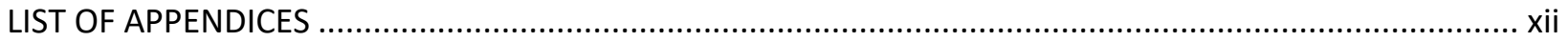

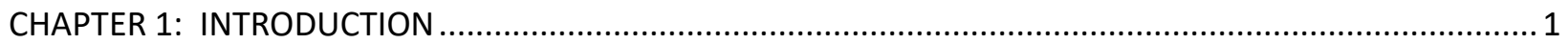

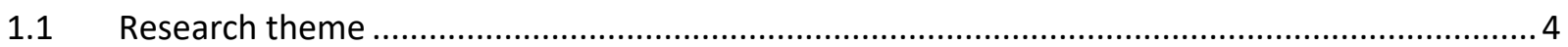

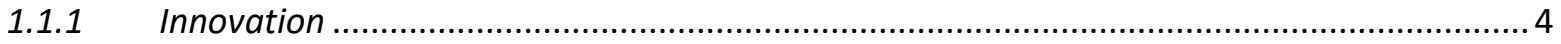

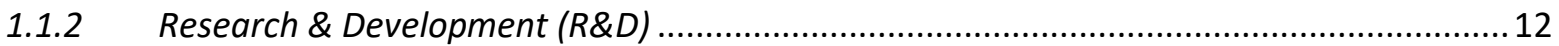

1.1.3 Scientific Research and Experimental Development (SR\&ED) tax incentives.....................14

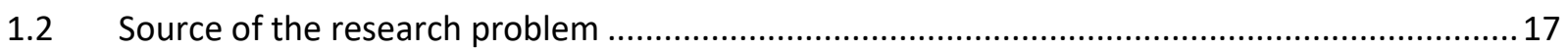

1.2.1 R\&D challenges: External pressures and internal challenges ........................................18

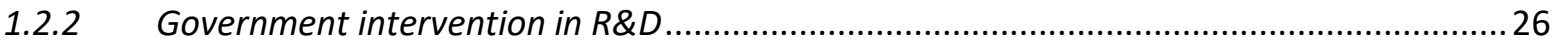

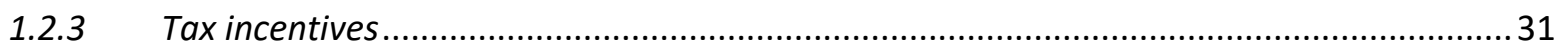

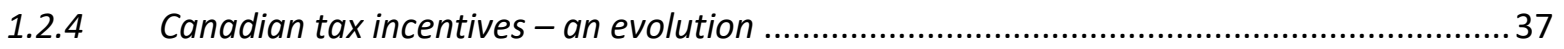

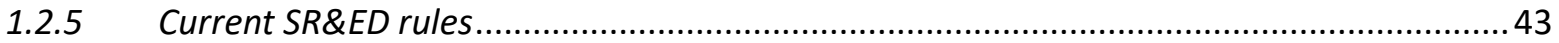

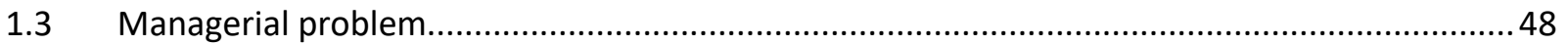

1.3.1 Small and Medium Enterprises (SMES) .......................................................................... 49

1.3.2 Managerial challenges of SMEs with the SR\&ED program ..............................................52

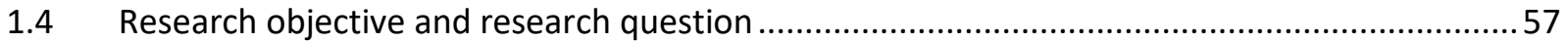

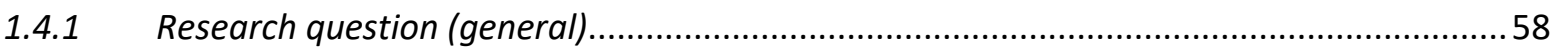

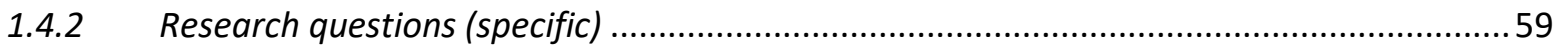

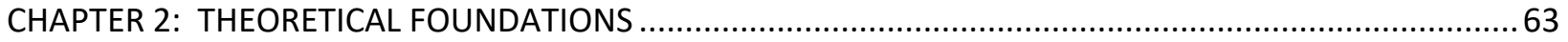

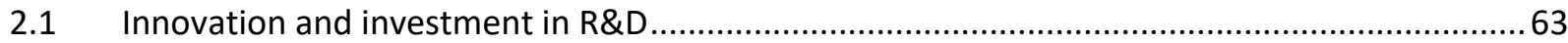

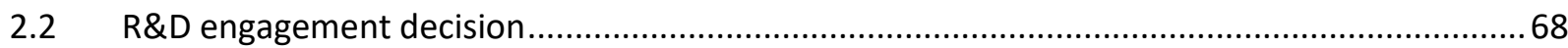

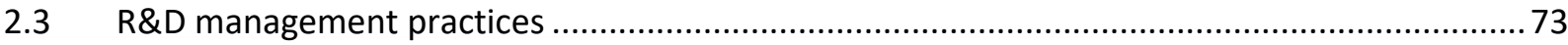

2.4 Application of contingency theory and organizational learning theory to R\&D.......................81

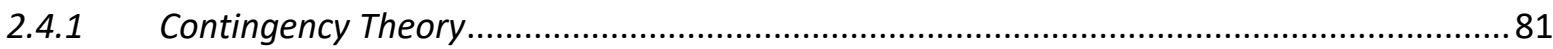

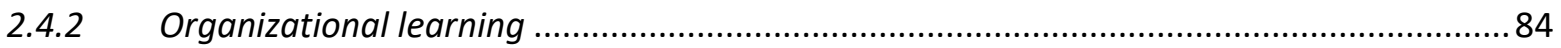




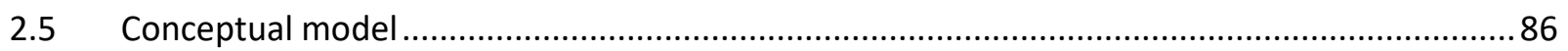

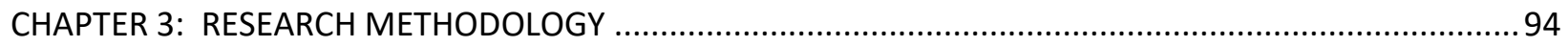

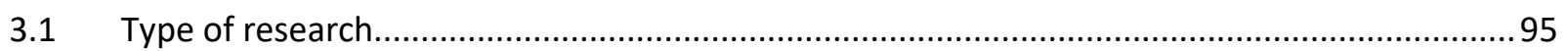

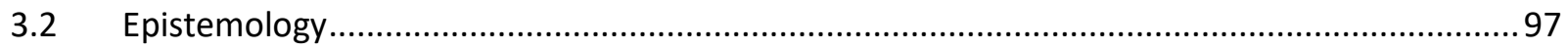

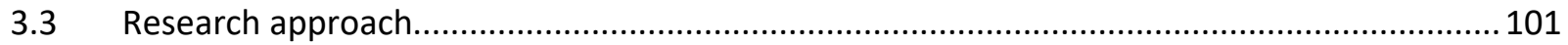

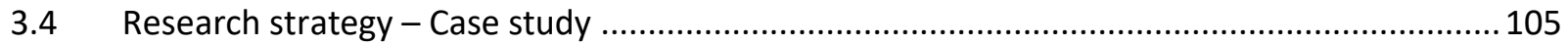

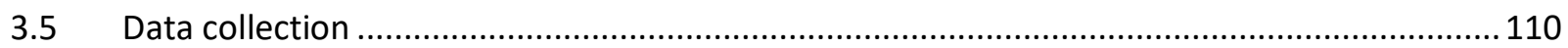

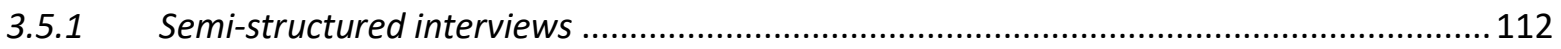

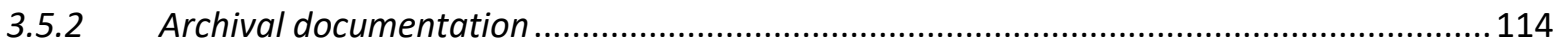

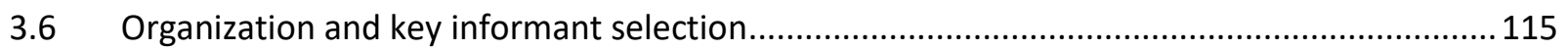

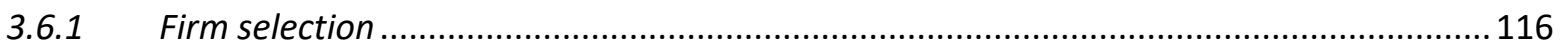

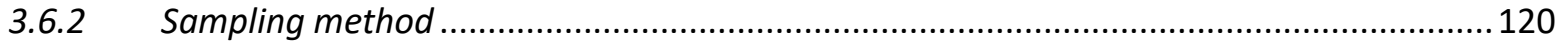

3.6.3 Key informant selection......................................................................................... 122

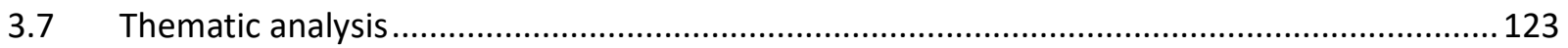

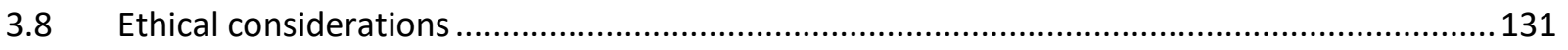

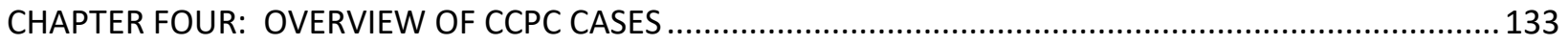

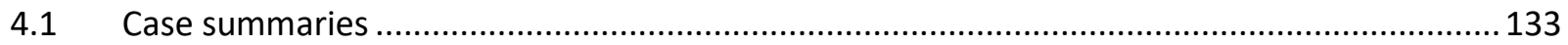

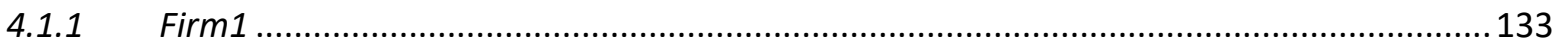

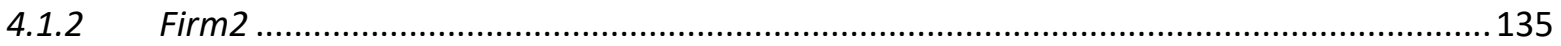

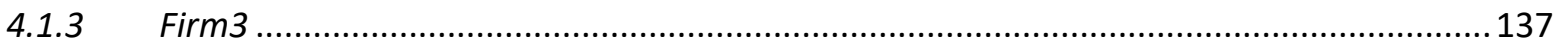

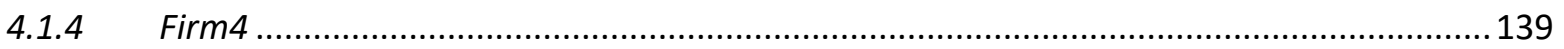

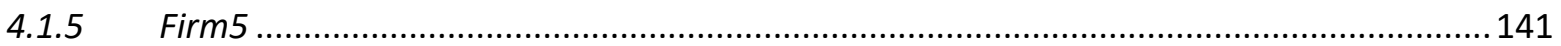

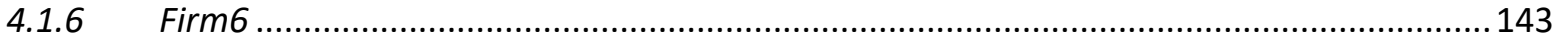

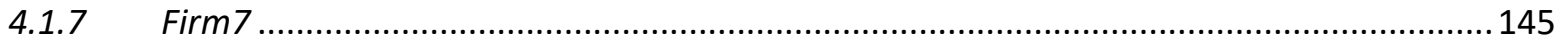

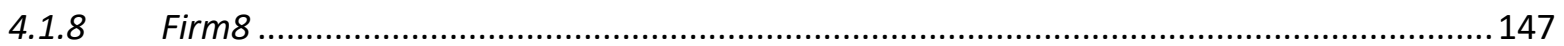

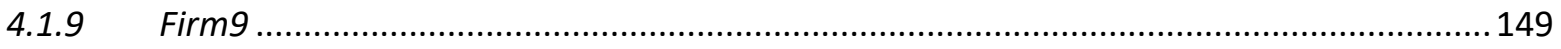

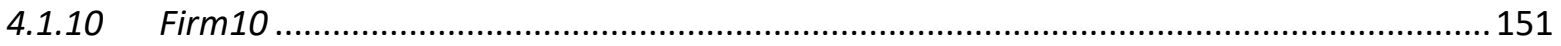

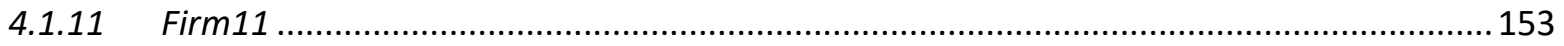

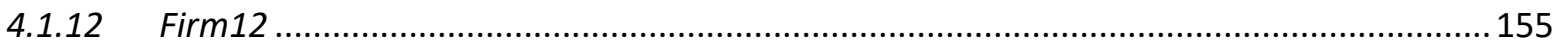

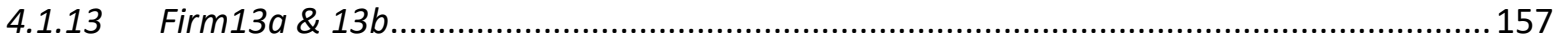

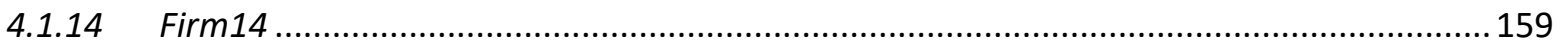

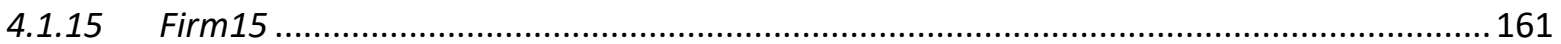




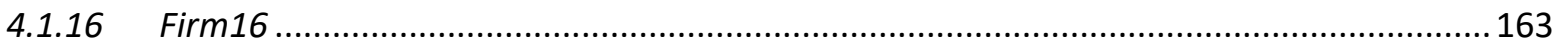

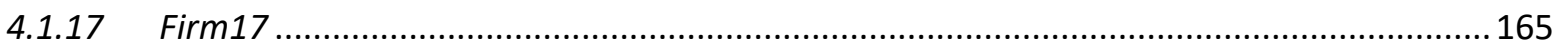

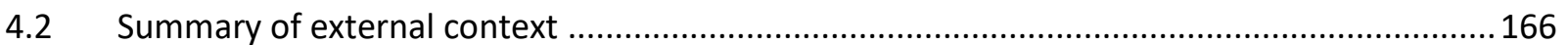

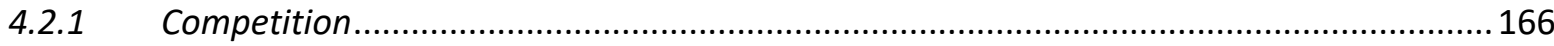

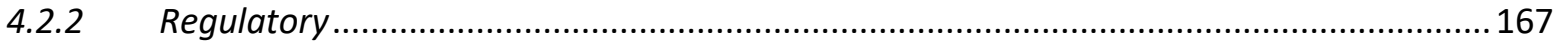

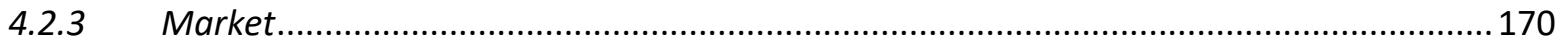

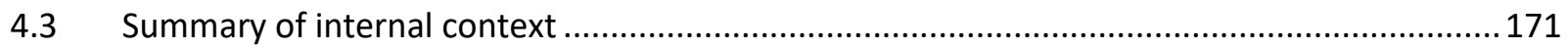

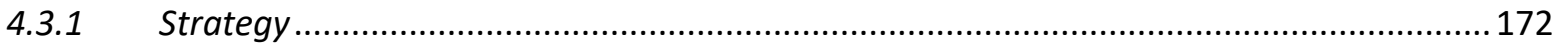

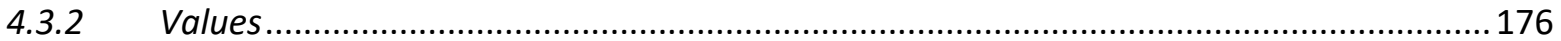

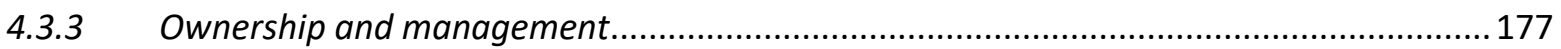

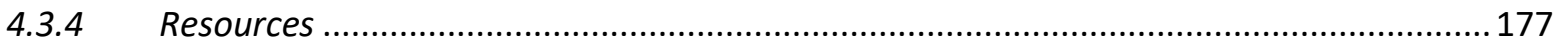

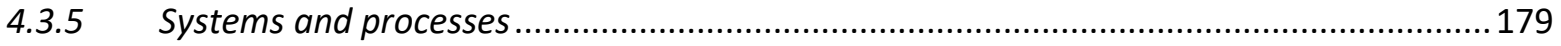

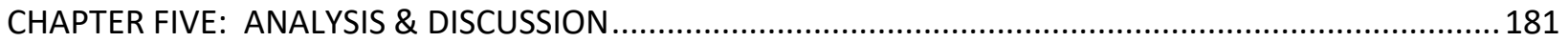

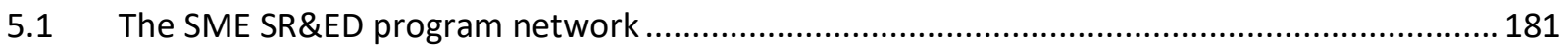

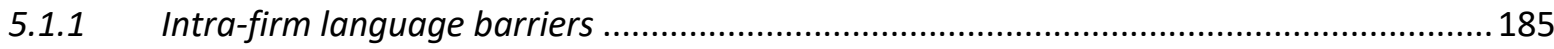

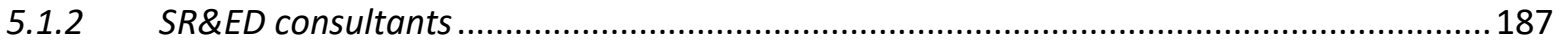

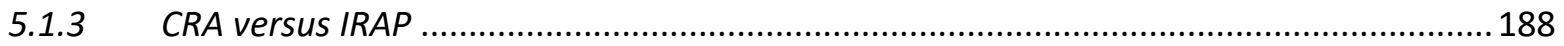

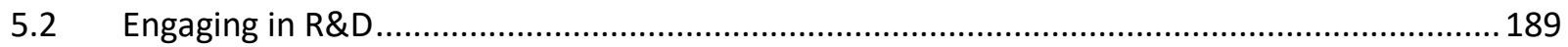

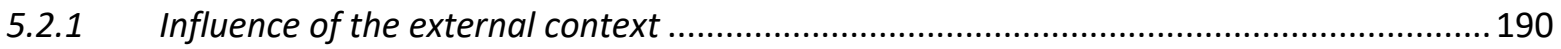

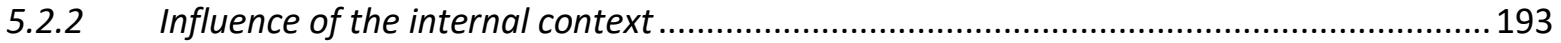

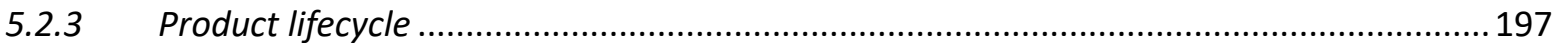

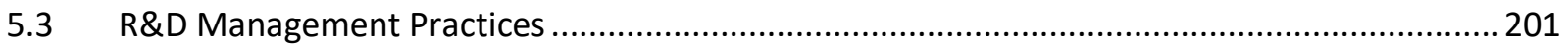

5.3.1 R\&D department structure and composition ...............................................................202

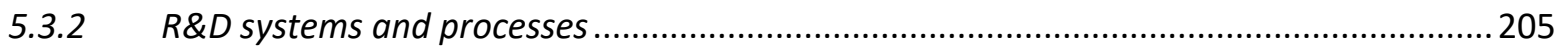

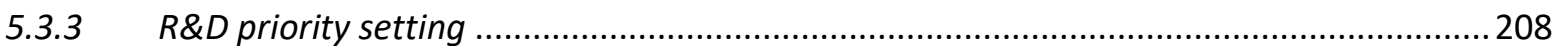

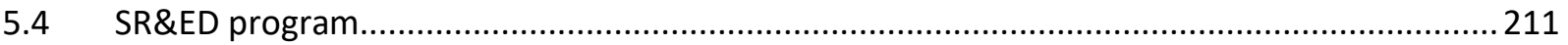

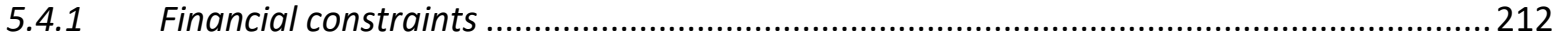

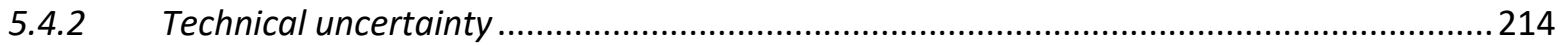

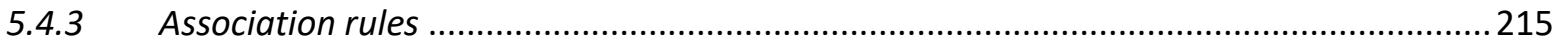

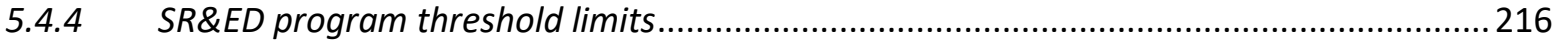

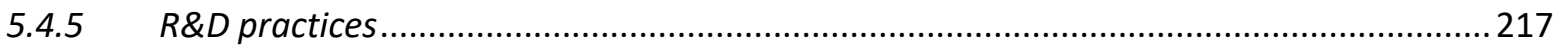

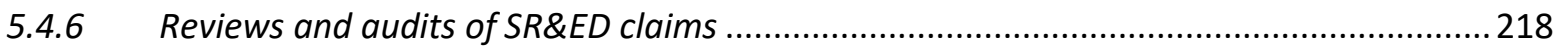




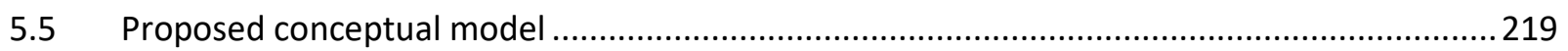

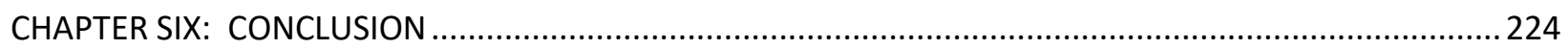

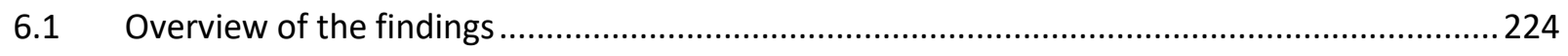

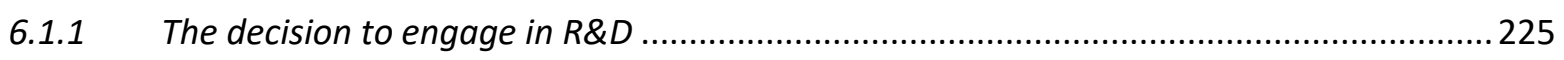

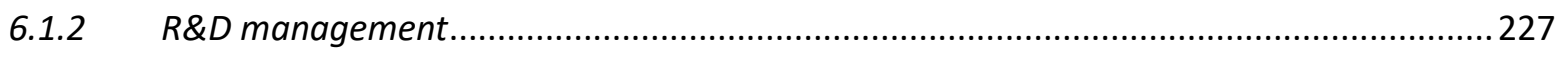

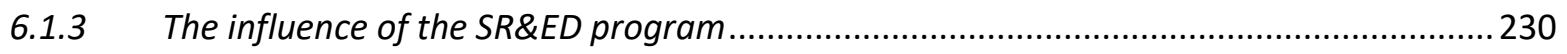

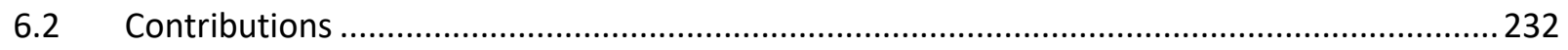

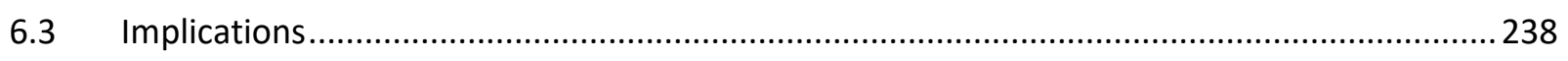

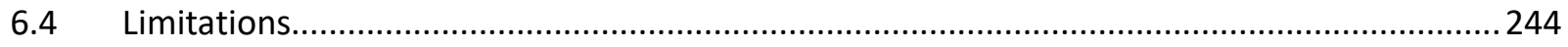

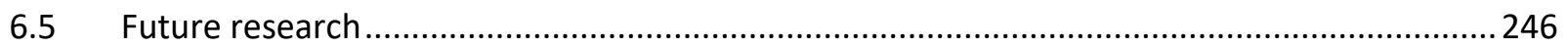

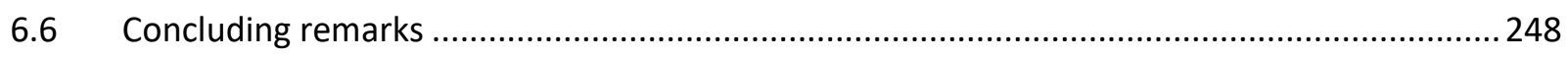

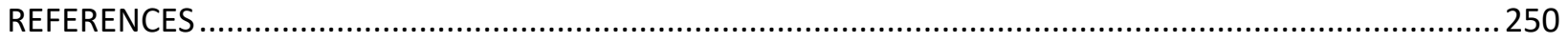




\section{LIST OF TABLES}

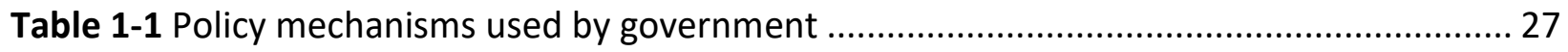

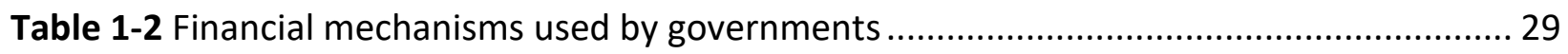

Table 1-3 Findings of R\&D tax incentive research sample ................................................. 35

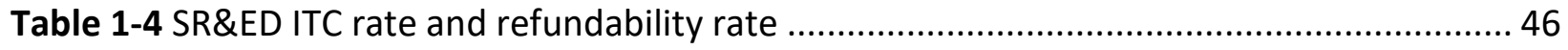

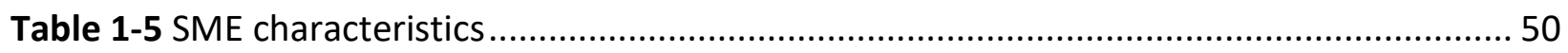

Table 1-6 Firm characteristics and advantages and disadvantages for the SR\&ED program ...... 56

Table 1-7 Synthesis of research problematization elements ............................................... 62

Table 2-1 Firm characteristics and impact on strategic decision-making ................................ 73

Table 3-1 Characteristics of the types of research ............................................................. 98

Table 3-2 Comparison of qualitative versus quantitative approaches................................... 104

Table 3-3 Steps to theory building case study research..............................................................111

Table 3-4 Region, industry, size, and age of firms interviewed.......................................... 121

Table 3-5 Types of cases used in case study research...................................................... 123

Table 3-6 Key informants from interviewed firms ......................................................... 125

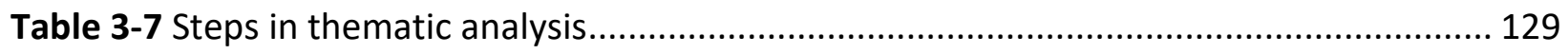

Table 3-8 Synthesis of research design with methodology ................................................. 132

Table 4-1 Summary of the regulatory environment............................................................. 171

Table 4-2 Summary of geographic location of customers of firms interviewed ...................... 173

Table 4-3 Strategic typologies of firms interviewed........................................................ 175

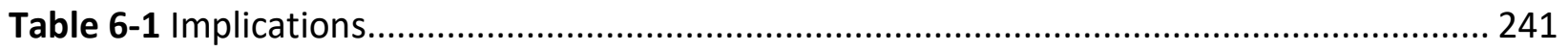




\section{LIST OF FIGURES}

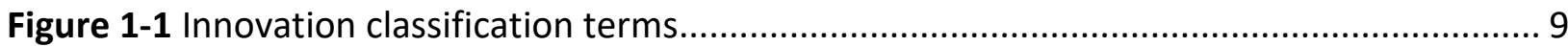

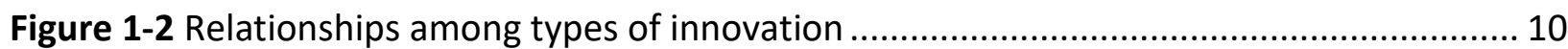

Figure 1-3 External pressures and internal challenges for R\&D....................................... 21

Figure 1-4 Evolution of Canadian government intervention for R\&D .................................. 39

Figure 1-5 Required characteristics of an innovative firm ................................................... 56

Figure 2-1 Leonard-Barton (1992) core capability framework .......................................... 78

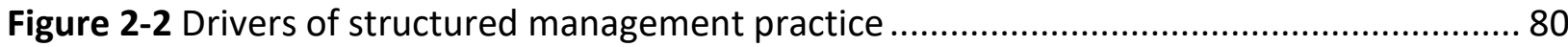

Figure 2-3 Preliminary conceptual model for R\&D engagement and management.................. 90

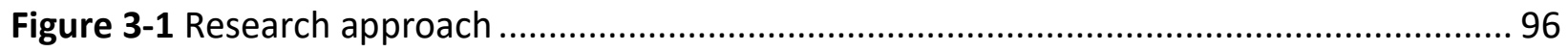

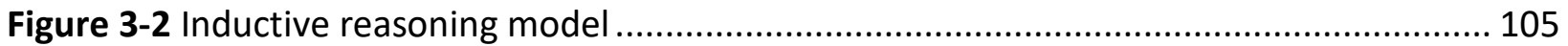

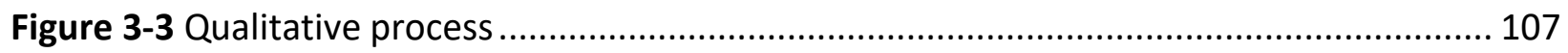

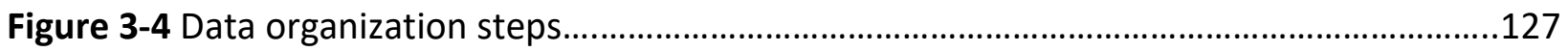

Figure 5-1 The SME SR\&ED program major steps ......................................................... 183

Figure 5-2 Relationships among actors in the SME SR\&ED program network......................... 185

Figure 5-3 Relationships among internal context factors and R\&D decisions ....................... 198

Figure 5-4 Interviewed firms and product lifecycle stage ................................................ 200

Figure 5-5 Influence of internal context and product lifecycle on strategic R\&D decisions ...... 201

Figure 5-6 Proposed conceptual model on R\&D engagement and management ................... 223 


\section{LIST OF ABBREVIATIONS}

\begin{tabular}{|c|c|}
\hline AICPA & Association of International Professional Accountants \\
\hline API & Application Programming Interface \\
\hline BDC & Business Development Bank of Canada \\
\hline Can-Spam & Controlling the Assault of Non-Solicited Pornography and Marketing \\
\hline CASL & Canada's Anti-Spam Legislation \\
\hline CCPC & Canadian-Controlled Private Corporation \\
\hline CEO & Chief Executive Officer \\
\hline CFO & Chief Financial Officer \\
\hline $\mathrm{ClO}$ & Chief Information Officer \\
\hline $\mathrm{CMO}$ & Chief Marketing Officer \\
\hline $\mathrm{COO}$ & Chief Operating Officer \\
\hline CRA & Canada Revenue Agency \\
\hline СTO & Chief Technology Officer \\
\hline DND & Department of National Defence \\
\hline EDO & Economic Development Organization \\
\hline ERP & Enterprise Resource Planning \\
\hline ETF & Exchange Traded Funds \\
\hline FDI & Foreign Direct Investment \\
\hline GDPR & General Data Protection Regulation \\
\hline HDD & Hard Disk Drive \\
\hline ISO & International Organization for Standardization \\
\hline ITC & Investment Tax Credits \\
\hline IRAP & Industrial Research Assistance Program \\
\hline IRDIA & Industrial Research and Development Incentives Act \\
\hline ITA & Income Tax Act \\
\hline NAICS & North American Industry Classification System \\
\hline NRC & National Research Council \\
\hline NRC ITA & National Research Council Industrial Technology Advisor \\
\hline OECD & Organization for Economic Co-operation and Development \\
\hline PAAS & Platform as a Service \\
\hline$R \& D$ & Research \& Development \\
\hline $\mathrm{REACH}$ & Evaluation, Authorisation, and Restriction of Chemicals \\
\hline RoHs & Restriction of Hazardous Substances \\
\hline RPV & Resources, Processes, and Values \\
\hline SBD & Small Business Deduction \\
\hline SDD & Solid State Drive \\
\hline SAAS & Software As A Service \\
\hline SME & Small and Medium Enterprises \\
\hline SR\&ED & Scientific Research \& Experimental Development \\
\hline SRTC & Scientific Research Tax Credit \\
\hline
\end{tabular}


TCEC

VP

WEEE
Taxable Capital Employed in Canada

Vice President

Waste Electronic and Electrical equipment 


\section{LIST OF APPENDICES}

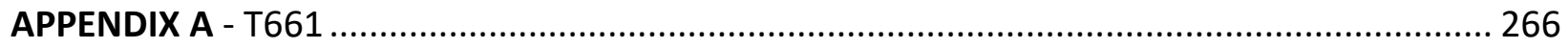

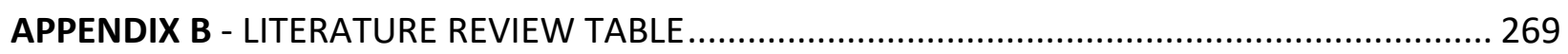

APPENDIX C - SR\&ED DEDUCTIONS USING TRADITIONAL OR PROXY METHOD ...................... 272

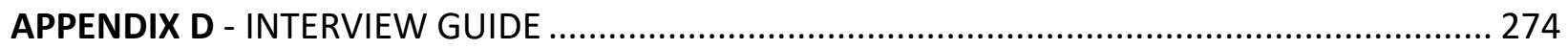

APPENDIX E - LIST OF ECONOMIC DEVELOPMENT ORGANIZATIONS .................................... 276

APPENDIX F - SAMPLE LETTER OF REQUEST FOR ASSISTANCE FROM EDOs.......................... 277

APPENDIX G - SAMPLE LETTER OF REQUEST FOR COLLABORATION FROM SMES.................... 279

APPENDIX H - SAMPLE LETTER OF INVITATION TO KEY INFORMANT .................................... 281

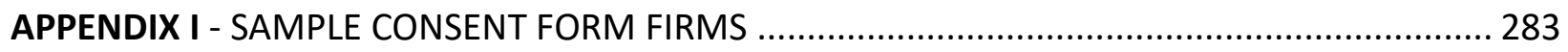

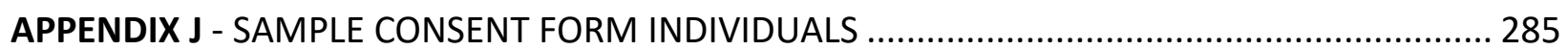




\section{CHAPTER 1: INTRODUCTION}

Innovation plays a vital role in the growth of an economy (Bound, Cummins, Griliches, \& Jaffe, 1984). Spending on research and development (R\&D) is an important determinant of the innovation process (Bound et al., 1984). Due to the risks and high costs of R\&D activity, many firms will not undertake R\&D for an unknown or potentially no return (Cuervo-Cazurra \& Un, 2010). This issue is particularly relevant for Small and Medium Enterprises (SMEs) because they face resource constraints, such as limited financial and human resources (Gibcus, Vermeulen, \& de Jong, 2009). Given the importance of innovation for growth, governments may be tempted to intervene to fix the R\&D under-investment issue through various mechanisms such as grants, loans, or tax incentives.

Since 1944, the Canadian government has used the Income Tax Act (ITA) and tax incentives to stimulate R\&D activity. The incentives have evolved, and since 1986, the primary mechanism used in Canada to encourage R\&D is the Scientific Research and Experimental Development (SR\&ED) program. The SR\&ED program comprises tax deductions and an investment tax credit. The current investment tax credit rate is more generous for smaller Canadian-Controlled Private Corporations (CCPCs) than for larger corporations. One can assume that the Canadian government perceives there is an issue with R\&D activities in SMEs, and therefore, have decided to provide greater incentives to SMEs to encourage R\&D.

Supporting SMEs is an important part of government policy as SMEs play a significant role in the Canadian economy. SMEs provide most of the employment in the private sector in Canada. In 
2017, SMEs employed 89.6 percent of the private labour force (Statistics Canada, 2019a). SMEs also play an integral role in the innovation sphere in Canada. Between 2011 and 2013, small businesses accounted for 27 percent of total R\&D spending, and medium-sized businesses accounted for 18 percent (Statistics Canada, 2016). Statistics Canada (2016) survey data reported that 41.7 percent of small business and 58.3 percent of medium-sized businesses implemented at least one type of innovation in 2014. SMEs also tend to have a higher rate of R\&D productivity (Teirlinck \& Spithoven, 2013).

Traditional research in $R \& D$ and tax incentives focused on whether government intervention results in increased R\&D expenditures or outcomes (e.g., Kobayashi, 2014; Koga, 2003; Lach, 2002). In addition, previous research has evaluated whether the incentives displace private investment in R\&D activities (crowding-out), or induce increased R\&D expenditures and projects (additionality) (Hsu, Horng, \& Hsueh, 2009). The extant literature, while expansive, is limited by the fact that the studies are primarily positivist and quantitative. Most of the literature is econometric-based and articulates the decision to engage and determine the scope of R\&D with tax incentives as an economic argument. Nonetheless, there is a small but growing body of work using organizational learning to explain R\&D decisions (e.g. Clarysse, Wright, \& Mustar, 2009; Hsu et al., 2009). At this point, there is little research on how firms decide to engage in $R \& D$, and how they manage their $R \& D$ practices. The objective of this thesis is to fill this gap in the literature to better understand why small Canadian firms decide to engage in, and how they manage, R\&D activities, specifically in the context of the SR\&ED program. 
This thesis is structured into six different chapters. Chapter 1 is the introduction which discusses the research themes of innovation, R\&D, and the SR\&ED program. This chapter also outlines the source of the research problem, including the challenges inherent to R\&D, and the managerial problem. The specific case of SMEs is also considered in this context. This chapter concludes with the research question.

Chapter 2 is the literature review, whose purpose is to familiarize the reader with the core concepts of $R \& D$ engagement and management practices. This section also examines the approaches and the relevant theories employed in the extant literature on R\&D and tax incentives. Subsequently, this chapter identifies the gaps in this research field, which provide the motivation for this thesis. Based on the core concepts and the relevant theories, a conceptual model is advanced.

Chapter 3 is the methodology chapter which provides an overview of the methodological assumptions used in this thesis. Further, this chapter describes the research approach, research design, sample, data collection, and analysis techniques that were employed. The chapter concludes with a discussion of ethical considerations.

In chapter 4, an overview of the CCPCs interviewed for this study is provided. In addition, a summary of the external and internal context of the CCPCs is detailed.

Chapter 5 is the analysis and discussion section, in which the findings of this study are described. This chapter comprises four sections, including the SME SR\&ED program network, engage, manage, and the SR\&ED program. 
Finally, this thesis concludes with chapter 6 . Chapter 6 provides an overview of the results and outlines the theoretical, practical, and policy contributions and their implications. In addition, this chapter discusses the study's limitations and opportunities for future research.

\subsection{Research theme}

The primary themes that are prominent in the extant literature of government intervention and R\&D are innovation and tax incentives. When governments provide tax incentives to encourage R\&D activities, their ultimate goal is to increase the economy's innovation capacity. This subsection is structured as follows. Firstly, this subsection will elaborate on the concept of innovation, common types of innovation, and its classification. This subsection also discusses the importance of innovation to society and firms. Subsequently, as the concept of innovation is closely linked to R\&D, this subsection describes R\&D and what it encompasses. Finally, the SR\&ED tax incentives and their link to R\&D are described.

\subsubsection{Innovation}

The concept of innovation has been described in different aspects in the literature.

Schumpeter (1934) asserts that innovation is the creation of new combinations of existing resources and forces. Schumpeter's definition allows for a broad spectrum of innovation, such as the combination of adding email and internet functionality to the traditional functions of a phone. Rogers (2003) avers that innovation is an idea, process, or item that someone perceives as new. This definition, however, is quite vague as the perception of new is fairly subjective. Other definitions are more specific. Damanpour (1996, p. 694) defines innovation as "a new 
product or service, new process technology, new organization structure or administrative systems, or new plans or programs pertaining to organization members."

Innovations are often classified by type and by impact. Rosenberg (1982) differentiates between product and process innovation: a product innovation is the development of a new product or service, while a process innovation is an innovation that does not change the production or delivery of an existing product or service, but rather creates a new or improved method of production or delivery. A process innovation may involve the reduction of delivery times or improvements in the efficiency of a manufacturing process. For example, the introduction of online check-in for airlines would be considered a process innovation.

The classification of an innovation as a product or process is highly dependent on the context (Rosenberg, 1982). For example, a new system that is created to automate a portion of a production process will be a product innovation for the system vendor. However, the new system will be a process innovation for the organization employing the new technology. This thesis will utilize Rosenberg's classification of a process or product innovation, as it encompasses a wide range of potential innovations.

As an innovation may be a product or process innovation, its impact can also further delineate the type of innovation. The innovation literature utilizes terms like incremental, sustaining, modular, architectural, disruptive, or radical to describe types of innovation. Some terms are used interchangeably and are dependent on the author. Henderson \& Clark (1990) outline the differences among incremental, modular, architectural, and radical innovations, according to whether the innovation changes the core concepts, or the linkages between the core concepts 
and components. Christensen (1997) classifies innovation as either being sustaining or disruptive, depending on their impact on the market.

Figure 1-1 provides an illustration of the terms using a combination of elements used to describe innovation. An innovation can be either a product or process innovation, and it can be categorized as a modular, architectural, incremental, or disruptive innovation, depending on the impact and change. An example of a modular innovation would be the digital camera. Both a digital and film camera take pictures, but the components within the cameras are different. An example of an architectural innovation is the innovation to reduce the hard disk drive (HDD) from 8-inch to 5.5-inch, as the core concept of the disk drive remained the same, while the components were made smaller. Incremental innovation builds on existing products or services by providing better performance or functionality. These innovations target higher-end customers and higher margins (Christensen, 1997). Disruptive innovation seeks new markets and customers; these innovations tend to be simpler, more convenient, and are usually less expensive (Christensen, 1997). For example, a solid-state drive (SSD) could be considered to be a disruptive innovation, as the SSD performs the same functions as an HDD, but there is no disk, nor any motor to spin a disk. 
Figure 1-1 Innovation classification terms

\begin{tabular}{|c|c|c|}
\hline $\begin{array}{l}\text { Product } \\
\text { New product or } \\
\text { service } \\
\text { (Rosenberg, 1982) }\end{array}$ & \multirow{2}{*}{$\begin{array}{l}\text { Modular } \\
\text { Utilizes a new } \\
\text { component or } \\
\text { concept in an existing } \\
\text { combination } \\
\text { (Henderson \& Clark, } \\
\text { 1990) }\end{array}$} & \multirow{3}{*}{$\begin{array}{l}\text { Incremental } \\
\text { Introduces relatively minor } \\
\text { changes to an existing artifact } \\
\text { and utilizes the existing } \\
\text { design as a basis for } \\
\text { improvement (Christensen, } \\
\text { 1997; Henderson \& Clark, } \\
\text { 1990; Nelson \& Winter, 1982) }\end{array}$} \\
\hline \multirow{4}{*}{$\begin{array}{l}\text { Process } \\
\text { New or improved } \\
\text { method of } \\
\text { production or } \\
\text { delivery (Rosenberg, } \\
\text { 1982) }\end{array}$} & & \\
\hline & \multirow{3}{*}{$\begin{array}{l}\text { Architectural } \\
\text { Reconfigures existing } \\
\text { components or } \\
\text { concepts into a new } \\
\text { combination } \\
\text { (Henderson \& Clark, } \\
\text { 1990) }\end{array}$} & \\
\hline & & $\begin{array}{l}\text { Disruptive (radical; creative } \\
\text { destruction) }\end{array}$ \\
\hline & & $\begin{array}{l}\text { Establishes a new dominant } \\
\text { design (Christensen, 1997; } \\
\text { Henderson \& Clark, 1990; } \\
\text { Schumpeter, 1934) }\end{array}$ \\
\hline
\end{tabular}

The relationships among the types of innovation are illustrated in Figure 1-2. Firstly, a product or process innovation can be modular or architectural. Subsequently, a modular or architectural innovation can be disruptive if the innovation results in a product or process that is less expensive, simpler, and more convenient. Alternatively, it can be incremental if it is an improvement to an existing artifact and seeks the same target market. As part of this analysis, all scopes of innovation will be considered, as management may choose to focus on different types of innovation at specific points in the business cycle. 
Figure 1-2 Relationships among types of innovation

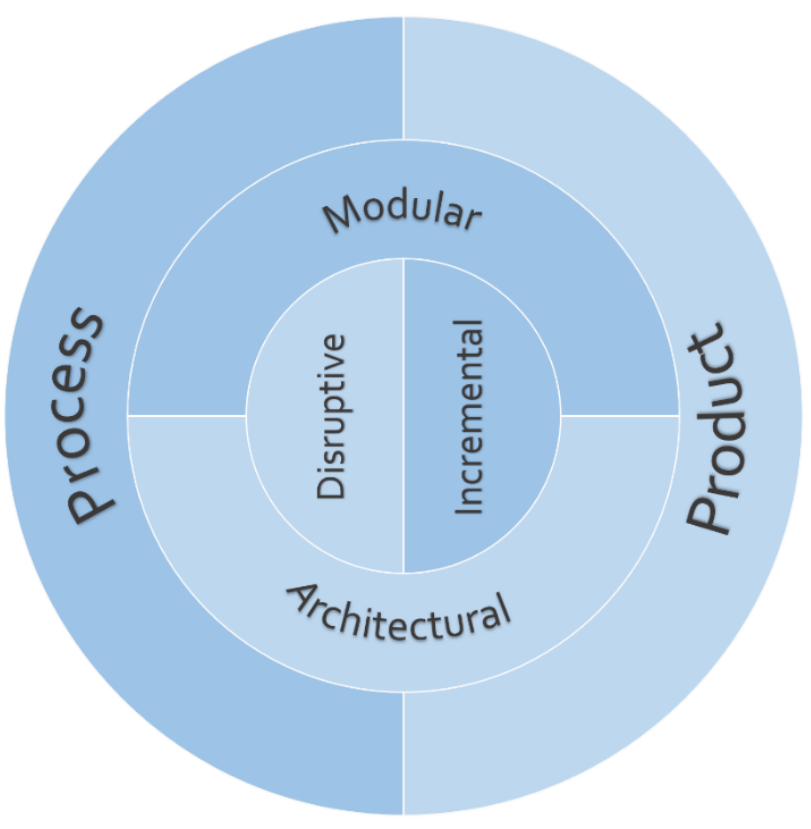

The benefits of innovation can be evaluated from societal and firm perspectives (Acs, Audretsch, \& Feldman, 1994). From society's standpoint, an innovation would be considered beneficial if it produces a social good or benefit. In this case, innovation would be evaluated against whether the innovation outcome or activities creates a social good. From a firm perspective, a benefit to a firm is generally measured by increased shareholder wealth.

On a societal level, innovation is thought to produce a social good by increasing economic growth opportunities, promoting healthy competition, and encouraging knowledge spillovers (Brown, Martinsson, \& Petersen, 2017). Economic growth is hastened by the introduction of new products and processes, in which resources are shifted from older industries to emerging new industries (Dosi \& Nelson, 2010). In effect, traditional industries that have matured have little room for growth. Conversely, emerging industries have significant growth opportunities to reach new customers and markets. The innovation process itself also can promote economic 
growth via increased spending and job creation (Cohen \& Levin, 1989; Tidd \& Pavitt, 2011). Highly-skilled R\&D employees tend to earn, on average, higher wages (Lokshin \& Mohnen, 2013). In turn, higher wages can lead to increased consumer spending and an increased personal tax base.

Innovation may also assist in creating a healthy competitive market by producing new products, processes, or services. For example, with the advent of digital cameras, consumers could choose between digital or film cameras. With digital cameras, consumers no longer had to wait to process the film to share their photos. Conversely, a lack of competition can inhibit innovation. Firms that have become complacent, due to a lack of competition, may not have the incentive to introduce new processes or products. Further, firms with monopoly rents may choose to erect barriers to entry for new firms (Mahmood \& Rufin, 2005). As an example, to retain their monopoly position, firms may contract for exclusive access with suppliers or distribution networks. If the barriers to entry are too high, new entrants may not be able to provide innovative alternatives that are cheaper or have improved features. Consequently, consumers may pay more for sub-standard products or services.

Innovation can also create spillover effects in the economy. Spillovers can be defined as knowledge that is shared as a result of formal and informal interactions by firms and individuals (Lester, 2012; Mahmood \& Rufin, 2005; Michael \& Pearce, 2009). The knowledge gained through the innovation activities can assist other firms in the industry, or even firms outside the industry. This technology or knowledge transfer enables firms to introduce complementary products or services, improve existing offerings, or reach new markets. For example, without 
the Shopify e-commerce engine, smaller retailers would need to create their own engine and estore for the online sale of their goods at considerable expense. Shopify's innovation reduces the technology cost for smaller firms, while creating new market opportunities.

At the firm level, shareholder wealth is amplified by an increased firm value. Increased firm value is a function of increased profits, cash flows, and asset values. Considerable research has found that innovation is highly correlated with firm value (Hall, Jaffe, \& Trajtenberg, 2005; Pandit, Wasley, \& Zach, 2011; Wang \& Zhao, 2014). Investing in R\&D has been linked to generation of abnormal profits and higher expected future benefits (Chan, Lakonishok, \& Sougiannis, 2001; Eberhart, Maxwell, \& Siddique, 2004). These profits and cash flows are a result of the firm commercializing the R\&D output or implementing the innovation internally to reduce costs. Tidd \& Pavitt (2011) state that innovation is a contributing factor in achieving competitive advantage. Competitive advantage allows a firm to earn monopoly rents on an innovative product or service that no other firm offers.

Firm and societal benefits can be considered to be part of a cycle, or to be self-reinforcing. Essentially, benefits to firms often benefit society and vice-versa. For example, firms that have a competitive advantage play an integral role in the firm's sustainability (Grant, 1996). Sustainability of firms is important to a country's economy because firms pay corporate taxes and create a healthy job market. Similarly, a growing economy attracts more workers and capital, which may allow firms access to these resources (Romer, 1990).

There are also criticisms of innovation. Innovation can eliminate or displace existing jobs (Schumpeter, 1934). For example, the introduction of digital cameras had an impact on regular 
camera and film sales and film development outlets. In addition, innovation outcomes can have unknown consequences. As an example, privacy concerns have become a growing concern with the capture of data by firms such as Google, Facebook, and other social media applications. Despite these challenges, it is broadly accepted that the overall benefits of innovation outweigh the potential downsides of innovation. The downsides of innovation can be mitigated with regulation and support programs for the transition.

Due to the potential benefits of innovation, there is considerable interest in the process of developing innovation. R\&D activities are seen to be part of the innovation process (Bound et al., 1984; Rosenberg, 1982; Teece, 2010b). Building on organizational strategy and process theory from Miles \& Snow (1978), Raymond \& St-Pierre (2010) indicate that the innovation process is the result of entrepreneurial, administrative, and engineering problems. In order to engage in innovation, a firm needs to solve the entrepreneurial problem of finding a new market, service or product to develop (Miles \& Snow, 1978; Raymond \& St-Pierre, 2010). Once a new product, service, or market has been decided upon, the firm needs to solve both the engineering and administrative problems. The engineering process involves determining the best technology to develop the innovation and the best practices to develop the relevant competencies (Raymond \& St-Pierre, 2010). The administrative process supports the engineering process by developing the structures and processes to support the engineering efforts (Raymond \& St-Pierre, 2010). R\&D can be part of the solution to the engineering problem, in that it seeks to develop the products or services to support the entrepreneurial decision of the firm. 


\subsubsection{Research \& Development (R\&D)}

In the extant literature, the term research and development (R\&D) has been in use for some time. Nelson (1962) equates R\&D with inventive activity. Rosenberg (1982, p. 120) indicates that R\&D "is a learning process in the generation of new technologies." Teece (2010b, p. 682) uses a more specific definition for R\&D by stating that "R\&D is the activity in which the talents of scientists, and/or engineers [...] are harnessed to create new products, processes, and services." Many governments and governmental organizations rely on the definition in the Frascati Manual published by the Organization for Economic Co-operation and Development (OECD) (Hall \& Van Reenen, 2000). According to the Frascati Manual (OECD, 2002, p. 30), R\&D is "the creative work undertaken on a systematic basis in order to increase the stock of knowledge [...] and the use of this stock of knowledge to devise new applications."

Nelson's (1962) view of R\&D is rather vague. Inventive activity can imply activities such as brainstorming. Both Rosenberg (1982) and Teece's (2010b) definitions are quite specific in that a new artifact must be created in the process. These definitions do not necessarily consider improvements to existing products, services, or processes. It also assumes that the advancement of knowledge may not be a goal. The definition in the Frascati Manual includes the goal of the advancement of knowledge and the intent to apply this knowledge and is also broad enough to encompass improvements to existing artifacts. Furthermore, the Frascati Manual's definition is widely used and accepted; therefore, this thesis uses this definition of R\&D. 
Firms can engage in R\&D in-house (intramural), contract it externally (extramural), or use a combination of both (OECD, 2002). Although extramural R\&D plays a complementary role in the innovation process, a distinction should be made between extramural and intramural R\&D. It can be assumed that intramural R\&D is primarily domestic as it relies on in-house expertise and resources. In contrast, extramural R\&D can be completed by foreign or domestic suppliers. Firms that decide to engage in R\&D must evaluate whether R\&D will be intramural, extramural, or a combination of both.

If a firm decides to engage in extramural R\&D, in contrast to intramural R\&D, there is little to no $R \& D$ learning process within the organization. During the intramural R\&D development process, a firm engages in knowledge acquisition through learning-by-doing and learning-byusing (Rosenberg, 1982). Learning-by-doing occurs after the design stage, while the product is in production. Incremental improvements to the product are initiated as more is known through experience in the production process. Learning-by-using occurs when the users of the innovation provide feedback on how the innovation works in the field, and how it interacts with other components or assets (Rosenberg, 1982). Through learning by doing, the firm can discover the limitations or trade-offs of the product. This learning process may have an impact on R\&D management and decisions such as the number of resources employed or limiting/increasing the scope of a project. This analysis focuses on intramural R\&D to better understand the R\&D management practices of firms.

R\&D consists of three primary types of research: basic, applied, and development research. Basic research is research that advances knowledge in a specific area without any known 
application (Mansfield, 1984; Sakakura \& Kobayashi, 1991; Teece, 2010b). Research carried out at universities and research centres may fall into this category, as the research may not be intended to be commercialized. Applied research is intended to extend knowledge in a specific area, although it is meant to be implemented for a specific purpose (Mansfield, 1984; Sakakura \& Kobayashi, 1991; Teece, 2010b). Development research is a combination of applied and basic research for the purpose of introducing new products, services or processes or improving existing ones (Mansfield, 1984; Sakakura \& Kobayashi, 1991; Teece, 2010b).

Firms and governments may value one type of research over another. Firms may attach more importance to development research than basic research, since basic research may generate little or no immediate return. Nevertheless, basic research has considerable value, as it may generate knowledge that can lead to applications at a future date. For this reason, governments may be inclined to incent the three types of research equally for their potential future economic and societal benefits.

\subsubsection{Scientific Research and Experimental Development (SR\&ED) tax incentives}

In Canada, the main mechanism to incent the three types of research is the SR\&ED tax incentive program. Under the SR\&ED program, R\&D activities that can be classified as SR\&ED-eligible activities are defined in Section 248(1) of the Income Tax Act (ITA):

\footnotetext{
"Scientific research and experimental development means systematic investigation or search that is carried out in a field of science or technology by means of experiment or analysis and that is

(a) basic research, namely, work undertaken for the advancement of scientific knowledge without a specific practical application in view,

(b) applied research, namely, work undertaken for the advancement of scientific knowledge with a specific practical application in view, or
} 
(c) experimental development, namely, work undertaken for the purpose of achieving technological advancement for the purpose of creating new, or improving existing, materials, devices, products or processes, including incremental improvements thereto,

and, in applying this definition in respect of a taxpayer, includes

(d) work undertaken by or on behalf of the taxpayer with respect to engineering, design, operations research, mathematical analysis, computer programming, data collection, testing or psychological research, where the work is commensurate with the needs, and directly in support, of work described in paragraph (a), (b), or (c) that is undertaken in Canada by or on behalf of the taxpayer,"

The three types of research defined as SR\&ED-eligible activities are consistent with the three types of research for R\&D outlined by Mansfield (1984), Sakakura \& Kobayashi (1991) and Teece (2010b). ITA 248(1)(d) explicitly details the work that would constitute a SR\&ED activity in relation to the three types of research. Beyond this, the ITA 248(1) also specifies what does not constitute SR\&ED-eligible activities:

(e) "market research or sales promotion,

(f) quality control or routine testing of materials, devices, products or processes,

(g) research in the social sciences or the humanities,

(h) prospecting, exploring or drilling for, or producing, minerals, petroleum or natural gas,

(i) the commercial production of a new or improved material, device or product or the commercial use of a new or improved process,

(j) style changes, or

(k) routine data collection."

Due to the exclusions, we cannot assume that R\&D is equivalent to SR\&ED. For example, ITA 248(1)(i) indicates that commercial production of a new or improved artifact is not eligible.

Essentially, a firm must demarcate when the research is completed versus when commercialization of the product commences. As a result, firms may face challenges ascertaining whether or not a change to a product post-commercial release is a SR\&ED activity (Viner, 2016). 
As part of the requirement to be eligible for SR\&ED tax incentives, the firm must submit a project description. Currently, firms are required to submit form T661 (see Appendix A) to be eligible for the incentives. In section B242 and B244 of T661, a firm must detail the scientific and technology uncertainty and how they overcame these uncertainties (Canada Revenue Agency, 2015a). The T4088 Canada Revenue Agency (CRA) guide to form T661 refers users to the Eligibility of Work for SR\&ED Investment Tax Credits Policy document to understand the requirements of technical or scientific uncertainty (Canada Revenue Agency, 2015b). In this CRA policy, the following five questions are used to determine eligibility based on uncertainty:

1. "Was there a scientific or a technological uncertainty?

2. Did the effort involve formulating hypotheses specifically aimed at reducing or eliminating that uncertainty?

3. Was the overall approach adopted consistent with a systematic investigation or search, including formulating and testing the hypotheses by means of experiment or analysis?

4. Was the overall approach undertaken for the purpose of achieving a scientific or technological advancement?

5. Was a record of the hypotheses tested and the results kept as the work progressed?" (Canada Revenue Agency, 2015c)

The requirements of technical or scientific uncertainty may make it more difficult to categorize an R\&D activity as a SR\&ED activity for tax purposes. For example, if the project is deemed to have a guaranteed outcome, the project will not be eligible. Similarly, routine engineering would not be considered to be a SR\&ED activity. The learning-by-doing process, described by Rosenberg (1982) as part of R\&D, does not necessarily align with SR\&ED. SR\&ED requires hypothesis development and testing; learning-by-doing does not necessarily mean that experience gained is through rigorous scientific testing. In effect, SR\&ED can be seen as part of $R \& D$, but not all R\&D is SR\&ED. 
As part of the SR\&ED claim, firms must manage and fully document the SR\&ED process. To support the SR\&ED claim, documentation such as project plans, project progress reports, hypotheses development and test results, design documents, and minutes of meetings should be retained and made available (Canada Revenue Agency, 2015c). SR\&ED claims may be rejected due to a lack of supporting documentation. Filling out the T661 form and the management and documentation of SR\&ED process can be a challenge for a number of firms that lack the appropriate infrastructure.

\subsection{Source of the research problem}

The study of R\&D and tax incentives can be divided into a research problem and a practical problem. From a research standpoint, innovation developed through R\&D activities is important to society and firms, so governments try to incent firms to engage in R\&D. Traditional research in tax incentives and R\&D has found that tax incentives increase R\&D expenditures and output (e.g., Bloom, Griffith, \& Van Reenen, 2002; Harris, Li, \& Trainor, 2009). This behaviour is often referred to as additionality behaviour (Clarysse et al., 2009; Hsu et al., 2009). Additionality behaviour assumes that by reducing user cost, firms will intensify their R\&D, but there is little understanding as to whether it has an impact on R\&D management practices (i.e., behavioural additionality). Behavioural additionality seeks to explain the changes in processes and strategies that take place within a firm once public assistance is provided (Clarysse et al., 2009). For example, Hsu et al. (2009) indicate that $R \& D$ tax incentives encourage changes to $R \& D$ strategies in which management takes on riskier R\&D projects. 
The concept of additionality may seek to explain the impact of R\&D incentives on management behaviour and output. However, from a research perspective, there is a lack of understanding of how firms reach the strategic decision to engage in $R \& D$. Most of the current research assumes that financing constraints and the potential for competitors to replicate the R\&D artifact are the main barriers to entry (e.g., Brown et al., 2017). There is little clarity on the impact of the challenges and obstacles that firms face, which can affect the decision to engage in R\&D.

From a practical standpoint in Canada, the Canadian government wants to incent firms to engage in R\&D. A number of firms do not engage in R\&D in Canada, and there is little insight into why they do not engage in $R \& D$ and/or use the SR\&ED program. It is uncertain if the design of government incentives, such as the SR\&ED program, addresses the obstacles to engaging in R\&D. Similar to the research perspective, the design of the incentives aims to resolve a financial constraint. To better understand the motivations for firms to engage in $R \& D$ and how firms manage their $R \& D$, this section reviews the challenges and pressures of R\&D.

\subsubsection{R\&D challenges: External pressures and internal challenges}

Before embarking on any decision, most firms evaluate the risks and challenges associated with the decision (March \& Simon, 1958). The same concept would apply to R\&D decisions; a firm should evaluate the challenges it will encounter if it decides to engage in R\&D. Figure 1-3 provides a pictorial representation of the external pressures and internal challenges that a firm will face when deciding to engage in $R \& D$; these elements may also influence each other. The 
external pressures include competitive, regulatory, and market pressures (Busom, Corchuelo, \& Martínez-Ros, 2014). While considering the external pressures, a firm should also evaluate its internal challenges. In order to engage in R\&D, a firm needs the appropriate resources and systems and processes in place (Christensen, 1997). These resources include human, financial, and physical resources. It should be noted that both the external pressures and internal challenges may also have an impact on how firms manage their R\&D process once the decision has been made. For example, without adequate internal resources, firms may be required to outsource their R\&D.

Figure 1-3 External pressures and internal challenges for $R \& D$

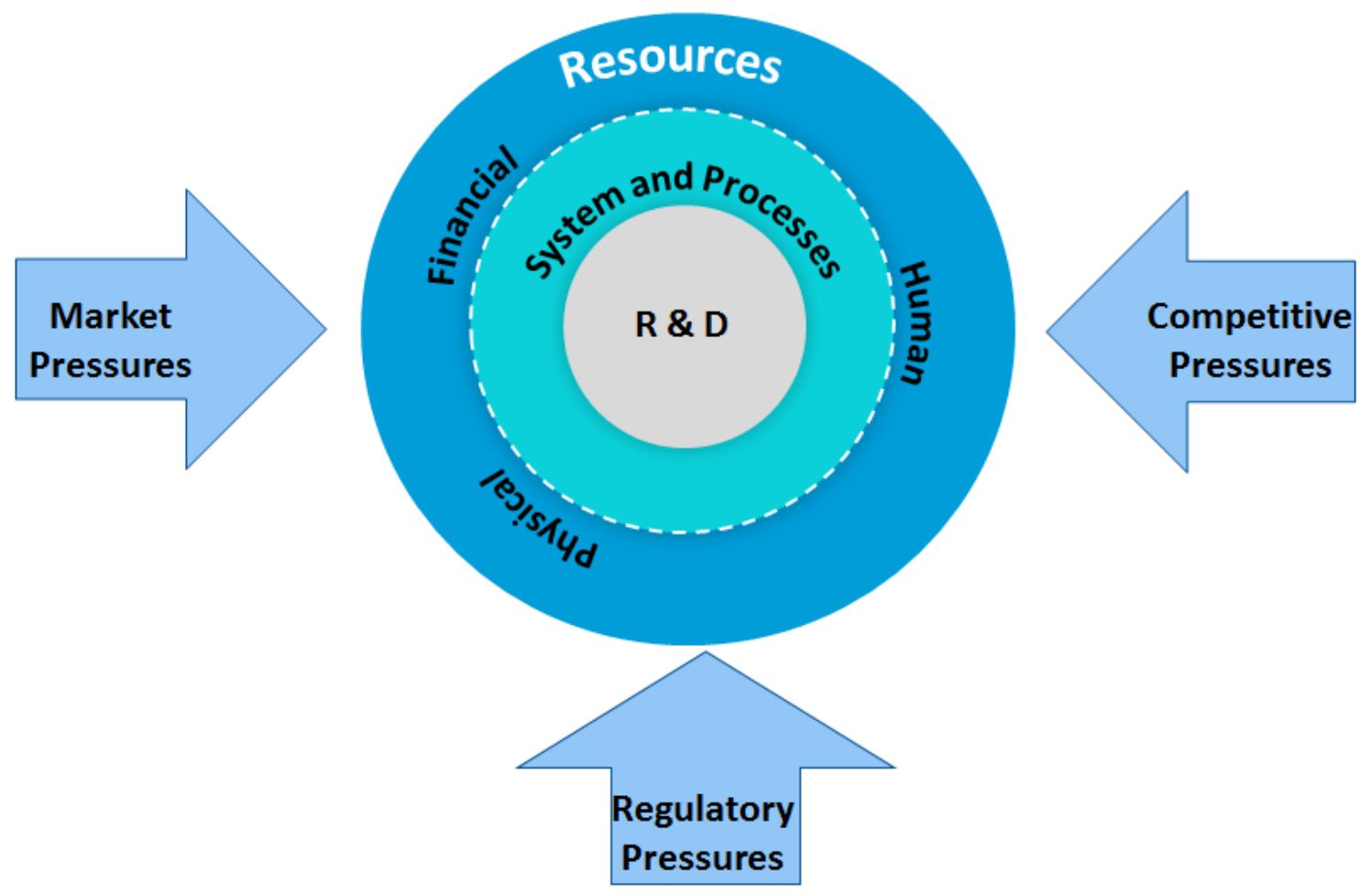

Competitive pressures have an impact on the firm's decision to engage in R\&D. After expending considerable time and effort, a commercially viable outcome may result, but 
competitors may quickly imitate the product. It is estimated that, on average, one dollar of R\&D spend in one firm reduces the imitator's cost by 56 cents (Parsons \& Phillips, 2007). Consequently, the firm that invested initially in the R\&D effort will have a lower marginal return than competitors who imitate the product. Raymond \& St-Pierre (2010) compare the investment decision to the poverty trap. In other words, innovation or the lack thereof is selffulfilling. If all firms are engaging in R\&D behaviour, the risks are mitigated for investments in R\&D. Conversely, if no other firms are participating in R\&D activities, a firm that engages in R\&D faces much higher risk, as other firms can benefit without investment due to the spillover effect.

Regulatory pressures from regulations, such as employment, privacy, and environmental regulations, can add complexity to the R\&D process. Employment regulations may place limitations on firms conducting R\&D. For example, if firms need to hire R\&D staff, there may be a lack of qualified people domestically, and firms may need to hire international workers (Cocolakis-Wormstall, 2018). Many countries have limits on the number of international workers and impose work visa restrictions. As a result, employment regulations may have an impact on whether a firm decides to engage in intramural or extramural R\&D.

Privacy regulations can also have an impact on the R\&D process in specific fields. Advances in biometrics allow users to authenticate themselves through unique biological identifiers. Firms deciding to engage in this type of research must be compliant with privacy regulations or envision future changes to privacy regulations in their design. Environmental regulations may also increase the development costs and add additional compliance costs. Regulations such as 
the Restriction of Hazardous Substances (RoHS) require non-lead soldering or limit the use of recycled components such as circuit boards, resulting in higher costs.

Regulations and laws, however, play an important role in innovation. For the purpose of protecting its investment, a firm requires laws that protect its intellectual property. Jurisdictions with efficient intellectual property rights provide positive incentives for a firm to engage in R\&D (Brown, Martinsson \& Petersen, 2012; Slivko \& Theilen, 2014). In jurisdictions with insufficient intellectual property rights, a competitor can appropriate the innovation without any financial penalty, thereby giving firms little incentive to innovate. Firms situated in jurisdictions with strong property rights may still encounter issues as they must enforce their property rights. Enforcement can be a time-consuming and expensive process that requires legal representation. In addition, if the property is usurped in other jurisdictions with weak property rights, enforcement may be very difficult.

Market pressures also have an influence on the firm's decision to engage in R\&D. An essential part of R\&D is monitoring market developments. An innovation that is not fully researched from a market perspective may not be a success commercially. This market uncertainty is dependent on factors such as the economic cycle, customer preferences, and demographics (Oriani \& Sobrero, 2008). For example, Google launched Google Glass for retail customers in 2013. The eyewear was not well-received due to the price-point (US \$1500), its limited use, privacy concerns, and its bulkiness (Farr, 2017). Google discontinued the retail product in 2015, although it has been repurposed for enterprise use (Farr, 2017). Most companies do not have the financial resources of Google, and therefore, cannot afford a costly market oversight. 
The R\&D process can be considered to be a learning and knowledge acquisition process. Consequently, R\&D relies on financial resources, human capital, and physical resources to produce innovation (Lev, 2001). R\&D inputs include research personnel salaries, materials, and the appropriate machinery and equipment to produce intangible R\&D knowledge (Crisan \& McKenzie, 2017; Fagerberg, Srholec, \& Verspagen, 2010).

The procurement of equipment, supplies, and personnel requires considerable financial resources. Consequently, the decision to engage in $R \& D$ is highly dependent on the availability of financial resources (Czarnitzki \& Hottenrott, 2011). A firm should have enough financial resources to sustain the funding of salaries until a successful innovation is commercialized. The $R \& D$ process is not linear in which $R \& D$ staff work on innovation opportunities and a product or process necessarily results. R\&D often involves a trial and error process (Rosenberg, 1982). Correspondingly, firms need medium-term R\&D financing to obtain the required competence and skills (Romijn \& Albaladejo, 2002). Once the competence and skills are developed, there is often a lag between development and commercialization. In light of this, a firm needs adequate R\&D financing for potentially several years until a product or process is successfully commercialized (Romijn \& Albaladejo, 2002).

Financing for the sourcing needs and ongoing R\&D process can be difficult to obtain, due to some of the risks associated with R\&D. Financing for R\&D can be obtained through equity, debt, internal cash flows, and government incentives. Debt financing would need to be secured from the public market, private debtholders, or financial institutions. External debt can be difficult to obtain due to the riskiness of R\&D and asymmetry of information (Parsons \& Phillips, 
2007). The risks include the "uncertainty of returns, the technical nature of R\&D projects and the unwillingness of firms to disclose information to investors in fear of imitation by competitors" (Parsons \& Phillips, 2007, p. 30). Due to the risk and asymmetry of information, debt financing may require collateral, high interest rates, and borrowing covenants. Similar to debt financing, equity financing requires that existing or new investors provide additional capital in exchange for equity instruments. Effectively, the firm must find investors willing to invest in the company for potential growth based on its R\&D efforts.

Due to the potential risks of R\&D, a firm may have difficulty in raising equity and debt financing specifically for R\&D activities. Therefore, it is assumed that firms often rely on operational cash flows to fund R\&D (Bhagat \& Welch, 1995). Relying on free cash flow poses a couple of issues. Firstly, it assumes that a firm has sufficient free cash flow. Secondly, investments in R\&D may conflict with other priorities, such as hiring more staff or investing in operations. Some firms may have to choose between funding growth and investing in R\&D. Alternatively, given the challenges in sourcing financing through debt, equity, and internal cash flows, firms may decide to seek government incentives to fund R\&D activities.

$R \& D$ activities pose a number of risks to the financial stability of a firm. R\&D expenditures differ from other investments in that a reduction of expenditures may have an impact on the value of the work completed. Knowledge gained may be lost if the resources are reassigned or terminated. Similarly, Pandit et al. (2011) discuss the value-relevance of R\&D investments; in other words, it is uncertain whether the potential market value of the investment is greater than the book value of the cost of R\&D. Compared to other corporate expenditures such as 
production, there is an inherent risk in investing in R\&D due to uncertain outcomes (Ciftci \& Darrough, 2016). Efforts to create an innovation may not produce the expected results or even any tangible results. If $R \& D$ does not result in an artifact or process, a firm may have to contend with a total loss of the investment.

Human resources play a significant role in R\&D. Firms must source qualified individuals to perform R\&D work. The ability to develop innovation is highly dependent on the technology capabilities of a firm's R\&D department (Cappelen, Raknerud, \& Rybalka, 2011; Tsai, 2005). Access to qualified personnel is often dependent on the supply in a specific location, and can often be attributed to proximity to a university research laboratory, or R\&D centres of other related firms (Audretsch \& Feldman, 1996a). Therefore, firms that are not located in close proximity to a research university or corporate research centres may have more difficulty in sourcing qualified resources.

R\&D personnel should have the appropriate knowledge, technical skills, and training to perform the tasks associated with R\&D. A risk in sourcing is obtaining the relevant technical skills. An R\&D employee's technical skill may be limited to a specific technology, and it then cannot be exploited to create new products or processes. For example, Henderson \& Clark (1990) provide the example of semiconductor photolithographic alignment equipment in which the leading maker of contact aligners was unable to make the jump to produce proximity aligners due to a lack of technical knowledge. The scientists were experts in their field but did not have the experience of assimilating knowledge from external sources to innovate. Without the "right" resource, there may be wasted expenditures without a tangible artifact being produced. 
In addition to sourcing qualified R\&D personnel, retaining the personnel is a constant challenge (Romer, 2000). Given that the learning process is time-consuming, a loss of qualified personnel can have an impact on the development of new products or services. Further, the knowledge gained through R\&D activities is often tacit rather than codified (Hall, 2002; Rosenberg, 1982). Nonaka (1994) indicates that tacit knowledge is both cognitive and technical. The cognitive element involves creating models through mental manipulation of patterns or analogies (Nonaka, 1994). The technical element comprises of "concrete know-how, crafts, and skills that apply to specific contexts" (Nonaka, 1994, p. 16). In contrast to tacit knowledge, codification refers to the process of documenting and organizing knowledge into a set of rules and relationships (Kogut \& Zander, 1992). Knowledge that is tacit and not codified is more difficult to communicate and disseminate throughout the organization. As a result, when a resource leaves or a project is terminated, tacit knowledge often disappears with the resource. Unlike physical or financial assets, the knowledge gained is intangible and it not easily sold, embodied, or reused (Hall, 2002; Lev, 2001).

Physical resources may include buildings, information technology, equipment, and materials. Similar to procuring talent, procuring physical resources may also be challenging depending on the geographic location. The Covid-19 pandemic has also highlighted the fragility of global supply chains (Sharma, Adhikary, \& Borah, 2020). Further, resources used in the R\&D process tend to be unique and often result in little or no resale value (Ciftci \& Darrough, 2016; Lev, 2001). 
In addition to resources, firms require the appropriate systems and processes to be in place to engage in R\&D. In Christensen's (1997) framework, processes are defined as an organization's patterns of coordination, communication, and decision-making which enable the transformation of resources to create a new artifact. Fundamentally, the processes determine how and where the R\&D project will proceed. Processes can be formal, informal, or cultural (Christensen, 1997). Formal processes can include policies and procedures. Informal processes tend to be habits or routines. Cultural processes tend to be processes that a firm has employed for an extended period of time, such that people unconsciously follow them (Christensen, 1997).

External pressures and internal challenges may have an impact on the decision to engage in $R \& D$ and the scope of the R\&D activities. For example, assuming that there are no financial constraints, a firm may be forced to outsource their R\&D function to a supplier if it cannot source qualified personnel. Given the inherent risk of investing in R\&D, firms may choose not to undertake the cost of R\&D for an unknown or minimal marginal return. Due to these challenges, R\&D is generally under-invested within a firm (Busom et al., 2014; Marino, Lhuillery, Parrotta, \& Sala, 2016; Michael \& Pearce, 2009). In order to respond to the tendency to underinvest in $R \& D$, governments have sought to encourage $R \& D$ and create an environment with appropriate protections.

\subsubsection{Government intervention in R\&D}

To address the perceived under-investment in R\&D, governments use both policy and financial mechanisms. Table 1-1 lists the types of policy used by governments for R\&D purposes. Policy 
mechanisms are generally policies to protect an R\&D investment; they are not necessarily designed to encourage R\&D. However, these mechanisms can have an impact on the decision to engage in R\&D. Common policy interventions for R\&D include intellectual property rights, tariffs, and foreign direct investment regulations.

Intellectual property rights, such as patent protection, provide some security to firms that their innovation will not be usurped. Patent protections are generally more important for product innovations than process innovations, due to the possibility for the products to be reverse engineered (Brown et al., 2012). Without strong intellectual property rights, a firm may be reluctant to invest in R\&D (Brown et al., 2017; Slivko \& Theilen, 2014).

Table 1-1 Policy mechanisms used by government

\begin{tabular}{|l|l|}
\hline Policy mechanisms & Description \\
\hline Intellectual property rights & $\begin{array}{l}\text { Regulations and laws that allow firms to protect their } \\
\text { intellectual property through patents, enforcement } \\
\text { mechanisms, and loss provisions (Brown et al., 2017) }\end{array}$ \\
\hline Tariffs and quotas & $\begin{array}{l}\text { A mechanism that either restricts the number of imported } \\
\text { goods, or applies financial penalties to imported goods to } \\
\text { protect domestic product innovations (Reitzes, 1991) }\end{array}$ \\
\hline Foreign direct investment & $\begin{array}{l}\text { Policies that can either encourage or restrict investment by } \\
\text { foreign entities in R\&D-intensive firms }\end{array}$ \\
\hline
\end{tabular}

Tariffs and quotas can also be used as a policy mechanism to protect innovation development in its early stages (Reitzes, 1991). The use of tariffs ensures that the innovation artifact is cheaper to produce domestically, while the cost to import substitutes is higher. Quotas limit the number of imports of a specified innovation artifact. Tariffs and quotas, therefore, reduce external competition and allow domestic suppliers to extend their monopoly rents. The 
reduction of tariffs and quotas signals that a government is encouraging competition in an industry, and that the infant industry no longer needs protection (Reitzes, 1991).

A country may allow for foreign direct investment (FDI) to encourage expertise from other countries to permeate to domestic industries (Branstetter, 2006). By allowing FDI, governments hope for international knowledge spillovers into their countries. The spillover is considered a technology transfer that is thought to encourage innovation by building on external expertise not found in the host country (Wang, 2010). Alternatively, a country may restrict foreign direct investment in R\&D-intensive industries to prevent intellectual property from being exported to other countries.

In contrast to policy mechanisms, financial mechanisms are intended to encourage firms to engage in $R \& D$ and/or increase their investment in $R \& D$, by either reducing the cost of $R \& D$ or by providing direct funding to R\&D activities (Lester, 2012). Table 1-2 details the most common financial mechanisms used as government intervention. The primary financial mechanisms used by governments to incent R\&D include grants, contributions, loans, and tax incentives (McKenzie \& Sershun, 2010; Warda, 2002). Loan guarantees and insurance are also offered, although they are not the primary mechanisms used to incent $R \& D$, but are provided as a protection as well. 
Table 1-2 Financial mechanisms used by governments

\begin{tabular}{|l|l|}
\hline Financial mechanisms & Description \\
\hline Grants & $\begin{array}{l}\text { An unconditional government transfer payment in which the } \\
\text { government seeks to advance a policy goal. Acceptance is based on } \\
\text { eligibility criteria and objectives (Treasury Board of Canada } \\
\text { Secretariat, 1995) }\end{array}$ \\
\hline Contributions & $\begin{array}{l}\text { A conditional government transfer payment based on reimbursing } \\
\text { the recipient for expenditures according to specified terms and } \\
\text { conditions (Treasury Board of Canada Secretariat, 1995) }\end{array}$ \\
\hline Loans & $\begin{array}{l}\text { A government transfer which is repayable, normally with interest, } \\
\text { and with a predetermined repayment schedule }\end{array}$ \\
\hline Loan guarantees & $\begin{array}{l}\text { A mechanism in which the government provides protection to a } \\
\text { creditor in case of default (Treasury Board of Canada Secretariat, } \\
\text { 1995) }\end{array}$ \\
\hline Loan insurance & $\begin{array}{l}\text { A mechanism in which the government protects a creditor in case } \\
\text { of default, but the loan recipient pays insurance premiums for the } \\
\text { guarantee (Treasury Board of Canada Secretariat, 1995) }\end{array}$ \\
\hline Tax incentives & $\begin{array}{l}\text { A mechanism to reduce a firm's taxable income and/or tax liability } \\
\text { (Warda, 2002) }\end{array}$ \\
\hline
\end{tabular}

Grants and contributions are generally part of a government program to encourage

investments in a particular sector or location. A contribution is similar to a grant; however, contributions tend to be conditional and the recipient firm is required to submit progress reports and provide a full accounting of the use of the funds (Lester, 2012). For example, the Industrial Research Assistance Program (IRAP) is a contribution program that is operated by the Canadian National Research Council and provides financial assistance for youth employment and technology innovation projects (National Research Council, 2019).

Government loans also consist of a transfer of funds, but there is a repayment schedule. For example, the Southern Ontario Fund for Investment in Innovation provides loans of up to $\$ 500,000$ to SMEs for late-stage commercialization, new products, services, applications or markets, and implementation of new process or technologies (Federal Economic Development 
Agency for Southern Ontario, n.d.). Although government loan guarantee and insurance programs do not provide direct funds, these mechanisms reduce the risk to creditors. As a result, creditors may be more willing to lend money to firms to engage in R\&D activities.

The benefit of grants, contributions, and loans is immediate cash flow for R\&D projects. Grants and contributions may be most beneficial to firms with capital constraints (Busom et al., 2014). Loans would require consistent cash flow to meet the repayment terms and interest payments; therefore, may not be the best option for cash-constrained firms. A criticism of these financial mechanisms may be the arbitrariness of firm selection by governments (Lester, 2012; Warda, 2002). Specific industries or firms may be targeted for grants and payments. In such cases, the government is determining what constitutes valuable R\&D, and what industry it is promoting (Lentile \& Maresse, 2009; Warda, 2002). Opportunities to obtain loans, grants, and contributions might also encourage lobbying efforts. For example, manufacturing firms or industry associations may lobby for additional subsidies for firms in their industry.

Tax incentives are considered an indirect form of assistance as these mechanisms reduce a firm's taxable income and/or tax liability, either after the R\&D activities are completed or after a set period of time (e.g., at the end of the fiscal year). Tax incentives are generally viewed as more neutral than direct subsidies or loans, as they apply to all firms that file taxes (Baghana \& Mohnen, 2009; Kobayashi, 2014). Once a firm files its taxes, the benefit to the firm from the tax incentive is evaluated through a set of criteria.

There is growing research interest in the evaluation of R\&D tax incentives. Approximately twothirds of developed countries use tax incentives as a mechanism to encourage innovation 
(Crespi, Giuliodori, Giuliodori \& Rodriguez, 2016). Developing countries, such as Argentina, have recently employed R\&D tax credits to encourage innovation and economic growth (Crespi et al., 2016). The increased interest in the study of R\&D tax incentives may be attributed to the need to determine the efficacy of these increasingly popular mechanisms in encouraging innovation. Similarly, this thesis focuses on tax incentives as a mechanism to encourage R\&D investment.

\subsubsection{Tax incentives}

Tax incentives include exemptions, rate relief, allowances, credits, accelerated depreciation, and deductions (Warda, 2002). Exemptions and rate relief are not used as extensively as the other tools for spurring R\&D activity (Warda, 2002). Exemptions allow firms to exclude expenditures or income from their tax base (Warda, 2002). For example, the Canadian personal lifetime capital gains exemption on the disposition of qualified property, such as qualified small busines corporation shares, allows for the exclusion of the proceeds from net and taxable income. Rate relief, on the other hand, reduces the corporate income tax rate for firms that conduct specific activities or operate in certain industries. The Canadian Small Business Deduction (SBD) (ITA 125) would be an example of a rate relief mechanism that reduces corporate income tax for small Canadian CCPCs.

The primary instruments used to encourage $R \& D$ include allowances, tax deferrals, tax deductions, and tax credits (Warda, 2002). Allowances permit firms to deduct additional sums over their current business expenses to reduce taxable income. In 1978, the scientific research 
allowance allowed for an additional deduction of $50 \%$ of scientific research expenditures for incremental spend over and above the previous three-year average.

Tax deferrals, in contrast, allow the firms to delay the payment of tax through methods such as accelerated depreciation (Warda, 2002). It should be noted that current deductions for R\&D expenditures can be considered as a form of tax deferral (Warda, 2002). Tax deductions allow firms to deduct expenses from their net and taxable income. In accounting terms, R\&D expenditures are not considered to be expenses as they do not generate immediate income; they are an investment to produce future income opportunities (Warda, 2002). By allowing the expenditures to be expensed in a given year, rather than to be expensed proportionally, the tax deduction operates similarly to accelerated depreciation (Hall, 2002).

Tax credits are a distinctly different mechanism as tax credits reduce a firm's tax liability (Busom et al., 2014). Once a firm's taxable income is calculated, a tax credit is applied to reduce the taxes payable to the government. As an example, in 1977, the Canadian government introduced investment tax credits (ITCS) for both capital and current expenditures related to R\&D activities. These ITCs allowed firms to deduct a percentage of their capital and current expenditures from their taxes payable to the government.

By reducing a firm's taxable income or taxable liability, R\&D tax incentives reduce a firm's cost of engaging to develop R\&D. The effectiveness in reducing $R \& D$ expenditures depends on the structure of the tax incentive and the firm's characteristics. For example, a tax credit that does not have any carry forward or refundability provisions may not be helpful to firms that do not have a tax liability. A refundable tax credit allows firms to claim a refund for the portion that 
exceeds their tax liability. Similarly, for tax credits that allow carryovers, the unused portion can be carried forward to future years when the firm presumably will have a taxable liability, or the unused portion can be carried back to previous years in which there was a tax liability. Refundable tax credits may be especially useful for smaller cash-constrained firms, as the credits not only reduce their tax liability but provide cash flow to continue their R\&D activities.

The design of a tax incentive may also influence the R\&D behaviour of firms. For example, tax credits can be level-based or incremental (Warda, 2002). Level-based (also called volumebased) tax credits reduce the tax payable by every dollar of R\&D expense incurred multiplied by the tax credit rate (Hall, 2002). The current SR\&ED tax credit qualifies as a level-based tax credit. In contrast, the increment-based tax credit reduces the tax liability only by the incremental spending over a base level. Currently, the U.S. R\&D tax credit is an incrementbased tax credit (Klassen, Pittman \& Reed, 2004). Given its design, incremental tax credits are meant to encourage increases in R\&D spending from a specified base level. Level-based tax credits, on the other hand, provide tax relief for R\&D spending, regardless of any change in spending level from previous periods.

Issues with tax incentives include a higher marginal cost of R\&D for those firms that cannot take advantage of the tax incentives (Berger, 1993). Other criticisms include the potential for encouraging short term R\&D projects rather than longer-term value-producing projects. Similarly, the participation persistence of R\&D tax credits has been raised as a potential issue (Busom, Corchuelo, \& Martínez-Ros, 2017). In effect, some firms appear to apply for the tax credit on an annual basis. The extent to which these firms would participate in R\&D without 
the tax incentive is unclear (Busom, 2000). Concerns also include the cost of the bureaucracy required to manage the tax incentives and ensure compliance, which should be factored into the cost of the programs (Parsons \& Phillips, 2007). However, the primary concern of researchers relates to whether tax incentives encourage additional R\&D investment (additionality) or displace private investment (crowding-out) (Marino et al., 2016).

Considerable research has been conducted on the efficacy of R\&D tax incentives on the R\&D behaviour of firms. It is assumed that the goal of government intervention is to encourage additionality behaviour. Additionality denotes that there is a positive change in the behaviour of a firm due to an event or a treatment (Clarysse et al., 2009; Hsu et al., 2009). The concept of crowding-out exists in juxtaposition to a positive change in firm behaviour. The concept of crowding-out can be described as using public funds for R\&D projects that would have been undertaken regardless of obtaining public funds (Marino et al., 2016).

From a sample of articles relating to R\&D tax incentives (see Appendix B), the findings, by and large, are concerned with additionality versus crowding-out behaviour. Table 1-3 outlines a summary of the findings concerning additionality versus crowding-out. A number of articles $(n=22)$ found that R\&D tax incentives resulted in additionality behaviour, while only one article did not. Four articles addressed the issue of crowding-out, with two indicating that there is evidence of crowding-out, and two indicating there is not. Eleven articles had mixed results on additionality and crowding-out based on the size of the firm, the industry, and the country in which the firms reside. 
Table 1-3 Findings of R\&D tax incentive research sample

\begin{tabular}{|c|c|}
\hline Findings & References \\
\hline$R \& D$ tax incentives increase $R \& D$ expenditures & $\begin{array}{l}\text { (Agrawal, Rossel, \& Simcoe, 2020; Berger, } \\
\text { 1993; Bernstein, 1986; Billings, Glazunov, } \\
\text { \& Houston, 2001; Bloom et al., 2002; } \\
\text { Castellacci \& Lie, 2015; Crisan \& McKenzie, } \\
\text { 2017; David, Hall, \& Toole, 2000; Hall \& } \\
\text { Van Reenen, 2000; Harris et al., 2009; } \\
\text { Klassen et al., 2004; Kobayashi, 2014; } \\
\text { Mansfield, 1986; Mansfield \& Switzer, } \\
\text { 1985a, 1985b; Minniti \& Venturini, 2017; } \\
\text { Rao, 2016; Russo, 2004; Yang, Huang, \& } \\
\text { Hou, 2012) }\end{array}$ \\
\hline $\begin{array}{l}R \& D \text { tax incentives do not increase } R \& D \\
\text { expenditures }\end{array}$ & (González \& Pazó, 2008) \\
\hline $\begin{array}{l}\text { R\&D tax incentives increase R\&D outcomes } \\
\text { such as patents and new products }\end{array}$ & $\begin{array}{l}\text { (Bérubé \& Mohnen, 2009; Bösenberg \& } \\
\text { Egger, 2017; Czarnitzki, Hanel, \& Rosa, } \\
\text { 2010) }\end{array}$ \\
\hline $\begin{array}{l}\text { R\&D tax incentives "crowd-out" private R\&D } \\
\text { expenditures }\end{array}$ & $\begin{array}{l}\text { (Mamuneas \& Nadiri, 1996; Marino et al., } \\
\text { 2016) }\end{array}$ \\
\hline $\begin{array}{l}\text { R\&D tax incentives do not "crowd-out" private } \\
\text { R\&D expenditures }\end{array}$ & $\begin{array}{l}\text { (Czarnitzki \& Delanote, 2015; González \& } \\
\text { Pazó, 2008) }\end{array}$ \\
\hline $\begin{array}{l}\text { Mixed results based on size, industry, and/or } \\
\text { country }\end{array}$ & $\begin{array}{l}\text { (Baghana \& Mohnen, 2009; Bhagat \& } \\
\text { Welch, 1995; Brown et al., 2017; Busom et } \\
\text { al., 2014; Cappelen et al., 2011; Clarysse et } \\
\text { al., 2009; Crespi et al., 2016; Koga, 2003; } \\
\text { Lach, 2002; Lester, 2012; Radas, Ani, } \\
\text { Tafro, \& Wagner, 2015) }\end{array}$ \\
\hline
\end{tabular}

The literature differentiates between three types of additionality: input, output, and behavioural. Input additionality can be described as the extent to which public intervention increases R\&D efforts (i.e. R\&D expenditures, projects, or employees) (Clarysse et al., 2009; Hsu et al., 2009). Output additionality refers to the number of outcomes such as patents, products, or publications that would not have been completed without government intervention (Clarysse et al., 2009; Hsu et al., 2009). Behavioural additionality are changes to a firm's behaviour as a result of government support (Clarysse et al., 2009; Hsu et al., 2009). These 
behaviours include increased project scope, strategy formulation, cost-effectiveness behaviour, and commercialization behaviours (Hsu et al., 2009).

Crowding-out has been studied due to concerns of a negative cost-benefit of the public support programs (Lester, 2012). If R\&D public incentives displace private funding, it would seem that the intended goal to encourage R\&D would not be met. Furthermore, if there is some crowding-out, the extent of the displacement (i.e., partial or total) is unclear. Crowding-out is not limited to R\&D investment. Crowding-out can also include R\&D projects and R\&D employees (Lach, 2002). Project crowding-out can be described as the undertaking of projects to meet the public funding requirements, in lieu of projects that would have been chosen without funding (Busom, 2000; Lach, 2002). Similarly, R\&D employee crowding-out can occur as a result of public funding, in which the increased demand for these employees results in higher labour costs. Consequently, non-funded projects that had been previously accepted may be terminated due to cost constraints (Hall \& Van Reenen, 2000; Lach, 2002).

With the lack of conclusive evidence for additionality or crowding-out behaviour, it would appear that there is a lack of understanding of the R\&D behaviour of firms in the context of $R \& D$ tax incentives. $R \& D$ tax incentives are a common government financial mechanism in both developed and developing countries, but the incentives tend to be applied in the same manner to all firms and sectors, without consideration of firm-specific characteristics (Crespi et al., 2016). For example, R\&D tax incentives are often the same across industries such as manufacturing and software development, even though the two industries may differ in required capital expenditure intensity. Due to the lack of targeting, there may be a 
misalignment of incentives due to asymmetric information (Crespi et al., 2016). Essentially, policy makers do not have the full information on firms' motivations to engage in and manage R\&D.

\subsubsection{Canadian tax incentives - an evolution}

In Canada, the government has used the Income Tax Act (ITA) to encourage R\&D activities (Murray, 1995; Warda, 2002). The government's motivation to assist in R\&D activities seems to have commenced as early as 1944. Since 1944, the Canadian government has used tax deductions, tax allowances, and ITCs to encourage R\&D activities. Figure 1-4 provides a pictorial representation of the changes to the main tax incentives.

Figure 1-4 Evolution of Canadian government intervention for R\&D

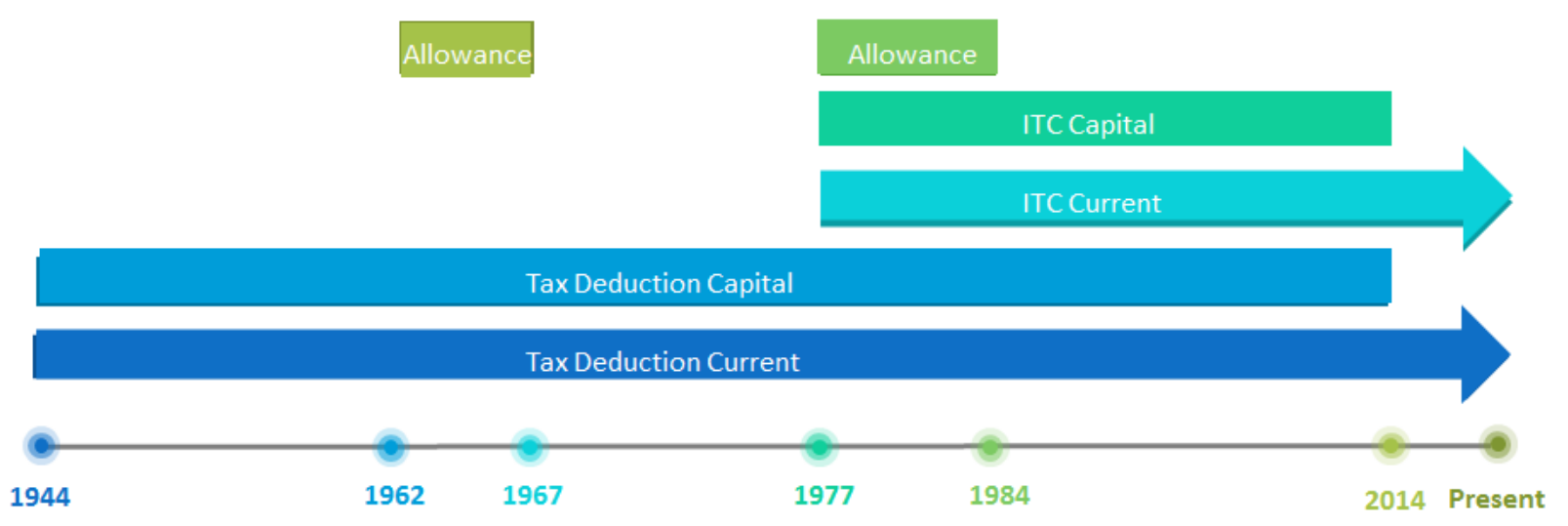

In 1944, the Government of Canada employed a mechanism that permitted firms to deduct 100 percent of their current expenditures and one third of their capital expenditures incurred while performing scientific research against their taxable income. The Income War Tax Act defined scientific research as "any activity in the field of natural or applied science for the extension of 
knowledge". The deductions introduced in 1944 against taxable income persisted with some minor changes and incentives for increased spending until 1967.

In 1967, the Canadian government changed course and added an additional measure other than tax deductions. The intent of the program was to provide funding to firms that did not benefit from a reduction of taxable income (Murray, 1995). From 1967 until 1975, the Industrial Research and Development Incentives Act (IRDIA) provided a grant equal to 25 percent of current and capital expenditures for incremental spending over a five-year average base level of expenditure. In 1975, the program was repealed due to government spending restraints (Murray, 1995).

Post the IRDIA program, the tax deductions for current and capital expenditures for scientific research remained in force. In 1977, the government introduced the scientific research investment tax credit (ITC) that provided a range of tax credit rates on current and capital expenditures dependent on region. From 1978 to 1983, a research allowance was also accessible to firms to obtain an additional tax credit on scientific research for incremental spending over a base level.

A revamp of the $R \& D$ tax incentive program was rolled out in the 1983 Government of Canada Budget. The research allowance was substituted with an increase to the scientific research ITC basic rate, along with an increase to the ITC rates for the Atlantic Provinces, the Gaspé region, and small CCPCs (Department of Finance, 1983). Modifications were also made to the carryover and refundability provisions. The carryforward period was extended to seven years, and a three-year carryback provision was introduced. In addition, limited refunds were 
available for unused ITCs. Therefore, if a firm's taxable income was lower than the ITC, the firm could receive a portion of the ITC as direct funds. The provisions allowed refundability of unused ITCs for small CCPCs up to 40\%; whereas larger firms were limited to 20 percent refundability. Finally, in order to encourage additional investment in R\&D, the Scientific Research Tax Credit (SRTC) was also introduced in 1983 in which firms could transfer their R\&D tax incentives to external investors in exchange for a 50 percent tax credit (Department of Finance, 1983).

Effective 1985, due to concerns about the "quick flip" of SRTC investments, the SRTC program was repealed (Department of Finance, 1985). In addition, in 1985, based on the feedback from the R\&D community (Department of Finance, 1985) expansion of the refundability provisions and changes to the definitions of eligible R\&D expenditures were announced. The refundability provisions were extended for small CCPCs in which CCPCs could take advantage of 100 percent refundability on unused ITCS on the first $\$ 2$ million of eligible current expenditures and $40 \%$ on capital expenditures. The scope of R\&D expenditures was also expanded by allowing "all or substantially all" and "directly attributable" to R\&D activities, replacing the requirement that $R \& D$ expenditures must be incremental (i.e., wholly attributed to R\&D activities) (Department of Finance, 1985). For example, if management personnel spent 95 percent of their time on R\&D activities, management salaries could be included as a qualified expenditure.

In 1986, the term "experimental development" was added to the Scientific Research investment tax credit. The Canada Revenue Agency refers to experimental development "as work undertaken for the purpose of achieving technological advancement for the purpose of 
creating new or improving existing materials, devices, products or processes, including incremental improvements thereto". Consequently, the tax incentive program was renamed to the Scientific Research and Experimental (SR\&ED) program. Since 1986, the SR\&ED tax incentives remain the main mechanism to encourage R\&D activities within Canada.

From 1987 to 1992 , minor changes to the program were made including the extension of the carryforward period and a fast-track mechanism to reduce the turnaround time to process SR\&ED (Iqbal, 1995). In 1992, the federal budget outlined changes to the calculation of eligible overhead expenses and the eligibility of capital expenditures. In order to determine overhead expenses, an alternate method, the proxy method, was introduced. The prescribed proxy rate was $65 \%$ based on the salaries attributed to SR\&ED-eligible activities. Previously, the only method available was the direct method in which taxpayers were required to delineate the incremental overhead expenditures (i.e., directly attributable to SR\&ED-eligible activities). In addition, the eligibility of eligible capital expenditures for machinery and equipment was expanded by allowing the capital asset to be dedicated to SR\&ED-eligible activities for a minimum of 50 percent, rather than the more restrictive requirement of at least 90 percent. From 1994 to 2012, no major changes were introduced to the SR\&ED program. In this time period, the ITC rate differential for regions was removed, however, the small CCPC limits on taxable income and taxable capital employed in Canada were increased. In addition, the expenditure limit for CCPCs was increased to $\$ 3$ million, and the carryforward was extended to 20 years. Other changes included allowing recognition of third-party contract expenditures for 
SR\&ED activity and expenditures incurred by Canadian resident employees carrying out SR\&EDeligible activities outside of Canada.

Significant changes were introduced in 2012 that became effective in 2014. Firstly, capital expenditures and lease costs were no longer considered qualified SR\&ED expenditures. Further, the prescribed proxy rate was reduced to $55 \%$ and the basic ITC rate (non-CCPC) was reduced to $15 \%$. Additional restrictions to third party contact payments were also introduced.

From 1944 to present, the changes to definitions and eligible expenses may indicate that the scope of R\&D and the character of R\&D expenditures has evolved. Initially, the R\&D expenses that were eligible were categorized as "scientific research". In 1986, the term "experimental and development" was added to amend the definition of eligible R\&D activities; thus, extending the scope of recognized $R \& D$ activities.

Over the span of the program, the definition of eligible expenses has changed. These changes may be in response to industry concerns or may be a response to specific challenges in the R\&D community. For example, the Canadian Government Budget in 1985 outlined that by allowing "all or substantially all" activities be attributed to R\&D activities would be of benefit to smaller firms whose management may engage in R\&D activities (Department of Finance, 1985).

Similarly, the inclusion of the proxy method was meant to reduce "the compliance burden on taxpayers, particularly for smaller firms which may lack detailed accounting systems" (Department of Finance, 1992, p. 156). However, some of the changes may be due to the cost of the program or compliance. The elimination of the SRTC was attributed to concerns of abuse of the program (Department of Finance, 1985). Comparably, the rationale provided in Budget 
2012 for the removal of capital expenditures as both a deduction and as a basis for an ITC was simplification of the program as the requirements to comply with the capital expenditures were deemed too complex (Department of Finance, 2012a).

The evolution of ITC rates may also be an indication of the government's desire to support specific regions and small CCPCs. For example, in 1978, the tax credit was $10 \%$ for large firms and $20 \%$ for firms located in the Atlantic provinces and Gaspé region (Mansfield \& Switzer, 1985a). In addition, smaller firms received a $20 \%$ credit (enhanced rate) for eligible expenditures. By 1994, the location provisions had been removed, although the tax credit rate differential between CCPCs and larger firms remained.

Similar to the retention of enhanced rates for CCPCs, the refundability provisions may also indicate the government's intent to assist small CCPCs. Prior to 1983, the unused credits could be used as a carryforward for five years. With the expansion of the carryforwards and the refundability of unused ITCs, it appears that the government was responding to the specific conditions of smaller firms that may not have extensive taxable income and are faced with resource constraints. The 1985 Budget Papers reflects this assumption as it states, "unused credits will be of most use to small start-up R\&D firms who may not otherwise be able to use tax incentives immediately and the measure will provide additional financing at this stage of their development" (Department of Finance, 1985, p. 15).

The forms, information, and documentation required to file for the SR\&ED program have also evolved. In 1998, form T2038 (Investment Tax Credit) was introduced as a form to be filed with the Ministry of National Revenue to obtain a SR\&ED tax credit. In 2008, CRA implemented a 
new short-form (T661) and also introduced a guide (T4408) to assist with filling in the appropriate forms. Due to the complex requirements of the SR\&ED program and the details required to fill out the T661, a number of firms may need assistance to file. Some SR\&ED advisory firms and specialized SR\&ED departments in accounting firms have been established to assist with the preparation of SR\&ED claims. In 2012, concerns about the contingency fees charged by some preparers and the potential impact on the SR\&ED program resulted in a call for public consultation by the Government of Canada (Department of Finance, 2012b). In 2013, the T661 was amended to require that firms report who assisted in the preparation of the form, and CRA introduced penalties for filing the T661 incorrectly.

\subsubsection{Current SR\&ED rules}

The Canadian government employs the SR\&ED program to incent R\&D activities. Specifically, the SR\&ED tax incentive aims to reduce the costs of eligible R\&D activities for firms by subsidizing a percentage of the investment in R\&D. This subsection's purpose is to outline the incentives for firms to apply for the SR\&ED program and the entities that are eligible for SR\&ED incentives. In order to better understand how SR\&ED tax incentives subsidize the costs of engaging in R\&D, this subsection evaluates what constitutes an eligible SR\&ED expenditure, how these expenditures are pooled to allow for a tax deduction and used to calculate the ITC, and the differences in treatment based on the type of taxpayer. This subsection also provides insight on the forms used to calculate SR\&ED rebates.

Firms are incented to apply for the SR\&ED program to reduce their taxable income by deducting their SR\&ED expenditures in the current year, or by carrying forward these 
expenditures indefinitely (ITA 37). In addition, for ITCs obtained after 1997, depending on the taxpayer and the tax liability, firms may be eligible for refundable ITCs, that can be either carried back three years or carried forward 20 years (ITA 127). The SR\&ED activity must have already taken place and expenditures must have been incurred. SR\&ED tax incentives are not a grant, as the funds are not provided in advance of work being done.

The SR\&ED program is open to claimants that incur eligible SR\&ED expenditures and meet the filing requirements. Specifically, CCPCs, other corporations (i.e., not a CCPC), proprietorships (individuals), partnerships, and trusts can apply for the SR\&ED program. In order to be classified as a Canadian-Controlled private corporation CCPC, as per ITA 125(7), a firm must meet all the following requirements at the end of the tax year:

- It is a private corporation

- The corporation resides in Canada and was incorporated in Canada

- It is not controlled directly or indirectly by a non-resident and/or public corporation - No class of shares is listed on a designated stock exchange

Not all expenditures related to SR\&ED-eligible activities can be claimed. Eligible current SR\&ED expenditures are defined under ITA 37 and include labour, materials consumed or transformed, subcontracts and third-party payments, and current expenditures that are directly related to SR\&ED-eligible activities. ITA 37(8) also allows firms to use the traditional or proxy method to calculate the eligible SR\&ED expenditures. Appendix C outlines the differences between the traditional method and the proxy method in the calculation of eligible current SR\&ED expenditures. Regardless of the method, eligible SR\&ED expenditures are recorded and allocated on a project basis. 
The eligible SR\&ED expenditures are first used to calculate the tax deduction. The tax deduction outlined in ITA 37(1) allows claimants to deduct current SR\&ED expenditures in the year they are incurred, or to carry forward these expenditures indefinitely. ITA 37(1) allows for the expenditures to be accumulated over time in a SR\&ED expenditure pool, and it is recalculated based on any new expenditures and adjustments necessary. The pool is calculated by taking the total current expenditures and deducting any government and non-government assistance for SR\&ED expenditures and SR\&ED ITC that had been claimed in the previous tax year. Subsequently, both the previous year's SR\&ED expenditure pool balance and the amount of ITC recaptured (as per ITA $37(1)(c 2),(c 3)$ ) are added to the SR\&ED pool. If there is a negative balance in the pool of deductible SR\&ED expenses at the end of the tax year, as per ITA $37(1)(c 1)$, the negative amount must be reported as income in that year to ensure that the pool has a nil balance for the subsequent year.

The expenditures included in the SR\&ED expenditure pool are also used to determine the "qualified expenditures" that are used to calculate SR\&ED ITCs as per ITA 127. According to ITA 127(9), qualified SR\&ED expenditures include SR\&ED salary and wages, expenditures for materials for SR\&ED, contract expenditures for SR\&ED performed on behalf of a claimant, thirdparty payments, and SR\&ED overhead. However, ITA 127(9)(ii) specifies that only $80 \%$ of arm's length contract expenditures and third-party payments can be considered qualified SR\&ED expenditures. Qualified expenditures are also reduced by any current expenditures that are not paid within 180 days of the end of the tax year. 
Once the qualified expenditures are calculated, the ITC is calculated at a specified rate depending on the taxpayer type and size. In addition, depending on the taxpayer type and size, once the tax liability is exhausted by the ITC, the unused portion of the ITC can be refundable. Table 1-4 outlines the ITC and refundability rates. The determination of whether a CCPC is eligible for the enhanced rate is outlined in ITA 127 (10.2). ITA 127 (10.2) specifies that eligibility is based on taxable income and taxable capital employed in Canada (TCEC).

Table 1-4 SR\&ED ITC rate and refundability rate

\begin{tabular}{|l|l|l|}
\hline Entity & ITC rate & Refundability rate \\
\hline Proprietorships (individuals), partnerships, or trusts & $15 \%$ & $40 \%$ \\
\hline CCPC & & \\
\hline Up to \$3 million expenditure limit (enhanced rate) & $35 \%$ & $100 \%$ \\
\hline Greater than \$3 million expenditure limit & $15 \%$ & $40 \%$ \\
\hline Corporations other than CCPCs & $15 \%$ & Not applicable \\
\hline
\end{tabular}

Rates effective as of 2020, Income Tax Act

For CCPCs with a year-end prior to March 2019, the taxable income must be less than $\$ 500,000$ to be eligible for the enhanced rate for the first $\$ 3$ million expenditures. If taxable income exceeds $\$ 500,000$, the $\$ 3$ million expenditure limit is reduced until its taxable income exceeds $\$ 800,000$. If its taxable income reaches $\$ 800,000$, the CCPC is ineligible for the enhanced rate. The taxable income restriction was removed in the Government of Canada Budget 2019, although ITA 127 (10.2) retains the TCEC restrictions (Government of Canada, 2019). If the TCEC exceeds $\$ 10$ million, the annual SR\&ED expenditure limit of $\$ 3$ million is clawed back. Once the TCEC reaches $\$ 50$ million, the SR\&ED expenditures incurred are no longer eligible for the enhanced rate. The $\$ 10$ million TCEC threshold for the SR\&ED program is similar to the TCEC threshold for the SBD described in ITA 125. The SBD can be employed by CCPCs with a TCEC of less than $\$ 10$ million. For CCPCs that have a TCEC that exceeds $\$ 10$ million, the SBD is 
clawed back until the TCEC reaches $\$ 15$ million. Essentially, CRA determines a CCPC to be small if the TCEC is less than $\$ 10$ million.

Currently, the SR\&ED ITC is $100 \%$ refundable for small CCPCs for qualified current expenditures, up to the expenditure limit. In effect, once the tax liability is exhausted, the CCPC can receive $100 \%$ of the residual amount as a cash payment. If the expenditures exceed the $\$ 3$ million threshold, the refundability rate reduces to $40 \%$ for expenditures that are now subject to the $15 \%$ ITC rate.

In order to apply for the SR\&ED claim, claimants are required to fill out form T661 (see Appendix A). Corporations other than a CCPC must also fill out $\mathrm{T} 2 \mathrm{SCH} 31$ and individuals must fill out a T2038(IND). Depending on the type of expenditure and if the CCPC is associated with other CCPCs, the claimant will be required to complete additional forms. If any of the SR\&ED expenditures are third-party payments, a T1263 form must also be completed. If CCPCs are associated, claimants also need to complete a $\mathrm{T} 2 \mathrm{SCH} 49$ form to allocate the expenditure limit among the associated corporations. Similarly, if a specified employee (i.e., not at arm's length) is allocated to SR\&ED projects and works at two or more of the associated companies, claimants must fill out a T1174 form. The required forms are filed together with the appropriate tax return for the entity (e.g., T1, T2, or T3). The taxpayer has up to 12 months after the filing due date to submit their SR\&ED claim.

CRA provides a number of advisory services to assist with the application for the SR\&ED program, including seminars and self-assessment tools (Canada Revenue Agency, 2015b). For example, CRA offers pre-claim consultations that will provide a preliminary written report 
outlining whether the claim/s are eligible for SR\&ED tax incentives (Canada Revenue Agency, 2015b). The pre-claim consultation can be requested for a maximum of three projects per year that are either in progress or have been completed.

\subsection{Managerial problem}

The aim of this section is to better understand the managerial challenges associated with engaging in the SR\&ED program and managing SR\&ED practices. The reasons for the evolution of the SR\&ED program may be multi-faceted, but it is unclear why firms may or may not apply for the SR\&ED program. The R\&D process can be complicated, and challenging to manage, document, and finance. These challenges may have an impact on a firm's decision to file for the SR\&ED program, how the program is employed, and the management of SR\&ED practices. As the history of the Canadian government intervention illustrates, the SR\&ED program has evolved to assist small SMEs through enhanced ITCs and refundability provisions. Governments often focus their innovation policies on SMEs assuming that these firms encounter financing constraints with investing in R\&D (Baghana \& Mohnen, 2009). Consequently, this section also evaluates the characteristics of SMEs and the managerial challenges with the SR\&ED program activities.

Based on the design of the SR\&ED program, the program assumes that underinvestment in R\&D may be due to financial constraints. The incentives assume that firms' R\&D program is not as robust due to financial constraints and competing demands on cash flow (Klassen et al., 2004). Nonetheless, the SR\&ED program may not adequately address the challenge with financial constraints. The SR\&ED ITC provides for a reduction of the tax liability or a refund of the 
unused portion only after the expenses have been incurred. Consequently, firms need adequate external financing or free cash flow to fund SR\&ED-eligible activities before they can receive the refund. The lag in funding may deter some firms from engaging in SR\&ED-eligible activities or limit the scope of their activities. It is also uncertain whether the ITC percentage is sufficient to entice firms to engage in the SR\&ED program or expand their SR\&ED-eligible activities.

It is broadly accepted that R\&D is expensive, time-consuming, and has uncertain outcomes (Lev, 2001). Given this, it can be assumed that the decision to engage in R\&D is not generally made in haste. However, a number of SMEs may engage in R\&D, but do not take advantage of the SR\&ED program. There is a lack of clarity as to which SMEs in Canada engage in R\&D, the type of R\&D, where the activities take place, the R\&D intensity, and how R\&D is practiced. Due to the specific characteristics and challenges of SMEs, this thesis focuses on SMEs and their association with the SR\&ED program.

\subsubsection{Small and Medium Enterprises (SMEs)}

SMEs cannot be assumed to be a smaller version of a large company (Welsh \& White, 1981). The characteristics of a larger firm do not necessarily manifest themselves in a SME. For example, most SMEs are owner-operated; as a result, a separation of ownership and management most likely does not exist. Given the differences, it cannot be assumed that decision-making and management within a SME operates in the same manner as in a larger firm. Table 1-5 outlines the distinctive characteristics of SMEs. 
Table 1-5 SME characteristics

\begin{tabular}{|c|c|}
\hline Firm characteristics & Description \\
\hline Ownership and management & $\begin{array}{l}\text { - Mostly owner-operated } \\
\text { - } \quad \text { Centralized decision-making }\end{array}$ \\
\hline Values & $\begin{array}{l}\text { - Behaviour and culture influenced by the owner } \\
\text { - Results-oriented }\end{array}$ \\
\hline Systems and processes & $\begin{array}{l}\text { - } \text { Simple and flexible structure } \\
\text { - } \text { Flexible communication flows } \\
\text { - Low degree of specialization } \\
\text { - Simple planning and control system } \\
\text { - Focus on operations rather than strategy } \\
\text { - Low degree of formal processes and procedures }\end{array}$ \\
\hline $\begin{array}{l}\text { Resources: financial, human, } \\
\text { and physical }\end{array}$ & $\begin{array}{ll}\text { - } & \text { Resource constraints } \\
\text { - } & \text { Versatile and low resistance to change } \\
\text { - } & \text { Closer and informal working relationships }\end{array}$ \\
\hline Market & $\begin{array}{l}\text { - Dependent on a small customer base } \\
\text { - } \quad \text { More frequent contact with customers }\end{array}$ \\
\hline
\end{tabular}

Adapted from Wong \& Aspinwall (2004)

SMEs are mostly owner-operated with a central decision-making function (Torres, 2004; Wong

\& Aspinwall, 2004). Owners and their managers set the goals and expectations and make the decisions within a firm. Consequently, management has a high degree in involvement in the day-to-day operations. In general, SMEs can be characterized by the existence of a management group that may have modest management skills and competencies (Laforet \& Tann, 2006; Wong \& Aspinwall, 2004).

With a small number of employees, SMEs often have shared values and vision. The values in SMEs are often heavily influenced by the owner of the firm (Laforet \& Tann, 2006; Wong \& Aspinwall, 2004). Another SME characteristic is that the firm is results-oriented (Wong \& Aspinwall, 2004). As there is little organizational slack, most of the team is focused on the goals set by the owner and management. 
SMEs often have a simple and flexible structure. Due to the flat structure and open lines of communication, goals, and expectations are often well known throughout the company (Wong \& Aspinwall, 2004). This structure also allows for easier diffusion of information throughout the organization. Due to this flexible structure, employees rarely specialize in a particular task. Employees tend to perform multiple functions and are generalist in nature.

Due to the flat structure and financial constraints, the systems, processes, and procedures in SMEs are relatively simple, in comparison to larger organizations (Wong \& Aspinwall, 2004). There may be little to no documented formal processes and procedures. This allows the SME to be nimble; although it may mean that knowledge accumulation and codification is more difficult without the appropriate structure in place. For example, documentation of the R\&D process may be more difficult as there is little administrative support. By and large, SMEs tend to focus on operations, rather than strategy (Wong \& Aspinwall, 2004).

Human resources within a SME tend to have closer and informal working relationships. However, the skill sets and competencies of employees in a SME tend to be more modest (Laforet \& Tann, 2006; Wong \& Aspinwall, 2004). The employees also tend to be flexible in nature with low resistance to change (Wong \& Aspinwall, 2004). Finally, due to their size, SMEs tend to be dependent on a small customer base (Laforet \& Tann, 2006; Wong \& Aspinwall, 2004). The firms also have more frequent contact with customers than a larger firm (Wong \& Aspinwall, 2004). 


\subsubsection{Managerial challenges of SMEs with the SR\&ED program}

Considerable research has been conducted on the characteristics of innovative firms (e.g., Christensen, 1997; Khan \& Manopichetwattana, 1989). Innovative firms generally have a strategic orientation for innovation with the accompanying values (Christensen, 1997; Laforet \& Tann, 2006). These firms also should have the supporting systems, technology, and human resources with the appropriate technical and learning capabilities to innovate (Laforet \& Tann, 2006). Similar to Laforet \& Tann (2006), Christensen (1997) outlines an organizational capabilities framework for innovation that consists of resources, processes, and values (RPV). In a study of small to medium manufacturing firms, Laforet and Tann (2006) found that the characteristics of strategic orientation, ownership and management, systems and process, human resources, and customer relationships influenced a firm's innovative capability. Firms that are goal-oriented with an owner/CEO who is committed to new product development have higher rates of new product introductions (Laforet \& Tann, 2006). Supporting systems and processes, qualified human resources, and close relationships with customers also influence innovation activities (Laforet \& Tann, 2006).

Under Christensen's RPV framework (1997), resources can be tangible or intangible, and can include people, equipment, technology, product designs, information, and relationships. A firm needs to have access to the appropriate resources to innovate. Christensen (1997) identifies processes as an organization's patterns of coordination, communication, and decision-making which enable the transformation of resources to create new products, processes, or services. The processes should support the allocation of resources to innovation opportunities and be 
able to communicate and disseminate information throughout the firm. Within the framework, the values are "the context within which a firm identifies and responds to customers' needs, solves problems, procures input, reacts to competitors, and strives for profit" (Christensen, 1997, p. 32). Christensen (1997) states the values of a firm, within the organizational framework, can influence the level of innovation. Essentially, values determine which R\&D projects will be initiated, put on hold, or terminated. A firm's values are often communicated through its vision, mission, and strategy.

Christensen's (1997) framework is fairly broad. For example, the framework does not specifically mention the characteristics of ownership and management, although it can be assumed that they are part of the values. Indeed, Christensen (1997) asserts that the formation of values is highly dependent on the founder's attitude and actions. Laforet \& Tann's (2006) organizational framework is more explicit; however, customer relationship and human resources are considered resources under Christensen's (1997) framework. Figure 1-5 combines elements of Laforet \& Tann (2006) and Christensen's (1997) frameworks and outlines the organizational framework required for an innovative firm. 
Figure 1-5 Required characteristics of an innovative firm

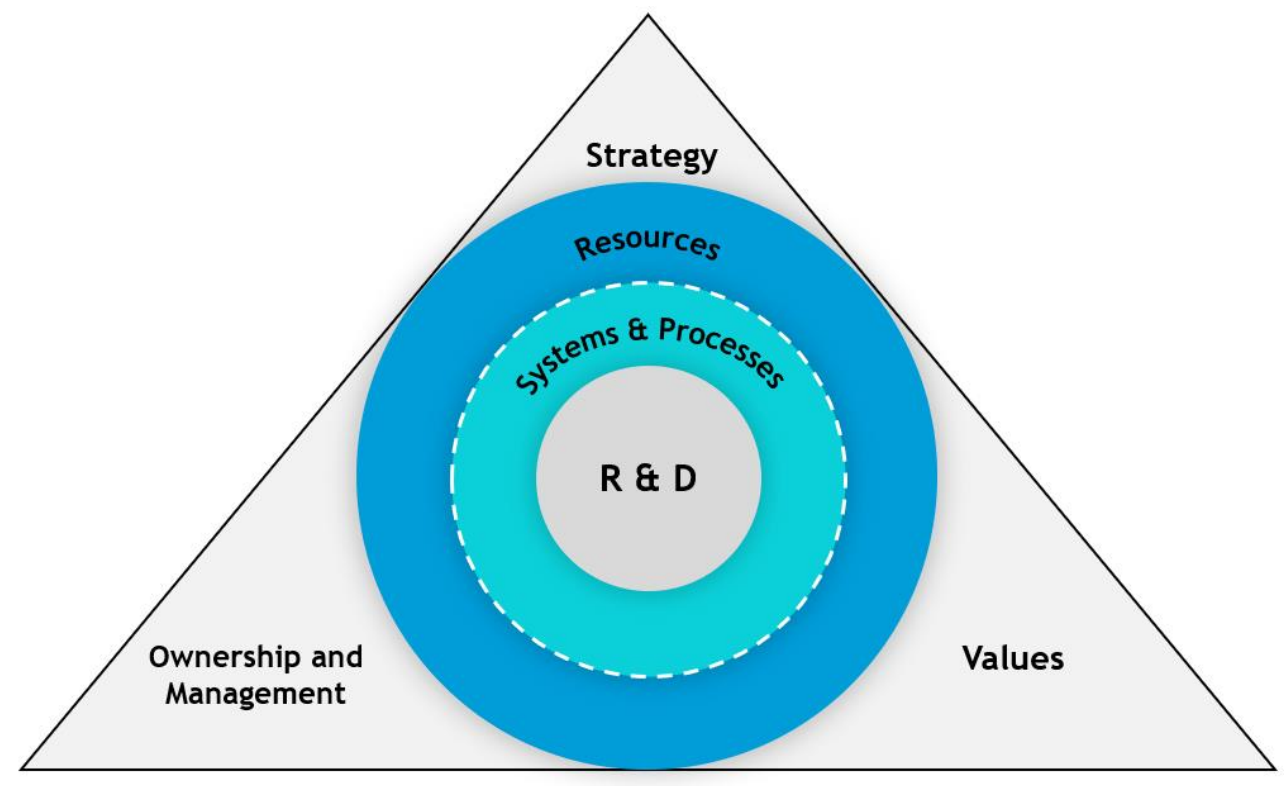

If these characteristics are endemic to innovative firms, it can be assumed that the absence or weakness of these characteristics would influence the firm's decisions to engage in R\&D. In other words, firms that have these characteristics are more likely to engage in R\&D than those that do not. It may also indicate that firms need to strengthen these characteristics if they would like to engage in R\&D. In addition, the absence or weakness of these characteristics may have an impact on R\&D management practices. For example, without strong systems and processes, issues found during the R\&D process may not be communicated or documented efficiently. Due to the disparities in firm characteristics among firms, some firms may be more effective in $R \& D$ and the management of their $R \& D$ processes.

Despite having a number of firm characteristics that may be conducive to innovation, the management challenges with engaging in, and managing, SR\&ED-eligible activities are more acute for SMEs. Laforet \& Tann (2006) assert that the main constraints of SMEs for innovation 
are customer dependency, sourcing talent, and developing the required skills and knowledge, due to lack of financial resources. Similarly, Welsh \& White (1981) assert that SMEs are subject to resource poverty. In effect, due to resource constraints, it is more difficult for SMEs to source talent, withstand external shocks, or recover from errors in judgement.

Resource constraints can pose additional challenges for firms that choose to take advantage of innovation opportunities (Busom et al., 2014). Small firms can be new entrants into a market and have incentives to produce a new good or service to the market, but they do not have access to extensive funds. Similarly, established SMEs may not have sufficient capital to take the risk to innovate as most of their cash flows are dedicated to operations and growth. Given the difficulty of raising funds through debt, equity, and cash flows for R\&D activities, SMEs are more likely to rely on government intervention such as the SR\&ED program (Michael \& Pearce, 2009).

Due to the resource challenges, Schumpeter (1934) believed that larger firms were better placed to engage in R\&D. Despite the advantages of a larger firm, some research has indicated that SMEs account for a disproportionate share of innovation (Acs \& Audretsch, 1990; Cohen \& Levin, 1989). Some of the reasons that smaller firms may be more innovative relate to their firm characteristics. Table 1-6 outlines the firm characteristics of SMEs and whether the characteristics pose an advantage or disadvantage for SMEs to engage in the SR\&ED program. 
Table 1-6 Firm characteristics and advantages and disadvantages for the SR\&ED program

\begin{tabular}{|c|c|c|}
\hline Firm Characteristic & Advantage for SR\&ED & Disadvantage for SR\&ED \\
\hline $\begin{array}{l}\text { Ownership and } \\
\text { management }\end{array}$ & $\begin{array}{l}\text { - Centralized decision- } \\
\text { making allows for rapid } \\
\text { responses to a changing } \\
\text { environment }\end{array}$ & $\begin{array}{l}\text { - May not recognize the } \\
\text { need for innovation }\end{array}$ \\
\hline Values & $\begin{array}{l}\text { An entrepreneurial owner } \\
\text { sets an innovation agenda } \\
\text { for the firm (Martínez- } \\
\text { Román \& Romero, 2017) }\end{array}$ & $\begin{array}{l}\text { - An owner who is not } \\
\text { predisposed to } \\
\text { innovation and risk-taking } \\
\text { may create a culture of } \\
\text { inertia (Ortega-Argilés, } \\
\text { Vivarelli, \& Voigt, 2009) }\end{array}$ \\
\hline Systems and processes & $\begin{array}{l}\text { - Less bureaucratic structure } \\
\text { allows for quicker } \\
\text { responsiveness to } \\
\text { innovation opportunities } \\
\text { (Ortega-Argilés et al., } \\
\text { 2009) }\end{array}$ & $\begin{array}{l}\text { - Lack of specialization may } \\
\text { result in lack of expertise } \\
\text { in management (Wong \& } \\
\text { Aspinwall, 2004) } \\
\text { - Do not have access to } \\
\text { extensive information to } \\
\text { make decisions (Gibcus et } \\
\text { al., 2009) } \\
\text { Documentation of the } \\
\text { SR\&ED process may be } \\
\text { more difficult without } \\
\text { adequate formal systems } \\
\text { and processes }\end{array}$ \\
\hline $\begin{array}{l}\text { Resources: Financial, } \\
\text { human, and physical }\end{array}$ & $\begin{array}{l}\text { Closer intra-firm } \\
\text { relationships allow for } \\
\text { greater acceptance of R\&D } \\
\text { strategies (Wong \& } \\
\text { Aspinwall, 2004) }\end{array}$ & $\begin{array}{l}\text { Limited capabilities and } \\
\text { lack of knowledge about } \\
\text { how to obtain the } \\
\text { necessary competence } \\
\text { (Ortega-Argilés et al., } \\
\text { 2009) }\end{array}$ \\
\hline Market & $\begin{array}{l}\text { Due to close relationships } \\
\text { with customers, SMEs } \\
\text { often involve them in the } \\
\text { innovation process (van de } \\
\text { Vrande, de Jong, } \\
\text { Vanhaverbeke, \& de } \\
\text { Rochemont, 2009) }\end{array}$ & $\begin{array}{l}\text { - May be more reluctant to } \\
\text { make changes that may } \\
\text { potentially upset } \\
\text { customers (Laforet \& } \\
\text { Tann, 2006) }\end{array}$ \\
\hline
\end{tabular}




\subsection{Research objective and research question}

The primary research objective of this thesis is to obtain an understanding of the SR\&ED-eligible activities of small CCPCs that are eligible for the enhanced rate. This study focuses on these smaller CCPCs, as this group feels the R\&D challenges more acutely. Additionally, there is little public information regarding this group. In contrast, public corporations often disclose their R\&D expenses and the treatment of their SR\&ED ITCs in their financial statements.

As many public corporations disclose their $R \& D$ expenses, the $R \& D$ intensity of public firms that engage in R\&D is visible. Statistics Canada also collects data through their annual Survey of Research and Development in Canadian Industry which collects information regarding intramural R\&D expenditures and personnel, sources of funding, and extramural R\&D expenditures (Statistics Canada, 2019b). From that survey, the Canadian government would have insight on the number of CCPCs that conduct R\&D but do not engage in federal assistance programs such as SR\&ED for funding. The survey does not collect information on whether or not the CCPCs had applied for the SR\&ED program, nor a firm's future intention to apply for the SR\&ED program. Even though the SR\&ED program has been in place since 1986, there is little understanding of firms' motivation to engage in the SR\&ED program.

Due to the potential for knowledge spillovers to the competition, few companies disclose their $R \& D$ projects or processes. As a result, there is little information on how the firms' internal and external environments affect their management of R\&D. For example, there is a lack of clarity as to the impact that access to resources, the market, and competitive forces have on R\&D projects and their scope. Further, without visibility of a firm's SR\&ED-eligible activities, the 
potential impact of the SR\&ED program on the management of SR\&ED-eligible activities is unclear. Due to the importance of SR\&ED-eligible activities for firms and the economy, this thesis seeks to gain insight on the SR\&ED-eligible activities of small CCPCs.

\subsubsection{Research question (general)}

As a result of the concerns about the use of tax dollars to subsidize research in R\&D, considerable research has been conducted on the crowding-out of private R\&D investments for firms that receive R\&D tax incentives (e.g., Czarnitzki \& Delanote, 2015). While the extant research in crowding-out evaluates whether the firm would have engaged in R\&D regardless of the tax incentive, the research does little to broaden the understanding of firms' motivation to apply for R\&D tax incentives. Crowding-out research assumes that the decision to engage in $R \& D$ incentives is simply to subsidize the cost of R\&D. Consequently, there is little knowledge of the conditions in which a firm decides to engage in R\&D and utilize R\&D tax incentives. This thesis seeks to answer the following research question:

How do small CCPCs decide to engage in R\&D activities?

There has been considerable research on the efficacy of R\&D tax incentives to increase R\&D expenditures and outputs (e.g., Baghana \& Mohnen, 2009; Castallecci \& Lie, 2015). The extant R\&D tax incentive research assumes that firms will display additionality behaviour and increase their R\&D scope and intensity based on the receipt of tax incentives. Similar to crowding-out research, the additionality research assumes that the primary factor in determining scope, the number of projects and R\&D employees, and intensity is financial. There is little information on 
the internal and external factors that may influence the R\&D process, the scope of R\&D projects, the location, and the R\&D intensity. Once the decision to engage in R\&D has been made, the next question is:

How do small CCPCs manage their R\&D practices?

\subsubsection{Research questions (specific)}

Expanding on the general research questions allows for the researcher to obtain more detailed information on how small CCPCs engage in R\&D activities and how they manage their R\&D practices. The first specific research question is why do some small CCPCs engage in R\&D activities while others do not? The differences will provide insight into the firm characteristics and external environments that motivate a firm to engage in R\&D, or not. Of specific interest are firms that engage in $R \& D$ but choose not to engage in the SR\&ED program.

The second specific question is how does the SR\&ED program influence the decision to engage in R\&D activities? The program's criteria may influence the decision to engage in $R \& D$ activities. For example, firms may decide not to apply for SR\&ED tax incentives if an R\&D project may have difficulty meeting the technical uncertainty threshold. The criteria may also have an impact on the selection of R\&D activities. For example, riskier projects may be undertaken to meet the technical uncertainty threshold. These projects may not be of the same calibre as R\&D projects that are not subject to these requirements. Alternatively, firms may not apply for the SR\&ED tax incentives for all R\&D projects. This thesis aims to better understand how the SR\&ED criteria influence the decision to engage in R\&D tax incentives. 
The third specific question is what is the scope of small CCPCs' R\&D activities? Firms that engage in R\&D activities must decide on their R\&D management practices. A firm's strategic decision may have an impact on the scope of their R\&D. For example, if a firm decides to introduce a new product to meet market demand, the scope of work of the R\&D department may increase. The scope may also be influenced by a number of factors including the availability of, and access to, resources, technical capabilities, and potential market demand (Teece, 2010a). By outlining the factors that influence the scope of R\&D activities, there can be greater visibility of the factors that encourage additionality behaviours by CCPCs.

The fourth specific question is what are the characteristics of R\&D projects, priorities, and processes in small CCPCs. Due to resource constraints, small CCPCs may be limited in the number of projects that they can conduct at one time. As a result, firms must set the priorities to determine which projects are undertaken. This study provides insight on how priorities are set, and projects are selected. Once priorities have been established and the projects selected, a process is necessary to develop the new product or service. The R\&D process within CCPCS may be formal, informal, or a mixture of both. Similarly, CCPCs may use a number of systems to support their R\&D process. Greater knowledge of CCPC's R\&D processes sheds light on their management practices.

The fifth specific question is how does the SR\&ED program influence the management of R\&D activities? The policies of the SR\&ED program may influence the management practices of the firm. For example, the SR\&ED program requires firms to document the R\&D process to provide proof of work done and the technical uncertainty of the project. Minutes of meetings, 
timesheets, developer's notes, testing results, etc. are documents that CRA may require as part of the SR\&ED review process. Consequently, firms should have the appropriate management systems in place to track time worked on the project, the progress of the project, and challenges encountered during the process.

Table 1-7 provides a synthesis of the research problematization elements outlined in chapter one. In this table, the overarching research theme and source of the research problem are delineated. Based on the source of the research and managerial problems, both the general and specific research questions are specified. 
Table 1-7 Synthesis of research problematization elements

\begin{tabular}{|c|}
\hline $\begin{array}{l}\text { Research theme } \\
\text { Innovation, R\&D, SR\&ED tax incentive }\end{array}$ \\
\hline $\begin{array}{l}\text { Source of the problem } \\
\text { Practical problem: Given the resource constraints of small CCPCs, engaging in R\&D poses } \\
\text { additional challenges. As a result, CCPCS often depend on government intervention to } \\
\text { engage in R\&D. } \\
\text { Theoretical problem: Research in tax incentives and R\&D has found that tax incentives } \\
\text { increase R\&D expenditures and output. However, there is a lack of understanding on } \\
\text { engagement and management of SR\&ED-eligible activities in the small CCPC context. }\end{array}$ \\
\hline $\begin{array}{l}\text { Managerial problem } \\
\text { How do small CCPCs engage in R\&D and manage their R\&D activities? }\end{array}$ \\
\hline $\begin{array}{l}\text { Research objective } \\
\text { Gain a better understanding of small CCPC R\&D activities eligible for the SR\&ED program. }\end{array}$ \\
\hline $\begin{array}{c}\text { General research question } \\
\text { How do small CCPCs decide to engage in R\&D activities? } \\
\text { How do small CCPCs manage their R\&D practices? }\end{array}$ \\
\hline $\begin{array}{c}\text { Specific research questions } \\
\text { Why do some small CCPCs engage in R\&D activities and others do not? } \\
\text { How does the SR\&ED program influence the decision to engage in R\&D activities? } \\
\text { What is the scope of small CCPCs' R\&D activities? } \\
\text { What are the characteristics of R\&D projects, priorities, and processes in small CCPCs? } \\
\text { How does the SR\&ED program influence the management of R\&D activities? }\end{array}$ \\
\hline
\end{tabular}




\section{CHAPTER 2: THEORETICAL FOUNDATIONS}

This chapter develops the theoretical foundations of this study, including concepts from innovation, $R \& D$ tax incentives, R\&D engagement, and R\&D management research. The extant research outlines the economic and management motivations of investing in R\&D and the impact of R\&D tax incentives on R\&D investment. Moreover, the extant research in R\&D management practice describes the necessary conditions to innovate and the influence of external factors on R\&D management practices. Nonetheless, the research does not consider the interrelation between the decision to engage in R\&D and how R\&D is managed. In effect, the factors that influence the decision to engage in R\&D also have an impact on how R\&D is managed. Similarly, a firm's R\&D management practices and capacity may influence the decision to engage in R\&D. This gap is particularly acute in the R\&D tax incentive literature that focuses on input or output additionality. Based on the core concepts and the relevant theories, a conceptual model is advanced to better understand how CCPCs decide to engage in R\&D and how they manage their R\&D practices in the SR\&ED context.

\subsection{Innovation and investment in R\&D}

Common themes prevail in innovation research. Innovation opportunities often involve acquiring external information, recognizing its potential, and commercializing the resulting innovation (Cohen and Levinthal, 1990; Zahra \& George, 2002). Several frameworks have been developed outlining how innovation is dependent on external information or technology (e.g., Chesbrough, 2003; Cohen \& Levinthal, 1990; Zahra \& George, 2002). Due to increased competition resulting from globalization, a firm needs to acquire external information to 
innovate, as its internal capabilities are no longer sufficient. (Martínez-Noya \& Narula, 2018).

Cohen \& Levinthal (1990, p. 128) assert that to innovate, organizations should possess the ability "to recognize the value of new, external information, assimilate it, and apply it to commercial ends." The authors define this ability as "absorptive capacity" (Cohen \& Levinthal, 1990). Therefore, the ability to value and incorporate external knowledge to innovate depends on an organization's absorptive capacity.

In order to effectively acquire and assimilate external information, the firm must possess previously acquired or related knowledge (Chesbrough, 2003; Cohen \& Levinthal, 1990). Related knowledge or experience assists a firm to determine the external information's potential value and how it can be applied. The firm's skill and knowledge base may not be sufficient for innovation. The appropriate conditions may also need to be in place for an organization to acquire and assimilate the external information.

Building on Christensen's (1997) RPV framework, a firm's resources, processes, and values may influence a firm's ability to acquire, assimilate, transform, and exploit external information. Even with the appropriate values, processes, and resources, innovation does not exist in isolation. For innovation to be successful, complementarities need to be in place (Rosenberg, 1982). Complementarities are resources, processes, or technologies that reduce the cost of use of an innovation, improve the ease of use, or increase profitability (Rosenberg, 1982). Dougherty (1992) discusses complementarities as technology-market linking. For firms to create successful product innovations, interdepartmental collaboration is required to build new knowledge and share their insights on the market demands and technological capabilities 
(Dougherty, 1992). Similarly, Christensen (1997) builds on the need for complementarities by discussing the need to establish a product's target market. In effect, the appropriate market conditions are required to introduce an innovation, or an innovator may need to search for alternative markets other than their original customer base.

In effect, the innovation literature outlines firms should have the appropriate internal context (i.e., RPV), target market, and capacity for innovations to be successful. As a result, firms may not only need to commit time, financial, and human resources to engage in R\&D, but also commit resources to build their absorptive capacity and ensure the appropriate conditions are in place.

Several empirical studies have found that despite the benefits of R\&D, many firms choose not to invest in R\&D. For example, Bound et al. (1984) indicated that 40 percent of U.S. firms did not report R\&D expenditures. However, this statistic assumes that firms that engage in R\&D report their R\&D expenditures. Further, due to the lack of clarity of what constitutes R\&D, SMEs may be under-reporting their R\&D expenditures (Smith, 2005).

The decision to invest in R\&D differs from other investments because of the intangible nature of knowledge gained in R\&D, the technical uncertainty, and the potential for the entire investment to be lost (Lev, 2001). This investment is costly to reverse, as there is little value earned or recovered if an R\&D project is terminated early (Lev, 2001).

When evaluating a firm's R\&D investment, the models in the extant research evaluate R\&D as an investment decision, not dissimilar to the decision to purchase a fixed asset. One of the 
assumptions is that the actors and the firm act in a rational profit-maximizing manner and that the actors will invest in an additional unit of R\&D as long as the expected rate of return is at least equal to its cost of capital (Billings et al., 2001).

In addition to assuming that all actors are rational, another common assumption in the extant research is that some financing constraints can be mitigated if a firm can take on debt or obtain government incentives to invest in R\&D (Parsons \& Phillips, 2007). However, due to the nature of $R \& D$, there is an asymmetry of information between a potential investor or debtor and the firm (Freel, 2006; Hall \& Lerner, 2010). It is difficult for investors and creditors to differentiate between good and poor projects and their potential for success, as this requires firms to disclose the details of their innovation (Hall \& Lerner, 2010). Due to this information asymmetry, increased liquidity risk, and higher monitoring costs, SMEs are less likely to receive debt financing for R\&D (Freel, 2006). As a result, extant research models may not reflect the ability of firms, particularly SMEs, to overcome financing constraints.

$R \& D$ investment also differs from regular investment decisions as most $R \& D$ expenditures are current, such as R\&D personnel wages and lab materials (Bloom, Van Reenen, \& Williams, 2019; Hall \& Lerner, 2010). As R\&D project expenditures are mainly current, investments in R\&D projects require funding from the beginning to the completion of a project. The ongoing operating costs may also explain why Agrawal, Rosell, \& Simcoe (2020) found that SMEs appear to treat hiring new technical talent as a fixed cost. In essence, employees, and their gained knowledge, are considered a long-term resource to the company that requires stable long-term funding. Due to the ongoing costs to fund R\&D with little short-term revenue expectations, 
innovation efforts can be constrained by the availability of financial resources (Bloom et al., 2019; Hall \& Lerner, 2010). Firms, especially SMEs, without access to adequate funds "must either abandon or reject the innovation project, or seek access to external finance" (Freel, 2006, p.24).

Given the financial resource requirements, a reduction in the cost of investing in R\&D should stimulate R\&D investment. Tax incentives, such as SR\&ED tax incentives, alter the cost of capital, and consequently, these incentives are expected to alter a firm's R\&D investments. For example, Klassen et al. (2004) studied the activities of 58 Canadian firms between 1991 and 1997 and estimates that one dollar of tax incentives stimulated 1.3 dollars in R\&D expenditures. Similarly, Bloom, Griffith \& Van Reenen (2002) found that a 10\% decrease in the cost of R\&D stimulates a $1 \%$ increase in R\&D expenditures in the short-run, and approximately a $10 \%$ increase in the long-run.

However, it is difficult to ascertain whether the tax incentives displace private R\&D investment (i.e., crowding-out). In order to test against crowding-out, some researchers evaluated the impact of a policy change that results in more generous tax treatment. Agrawal et al. (2020) evaluated the 2004 change in the SR\&ED program that increased the CCPC enhanced rate threshold of taxable income from $\$ 200,000$ to $\$ 500,000$. The authors found that following the increase in the taxable income threshold, CCPCs increased their R\&D expenditures by an average of 17 percent. Similarly, Dechezleprêtre, Einiö, Martin, Nguyen, \& Van Reenen (2016) measured the changes in R\&D expenditures and patents in firms from the United Kingdom affected by an increase in the SME size threshold in 2008, permitting the firms to access a 
preferential rate. This study also found that the policy changes resulted in increases in R\&D expenditures and patent activity.

Tax incentives may reduce the financial constraints that result from information asymmetry (Dahlby, 2005). As a result, R\&D tax incentives appear to stimulate additionality behaviour greater than the extant research's frameworks for R\&D tax incentives would suggest (Dahlby,

2005). However, this perspective assumes that the decision to engage in $R \& D$ is an investment decision that is dependent primarily on a firm's internal cost of capital for R\&D. Given the risks in investing in R\&D with no guaranteed return, the decision to engage in R\&D would appear to be more complex.

\subsection{R\&D engagement decision}

The extant research on the motivations for firms to engage in R\&D is primarily economic in nature. Dahlby $(2005$, p. 45$)$ states that firms invest in "R\&D in order to lower their costs of production or to develop new products, thereby enhancing productivity and boosting economic growth." However, the literature on whether innovative firms have superior firm performance than non-innovative firms is mixed. For example, Freel (2000) found that small firms that are innovators are significantly smaller and had lower profitability levels than their comparative non-innovator firms. However, innovators are more likely to grow than non-innovators (Freel, 2000). Consequently, SMEs that engage in R\&D should be realistic about the prospects of profits in the short-term (Freel, 2000).

As there is no guarantee of increased firm performance when firms engage in $R \& D$, some of the extant research acknowledges that investment or neoclassical economic theories do not 
account for all the aspects of a firm's R\&D behaviour. For example, Greve (2003) employed the behavioural theory of the firm based on Cyert \& March (1963), in conjunction with investment theory in his analysis of R\&D intensity and tax incentives. In his article, Greve (2003) asserts that management will engage in R\&D depending on firm performance, management aspirations, and risk tolerance. The decision to engage in R\&D is based on firm performance mitigated by the aspiration level to find solutions based on the risk tolerance.

Greve (2003) hypothesizes that firm performance may have a significant effect as management may feel pressure to deliver results. R\&D, if successful, promises to improve a firm's sustainability and profitability. In effect, if management aspirations exceed firm performance, management may be compelled to take action to improve performance. As a result, Greve (2003) hypothesizes that a firm performing lower than its aspirations is more likely to engage in R\&D. Similarly, firms with a higher risk tolerance may choose to engage in R\&D. Alternatively, firms with poor performance may be more desperate to try new solutions to improve performance (Greve, 2003). Greve's (2003) study shows that the decision to engage is not merely an economic decision. A firm's internal characteristics, including its values, also influence a firm's decision to engage in R\&D and the intensity of the R\&D efforts.

Other research indicates that firms have additional reasons to engage in R\&D than for increased productivity, profits, and growth. Firms may also engage in R\&D to improve their capabilities or send a signal. Arora, Belenzon, \& Sheer (2017) evaluated whether firms invested in research to boost their absorptive capacity or as a signalling mechanism. In effect, when firms invest in $R \& D$, they may be attempting to attract technical talent and customers, or send a message to 
regulators and capital markets (Arora et al., 2017). From their analysis, Arora et al. (2017) found that the primary reason to invest in research was that the research activities were an input to their "inventive" activities. The knowledge gained boosted their absorptive capacity and capabilities for product innovation.

The research conducted in $R \& D$ as a signalling mechanism tends to focus on R\&D collaboration with universities and research centres. Audretsch \& Stephan (1996b, p. 646) indicate that collaborations with university scientists not only promote knowledge transfer, "they signal the quality of the firm's research to both capital and resource markets." Firms may also use the outcomes of R\&D activity to signal to investors, creditors, and the R\&D community. For example, firms may choose to patent their innovation to send a signal of their R\&D competence to attract investment, collaboration opportunities, or talent (Fontana, Geuona, \& Matt, 2006).

In effect, although the decision to engage in R\&D is an economic decision, management's values also influence the decision to engage in R\&D. For example, if the firm's values are to attract high-quality talent, the firm may choose to engage in high-quality R\&D and communicate it publicly to send a signal to the R\&D community and potential employees.

As the characteristics of a SME are different than larger organizations, the decision to engage in R\&D may differ in SMEs than in larger firms. Gibcus, Vermeulen, \& de Jong (2006) assert that decision-making in SMEs differs for three reasons. Firstly, smaller firms encounter a more uncertain environment than larger firms (Gibcus et al., 2006). Essentially, smaller firms do not have access to information as easily as larger firms, nor do they have as many resources to scan the external environment (Salles, 2006). As a result, analyzing an opportunity or problem and 
creating alternatives are more difficult without adequate resources. Consequently, decisions are made with a higher level of ambiguity. A second reason is the lack of formal systems and processes, as small firms may not have decision-making protocols as formally established as those in larger firms (Salles, 2006). Decision-making in small firms is often based on biases and heuristics (Gibcus et al., 2006). Thirdly, entrepreneurial owners are believed to have specific characteristics such as impatience and goal-oriented behaviour, which have an impact on the decision-making process (Gibcus et al., 2009; Michael \& Pearce, 2009)

Revisiting the SME characteristics identified in chapter 1, Table 2-1 outlines the firm characteristics and their impact on strategic decision-making.

Table 2-1 Firm characteristics and impact on R\&D decision-making

\begin{tabular}{|c|c|}
\hline Firm characteristics & Impact on strategic decision-making \\
\hline Ownership and management & - Centralized decision-making \\
\hline Values & $\begin{array}{l}\text { - As the owner influences behaviour and culture, } \\
\text { strategic alignment is more certain }\end{array}$ \\
\hline Systems and processes & $\begin{array}{l}\text { - Decisions can be communicated quickly through } \\
\text { informal processes and a flatter structure } \\
\text { - Nimble implementation due to low degree of formal } \\
\text { processes and procedures } \\
\text { - Without strong information-gathering systems, it is } \\
\text { more difficult to obtain accurate and timely } \\
\text { information }\end{array}$ \\
\hline Resources & $\begin{array}{l}\text { - Resource constraints affect resource allocation and } \\
\text { scope } \\
\text { - Employees tend to be versatile with a low resistance } \\
\text { to change }\end{array}$ \\
\hline Market & $\begin{array}{l}\text { - } \text { Reliance on a small number of customers } \\
\text { - } \quad \text { Frequent communication with customers }\end{array}$ \\
\hline
\end{tabular}

In a SME, ownership and management are generally limited in number, and as a result, decision-making is centralized. Therefore, decisions can be made fairly quickly as the goals of 
management and the firm are aligned. Similarly, the owner, or founder, influences the firm's values through their actions and attitude (Christensen, 1997). SMEs tend to be goal-oriented, so decisions are made to achieve the stated goals.

The systems and processes of SMEs have advantages and disadvantages. Firstly, there are flexible communication flows, so the decision's importance and rationale can be easily disseminated throughout the organization. While the low degree of formal processes may allow for a decision to be quickly implemented, the lack of structure may have an impact on the implementation. Without a formal process, important elements may be missed, or the decision's impact may not be foreseen. Emergent strategies may occur if there is a lack of formal documentation and understanding of a specific strategic direction.

Resources have a significant impact on the decision-making process. Resource constraints may inhibit a firm's ability to make optimal decisions. Management may need to satisfice; that is, pick an alternative that is good enough (Cyert \& March, 1963). In general, there is more alignment in SMEs among the management and employees. Consequently, there is a lower resistance to change (Wong \& Aspinwall, 2004). SMEs, in general, have less organizational slack and may not be able to take advantage of opportunities (Michael \& Pearce, 2009).

A SME's market, specifically its existing customers, may have an impact on its strategic decisions. Decisions that may benefit their existing customer base may be easier to accept, while decisions that may negatively affect their market may not be taken regardless of the benefit to the company. For example, it may be in the firm's best interest to streamline the 
ordering process to obtain efficiencies, but fears of repercussions from customers may deter a SME from implementing this solution.

In summary, a SME's firm characteristics and their market may influence the decision to engage

in R\&D. Due to their centralized decision-making and flat structure, there is likely internal alignment for the reasons to engage in R\&D. If management and ownership decide to engage in R\&D to improve firm performance, send a signal, or build their R\&D capabilities to develop innovation, SMEs may be challenged by their financial constraints and market pushback, but not necessarily challenged by resistance from their employees. The decision to engage in R\&D may be stimulated by the utilization of R\&D tax incentives to lower their R\&D cost of capital; however, it is unclear whether R\&D tax incentives have an impact on the firm characteristics that influence the R\&D engagement decision.

\subsection{R\&D management practices}

Once the decision to engage in $R \& D$ is made, firms manage the allocation of resources, including human resources, and the R\&D process. Management practice of R\&D differs from other areas such as production due to the intangible nature of R\&D and the complexity (nonlinear) nature of the process (Lev, 2001). R\&D management practices may also differ based on the structure of the firm. For example, if $R \& D$ is part of production rather than a separate department, priorities and resources may be periodically assigned to customer orders rather than R\&D. Furthermore, as R\&D is highly dependent on human capital, management practice can influence the innovation performance of a firm (Huang \& Lin, 2006). 
$R \& D$ management can refer to the management of the R\&D team, other units of the firm, and the external environment (Winn \& Roome, 1993). R\&D management practices are based on the firm's strategy that was developed in conjunction with other business units, and considered both the external environment and inputs required for $R \& D$. Due to the complexity of the external environment, the other business units and the R\&D department work collaboratively on setting priorities and implementing R\&D projects (Winn \& Roome, 1993). The external environment has an influence on a firm's R\&D strategy implementation through political (i.e., regulation), economic (market forces and financial resources), social, technological, and environmental factors (Winn \& Roome, 1993).

Winn \& Roome's (1993) definition of R\&D management also extends to management of the R\&D process by setting time limits, goals, and priorities based on collaboration with other business units (Sakakura \& Kobayashi, 1991). Winn \& Roome (1993) also discuss an internal $R \& D$ department perspective in which management focuses on setting priorities between basic research and new product development based on identified external opportunities and internal capabilities. In this definition, the R\&D department continually scans for external opportunities to identify and seize opportunities to obtain a competitive advantage (Teece, 2007).

In the extant R\&D and tax incentive literature, some research has utilized external environment scanning theories in conjunction with neoclassical economic theory to evaluate the capabilities of the R\&D department post receipt of government funding. For example, Radas et al. (2015) use absorptive capacity to assess a firm's technical capabilities and its R\&D projects. Radas et 
al. (2015) found that government intervention in R\&D through tax incentives and direct subsidies had a positive impact on SMEs' absorptive capacity allowing for future growth.

To better understand how a firm manages its R\&D capabilities, it is essential to understand the context in which the firm operates. In an industry, all firms theoretically have access to the same knowledge, talent pool, suppliers, and customers; however, there are differing levels of performance within an industry. Core capabilities may assist in explaining a firm's strategic differentiation due to its knowledge, managerial systems, and technical systems (LeonardBarton, 1992).

Leonard-Barton (1992) outlines four main dimensions of core capabilities, including employee knowledge and skills, technical systems, managerial systems, and values, as illustrated in Figure 2-1. Employee knowledge and skills can be both technical and firm-specific. For example, in addition to technical knowledge, R\&D employees may have knowledge of the firm's systems and experience developing its products. The employee knowledge and skills dimension is tightly linked with technical systems (Leonard-Barton, 1992). Technical systems represent the codification of employees' tacit knowledge in procedures and information systems (LeonardBarton, 1992). 
Figure 2-1 Leonard-Barton (1992) core capability framework

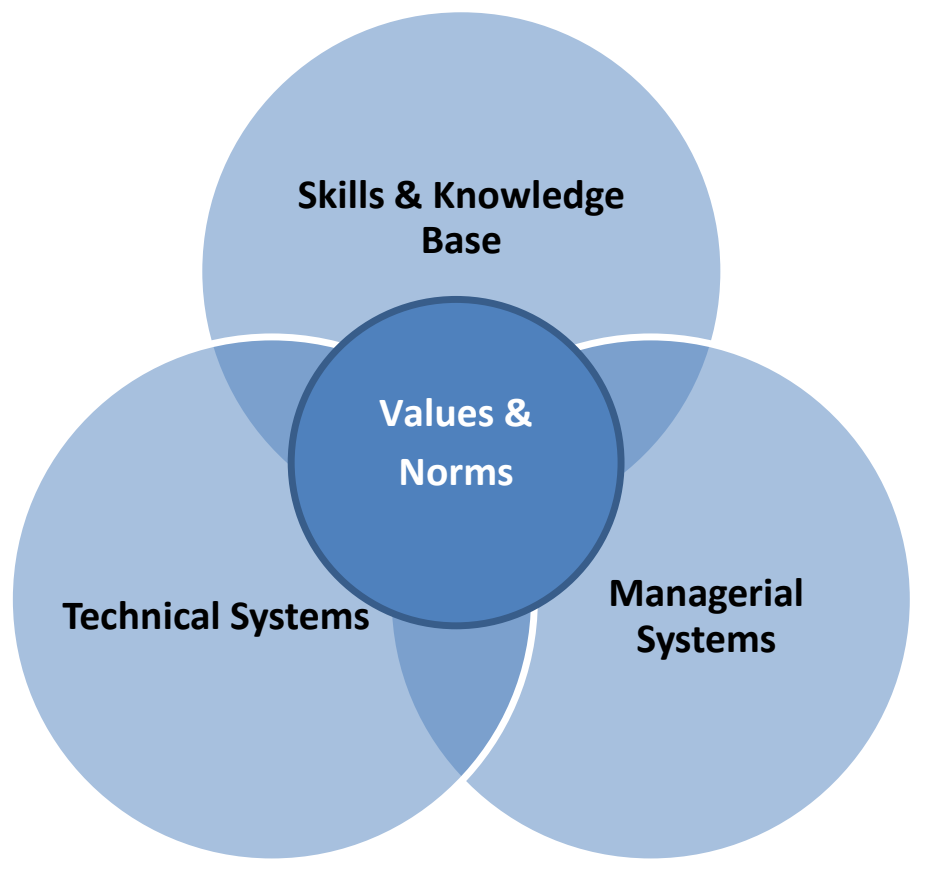

Adapted from Leonard-Barton (1992, p. 114)

Managerial systems include mechanisms, such as performance management systems, to create knowledge such as training and apprentice programs, and this knowledge is controlled by incentive and reporting structures (Leonard-Barton, 1992). The performance management system must encourage developing core R\&D capabilities and monitoring the capabilities without constraining them. As appropriate human resources may be the most critical component of $R \& D$, effective $R \& D$ management practices should attract and retain the right talent (Huang \& Lin, 2006). The managerial systems to attract and retain R\&D talent should incorporate environment facilitations, incentives, and encouragement. Environment facilitations include the hiring and firing process, suppression of status differences, venues for information, and information sharing (Huang \& Lin, 2006). Incentives and encouragement include compensation, reward, trust, recognition, and affirmation. 
Values rest at the heart of the core capability framework. The values determine the knowledge that is accumulated, how the knowledge is acquired, and the dissemination and control of the knowledge (Leonard-Barton, 1992). Values also influence the structure of the technical and managerial systems. In the managerial systems, the choice of controls is determined by whether the objective of management is to obtain performance or compliance (Tessier \& Otley, 2012). In the context of R\&D capabilities, management may choose to focus on performance objectives rather than compliance. In effect, management may be focused on measuring R\&D capability indicators such as knowledge creation.

Within a firm, the management practices to create knowledge, codify knowledge, and manage employees may range from ad hoc to structured. For example, some firms may set targets and measure them infrequently, or set unrealistic targets. Structured management practices have a positive effect on productivity and innovation (Bloom et al., 2017). Management practices become "part of the organizational structure and behavior of the firm, typically evolving slowly over time" (Bloom \& Van Reenen, 2007, p. 1355). The development of management practices is often influenced by a firm's human resources and external factors such as competition, knowledge spillovers, the regulatory environment, and human resources (Bloom et al., 2017; Bloom \& Van Reenen, 2007). Figure 2-2 illustrates the drivers of structured management practices. The degree of influence of these drivers may differ depending on firm size (Bloom et al., 2017) 
Figure 2-2 Drivers of structured management practice

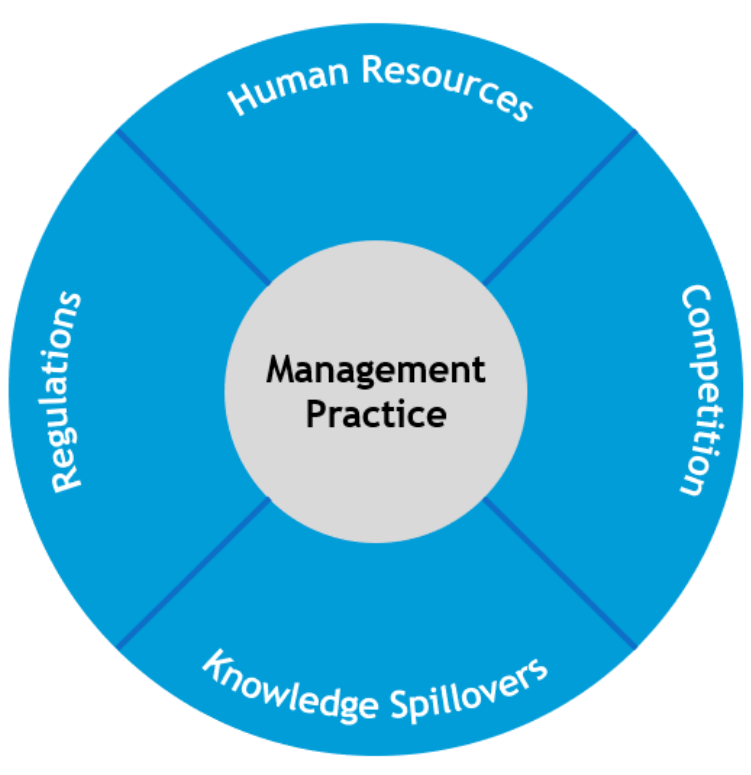

From a human resource perspective, a skilled and educated workforce has a positive association with structured management practices and productivity. Consequently, close proximity to higher education centres and concentration of firms in knowledge industries have a positive impact on structured management practices (Bloom et al., 2017).

Competition has a positive effect on the adoption of structured management practices as poorly managed firms are forced to exit or require greater managerial effort (Bloom et al., 2017). For example, firms that have poor management practices may lose employees or customers to better managed firms. Similarly, knowledge spillovers also have a positive impact on structured management processes (Bloom et al., 2017). Best practices from other firms can permeate into a local firm's ecosystem. 
The regulatory environment, particularly safety and employment regulations, also have an impact on management practices (Bloom et al., 2017). For example, regulations may require better monitoring and documentation from a firm to ensure that the firms comply with regulations.

Similar to the decision-making processes, SMEs' management practices may differ from those in larger organizations (Bloom \& Van Reenen, 2007). Although structured management practices are positively associated with increased innovation, the implementation of structured management practices can be costly (Bloom \& Van Reenen, 2007). In addition, the impact of the four drivers of structured management practice on SMEs may differ than in larger firms.

In comparison to larger firms, SMEs may face higher levels of asymmetry of information and less educated management, which contributes to less structured management practices (Aragón-Sánchez \& Sánchez-Marín, 2005). In effect, access to skilled management and information is costly, which may have an impact on management practices in SMEs.

The managerial characteristics, which include the motivations, goals, and objectives of the owner/manager of SMEs, also have an impact on management practices (Fiegenbaum \& Karnani, 1991). The management/ownership of small firms have a greater tendency to take considerable but calculated risks (Fiegenbaum \& Karnani, 1991, p. 102). In addition, due to the close customer relationships, SMEs have a stronger market or customer focus (Pelham, 2000). Consequently, the strategic orientation of SMEs tends to be more reactive to market forces (Aragón-Sánchez \& Sánchez-Marín, 2005). 
As a result, SMEs may have a competitive advantage due to their flexibility, which provides greater speed of response, increased ability to innovate, and higher adaptability (AragónSánchez \& Sánchez-Marín, 2005; Fiegenbaum \& Karnani, 1991). This flexibility is due to SME's relatively flatter structure, which often translates to flexible management practices (AragónSánchez \& Sánchez-Marín, 2005). However, due to the lack of diversity in R\&D projects, it may be more difficult for SMEs to capitalize on knowledge spillovers (Tsai, 2005). Similarly, due to the insular and autonomous nature of many SMEs, they may not have established strong networks to be able to take advantage of knowledge spillovers (Laforet \& Tann, 2006).

In contrast, employment regulation tends to be more flexible for SMEs than for larger firms, which limits the constraints on management practices with SMEs (Aragón-Sánchez \& SánchezMarín, 2005). Even though SMEs may have less structured management practices, these practices may be more effective to innovate and respond to customer demands.

In summary, Leonard-Barton's (1992) core capability framework can help explain how firms manage their R\&D practices, including the development of their R\&D capabilities. R\&D tax incentives may also have a positive impact on a firm's R\&D capabilities, as measured by absorptive capacity (Radas et al., 2015). The management practices to utilize and develop R\&D capabilities can be structured or adhoc. The degree of structure is influenced by a firm's human resources, competition, knowledge spillovers, and regulatory environment. Due to SMEs' firm characteristics, SMEs may have less structured management practices, which allows SMEs to be more responsive to changes in their environment. As R\&D tax incentives have an impact on R\&D capabilities, these incentives may also have an impact on R\&D management practices. 


\subsection{Application of contingency theory and organizational learning theory to R\&D}

From the literature review above, a firm's absorptive capacity is important for innovation. In order to innovate, the firm should have the appropriate conditions and consider the potential market. Firms may engage in R\&D for economic reasons (e.g., boost firm performance), but as described above, other factors also influence the decision. Once the decision to engage in R\&D is made, firms are required to manage their R\&D activities. The development and management of their R\&D capabilities are dependent on a firm's knowledge, managerial, and technical systems.

Two branches of theory can assist with understanding R\&D engagement and management. Contingency theory, as articulated by Hofer (1975), was first conceived to elucidate the factors in developing business strategy. This theory can offer further understanding of how small CCPCs decide to engage in R\&D and the factors that may influence their decision. In order to innovate, R\&D management practices include setting up the systems and processes to develop the capabilities to acquire, assimilate and transform external information. Transforming external information, implies a learning process is engaged. Consequently, organizational learning theories may assist in providing insight on how a CCPC manages its R\&D practices.

\subsubsection{Contingency Theory}

Contingency theory is based on the premise that there is no universal solution, system, or approach that will apply to all firms in all circumstances (Hofer, 1975; Otley, 1980). Luthans \& Stewart (1977, p. 183) define contingency theory as "identifying and developing functional relationships between environmental, management and performance variables." In effect, 
firms should evaluate their management and internal capabilities and the external environment to determine an appropriate strategy or system.

Hofer (1975) contends that product life cycle and external environmental conditions, internal firm characteristics, and resources have an impact on the choice of strategy. For example, firms with a product life cycle at the initial stages with limited resources would behave differently than firms with a product life cycle in the mature phase with significant resources. In essence, there is no one optimal strategy for firms; instead, strategy and firm structure should be aligned with the product life cycle, and the internal and external contexts.

According to Hofer (1975), the product life cycle is the most important factor in determining strategy. Hofer (1975) identifies five stages of a product life cycle including introduction, growth, maturity, saturation, and decline. At each stage, the external environment conditions affect the firm differently. For example, at the introduction and growth stage, firms are trying to establish a market for their product or services. In the maturity and saturation stages, the firms may be employing tactics to guard market share. In the context of the SR\&ED program, in order to be eligible for the tax incentives, the new product, service, or process must meet the technical uncertainty threshold. As a result, one can assume that products in the introduction or growth cycle are more likely to be eligible for the SR\&ED program, as firms apply for assistance during the development process. This being said, improvements to products or services are also eligible for the SR\&ED program. These products or services may be in the latter stages of the product life cycle. 
The external environmental conditions also influence the strategic decisions and the management of the firm. Hofer (1975) outlines broad environmental conditions, suppliers, industry, competition, and consumer and market behaviour as external conditions. Broad environmental conditions include economic conditions, demographic trends, sociocultural trends, and political/legal factors (Hofer, 1975). In addition to external environment, Hofer (1975) included firm characteristics and resources as contingency factors. Hofer (1975) did not include values as a factor, as he asserted that values did not have an impact on the economic feasibility of a firm's strategy.

In total, Hofer's (1975) contingency framework has 54 factors in determining the optimal strategy and management structure. It should be noted that cash flow and capital investment are considered a contingency factor. However, this factor is only one of the 54 factors. The contingency factors can be divided into external and internal contingency variables (Luthans \& Stewart, 1977; Otley, 2016). In a literature review of contingency theory from 1980-2014, the most common external variables include "technology, market competition or hostility, environmental uncertainty and national culture," and the internal variables comprised “organizational size, structure, strategy, compensation systems, information systems, psychological variables (e.g., tolerance for ambiguity), employees' participation in the control systems, market position, product lifecycle stage, and systems change" (Otley, 2016, p. 48). Based on the number of factors found in the extant literature, this theory may be empirically challenging to test and operationalize. 
However, contingency models often do not consider organizational learning capabilities as a resource. Similarly, not all models consider a firm's values as a contingency factor. A firm may have significant resources and an amenable external environment, but without the appropriate values and organizational learning capabilities, the ability to innovate may be compromised.

\subsubsection{Organizational learning}

Organizational learning theories focus on how a firm's behaviour is modified through its learning processes (Clarysse et al., 2009). Absorptive capacity (Cohen \& Levinthal, 1990) and Nonaka's (1994) spiral of knowledge framework are both examples of organizational learning theories. Organizational learning has an impact on the decision-making and management practices of a firm as experience is accumulated within the firm (Clarysse et al., 2009).

Some researchers indicate that collaboration with other firms or obtaining external information is required to ensure that the learning capabilities to innovate do not stagnate (e.g., Chesbrough, 2003). This assertion is consistent with the concept of core rigidities by LeonardBarton (1992), in which previously accumulated knowledge sets can create inertia. In congenital learning, a selection process or information filter is applied to evaluate external opportunities and diffuse the information throughout the organization. However, there is a risk that previous knowledge may hinder innovation as the previous experience may blind the organization to new possibilities or new ways of thinking (Henderson \& Clark, 1990; LeonardBarton, 1992). Consequently, a firm should leverage their existing knowledge but challenge any rigidity in thinking (Leonard-Barton, 1992). 
In addition to potential inertia, the knowledge base and skills with an organization can have a limited utility lifetime. Helfat \& Peteraf (2003) outline a lifecycle of firm capabilities. A capability lifecycle starts at the founding and development stage and evolves into the maturity phase. The founding and development stage of capabilities engages a learning process in which experience is accumulated, and activities are modified accordingly (Helfat \& Peteraf, 2003). At the maturity phase, the capability is well entrenched in the organizational memory (Helfat \& Peteraf, 2003). Depending on events within the internal or external environment during the maturity phase, the capability can retire, renew, redeploy, recombine, replicate or retrench (Helfat \& Peteraf, 2003). Just as firm capabilities may have a life cycle, a firm's learning capabilities may be tied to its product life cycle. Repeated R\&D activity will have less of an impact on the R\&D behaviour of a firm once the initial learning curve is overcome. Consequently, the product life cycle may influence R\&D management practices. Organizational learning theories have been utilized in the R\&D tax incentive literature. For example, Clarysse et al. (2009) employed organizational learning to determine why R\&D expenditures increase when recipient firms receive government R\&D incentives. The authors base their analysis on three types of organizational learning: experiential, congenital, and interorganizational learning. The learning capabilities of firms had an influence on the efficacy of the incentives, and played a role in the management of R\&D projects as firms modified their processes to meet the needs of the government R\&D incentives (Clarysse et al., 2009).

Experiential learning is consistent with Rosenberg's (1982) learning-by-doing and learning by using. In effect, learning in the firm is based on development experience and from the product 
being used. Congenital learning refers to utilizing a firm's existing knowledge to assist in future learning to develop new knowledge or practices (Clarysse et al., 2009). Congenital learning is consistent with absorptive capacity (Cohen \& Levin, 1989) and combinative capabilities (Kogut \& Zander, 1992) in that a firm needs existing knowledge to assimilate and transform external information. Inter-organizational learning refers to firms obtaining other organizations' tacit knowledge and can include technical knowledge and management practices (Clarysse et al., 2009). The knowledge can be gained by formal networks with other firms (Chuluun, Prevost, \& Upadhyay, 2017) or through knowledge spillovers (Autio, Kanninen, \& Gustafsson, 2008).

The three types of learning are evident at different times of the R\&D process. Experiential learning is most evident at the outset of product development or in a firm's start-up phase (Clarysse et al., 2009). There is a learning curve in both development of new technical skills and management of R\&D projects. Congenital learning occurs once some experience has been accumulated. Management and technical employees can decide which R\&D projects to engage in and modify their R\&D practices based on external information. Inter-organizational learning can occur at any point in the process, depending on a firm's collaboration efforts. For example, firms that intend to apply for the SR\&ED tax incentives can take advantage of the pre-claim services to better understand what constitutes SR\&ED-eligible activities and how to document their SR\&ED practices.

\subsection{Conceptual model}

This section aims to discuss the conceptual model of R\&D engagement and R\&D management practices. The conceptual model seeks to provide a foundation to explain how a CCPC decides 
to engage in R\&D and outlines the factors that influence the decision. The model also seeks to describe how CCPCs manage their R\&D practices and the factors that have an impact on these practices. By understanding the factors associated with the decision to engage in R\&D and how a CCPC manages their R\&D practices, the model can assist in understanding how the SR\&ED program affects the decision to engage in $R \& D$ and its $R \& D$ management practices.

The conceptual model (Figure 2-3) is based on utilizing contingency theory to explicate the factors that firms consider when deciding to engage in R\&D. The conceptual model also leverages organizational learning theories to describe the R\&D capabilities and the learning capacity of a firm.

A firm's contingency factors and the degree of organizational learning capability is dependent upon a firm's characteristics. A firm's characteristics include its strategy, values, ownership and management, resources, systems, and processes. These firm characteristics are consistent with Leonard-Barton's (1992) core capabilities and Christensen's (1997) RPV frameworks. Both these frameworks argue that the values, resources, systems, and processes are integral to developing innovation or providing a competitive advantage. Although their frameworks do not specifically identify strategy or ownership and management, the conceptual model below delineates these elements. Strategy, ownership, and management are interrelated and should be demarcated. 
Figure 2-3 Preliminary conceptual model for R\&D engagement and management

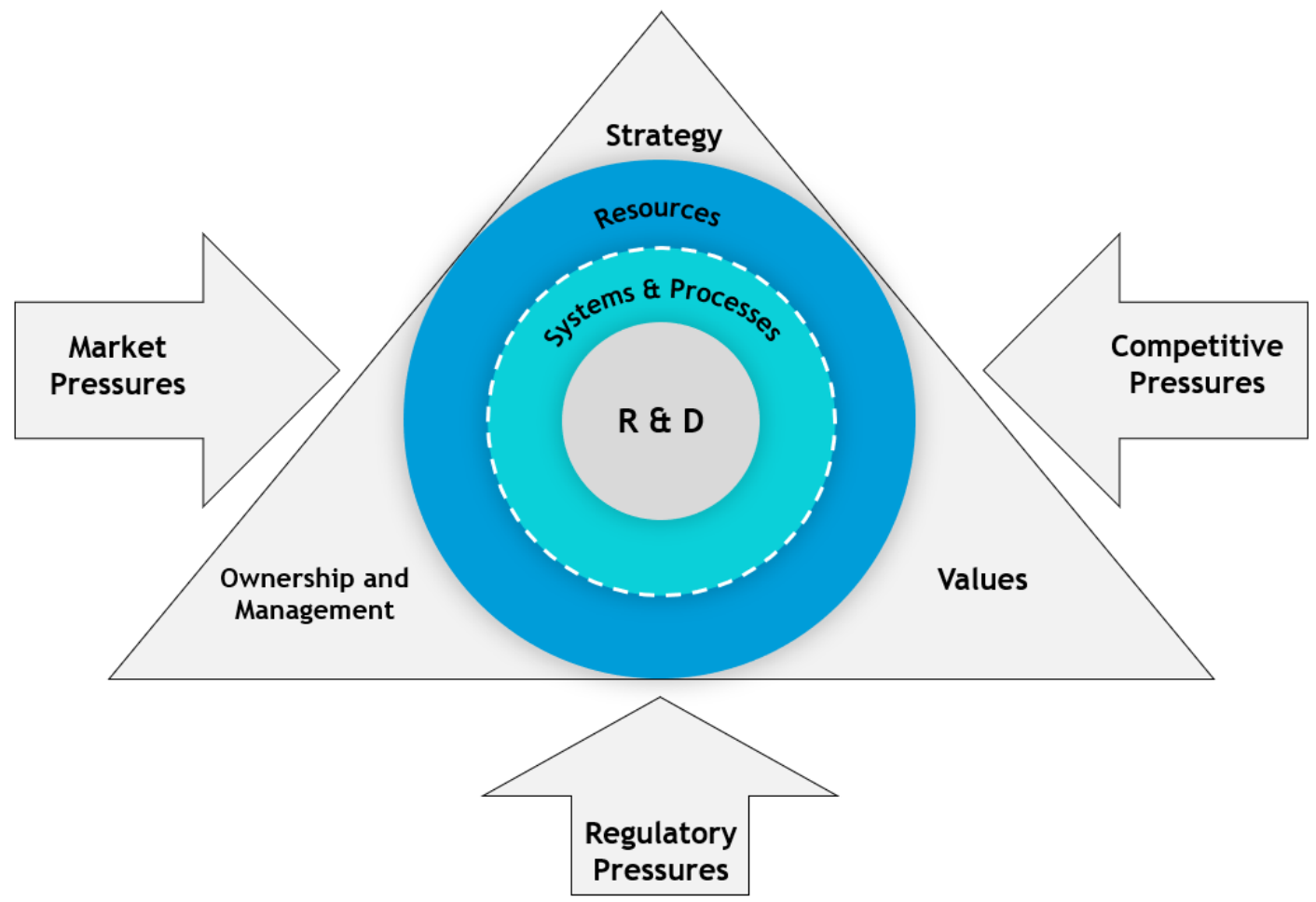

Within CCPCs, a strategy can be deliberate or emergent (Mintzberg \& Waters, 1985).

Mintzberg \& Waters (1985) found that deliberate strategies focus on direction and control, whereas emergent strategies focus on flexibility and learning. Firms with deliberate strategies may have more structured management practices based on the internal and external context. In firms with emergent strategies, with no set objectives, managers need to be cognizant of the environment and react accordingly (Inkpen \& Choudhury, 1995). Essentially, regardless of whether there is a deliberate strategy or not, the internal and external environment has an impact on whether a firm engages in R\&D and the structure of its management practices. 
A firm's values have an impact on a firm's ability to innovate (Chesbrough, 2003; Christensen, 1997; Teece, 2007). Values are a significant factor in determining which innovation is pursued. For example, organizations with a robust customer-centric value system may not pursue an innovation that may be disruptive and have lower margins; alternatively, minimal resources will be assigned to the project. Specifically, values influence the allocation of resources for R\&D via a strategic review or business planning process. Consequently, firms may miss out on good opportunities, as sufficient resources are not allocated. Further, firms with structured management practices that include metrics and measures, such as return on investment (ROI), may be employed as part of a project approval process, resulting in an innovation being discontinued before it can germinate (Chesbrough, 2003; Christensen, 1997).

The values also have an impact on the learning capabilities and the environment in which these capabilities can develop. For example, values can create an environment where mistakes are permitted, as long as lessons are learned. Values can also include openness to external ideas and not permit a culture of "not invented here syndrome" (Chesbrough, 2003).

Ultimately, the decision to engage in R\&D rests with a firm's ownership and management. The degree to which a firm's employees have an impact on the decision depends on if the firm has a centralized or participatory decision-making process. While SMEs tend to have centralized decision-making processes, SMEs also have relatively flat structures with flexible communication flows (Wong \& Aspinwall, 2004). The ownership and management structure also has an impact on R\&D management practices. Christensen (1997) and Teece, Pisano, \& Shuen (1997) discuss how decentralization with greater autonomy can encourage innovation. 
Firms with a decentralized R\&D department allow R\&D personnel to be flexible and responsive to customer and supplier feedback, rather than obtaining approval from ownership and management for R\&D decisions (Teece, 2007). In effect, a decentralized R\&D department encourages inter-organizational learning.

Adequate and appropriate human, physical, intangible, and financial resources need to be available to support innovation. Without adequate financial resources, firms may choose not to engage in $R \& D$, or they decide to have a less robust $R \& D$ program than desired. $R \& D$ management practices are also affected by resource constraints, as firms may not be able to attract and retain the appropriate technical and supervisory talent. In addition, resource constraints may have an impact on the acquisition of systems and physical resources to facilitate the R\&D process.

The systems and processes are a significant component of a firm's R\&D capability (Christensen, 1997; Leonard-Barton, 1992). Leonard-Barton (1992) makes a distinction between technical and managerial systems. The technical systems support the retention of knowledge and skills. Retrievability of this information assists in developing a firm's learning and R\&D capabilities. Managerial systems, such as incentive and training systems, can also develop a firm's capabilities. Consequently, a firm's systems have a direct impact on a firm's R\&D management practices; however, without adequate systems to engage in $R \& D$, firms may be required to invest in systems to develop their R\&D capability.

A firm's processes can help develop or hinder a firm's R\&D capabilities. For example, Dougherty (1992) found that processes, such as coding sheets for product development, 
inhibited learning and resulted in employees being less likely to search for external information. A firm's formal, informal, or cultural processes can assist in the development of R\&D capabilities through experience accumulation, knowledge articulation, and knowledge codification processes (Zollo \& Winter, 2002). Nonetheless, similar to core rigidities, firms should ensure that processes do not discourage inter-organizational learning.

As the conceptual model illustrates, the internal firm characteristics are interrelated. Ownership and management influence the strategy and values of the firm. Subsequently, these three elements influence the resources, systems, and processes that support R\&D practices. Similarly, the systems and processes used to support R\&D, can help or hinder the R\&D management practices that develop intangible resources such as R\&D capabilities.

A firm's internal context does not operate in isolation. The external environment also has an impact on a firm's characteristics. As argued by Hofer's (1975) contingency theory, the external environment has an impact on a firm's strategy formulation and structure. In this conceptual model, the competitive, regulatory, and market environments have an impact on the strategic decision to engage in R\&D. Similarly, as asserted by Bloom et al. (2017), competition and the regulatory environment influence R\&D management practices.

Competition, and the potential for knowledge spillovers, can have both a positive and negative influence on the decision to engage in R\&D. For example, depending on the degree of competition and the product life cycle, a firm may choose an innovator or imitator strategy (Slivko \& Theilen, 2014). Firms with products in the growth phase may encounter greater competition from new entrants who choose an imitator strategy. Competition also can 
influence a firm's R\&D management practices. For example, a firm may choose to implement a system used by its competition if the firm receives positive feedback from customers or suppliers.

Competition can also result in scarcity or more expensive acquisition of resources. If all firms in an industry are trying to acquire the same technical talent or physical resources, the cost to obtain the resource may increase. It should be noted that a number of firms do not often consider competitor reaction in their strategic decisions (Zajac \& Bazerman, 1991). Social factors, such as over-confidence or underestimation of the competitive landscape, can inhibit a firm's ability to interpret or learn from the external environment (Zajac \& Bazerman, 1991).

The regulatory environment also affects resources, systems and processes, and R\&D management practices. Depending on the regulation, there may be limitations on the data that can be collected, employment standards, health and safety standards, and technical standards that may affect the acquisition of resources, the systems and processes, and management practices.

From an external perspective, the market may be the most significant factor in the decision to engage in R\&D. If there is no perceived market for a product or service, a firm may not engage in R\&D. Furthermore, the decision to engage in R\&D may be spurred by customers' demand to improve an existing product or service. From an internal perspective, opportunities to leverage information and best practices (i.e., knowledge spillovers) from customers also have an impact on a firm's learning capabilities and its R\&D management practices. 
By capturing the internal and external context of a firm, this conceptual model should establish a foundation to better understand how a small CCPC decides to engage in R\&D and how it manages its R\&D practices in the context of the SR\&ED program. In addition, contingency theory and organizational learning theories may be applied to the decision to engage in the SR\&ED program and how CCPCs manage their SR\&ED eligible activities.

Some of the contingency factors may influence a small CCPC's decision to engage in SR\&ED. For example, CCPCs may not have robust systems to allow them to easily document information on their R\&D processes. As a result, CCPCs may choose not to apply for the SR\&ED program, or CPCCs may submit a suboptimal claim due to lack of supporting documentation. Consequently, due to financial constraints and SME firm characteristics, small CCPCs may encounter different challenges and opportunities when deciding to engage in the SR\&ED program.

Similarly, small CCPCs may manage their SR\&ED practices differently than larger firms due to their internal and external context. For example, without adequate systems and processes to scan for external information from customers, suppliers, or the competition, a small CCPC may not be able to leverage potential knowledge spillovers and implement best practices in their $R \& D$ development processes. 


\section{CHAPTER 3: RESEARCH METHODOLOGY}

This chapter explains the methodological approach used in this thesis. The literature review has revealed that the extant research on $R \& D$ and tax incentives utilizes a positivist epistemology and quantitative approach. Data was most often collected through secondary sources, such as documentation from government sources and surveys. The findings suggest that there is agreement that, in most cases, $R \& D$ tax incentives result in an increase in $R \& D$ expenditures. However, there is little understanding of how firms, particularly small CCPCs, decide to engage in the SR\&ED program and how these firms manage their SR\&ED practices. To fill this gap, this thesis takes an interpretivist epistemological position and utilizes a qualitative approach. Figure 3-1 summarises the research approach that is employed in this thesis.

Figure 3-1 Research approach
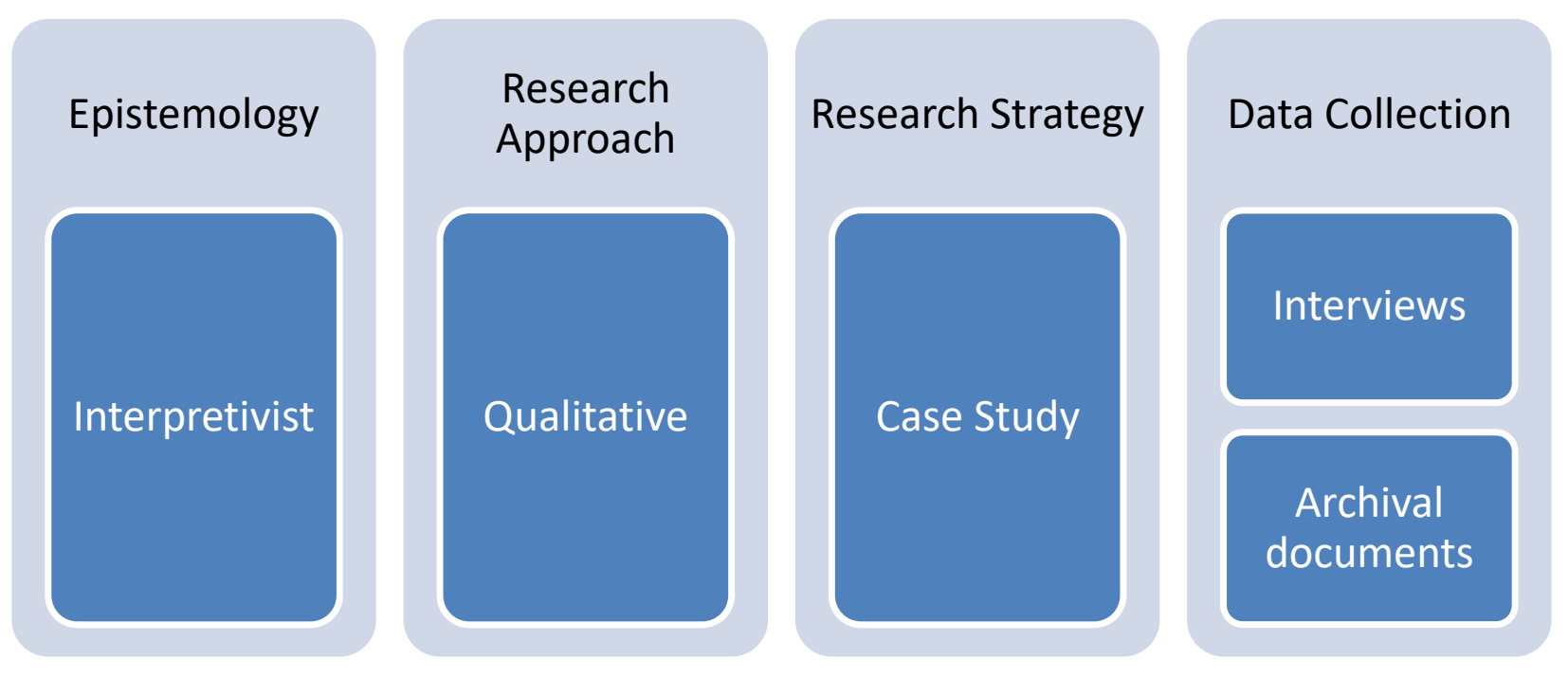
This chapter is structured as follows. First, the type of research and the epistemology chosen for this thesis is discussed. Based on these two elements, the next section describes why a qualitative research approach is taken. It then outlines the reasoning for choosing a case study approach as the research strategy. Following the description of the research strategy, the subsequent sections outline the data collection procedures and the sampling techniques employed. Finally, the data analysis techniques and ethical considerations are described in detail.

\subsection{Type of research}

This section examines how the research question determines the type of research undertaken. Following a discussion of the characteristics of each type of research, this section articulates this thesis's research type. The type of research has implications on the research design (Singleton \& Straits, 2010). As a result, the implications of the research type on the research design of this thesis are explained.

The research question and objectives generally determine the type of research that will be employed (Guest, MacQueen, \& Namey, 2014). Research is pursued to

“(1) explore a phenomenon such as a group or setting in order to become familiar with it and gain insight and understanding about it ... (2) to describe a particular community, group, or situation as completely, precisely, and accurately as possible; and (3) to estimate and formally to test relationship among variables" (Singleton \& Straits, 2010, p. 107).

Consequently, the research question can lend itself to exploratory, descriptive, or explanatory research. Table 3-1 lists the characteristics of exploratory, descriptive, and explanatory research. 
Table 3-1 Characteristics of the types of research

\begin{tabular}{|l|l|l|l|}
\hline Characteristics & Exploratory & Descriptive & Explanatory \\
\hline Objectives & Generate insights & $\begin{array}{l}\text { Accurately describe } \\
\text { phenomena or } \\
\text { elements thereof }\end{array}$ & Verify insights \\
\hline $\begin{array}{l}\text { Degree of } \\
\text { uncertainty }\end{array}$ & Ambiguous & Partially defined & $\begin{array}{l}\text { Well-defined, low } \\
\text { uncertainty }\end{array}$ \\
\hline Drivers & Content-driven & Observation-driven & Hypothesis-driven \\
\hline Research structure & Flexible & Structured & Structured \\
\hline Data requirements & Not well defined & Well-defined & Well-defined \\
\hline
\end{tabular}

Adapted from Guest, MacQueen \& Narney, 2014

Given the three main types of research, this thesis's research question takes an exploratory mindset. Exploratory research tends to be used when there is a high degree of uncertainty, and when little is known about a phenomenon. The reasons that Canadian firms engage in the SR\&ED program are not well known, particularly for SMEs. Further, little is known about how SMEs manage their practices, once the decision to engage in the SR\&ED program is taken.

Consequently, this type of research has an impact on the research design including the sampling and data source requirements. Exploratory studies generally employ non-probabilistic samples (Guest et al., 2014). Exploratory studies also generate primary data and require using strategies in which information can be gleaned from participants. Exploratory research is usually characterised by a high degree of flexibility and a lack of formal structure (Guest et al., 2014; Singleton \& Straits, 2010). Although the methods to collect and develop data may be initially identified, the researcher may need to deviate from the plan depending on what emerges from the interaction between the researcher and the participant (Guest et al., 2014). 
Furthermore, the content obtained becomes the basis of the development of a conceptual or theoretical model via an inductive approach using themes and patterns that surface from the primary data (Guest et al., 2014; Singleton \& Straits, 2010). The initial stages of the exploratory research generally commences with a description of the phenomenon, and progresses with the development of additional content for analysis purposes (Guest et al., 2014).

The main advantage of exploratory research is its flexibility and adaptability. Its flexibility allows for any emergent themes to be probed to better understand a phenomenon. It should be noted that exploratory research does not aim to provide a conclusive answer to a research question (Singleton \& Straits, 2010). Exploratory research can be seen to be "initial research" which forms the basis for further study. The disadvantages of exploratory research include the substantial data that is collected and the reliance on the researcher for interpretation. In addition, due to its generally smaller samples, it may not be representative of the target population (Guest et al., 2014; Singleton \& Straits, 2010).

\subsection{Epistemology}

This section has three goals: to discuss the epistemology that guides this thesis, to articulate how this epistemology differs from other epistemologies used in R\&D tax incentive research, and to explain the implications of this philosophical approach for this thesis. However, this section first needs to explain the concept of a research paradigm and the three common epistemologies employed, to justify the choice of epistemology used.

Burrell \& Morgan (1979, p. 23) define a research paradigm as "meta-theoretical assumptions which underwrite the frame of reference, mode of theorising and modus operandi of the social 
theorists who operate within them." In effect, a research paradigm influences a researcher's actions within a research study. Lincoln, Lynham \& Guba (2017) outline the three elements of a research paradigm as ontology, epistemology, and methodology. Ontology is based off the Greek words "existence" and "study." Ontological beliefs are beliefs held concerning the fundamental nature an entity or phenomenon under investigation (Orlikowski \& Baroudi, 1991). For example, from an ontological standpoint, accounting concepts such as revenue, profit, and depreciation are assumed to exist (Lukka, 1990). Epistemology relates to the foundation of knowledge and understanding, or the question of "How do I know the world?" (Lincoln et al., 2017). Lastly, methodology relates to the tools used to develop knowledge of "reality" (Lincoln et al., 2017).

From an ontological viewpoint, research can be either objective or constructionist (Bryman, Bell, Mills, \& Yue, 2011). An objective ontological position "implies that social phenomena and their meanings have an existence that is independent of social actors" (Bryman et al., 2011, p. 62). For example, the extant $R \& D$ and tax incentive literature primarily assumes that the actors are rational and use tax incentives to reduce the marginal cost of R\&D activities. In contrast, a constructionist viewpoint asserts that an entity only exists "through the action of humans in creating and recreating it" (Orlikowski \& Baroudi, 1991, p. 7). In this context, the interpretation of what constitutes $R \& D$ and why the entity engages in $R \& D$ is dependent on the actor.

Within a research paradigm, ontology and epistemology are interrelated in that an ontological position can shape the epistemology employed in a research study. Myers (2009) suggests three major epistemologies: positivism, interpretivism and criticalism. The three research 
epistemologies are distinctly different. The epistemologies differ due to the aim of the inquiry, nature of the knowledge, knowledge accumulation, and values of the researcher (Lincoln et al., 2017). The aim of the inquiry can be described as the goal of the research study; whereas, the nature of knowledge can be described as "how the researchers view the knowledge that is generated through inquiry/research" (Lincoln et al., 2017, p. 120). In this context, knowledge accumulation means how researchers build off prior knowledge to obtain better understanding, and values indicate what elements are deemed to be important within a research study (Lincoln et al., 2017).

The aim of a positivist approach is to confirm or reject a hypothesis through empirical testing to provide some ability to predict behaviour based on a set of conditions (Myers, 2009; Orlikowski \& Baroudi, 1991). In positivist research, knowledge that is obtained through hypotheses is deemed to be factual and knowledge accumulates from further testing and analysis (Lincoln et al., 2017).

The goal of interpretive research is to understand phenomena through accessing the meanings that participants assign to them (Orlikowski \& Baroudi, 1991). An interpretivist approach assumes that people develop their own "truth" based on their beliefs and experiences. Since knowledge is obtained through participant interaction, knowledge accumulates via "more informed and sophisticated reconstruction, vicarious experience"(Lincoln et al., 2017, p. 110). Interpretive researchers do not take a value-neutral stance and recognize the values of the researcher and participants can influence a research study (Lincoln et al., 2017; Orlikowski \& Baroudi, 1991). In contrast, a criticalist approach aims to challenge the status quo. The current 
structures and systems have inherent contradictions embedded, and critical researchers aim to expose and transform these restrictive social conditions (Orlikowski \& Baroudi, 1991).

This thesis uses an interpretivist epistemological position. An interpretivist epistemology is appropriate when the goal of the research is to understand the context in which a phenomenon exists, and the process whereby the phenomenon influences and is influenced by its context (Klein \& Myers, 1999). A positivist approach is not realistic for this thesis as there is no comprehensive theory to test. The reality of R\&D engagement and practice is grounded in the environment and experience of each firm and its employees. The decision to engage in R\&D and how firms manage their R\&D practices are social constructs of the actors involved. As this thesis's research question seeks to determine why Canadian CCPCs engage in the SR\&ED program and how they manage their SR\&ED practices, an interpretivist position allows the researcher to evaluate a firm's characteristics and external social contexts, which may influence its SR\&ED behaviour.

This epistemological position differs from existing research in R\&D tax incentives. The extant $R \& D$ tax incentive research focuses on the efficacy of tax incentives on R\&D or potential crowding-out behaviour. The extant research had taken a positivist epistemological position. However, the research has not extensively evaluated how the internal and external contexts influence R\&D engagement and management. As a result, there is a gap in the understanding of the motivations and management practices of firms. By utilizing an interpretivist epistemology, this thesis aims to bridge the gap in understanding. Consequently, the 
contribution of this thesis is to provide a voice to SMEs of their R\&D and SR\&ED program experience, allowing greater understanding of their motivations and management practices.

Interpretivist research gleans subjective meanings found in the social world, and the researcher's role "is to acknowledge their existence, to reconstruct them, to understand them, to avoid distorting them, to use them as building-blocks in theorizing" (Goldkuhl, 2012, p. 138). As a result, the interpretivist epistemological position influences the research approach, strategies, data collection, and analysis.

\subsection{Research approach}

This section describes the research approach chosen for this thesis. Research approaches can be defined as "plans and the procedures for research that span the steps from broad assumptions to detailed methods of data collection, analysis, and interpretation" (Creswell, 2014 , p. 31). Subsequently, this section provides the rationale for using a qualitative approach and outlines the research implications of such an approach.

Depending on the epistemological position, the research could undertake a qualitative, quantitative, or mixed methods approach (Creswell, 2014). A qualitative research approach studies phenomena in its "natural settings, attempting to make sense of or interpret phenomena in terms of meanings people bring to them" (Denzin \& Lincoln, 2012, p. 33). In contrast, quantitative research "emphasize the measurement and analysis of causal relationships between variables, not processes" (Denzin \& Lincoln, 2012, p. 44). As a mixed methods approach is a combination of the two approaches, a comparison of qualitative and 
quantitative approaches and their implications is evaluated. Table 3-2 compares the two approaches.

Table 3-2 Comparison of qualitative and quantitative approaches

\begin{tabular}{|c|c|c|}
\hline Characteristics & Qualitative & Quantitative \\
\hline Type of research question/s & $\begin{array}{l}\text { Open-ended } \\
\text { Process-oriented }\end{array}$ & $\begin{array}{l}\text { Defined } \\
\text { Outcome-oriented }\end{array}$ \\
\hline Logic & $\begin{array}{l}\text { Inductive inference } \\
\text { Subjectivity } \\
\text { Meaning }\end{array}$ & $\begin{array}{l}\text { Deductive inference } \\
\text { Objectivity } \\
\text { Causation }\end{array}$ \\
\hline Use of data & $\begin{array}{l}\text { Explore a phenomenon } \\
\text { Identify themes and patterns }\end{array}$ & Evaluate hypothesis \\
\hline Analysis & $\begin{array}{l}\text { Narrative description } \\
\text { Comparison }\end{array}$ & $\begin{array}{l}\text { Numerical estimation } \\
\text { Statistical inference }\end{array}$ \\
\hline Theory & Theory building & $\begin{array}{l}\text { Falsification or verification of } \\
\text { an existing theory. }\end{array}$ \\
\hline
\end{tabular}

Adapted from Bryman et al. (2011) and Saunders, Lewis, \& Thornhill (2012)

Qualitative research is more likely to be associated with open-ended and process-oriented research questions. In other words, the research question is interested in the means to an end and does not expect a yes/no answer. The understanding is that open-ended questions allow research participants to express their viewpoints (Crotty, 1998). Qualitative research is subjective by nature as it focuses on the meanings assigned by participants and the researcher. In contrast, quantitative research is objective and seeks to determine causation. The inference methods of qualitative and quantitative research also differ. Qualitative research uses a "bottom up" approach, as illustrated in Figure 3-2, which commences with the collection of data and concludes with the building of theory or comparing the patterns with existing theories. 
Figure 3-2 Inductive reasoning model

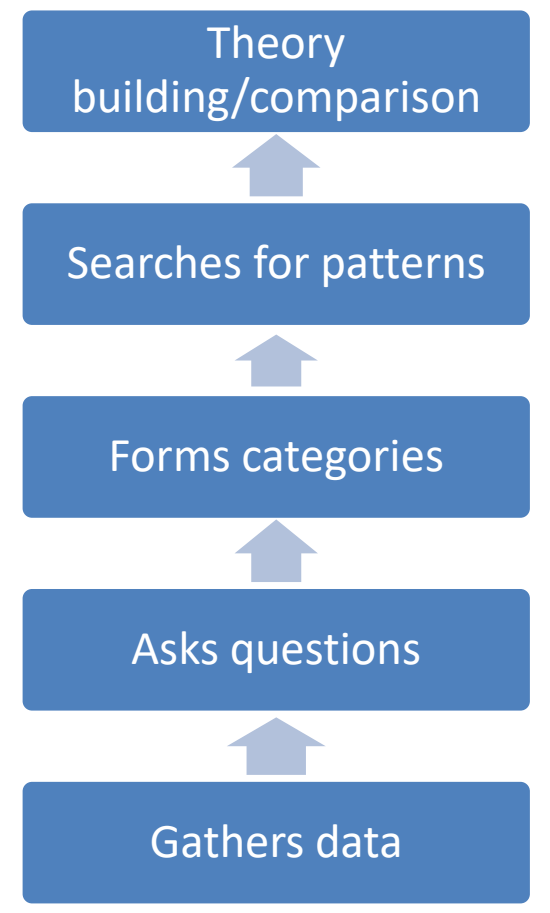

Adapted from Creswell (1994, p. 96)

The extant research on R\&D tax incentives primarily employs a positivist epistemology using a quantitative approach. In these studies, a change in an independent variable or variables is tested to determine the impact on another variable (i.e., dependent). For example, an R\&D tax incentive should result in an increase in R\&D expenditures. However, the motivation to decide to use R\&D tax incentives and how a firm manages its practices are not well known. Therefore, the extant research evaluated the efficacy of the R\&D incentives that were used by firms but did not evaluate why other firms did not engage in R\&D or use incentives. Further, there is little understanding of how firms managed their R\&D practices with R\&D tax incentives.

A qualitative research approach was selected as there is little understanding of the motivations to engage in the SR\&ED program or how CCPCs manage their SR\&ED practices. In addition, an 
interpretivist epistemology is consistent with a qualitative approach in that an interpretivist seeks to understand phenomena by examining the meaning assigned by actors. Qualitative research searches for the unique perspective in individual firms or populations to generate greater understanding. A qualitative approach can provide a voice to smaller firms by obtaining their perspective on the SR\&ED program. Small CCPCS are not often included in accounting and finance research due to the difficulty in obtaining private information.

A qualitative research approach is appropriate when the existing theories do not reflect the complexity of a research problem (Creswell, 2013). For example, the patent rights protection hypothesis does not explain R\&D behaviour in firms that do not patent or are not concerned with intellectual property. The existing theories do not capture the complexity of the R\&D engagement decision and management practices, nor do they reflect the specific distinctiveness of SMEs. By employing a qualitative approach, information can be gleaned directly from CCPCs regarding firm characteristics and their external environment. Qualitative research can simplify understanding of complex issues by going more in depth and breaking it into more manageable components. To break down complex issues, the context and features should be articulated, to capture the complexity or subtleties of how actors interact with a phenomenon (Creswell, 2013).

The research approach has an impact on a study's research design. Creswell (2013) specifically identifies that qualitative research includes characteristics such as examination within the unit of analysis's natural setting, the role of the researcher, inductive logic, and emergent design. To better understand the context that influences a phenomenon, qualitative research is often 
done in its natural setting. By conducting research in the field at the site of the participants, qualitative researchers can also gather non-verbal information and see how participants react in their own setting.

The role of the researcher is also important for qualitative research. Researchers are responsible for collecting data through examining documents, observing behaviour, and interviewing participants (Creswell, 2013). As illustrated in Figure 3-3, a researcher records observations and searches for patterns or themes.

Figure 3-3 Qualitative process

\section{Obervations}

Patterns or Themes
Conceptual model

This process involves the researcher engaging in constant comparison of the observations and the themes/patterns, until a comprehensive set of themes emerges (Creswell, 2013). The themes or patterns that emerge can be used to develop a conceptual model, and they can also be used to add additional texture to existing theories and models.

\subsection{Research strategy - Case study}

A research strategy allows the researcher to answer the research question by using a method that is consistent with the research approach (Creswell, 2013). Research strategies include action research, archival research, case study, ethnography, experiment, grounded theory, 
narrative inquiry, phenomenology, and survey (Bryman et al., 2011; Creswell, 2014; Saunders, Lewis, \& Thornhill, 2012). Some of these research strategies are more suited to quantitative analysis, such as experiments, in which there is a cause and effect. Many of these research strategies, such as case study, can be used in qualitative and quantitative research (Eisenhardt, 1989; Yin, 2014). Creswell (2013) outlines five research inquiry approaches that are consistent with qualitative research including case study, ethnography, grounded theory, narrative inquiry, and phenomenology.

The case study strategy has been selected as a research strategy to explore CCPCs' R\&D engagement decisions and their management practices. Yin (2014) defines a case study as an empirical research strategy that investigates a phenomenon in depth within its context; however, the boundaries between the phenomenon and the context may not be clear (Yin, 2014). Given this, a case study is justified as a strategy as the boundaries are not clear both as to why a CCPC would or would not engage in R\&D and the SR\&ED program, and how CCPCS manage their R\&D and SR\&ED practices.

In addition, Yin (2014) outlines three conditions in which a case study is appropriate. These conditions are dependent on the type of question, the control of behavioural events, and whether the research studies historical or contemporary events (Yin, 2014). If these conditions are not met, other research strategies should be deployed. For example, an experiment may be more appropriate when the researcher needs to control the behavioural events to test theoretical constructs. 
The type of research question can be categorized by the use of "who," "what," "where," "why," and "how" questions. A case study research strategy is appropriate if the research question is asking "How?" or "Why?" questions (Yin, 2014). "How" and "why" questions are more exploratory in nature in that they seek deeper understanding of a phenomenon and its complexity. Furthermore, case study research is well placed to answer "how" and "why" questions, as these questions require information on the operational links over a span of time (Benbasat, Goldstein, \& Mead, 1987). Given the two general research questions, a case study research strategy is appropriate as the research questions are trying to ascertain "Why?" and "How?"

The second condition is that the researcher has little or no control of the behavioural events (Yin, 2014). In effect, the research does not need to manipulate the events to determine cause and effect. Researchers who would like to investigate phenomena in their natural setting do not require or wish for control, as the study would then not be a good representation of participants' actions. The research questions for this study do not require any control of the behaviour of the participants as it is not testing their behaviour with regard to R\&D tax incentives.

Thirdly, Yin (2014) indicates that case studies are appropriate when the research focuses on contemporary events or phenomena, as opposed to historical events. In effect, case study is not an appropriate tool to ascertain why an event or phenomena occurred in the past. The research question seeks to determine why CCPCs engage in R\&D and the SR\&ED program and 
how they manage their R\&D in real-time. Although some of the decisions may have been made in past, this study does not evaluate past behaviour.

Case studies can be composed of a single case or multiple cases (Benbasat et al., 1987; Yin, 2014). Case study research can provide a high level of detail of a phenomenon and can combine multiple sources of data to achieve in-depth understanding (Benbasat et al., 1987; Yin, 2014). With this in-depth information, a case study can establish constructs, and build or extend theory (Eisenhardt, 1989). Consequently, a multiple case research study was employed to understand and possibly develop a conceptual model of SME R\&D engagement and management based on firm characteristics and external environment.

To commence a case study, the research problem should be delineated including the research question and identification of the a priori constructs. Table 3-3 outlines the steps to conduct case study research. Within a case study, there may be many different variables of interest and researchers most likely have "less a priori knowledge of what the variables of interest will be and how they will be measured" (Benbasat et al., 1987, p. 370). Although researchers may not know all the potential variables of interest, there should be some theoretical basis for their research, to ensure there is rigour to the research (Yin, 2014). 
Table 3-3 Steps to case study research

\begin{tabular}{|c|c|}
\hline Steps & Description \\
\hline Research problem & $\begin{array}{l}\text { - Definition of research question } \\
\text { - Possible identification of a priori constructs }\end{array}$ \\
\hline Selecting cases & $\begin{array}{l}\text { - Unit of analysis } \\
\text { - Sampling strategies }\end{array}$ \\
\hline Establish case study protocols & $\begin{array}{l}\text { - Data requirements } \\
\text { - Data collection methods }\end{array}$ \\
\hline Gathering data in the field & $\begin{array}{l}\text { - Data collection, including field notes } \\
\text { - Flexibility of data collections methods, } \\
\text { depending on emerging primary data }\end{array}$ \\
\hline Analyzing the data & - Techniques for cross-analysis \\
\hline Developing constructs or hypotheses & - Iterative techniques to develop constructs \\
\hline Linking constructs to theory & - Compare and contrast against existing theories \\
\hline
\end{tabular}

Adapted from Eisenhardt (1989) and Yin (2014)

At the outset of the research study of CCPC's R\&D engagement decision and management practices, the variables of interest include resources, systems and processes, ownership and management, values, and strategy. With the identification of possible a priori constructs, the cases and the case study protocols were identified and are discussed in sections 3.5 and 3.6.

There are limitations with using case study as a research strategy. The limitations include building theory with too many constructs, due to the richness of the data available (Eisenhardt, 1989). Other concerns with case study research include lack of generalizability and rigour (Yin, 2014).

Generalizability denotes that the findings of the phenomena should apply not just in the settings being studied, but also in other settings (Gibbert, Ruigrok, \& Wicki, 2008). Yin (2014) adds that case studies do not represent a sample as the goal is not statistical generalization, but rather analytic generalization. Analytical generation is the generalization from empirical 
observations to theory (Gibbert et al., 2008; Yin, 2014). Eisenhardt (1989) indicates that crosscase analysis of four to ten cases is sufficient for analytical generation. As this thesis is a multicase study of more than ten cases, the cross-case analysis should allow for adequate analytical generalization to mitigate concerns regarding generalizability.

In order to defend against any claims of a lack of rigour, Yin (2014) recommends that researchers ensure transparency in the research and reporting processes. Issues with rigour are more likely to arise during the data collection phase, and the tactics used as mitigation are discussed in the following section.

\subsection{Data collection}

A significant amount of the literature concerning R\&D tax incentives obtained their data from government and/or financial databases such as Compustat. Most of these articles used panel data, that is, data over time from a cross-section of firms or industries. Surveys are the second most commonly used data collection method. The surveys used in these studies are often conducted by a governmental body, and the researchers employ the data gleaned from the survey for their analysis. In some instances, researchers used more than one data collection technique. It was common, for example, to use archival information from company documents to support financial information from a database (e.g. Greve, 2003). In the literature review, interviews were not used as a form of data collection. Consequently, the extant research has not obtained primary data directly from firms.

Case studies use numerous data collection techniques including surveys, interviews, observations, and collection of secondary or archival documentation (Eisenhardt, 1989; Yin, 
2014). Interviews, observations, and collection of secondary data are associated with qualitative case studies (Yin, 2014). Interviews and observations generate primary data. In contrast, secondary data is the collection of archival documentation, web pages, government statistics, etc.

Interviews can be structured, semi-structured, or unstructured (Bryman et al., 2011). Interviews related to qualitative research are unstructured or semi-structured (Bryman et al., 2011; Singleton \& Straits, 2010). Unstructured interviews can be viewed as interviews in which the researcher does not impose any a priori categorization that may limit the scope of the interview (Bryman et al., 2011). Semi-structured interviews include a pre-determined list of questions, often referred to as an interview guide (Bryman et al., 2011; Singleton \& Straits, 2010). Questions may not follow the sequence prescribed by the guide and researchers are not limited to asking questions that are included in the interview guide (Bryman et al., 2011).

Observations can be direct observations or participant observations (Yin, 2014). Direct observations involve the researcher observing people without interacting with them, and often without their knowledge. Participant observations are a method in which data is collected through a researcher immersing themselves "in a social setting for an extended period of time, observing behaviour, listening to what is said in conversations both between others and with the fieldworker, and asking questions" (Bryman et al., 2011, p. 578).

Secondary, or archival, documentation is documentation that has been produced by a firm and usually provides a summary of activities or tasks (Singleton \& Straits, 2010). Within a case 
study, collection of archival data may include minutes of meetings, progress reports, etc. that allow context into the decisions, processes, or events within a firm (Yin, 2014).

To improve generalizability, one of the tactics recommended by Yin (2014) is for multiple chains of evidence. Consequently, this thesis employed semi-structured interviews and the collection of archival data. Interviews have been selected, as qualitative interviews allow researchers to gather rich data from individuals in diverse contexts (Myers, 2009). The qualitative interview comprised of open-ended interview questions (see Appendix D for the Interview Guide). Openended interview questions are advantageous to researchers as they allow for greater depth of explanation that is not possible in the survey format (Bryman et al., 2011).

Archival documentation can corroborate information provided by the key informants. In the context of this research, key informants were asked if they are willing to provide T661 forms that were used to file for SR\&ED program claims. No participant was willing to share this information; however, one participant provided the Federal Court ruling in favour of the firm for an appeal of two SR\&ED program rejections. Other secondary data such as information from a firm's web page and related news articles was used to provide additional background information, such as defined values and mission statements, products, and history.

\subsubsection{Semi-structured interviews}

The research questions and the conceptual model provided the direction of the interview questions found in the interview guide (Appendix D). The interview questions sought to obtain the experience of the participant in the decision to engage, or not, in R\&D and the SR\&ED 
program, and to better understand the R\&D management practices within CCPCs. The questions in the interview guide were not always asked in a prescribed order as this was dependent on the flow of the interview. Further, several additional probing questions were asked to obtain further clarity from the key informants.

Most of the interviews ( $n=16)$ were conducted between October and December 2019, with additional interviews $(n=5)$ conducted in May 2020 (during the Covid-19 pandemic period). All key informants gave their permission to record the interviews for accuracy as part of their informed consent form. Bryman et al. (2011) indicate that recording and subsequent transcription of interviews allow the researcher to examine an interviewee's statements more thoroughly and repeatedly and allows public scrutiny from other researchers for content or bias. Some basic notes and observations were jotted down during the interviews. The audio data was transcribed by the researcher. The audio recordings were deleted once transcribed, and the transcriptions were stored on the researcher's computer in the researcher's office.

Some face-to-face interviews ( $n=11)$ were conducted. For interviews where face-to-face was not feasible, a telephone or Skype interview was conducted $(n=10)$. Fontana \& Frey (2008) identify several elements that a researcher should consider when conducting an open-ended interview. Researchers should consider the language and culture of respondents, establish a rapport with the participants, consider how they should present themselves, and gain trust (Fontana \& Frey, 2008).

Jargon and behaviours may be specific to a domain or industry (Fontana \& Frey, 2008). The researcher has experience with SR\&ED program claims and the R\&D process; therefore, there 
was no issue with the language and culture of the participants. As a result, the researcher was able to quickly build rapport with the interview participants.

Fontana \& Frey (2008) also assert that the manner in which a researcher presents oneself can have an impact on the study's success as the participants' impression of the researcher may influence their responses. In order to mitigate issues regarding self-presentation, the researcher emphasized that they want to see the situation from the participants' perspective.

Gaining trust is also an important component of the success of a study. Once trust has been gained, participants are more likely to provide accurate information. However, compared to face-to-face interviews, it is more difficult to establish trust and rapport over the phone (Singleton \& Straits, 2010). With a lack of rapport and trust, an interview's duration and complexity may be affected. Phone interviews that last more than 30 minutes face a higher risk of mid-interview termination (Singleton \& Straits, 2010). Furthermore, more complex, or sensitive questions may be more difficult for the researcher to communicate effectively, and the respondent may not be as willing to answer fully. With these challenges in mind, the researcher was able to gain trust quickly by establishing rapport and emphasizing the privacy and data protection methods.

\subsubsection{Archival documentation}

There are numerous advantages in using archival documentation for case study research including corroboration, stability, unobtrusiveness, and non-reactivity (Singleton \& Straits, 2010). The primary advantage of archival documentation is that it can corroborate or augment evidence obtained from other sources (Yin, 2014). Archival documentation is also stable, in 
that it can be reviewed repeatedly. Unlike interview data, archival documentation is not obtrusive, nor is it a result of the case study research. Finally, the data is non-reactive since it is not influenced by the researcher. For example, regardless of how the researcher presents oneself, the data will not change.

There are disadvantages with the use of archival documentation. The primary disadvantage is the retrievability of the documentation (Singleton \& Straits, 2010; Yin, 2014). This was the case in this study, as firms were not willing to provide copies of the T661 claim for privacy reasons. The researcher was able to validate some of the information provided by the key informants by reviewing the firms' websites and from news releases.

\subsection{Organization and key informant selection}

Given the case study research strategy, a sampling strategy was required to select firms and solicit participants for interview purposes. The process of sampling to obtain primary data collection employing a case study can be delineated in the following stages: defining the target population, determining the sample size, and selecting a sampling method (Singleton \& Straits, 2010).

Before defining the target population, the unit of analysis should also be specified. Units of analysis can be defined as the "entities (objects or events) under study" (Singleton \& Straits, 2010, p. 81). The unit of analysis found in the R\&D tax incentive literature sample included aggregate macro-economic data, firms, and industries. Some of the articles that use aggregate data focused on macro-economic data such as government reported R\&D expenditures, patent filings, and government data on R\&D tax incentives (e.g., Bösenberg \& Egger, 2017). The most 
frequent unit of analysis is at the firm level. In addition, some of the articles divide the firms by size, country of origin, and industry (e.g., Koga, 2003).

Using aggregate macro-economic data has advantages in that most of the information is publicly available and is usually not expensive (if not free) to obtain. However, the use of aggregate data, can result in ecological fallacies in the research findings. This fallacy can occur when studies use aggregate data on firms and make inferences or generalizations as though they apply to each individual firm (Singleton \& Straits, 2010). Similar issues can occur with using industry-level data. Certain behaviours or events may be limited to a small group of firms (e.g., leader firms), rather than the entire industry.

By focusing on firm level data, the extant research was better able to generalize their findings. The disadvantage in using the firm as a unit of analysis is the data can be difficult to access. The data is not always publicly available, and therefore, can be more difficult and costly to obtain. Consistent with the extant literature on R\&D and tax incentives, the unit of analysis for this thesis are firms, and whenever possible, the R\&D department as the research questions relate to CCPC behaviour. By limiting the unit of analysis to firms, greater clarity can be obtained regarding CCPCs' R\&D behaviour, their firm characteristics, and their external environment. Studying macro-economic data or industry data may not be able to provide the same level of insight on CCPC's motivations and behaviours.

\subsubsection{Firm selection}

The first step in creating a sample is to identify the target population. The target population is the population for which the research would like to make generalizations (Singleton \& Straits, 
2010). In order to identify the target population, the criteria for selection needs to be outlined (Singleton \& Straits, 2010). By identifying a target population, this study can also bracket the scope of the research.

Given the number of small CCPCs within Canada, the target population criteria were established to operationalize the sampling strategy. Firstly, the CCPCs must be eligible for the enhanced SR\&ED program rate (i.e., the firms have a TCEC less than 10 million). The CCPC sample should include firms that engage in R\&D or have the intent to engage in R\&D at some point in the future. For firms that engage in $R \& D$, the researcher should be able to query their decisions to engage in $R \& D$, and how these firms manage their R\&D practices.

A sample size should be sufficiently substantial to provide insights and allow for crosscomparisons. There are number of factors that have an impact on the sample size. These include the heterogeneity of the population, the type of sampling design, and the available resources (Singleton \& Straits, 2010). Guest, Bunce \& Johnson (2006), compiled sample size recommendations from other researchers. Depending on the nature of the study, the sample size differs. In their analysis of the attitudes towards sex of women in Nigeria and Ghana, Guest et al. (2006) used semi-structured interviews with open-ended questions. The authors found that a minimum of six interviews for homogeneous samples was required, while a minimum of 12 interviews for more heterogeneous samples were recommended (Guest et al., 2006).

Based on the guidelines established by Guest et al. (2006), a target was established for 15 interviews for the decision to engage, and 12 small CCPCs for their R\&D management practices with at least one key informant such as the CEO, the CFO, and the R\&D director or manager. 
To solicit participants for the interview, the researcher contacted several Economic Development Organizations (EDOs) in different regions of Canada (see Appendix E). These EDOs have regular contact with firms that engage in R\&D or are in the process of engaging in R\&D. The Letter of Request for Collaboration (see Appendix F) was sent to the list of EDOs to ask for assistance. Reaction from the EDOs was mixed. One EDO was able to provide candidate firms, and they also provided contacts of EDOs in other provinces. The researcher also reached out to the Canadian Manufacturers \& Exporters Association and an accounting firm that processes SR\&ED program claims.

For the CCPCs identified by the EDOs, the Letter of Request for Collaboration for SMEs was sent to the firms to request assistance. The sample template can be found in Appendix G. From the candidate firms, a total of 18 firms are included in the interview sample, with 21 key informants agreeing to be interviewed.

Table 3-4 outlines the code name and the pertinent details of each firm. The size of the company is determined by the number of employees. For firms with less than 25 employees are labeled as very, very small, with 25-50 employees are very small, with 51 to 150 employees are small, and firms with 151 to 500 employees are considered medium. Initially, there were concerns that CCPCs that are very, very small may not be able to provide a robust representation of SMEs that engage and manage R\&D. Of the firms interviewed, Firm2 and Firm17 had less than 25 employees. These two firms were kept in the sample, as they brought a different perspective than firms with a larger employee base. This sample is also made up of 
firms of different industries and age ranges (in years). The industry is represented by its North American Industry Classification System (NAICS) code.

Table 3-4 Firm code, industry, size, and age of firms interviewed

\begin{tabular}{|l|c|c|c|}
\hline Firm Code $(\mathrm{n}=18)$ & Primary NAICS & Size* & Age range of firm \\
\hline Firm1 & 541330 & VS & $5-10$ \\
\hline Firm2 & 511210 & VV & $<5$ \\
\hline Firm3 & 541690 & VS & $5-10$ \\
\hline Firm4 & 541511 & VS & $5-10$ \\
\hline Firm5 & 518210 & VS & $11-20$ \\
\hline Firm6 & 511210 & VS & $<5$ \\
\hline Firm7 & 541511 & VS & $11-20$ \\
\hline Firm8 & 511210 & VS & $5-10$ \\
\hline Firm9 & 334519 & S & $>20$ \\
\hline Firm10 & 334290 & M & $>20$ \\
\hline Firm11 & 518210 & S & $5-10$ \\
\hline Firm12 & 518210 & M & $11-20$ \\
\hline Firm13a & 511210 & S & $11-20$ \\
\hline Firm13b & 312140 & S & $<5$ \\
\hline Firm14 & 541511 & S & $11-20$ \\
\hline Firm15 & 511210 & S & $11-20$ \\
\hline Firm16 & 336411 & VS & $<5$ \\
\hline Firm17 & 541511 & VVS & $<5$ \\
\hline
\end{tabular}

*VVS = very, very small, $\mathrm{VS}=$ very small, $\mathrm{S}=$ small, $\mathrm{M}=$ medium

The structure of NAICS is hierarchical. There are 20 sector level classifications that commence with two digits. As Table 3-4 illustrates, most firms were categorized in the 31-33, 51, and 54 sector classifications of NAICS. Firms that have a NAICS that commences with 31-33 are considered to be in the manufacturing classification. NAICs that commence with 51 are part of the information industry, and NAICs that commence with 54 are part of the professional, scientific, and technical services classification. Subsequently, the NAICs code is further classified by subsector ( 3 digits). For example, 518 is classified as data processing, hosting, and related services. Four-digit codes outline the industry group. For example, 5413 represents 
specialized design services and 5415 represents computer systems design and related services. With the NAICs hierarchy, Canadian industries are classified by 6 digits.

The age of the firm ranged from early stages (i.e., less than 5 years) to over 20 years in operation. The diversity of age, region, size, and industry provided some interesting contrasts in respect to their internal and external environments, and experiences with the SR\&ED program.

\subsubsection{Sampling method}

The sampling method outlines how a researcher will select cases (Bryman et al., 2011; Singleton \& Straits, 2010). Non-probability sampling is often associated with qualitative research studies (Bernard \& Ryan, 2010; Bryman et al., 2011). Singleton \& Straits (2010) outline four types of non-probability sampling including convenience sampling, quota sampling, purposive sampling, and referral sampling. This study employed purposive sampling to be able to obtain firms of different sizes, varying industries, and at different stages of their R\&D process.

Purposive sampling relies on the researcher to use their judgement to identify "important sources of variation in the population and then to select a sample that reflects this variation" (Singleton \& Straits, 2010, p. 173-174). Advantages of purposive sampling include that it is costeffective and timely. Disadvantages of purposive sampling include the potential bias of the researcher and the inability to generalize research findings (Singleton \& Straits, 2010).

In order to mitigate the issues of bias and generalizability, the case selection process should be documented. Within purposive sampling method, a researcher needs to select a variety of 
entities to be able to come up with a sample. Table 3-5 outlines the types of cases, which include typical, extreme, and critical cases. The sample can also be heterogeneous or homogeneous. The selection of the type of case is dependent on the research question and the research objective (Bernard \& Ryan, 2010). For example, a researcher may select an extreme case to illustrate "best in practice" or "worst in practice." Similarly, a researcher may choose a homogeneous sample, as the research question aims to generalize among a specific population.

Table 3-5 Types of cases used in case study research

\begin{tabular}{|l|l|}
\hline Types of cases & Description \\
\hline Typical case & $\begin{array}{l}\text { A case that is representative of the sample being } \\
\text { investigated }\end{array}$ \\
\hline Extreme case & A case that may be unusual or rare \\
\hline Critical case & $\begin{array}{l}\text { A case that can be considered important or } \\
\text { necessary to study }\end{array}$ \\
\hline Heterogeneous sample & $\begin{array}{l}\text { Cases with diverse characteristics to allow for } \\
\text { maximum variation when generating primary data }\end{array}$ \\
\hline Homogeneous sample & $\begin{array}{l}\text { Cases that focus on one particular subpopulation } \\
\text { with similar characteristics }\end{array}$ \\
\hline
\end{tabular}

Adapted from Bryman et al. (2011) and Bernard \& Ryan (2010)

The sample was heterogeneous in that it included a cross-section of small CCPCs of different sizes, from different regions in Canada, and different industries. The majority of the cases are typical cases. However, there were a few cases that could be considered critical, such as Firm13a and Firm13b since the firm's circumstances illustrated the impact of the SR\&ED program rules and criteria on their R\&D decisions and management practices.

During the course of interviewing the firms, key informants were also requested to provide contact information of other firms that may be willing to be included in the study. The advantages of referral sampling include the ability to recruit hidden populations, and time and 
cost effectiveness (Bernard \& Ryan, 2010; Singleton \& Straits, 2010). The key informants did not provide any specific contacts from other firms; however, some firms did suggest contacting associations for assistance.

\subsubsection{Key informant selection}

Key informants are "people who know a lot about their culture and are for reasons of their own, willing to share all their knowledge with you" (Bernard \& Ryan, 2010, p. 370). The key informants in this study will be individuals working in the selected firm who are familiar with the CCPC's reasons for engaging in R\&D, the reasons for applying for the SR\&ED program, and the management practices of the group engaging in R\&D activities. Individuals who have been identified as interested in participating in the interview were sent the Letter of Invitation (see Appendix H). Table 3-6 outlines the persons interviewed at each firm. The 21 key informants in this study included different hierarchical levels or functional areas within a firm, so that diverse perspectives can be obtained. Of the 21 key informants, five key informants identified as female, and the remainder identified as male. Table 3-6 also details the job position or group to which the key informants belong. Three key informants were classified as "other." These three informants are a Vice President (VP) of Operations, a manager in internal audit, and a director. 
Table 3-6 Key informants from interviewed firms

\begin{tabular}{|c|c|c|c|c|c|}
\hline Firm & $\begin{array}{c}\text { Chief } \\
\text { Executive } \\
\text { Officer } \\
\text { (CEO) }\end{array}$ & $\begin{array}{c}\text { Chief } \\
\text { Technical } \\
\text { Officer } \\
\text { (CTO) }\end{array}$ & $\begin{array}{l}\text { Chief Financial } \\
\text { Office (CFO)/ } \\
\text { Comptroller }\end{array}$ & $\begin{array}{c}\text { R\&D } \\
\text { management }\end{array}$ & Other \\
\hline Firm1 & & $x$ & & & \\
\hline Firm2 & $x$ & & & & \\
\hline Firm3 & $x$ & & & & \\
\hline Firm4 & $x$ & & & & \\
\hline Firm5 & & & & & $x$ \\
\hline Firm6 & $x$ & & & $x$ & \\
\hline Firm7 & $x$ & & & & \\
\hline Firm8 & $x$ & & & & \\
\hline Firm9 & $x$ & $x$ & & & \\
\hline Firm10 & & & $x$ & $x$ & $x$ \\
\hline Firm11 & & & $x$ & & \\
\hline Firm12 & & & $x$ & & \\
\hline Firm13a* & $x$ & & & & \\
\hline Firm13b* & & & & & $x$ \\
\hline Firm14 & & & & $x$ & \\
\hline Firm15 & $x$ & & & & \\
\hline Firm16 & $x$ & & & & \\
\hline Firm17 & $x$ & & & & \\
\hline Percent & $50 \%$ & $9 \%$ & $13.6 \%$ & $13.6 \%$ & $13.6 \%$ \\
\hline
\end{tabular}

*The same individual was interviewed for Firm13a and Firm13b.

\subsection{Thematic analysis}

The data collected from interviews in a qualitative case study is primarily word-based.

Consequently, a data analysis technique should allow for parsing of the data for pertinent

themes. Qualitative research aims to find patterns and themes in the data collected. Data analysis techniques common in qualitative research include content analysis, narrative analysis, discourse analysis, grounded theory, and framework analysis techniques such as thematic analysis (Bernard \& Ryan, 2010; Bryman et al., 2011; Singleton \& Straits, 2010). 
Thematic analysis was selected as the data analysis method as this approach can accommodate research questions that deal with people's experiences or phenomena in specific contexts (Braun \& Clarke, 2006). Thematic analysis also differs from other qualitative data analytic methods as it aims to identify patterns across qualitative data sets rather than within a specific narrative, discourse, or incident (Braun \& Clarke, 2006). Thematic analysis can work with small to large data sets and can be used to produce theory-driven or data-driven analysis (Braun \& Clarke, 2006).

In order to mitigate concerns about rigour, Yin (2014) suggests that both the data collection and analysis be transparent and well articulated. As a result, this section discusses the organization of data to assist in analysis. Subsequently, this section describes the thematic analysis techniques with a particular focus on initial coding, identifying themes, and linking themes to theory.

The focus of thematic analysis is on identifying and describing implicit and explicit information from the data to develop themes. The researcher reads and reviews the data and then performs coding and creates categories to uncover themes pertinent to a phenomenon (Fereday \& Muir-Cochrane, 2006). A theme can be defined as an important element "about the data in relation to the research question, and represents some level of patterned response or meaning within the data set" (Braun \& Clarke, 2006, p. 87). Thematic analysis requires significant involvement and interpretation from the researcher, as the researcher must use his or her judgement to determine themes from the data set (Guest et al., 2014). 
Due to the inductive and emergent nature of interpretivist research, it can be difficult to predict the themes that may emerge from the data. Consequently, to manage this unpredictability, the researcher used QSR-Nvivo 12, which allows to sort and code the interview data. The transcribed interviews were imported into QSR-Nvivo. The steps used to organize data are illustrated in Figure 3-4.

Figure 3-4 Data organization steps

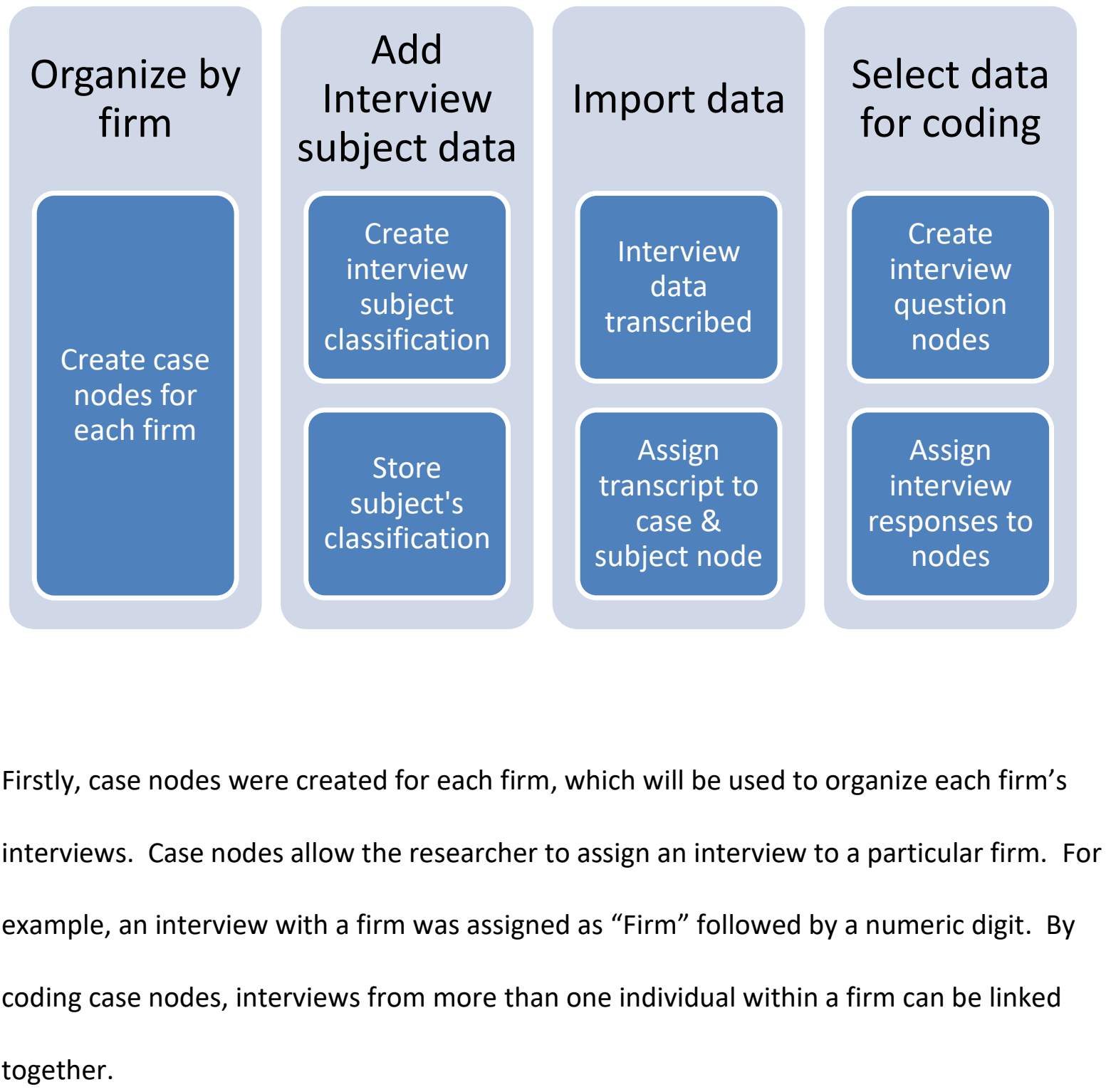


Once a case node was created, each interview subject was assigned an interview subject classification. The interview subject classification tracked information regarding the subject's job classification. This classification was important to allow for a comparison of responses among job classifications. For example, responses from CFOs in different firms were compared to find patterns.

The third step in organizing the data was to enter the transcribed interviews and the archival documentation into the appropriate case node and subject classification. Once the interview questions notes were created, the transcribed interview data was organized by interview question to allow for data analysis.

Clear demarcation of the data analysis techniques is required to ensure that the study is not criticized for lack of rigour (Gibbert et al., 2008; Yin, 2014). Guest et al. (2014) identify the following steps that should be followed to proceed with thematic analysis: read the primary data, identify possible themes, compare and contrast themes, and review the themes against the conceptual model. Braun \& Clarke (2006) outline a similar process, with more detail, that is outlined in Table 3-7. 
Table 3-7 Steps in thematic analysis

\begin{tabular}{|c|c|}
\hline Step & Description \\
\hline Become familiar with the data & $\begin{array}{l}\text { - } \text { Transcribe data (if necessary) } \\
\text { - } \text { Review the data } \\
\text { - Jot notes on initial impressions }\end{array}$ \\
\hline Generate initial codes & $\begin{array}{l}\text { - Assign codes to interesting features of the data } \\
\text { - Collate data relevant to each code }\end{array}$ \\
\hline Search for themes and patterns & - Collate codes into potential themes and patterns \\
\hline Review themes & $\begin{array}{l}\text { - Determine if themes are consistent with the initial } \\
\text { coding and data set } \\
\text { - Generating a thematic 'map' of the analysis }\end{array}$ \\
\hline Define and name themes & $\begin{array}{l}\text { - Ongoing analysis to refine the specifics of each } \\
\text { theme } \\
\text { - Create a compelling story } \\
\text { - Generate clear definitions and names for each theme }\end{array}$ \\
\hline Producing the report & $\begin{array}{l}\text { - Include compelling extract examples, final analysis of } \\
\text { selected extracts } \\
\text { - } \quad \text { Relate back to the research question and literature }\end{array}$ \\
\hline
\end{tabular}

Adapted from Braun \& Clarke (2006, p. 85)

The first step is for the researcher to familiarize themselves with the data. The researcher was able to become familiar with the data by transcribing the interview data and organizing the data into QSR-Nvivo. As part of the transcription process, the researcher also noted the impressions of the interviews to assist in the identification of codes and themes. The remaining steps can be divided into basic categories of coding, identifying themes, and linking themes to theory.

Once the transcription of, and familiarization with, the data has been completed, the next step was the initial coding. Coding allows a researcher to "define what is happening in the data and begin to grapple with what it means" (Charmaz, 2014, p. 113). Initial coding can follow a few different approaches including evaluation of the data word by word, line by line, or incident by incident (Guest et al., 2014). Codes are generally derived by reviewing the data and identifying 
instances of "something unusual, unexpected, interesting, or emotionally compelling" stands out (Guest et al., 2014, p. 67).

The coding approach can be data-driven or theory-driven (Braun \& Clarke, 2006). Data-driven coding creates themes directly from the data; whereas, in theory-driven coding, coding will be driven by specific questions related to theory or a proposed conceptual model (Braun \& Clarke, 2006). For example, in data driven coding, a researcher may be searching for words or phrases that are repeated frequently. In the context of this thesis, theory-driven coding was used. The researcher analyzed themes regarding the firm's internal and external environment in association with R\&D engagement and management practices.

At first, the researcher conducted an in-depth analysis of each case individually. Using both the interview and archival documentation, the researcher evaluated the firm's characteristics, external environment, R\&D and SR\&ED program decision-making processes, R\&D management practices, and the firm's experience with the SR\&ED program. Data that was considered significant to better understand SME engagement and management were highlighted.

Once a deeper familiarity of each case was attained, the researcher performed a cross-case analysis to find any similarities and differences among the CCPCs and the key informants. As part of the process, the researcher added additional themes of language barriers and financial constraints based on the recurring observations obtained from the interview data. Similarities and differences were also evaluated against firm size, age, and industry. 
Once the coding had been completed and the links between the data and their significance has been established, the next step in thematic analysis is to establish a link with the themes to the conceptual framework (Guest et al., 2014). For this study, the themes were compared against the preliminary conceptual model established in section 2.4. Firstly, the internal and external context was contrasted against the decision to engage in R\&D and the SR\&ED program. In addition, the relationship among the factors were also compared to the relationship identified in the conceptual model.

Subsequently, R\&D management practice and R\&D management practice in a SR\&ED environment were contrasted against the preliminary conceptual model. R\&D management practice was studied considering the characteristics of a SME, its age, its size, the industry, and its external environment. The relationship between R\&D management practice and management practice for projects that had been designated as SR\&ED-eligible activities was also contrasted against the preliminary conceptual model.

Table 3-8 combines both the research design outlined in this chapter with the problematization elements established in chapter 1 . This table outlines how the methodology supports the research themes and questions. 
Table 3-8 Synthesis of research design with methodology

\begin{tabular}{|c|c|}
\hline \multicolumn{2}{|l|}{$\begin{array}{l}\text { Research theme } \\
\text { Innovation, R\&D, SR\&ED tax incentive }\end{array}$} \\
\hline $\begin{array}{l}\text { Source of the problem } \\
\text { Practical problem: Given the resource constraints of small CCPCs, eng } \\
\text { additional challenges. As a result, CCPCS often depend on governmer } \\
\text { engage in R\&D. } \\
\text { Theoretical problem: Research in tax incentives and R\&D has found } t \\
\text { increase R\&D expenditures and output. However, there is a lack of } \\
\text { engagement and management of SR\&ED-eligible activities in the sm }\end{array}$ & $\begin{array}{l}\text { ging in R\&D poses } \\
\text { t intervention to } \\
\text { lat tax incentives } \\
\text { Aderstanding on } \\
\text { Il CCPC context. }\end{array}$ \\
\hline \multicolumn{2}{|c|}{$\begin{array}{l}\text { Managerial problem } \\
\text { How do small CCPCs engage in R\&D and manage their R\&D activities? }\end{array}$} \\
\hline $\begin{array}{c}\text { Research objective } \\
\text { Gain a better understanding of small CCPC R\&D activities eligible for th }\end{array}$ & SR\&ED program. \\
\hline \multicolumn{2}{|l|}{$\begin{array}{l}\text { General research question } \\
\text { How do small CCPCs decide to engage in R\&D activities? } \\
\text { How do small CCPCs manage their R\&D practices? }\end{array}$} \\
\hline \multicolumn{2}{|c|}{$\begin{array}{c}\text { Specific research questions } \\
\text { Why do some small CCPCS engage in R\&D activities and others do not? } \\
\text { How does the SR\&ED program influence the decision to engage in R\&D activities? } \\
\text { What is the Scope of small CCPCs' R\&D activities? } \\
\text { What are the characteristics of R\&D projects, priorities, and processes in small CCPCS? } \\
\text { How does the SR\&ED program influence the management of R\&D activities? }\end{array}$} \\
\hline Type of research & Exploratory \\
\hline \multicolumn{2}{|l|}{ Interpretivist } \\
\hline \multicolumn{2}{|l|}{ Research approach } \\
\hline \multicolumn{2}{|l|}{ Research strategy } \\
\hline $\begin{array}{l}\text { Data collection methods } \\
\text { Interviews, archival documents }\end{array}$ & \\
\hline $\begin{array}{l}\text { Organization and participant selection } \\
\text { Small CCPCS, Executives and R\&D management }\end{array}$ & \\
\hline
\end{tabular}




\subsection{Ethical considerations}

With any qualitative inquiry in which the researcher and participants interact, there is an increased need to consider the ethical implications. Bryman et al. (2011) outline elements that should be considered in business research: potential harm to participants, deception, affiliation and conflict of interest, informed consent, privacy, and data protection.

Although potential harm to participants in business research is rare, given the design of research, participants can be harmed through embarrassment or humiliation, both psychologically and socially (Singleton \& Straits, 2010). In the context of this research study, interviews and documents are highly unlikely to cause personal harm. Nevertheless, there are a few practices that are discussed in this section on voluntary participation and consent, that can mitigate any potential harm.

Deception involves a researcher deliberately misleading or misinforming participants regarding certain aspects of a study (Bryman et al., 2011; Singleton \& Straits, 2010). Deception is more commonly used in experiments than interviews or surveys (Singleton \& Straits, 2010). This research does not require any form of deception as part of its design.

With respect to affiliation and conflict of interest, the researcher has over two decades of experience working in accounting, commercial banking, and information technology. The researcher did encounter a participant within a firm with whom she has had a previous working relationship. When asked about any concerns, the interview participant indicated that they were comfortable proceeding in the interview. 
Given the nature of qualitative interviews and the request for the T661 form, the concepts of informed consent and privacy were paramount to consider in the context of ethics. It was perceived that the interview was low risk to participants. Since the participants were often recruited by an EDO, association, or SR\&ED consultant, the researcher advised the participants (both verbally and in the written consent form) that participation was voluntary, and they had the right to withdraw from the study during or after the interview. All respondents and firms were asked to sign a consent form, and all key informants agreed. The consent form template for firms can be found in Appendix I, and the consent form for individuals can be found in Appendix J. The form not only asked for explicit consent, but it also provided information on how to withdraw and contact information if the key informants had any questions or concerns regarding the study.

As some of the information provided in the interview involved financial and competitive details, in order to ensure privacy, during the coding process, each firm was assigned a generic title such as Firm10 during the coding process. The names and contact information relating to the generic titles are password protected and stored in a locked cabinet.

As indicated in the consent form, all research data, including audio-recordings and any notes were password protected. The hard copies of the data are kept in a locked cabinet, and the data will only be accessible by the researcher and the research supervisor. Once the project is completed, the data will be kept for a maximum of five years, after which it will be destroyed. 


\section{CHAPTER FOUR: OVERVIEW OF CCPC CASES}

This chapter provides an overview of the CCPCs that were interviewed as part of this thesis.

The overview outlines the specific internal and external context present for each firm.

\subsection{Case summaries}

This section provides a brief description of the operations and industry of the firms that were interviewed. For the internal context, information gleaned was primarily based on responses provided by the interviewees. The researcher also obtained information from archival documentation, such as marketing literature and websites. For example, the websites were reviewed to determine if the firms published their mission, vision, and value statements. The descriptions of the external context were primarily provided by the interviewees. Specifically, interviewees were queried on their market, competitive, and regulatory pressures in the context of the R\&D decisions.

\subsubsection{Firm1}

Firm 1 creates systems to treat water and solve wastewater issues. For example, one of their product offerings treats frac water (oil production) to allow for reuse. The systems devised can be a combination of mechanical, chemical, and electrical engineering.

The founder is the owner and CEO of the company. The company structure is relatively flat and has a matrix-like structure based on projects. When asked about strategy, the strategy is primarily customer driven. In effect, they are approached for assistance by customers and then decide whether to take on the work. There is no product strategy or technical road map. The 
values are derived by the ownership and management, and they are driven to solve problems. The CTO states, "I'm a chronic inventor. We have corporate support here to do that." As a result, there is a risk-taking culture to take on projects that seem "impossible."

The company does not require many physical resources. In terms of human resources, they rely on expertise in different streams of engineering including chemical, electricity, microbiology, etc. Financial constraints have had an impact on the projects undertaken. The CTO indicated that if a similar project had not been done previously, they will probably not make a profit, as the time and effort expended are generally not fully compensated. They need subsequent similar projects to generate positive returns.

The primary competition is larger multi-national industrial water treatment companies. There are also several small to medium-sized environmental engineering firms; however, the competitors tend to focus on one type of engineering for their solutions (e.g., mechanical or chemical). As the company is dealing with water, environmental regulations such as the concentration of contaminants are a big part of their context. Overall, the regulatory environment helps their business as organizations need their services to meet their regulatory requirements. Their customers are larger organizations such as municipalities, cities, mining companies. Most of their business is domestic, but they have some contracts outside of Canada.

$R \& D$ is structured on a project basis; ultimately, all projects report to the CTO. The primary driver is to take on projects in which there are "problems that haven't been solved." However, 
the CTO stressed they also evaluate if the project fits within their skill set, their current workload and if the solution can be replicated for future work or other applications.

The company takes an Agile methodology approach, an iterative development methodology, for R\&D with a focus on developing a prototype quickly. The CTO believes that a prototype is valuable not only for the client, but also for SR\&ED program claims. Within their modified Agile methodology, they take a systematic approach which includes process flow diagrams. The results of the experiments are documents in lab books and indicate their engineer's notes and data. As part of their client experience or contract requirements, they write reports of their progress. The company also maintains time sheets tracking hours worked on projects.

The company has filed several SR\&ED program claims. The CTO completes the project details and obtains assistance from an external SR\&ED consultant for the financial components. He notes that the SR\&ED program, "decreases risk, not eliminate risk, and forced us to determine whether or not this was worth all pursuing." The company has not had issues with SR\&ED program claims; however, he noted that some engineers are concerned with filing SR\&ED program claims when they have had a previous review or audit experience at a different company. "Some of them who've been reviewed in particular, can be a bit gun shy after having maybe an onerous review."

\subsubsection{Firm2}

Firm2 offers a software solution that employs in-house cameras and machine learning to detect weapons. The software was first created to detect firearms and was expanded to detect knives. Initially, the company tried to create a robbery detector but found that with machine learning 
and Al performing video analysis, weapon detection was more technically feasible. Based on their feasibility analysis, the founders developed a technology roadmap to provide strategic direction.

The company was founded by three individuals. The CEO, who has the PhD in Computer Science, focuses on administration and external relationships (e.g., suppliers). The second founder, an engineer, is responsible for the R\&D department and liaises with the third founder, a police officer, as the subject matter expert. The values of the firm were derived by the three founders and their focus on public safety and technology.

The CEO indicated that resources and financial constraints were an obstacle. The machine learning algorithms to detect weapons require substantial computing power and they initially purchased $\$ 12,000$ of computing equipment. For the first 15 months, they did not take any salary. Eventually, they were able to secure IRAP funding and provincial funding to subsidize hiring new graduates. At the time of the interview, due to capital constraints, the firm was in the process of being purchased by a public company that is in the same field. To achieve its strategic goals, the company needed computing equipment at an estimated cost of $\$ 1.4$ million. Due to the acquirer's relationship with Cisco, Firm2 was able to obtain the computing equipment for $\$ 350,000$. Due to the improved hardware, they are able to run numerous experiments in shorter periods of time.

The CEO indicated that when they first rolled out the product, it was unique, and there was no competition at the time. Large multi-nationals provided video surveillance and analysis solutions; however, their products did not offer real-time analysis. In the last year, some small 
competitors have entered the market and are now offering similar products. In terms of the regulatory environment, the CEO indicated that they do not believe that there is any impact on their company. The customers for this product are first responders and security firms.

The CEO states that since the head of the R\&D department is a rigorous engineer, there is a strong documentation and process focus. The company used an online work platform to collaborate and document the R\&D development iterations and experiment results.

In their third year of operation, the company decided to apply for the SR\&ED program. The CEO attended CRA SR\&ED information sessions, but he found it difficult to ascertain what would be eligible and what would not. They engaged a SR\&ED consultant to assist with the SR\&ED program claim. Based on advice from the consultant, the company decided not to proceed with the claim, as they would need to reduce its claim based on their funding from other government agencies.

\subsubsection{Firm3}

Firm3 is a cybersecurity company that provides solutions to manage cybersecurity risk in organizations. Reporting mechanisms, a learning management system, and user account simplification tools are Firm3's three main product offerings. Firm3's central platform is an aggregate database with a web user interface that provides metrics, measurements, and risk indicators. The learning management system allows users to engage in educational opportunities to improve their risk mitigation behaviours. The firm also offers a phishing platform simulation to gauge user behaviour within a firm. 
The founder is the owner and CEO of the company. The company also has a CTO, Chief Operating Officer (COO), and Chief Security Officer. When asked about strategy, the CEO stated that there is an "aggressive product roadmap so cybersecurity technology is main central platform play with lots of different derivative offshoots and things that we can do."

The company's website outlines three core values: people, entrepreneurship, and team. The CEO credits the culture to allow, "people feel empowered and welcomed and part of something greater, which is tied to our mission." The CEO believes that the culture has made it easier for the company to recruit.

Even though the CEO states that there is no issue with recruiting IT talent, financial constraints were a significant issue at the company's outset. Initially, they obtained provincial funding to hire new graduates for their R\&D department. $R \& D$ is now primarily derived from the cash flows from the recurring revenue (subscription) from their software.

The CEO indicates that the competition consists of large multi-nationals. However, the competition is fragmented as the competition focuses only on the technical side of cybersecurity for a couple of systems, without considering user behaviours. In terms of regulation, the CEO asserts that data security laws are weak in Canada. The lack of data security laws has had an impact on their sales, as the fines for a breach are minimal in Canada compared to other countries. Therefore, customers are not necessarily as compelled to have strong cyber-security protections. The company has over 100 clients who are primarily domestic, but its customer base is dominated by one large banking client. 
There is a R\&D department, which is led by the CTO. To manage their R\&D projects, the R\&D department uses Microsoft Teams and Azure that enables the firm to have a central code repository, create tasks, monitor task completion, create queries, validate code, and push to their production environment. Firm3's priorities are often driven by their largest customer. The banking client has provided them with suggestions for new features and improvements to existing ones. These improvements have assisted Firm3 in offering better products to smaller customers.

The firm has evaluated whether to apply for the SR\&ED program. They had concerns about whether their development processes would meet the SR\&ED criteria. The CEO indicates that he finds the criteria opaque. The firm also asked for an opinion from a SR\&ED consultant. The SR\&ED consultant indicated that since they are a software as a service (SAAS) provider, the claims may be challenged by CRA. The CEO stated that from a tax policy standpoint, he believes there should be "some acknowledgement of that bootstrapping process, whether that's a personal income tax credit, etc., for all those hours put in in sweat equity, but I don't know how you would monetize that, account for it, or avoid abuse."

\subsubsection{Firm4}

Firm4 is a firm that specializes in remote support systems using augmented reality. The company originated from the founders' experiences assisting workers working in remote locations to solve technical problems. By using this product, the workers in remote locations can access outside expertise to conduct repairs or other maintenance. 
Firm4 was founded by three individuals. The three founders were well known in the technology sector in their province and were able to secure funding based on their reputations. The company was originally funded with private funds and IRAP funding. The company has a defined structure with a CEO, CTO, COO, as well as several Vice Presidents (VPs).

When asked about strategy, the CEO indicated that there was a roadmap for development. The roadmap is influenced by the IRAP framework, SR\&ED program criteria, and their customers' needs. However, the CEO does recognize that, "sometimes the market doesn't know what to ask for." The values of the company are outlined on the company's website. The values are consistent with the founders' vision, in which they are driven by overcoming challenges and belief in the power of technology to help their customers.

The company relied on outside funding until their first commercializable project in 2017; subsequently, the company uses cash flow to fund R\&D. In addition to financial constraints, it is difficult to hire senior virtual reality developers. This talent is not readily available in Canada, so the company hires high potential software developers and trains them in 3D technology.

Regarding the external context, the CEO indicated that they have partnered with larger firms such as Microsoft and the Department of National Defence (DND). Consequently, they do not have considerable competition, as these firms have recommended them to customers. Regulation considerations are dependent on the industry. For example, for DND, the company must comply with Controlled Goods Certification. The company has a mix of public and private sector clients in Canada and internationally in the defense industry, oil and gas, and utilities. 
The CEO states that since individuals with engineering and research backgrounds founded the firm, they have implemented systems and processes to aid in the development of R\&D. As the company has a partnership with Microsoft, the R\&D departments uses Microsoft tools for version control, source code repository, and documentation.

Initially, the firm did not apply for the SR\&ED program, as they were focused on creating a viable product. The CEO speaks of a "gray zone" for R\&D expenditures based on technical uncertainty. The firm does not want to claim anything in the gray zone. Initially, the CEO indicated that the project description he wrote was "a bit too poetic." He found the reviewers were far removed from the industry, and "they ended up trying to bully on you their own opinion, their own philosophy when it comes to software development, or technology in general, and you have to fight pretty hard to just get past that initial barrier." He does not believe that this makes the process any better, nor does it encourage companies to file for the SR\&ED program.

\subsubsection{Firm5}

Firm5 is a firm that offers tools to deploy and measure public health programs, including enrolment, disease registries, gaps in care, outreach, and engagement. The owners of the company are two brothers. One brother is the CEO, and the other brother is the President and CTO. They also have a VP of Operations and two directors that make up the executive team.

The VP of operations and the company's website states the company's values are to achieve better global healthcare outcomes. This is driven by one of the founders. The company was initially structured as a healthcare consulting company. The company's mission morphed into a 
cloud-based healthcare solution company after consulting experiences in the developing countries.

The VP emphasized that they have a strong strategic planning focus with a roadmap and product strategy. The VP indicates that they have a combined product development and a customer development strategy. The company does not believe in, "we will build it and they will come." However, the customer does not always know what they need. Consequently, they may provide a design or prototype and obtain feedback on whether it will be useful.

At the outset, financial resources were a very significant issue. Succeeding in their first big project in which they applied for the SR\&ED program was critical. Consequently, when the company was denied SR\&ED program funds, it was a big blow to the company. The company appealed the notice of assessment, and after ten years, the case was brought to court, and the company successfully overturned the denial of funds. R\&D is now funded through cash flow. The VP states that the company is easily able to recruit talent due to its culture and its emphasis on training.

The primary competitors are large multi-national electronic health record companies. The company has developed its cloud-based solutions to comply with privacy regulations, through anonymization and other tools. As their solution is cloud-based, data security and privacy are critical to their customers. The company's primary market is health agencies in countries outside of Canada and the United States.

$R \& D$ became a central focus once the direction of the company changed to provide comprehensive health technology solutions. The company refers to it as R\&D as "translational 
research." The VP stressed they are not conducting R\&D for the purposes of SR\&ED tax incentives but to improve health outcomes globally. They have implemented a development process using Agile development strategies. However, before Firm5 engages in the SR\&ED program once again, the VP of operations states that the company needs to have the appropriate processes and systems. In the court proceeding appealing their SR\&ED notice of assessment, the lack of a system and supporting paperwork was an issue. Firm5 was doing fieldwork and had hand-written notes; however, the retention of the testing documents and white board design work was not well managed.

Given their negative experience in applying for the SR\&ED program, the VP states they have not applied for the SR\&ED tax incentives again, but it is having an impact on their growth. The VP believes the SR\&ED program review process can be arbitrary depending on the reviewer. As a result, the VP believes it is essential to obtain outside SR\&ED consultants to speak the language of the reviewer: "I think using experts outside is a great thing, and I think sometimes just making it easier to understand."

\subsubsection{Firm6}

Firm 6 creates civic simulations to assist in urban planning. The company develops interactive touch-screen maps of a part of a city that can show the impact of adding or removing elements on greenhouse gas emissions, traffic, and density.

The owner of the company is the CEO. Management also includes directors of operations and technology. Firm6 is the CEO's second company involving imaging technology. The values of the company are posted on the company's website. The CEO and director of operations also 
reiterate that they hope that the product will assist in reducing the impact of climate change, improve health outcomes, and reduce poverty through interactive civic planning.

Financial constraints are a significant barrier to development. To fund R\&D, the company relies on customers paying in advance to develop projects. However, given that its customers are public sector organizations, the process can take over a year for approval. He indicates that "sequence is all messed up," in that a firm needs to invest in R\&D before receiving a reimbursement of funds. The CEO indicates that finding talent has not been an issue, but he feels that the entrepreneurial spirit is not taught well at universities.

Firm6's competitors are large multi-national companies, such as Google and IBM, that can aggregate big data with proprietary client data. The CEO states that the regulatory environment is not a significant factor in their context. Most of the information used to develop the models are publicly available. Their market is primarily domestic and includes cities and municipalities.

The CEO indicates that it is a "project-driven" company. Since it is a new company, the customers they obtain set the priorities for development. The CEO describes this decisionmaking process as linear - "obtain customers and make the product." The CEO and director of operations indicate that the processes and systems are dynamic and informal. The developers create bubble diagrams and flow diagrams to tackle complex problems and communicate quickly and clearly with clients and collaborators. However, the director and CEO indicate that documentation is essential to the process. The company has implemented time sheet 
processes and project definition/scope documents for the R\&D department to aid in the SR\&ED process.

The CEO had experience with his first company with the SR\&ED program. The CEO indicated that he had received a letter regarding the claim that was "really odd - speaking a different language than the claimant," in that it seemed to be more about the process rather than the actual project. The SR\&ED program criteria's language is "too technical academic - too invention focused" and does not consider new areas such as behavioural sciences. Firm6 has not yet applied for the SR\&ED program, but it plans to do so in the upcoming year. The CEO stressed that R\&D is not designed to meet the SR\&ED program criteria. Firm6 builds what it is required for its projects. Subsequently, the company will try to frame the project description to obtain SR\&ED program funding.

\subsubsection{Firm7}

Firm7 is a software company specializing in consumer engagement and marketing, as well as emergency alert systems. Their consumer offering is Platform as a Service (PAAS) in which they aggregate communication links to one platform.

The founder is the owner and CEO of the company. The management structure includes a CTO, CFO, and an advisory board of directors. The founder has a previous background in starting companies and considers himself a serial entrepreneur. The strategy and priorities are primarily driven by the founder, who created a five-year roadmap. The founder feels that the day-to-day operations are almost run as a separate organization given the focus on innovation. 
As this is a software and communications company, the company does not require extensive machinery or equipment. In terms of human resources, the company has had no issue procuring talent and often trains new graduates since they are situated near a few universities.

The primary competition is vendors that offer communication packages that are not as well integrated. "Everybody that's competing with us is only doing one or two channels or three. We're the only one that has 30 channels built today, and we have another 30 to build." The regulatory environment has changed rapidly as new communication technologies are in place. In North America, they comply with privacy and data security, specifically, the European Union (EU) General Data Protection Regulation (GDPR), the Controlling the Assault of Non-Solicited Pornography and Marketing (Can-Spam) and Canada's Anti-Spam Legislation (CASL). The regulatory environment has not been deemed an issue, as they have built the platform to be compliant with the regulations. As cybersecurity has become a concern, the company is also International Organization of Standardization (ISO) 37001 certified. The founder indicated that their primary market is larger organizations in approximately 175 countries, including banks, universities, and larger corporations that want to have one system instead of multiple vendors to handle their communication needs.

The founder is a computer scientist and has implemented a modified Agile software development process. The company uses Phabricator (created by Facebook) that allows the company to document every phase, an experiment, or prototypes. However, the CEO notes that many engineers keep notebooks and can be resistant to documenting their R\&D work in the system directly. 
R\&D is funded through internal cash flow, but they have applied for the SR\&ED tax incentives annually. For the first six years, the company did not have issues with SR\&ED program claims. However, in the last four years, the company has encountered issues with their claims, and Firm7 has filed four notices of objection. The founder believes the issues revolve around the "personal opinion based on the reviewer's knowledge and feedback or knowledge and experience in the sector." Due to the SR\&ED program claim rejections, they have been unable to hire 10-20 people to work on R\&D projects. The CEO states, "we're not conducting R\&D work and then we're now two years, three years behind because we're not upping our game in the R\&D spectrum within our organization." In addition, filing notices of objection takes significant effort from management, and the pre-determination services were of little help.

\subsubsection{Firm8}

Firm8 is a firm that offers equity valuations of companies and Exchange Traded Funds (ETF). The system can also provide detailed reports on companies and ETFs, and value a stock portfolio.

The founder of the company is the CEO, and given his financial background, he acts as the CFO as well. There is not a strong management structure to support the CEO. The company's values are not explicitly articulated on the website. The CEO envisions a company that will make valuations easier for financial advisors and retail clients. Independent of growing the company, there is no identified strategy.

The company was originally funded through angel capital, funds from family and friends, and IRAP funding. The revenue model is subscription-based; therefore, the company has significant 
recurring revenue and does not feel the same financial constraints as they did at the outset.

Obtaining human resource talent, particularly salespeople, has been challenging. In addition, obtaining quality data for their analysis is very expensive.

The CEO is a chartered business valuator. As part of the analysis to create the company, he evaluated retail financial sites, including Yahoo finance, Google finance, and Stockhouse. He found that none of the sites offered valuation. Since launching the site, competition has increased in this space. Given that the product involves financial data for financial advisors, the company was initially audited by the provincial government to ensure it was in compliance with investment advice regulations. Subsequently, there have been no issues with government regulation. The market is primarily domestic, and the company has two large clients: a national newspaper and a discount brokerage. The service is also offered to individual financial advisors and their firms.

Since this company is in the early stages, there is no formal R\&D department. When asked how the R\&D projects are prioritized, the CEO indicates that it was initially driven by customer feedback and potential customers. Now, the priorities are mostly determined in-house to improve the product and drive sales.

The CEO credits a representative from IRAP in assisting in building processes and documentation for R\&D development. The representative from IRAP, a National Research Council Industrial Technology Advisor (NRC ITA), was able to help them set up for SR\&ED program claims by providing guidance on SR\&ED program requirements. The CEO also credits the SR\&ED program requirements for the rigour in documentation activities. The CEO tries to 
instill a culture in which the developers are documenting and asking themselves the following, "what's the thesis that you're trying to resolve, and what are the steps that you're taking?" The documentation activities extend to the lead developer creating an annual write-up of the projects undertaken, what they did, how they conducted $R \& D$, and the purpose of the projects. The write-up is provided to their SR\&ED consultant to assist in the creation of the claim.

The CEO states that they have applied for the SR\&ED program for five years, and Firm8 has used a SR\&ED consultant for each claim. The CEO finds that there is merit to the program; however, IRAP funding was more helpful for up-front funding for R\&D. In contrast, the SR\&ED tax incentives can defray some of the costs, but the SR\&ED program is not as helpful for cashflow as other government programs.

\subsubsection{Firm9}

Firm9 is an advanced manufacturing facility that develops custom machinery for nuclear, industrial, and automotive purposes. Initially, the company developed machinery and automation for the automotive industry. In the last decade, the company expanded into developing nuclear and industrial machinery and components.

The CEO is the owner and founder. There is a strong management structure, including a CFO and VPs per product line. Upon entering the manufacturing facility and on their website, the company's vision and values statements are displayed. There is also a strong commitment to safety and quality assurance, as indicated by the posted number of days without injury and quality metrics. The CEO and the President indicate that their strategy is to double their revenues in three years while maintaining product excellence. 
Since it is a manufacturing facility, there are significant capital asset requirements. The CEO and President of the nuclear division stated that the removal of capital expenditures in the SR\&ED program had a disproportionately negative impact on manufacturing. In terms of human resources, finding the right talent has been a challenge. In administration, the CEO stated that he found it difficult to hire resources with an entrepreneurial spirit.

The CEO indicated that international competition is fierce. For example, he indicated that since most of his R\&D is funded by cash flows, that he is falling behind his German competitors who are able to access government incentives more easily. The regulatory environment has a significant impact on their operations. As a manufacturing facility with three product lines, they have several certifications and are subject to strict regulatory standards for their nuclear division. Their market is dependent on the product line. For the automotive and industrial lines, the company has customers both within Canada and the United States. For the nuclear division, most of the customers are the public sector or electrical power companies.

The R\&D department is divided upon product lines and is further divided by sustaining engineering and innovation. When asked about how they prioritize R\&D projects, development is dependent on customer requests and financial constraints. The CEO states that management must decide which orders they will take based on the risks taking on the order - will it require them to completely innovate or tweak existing capabilities. Firm9 does have a technology roadmap in which they try to anticipate customer requirements four to five years in the future.

Firm9 has an ERP system to monitor and manage the manufacturing and R\&D development process. The CEO indicates that the ERP system is not as integrated as he would like. In the 
next couple of years, he will be upgrading the ERP system to integrate with all the other systems used in the company.

The CEO states that they have applied for the SR\&ED program in the past and have used a SR\&ED consultant. He does not apply every year as it has depended on his taxable income. When the company's taxable income exceeded the threshold, they did not apply for the SR\&ED program. At present, since they are profitable, SR\&ED program claims only reduce their tax liability. The CEO believes that the taxable income threshold had constrained firms from innovating to ensure that they remain under the threshold.

There is resistance among some management to continue to apply for the SR\&ED program. The President states that the SR\&ED program claim is "going to slow you down. It's going to give us a lot of paperwork and everybody hates it." The CEO indicates that the SR\&ED program should be treated in a similar way as a trusted traveler program in which certain companies are pre-approved, however, a company would undergo random audits to ensure compliance.

\subsubsection{Firm10}

Firm10 is an advanced manufacturing facility with several product lines and offers professional consulting services. Manufacturing and R\&D are conducted in-house. Firm10 has also acquired smaller companies to build their R\&D capacity in software, artificial intelligence, and robotics.

The company's founder is no longer part of the company, but his son is now the company's CEO. The company has an extensive management structure and is divided along its product lines. The company's values, mission statements, and code of ethics are posted upon entry in 
both the administration and manufacturing facilities. The CFO indicates that their core values of customer service through its continued support of older products have had a negative impact on their R\&D development and profitability.

As Firm10 is a manufacturing facility, the company requires significant investment in capital resources. The CFO and R\&D manager indicated that financial constraints had an impact on investment in the facilities and systems.

At the inception of the company, there was little competition. Since then, there is considerable competition from American competitors. The company feels that their R\&D and their focus on customer service is their unique selling proposition. The CFO and the R\&D department do not feel that the regulatory environment has much of an impact. They conform to RoHS and Waste Electronic and Electrical Equipment (WEEE) standards for the EU. Given the number of product lines, the market is diverse - both large and small customers in several countries.

$R \& D$ is divided by product line with a separate management structure that ultimately reports to the CIO. The technical roadmap establishes the R\&D priorities. The roadmap reflects the CEO, $\mathrm{ClO}$, and Chief Marketing Officer's (CMO) vision and input from customers.

The R\&D managers and the CFO indicated that there are disparate systems throughout the company. Firm10 indicates that they use Dayforce and SAS as their primary systems for manufacturing and accounting. They have created more processes to assist in the SR\&ED program application. For example, Firm10 time codes certain activities specifically for SR\&EDeligible activities, such as creation of documentation. 
Firm10 has applied for the SR\&ED tax incentives for many years. Most recently, the taxable income and the taxable capital employed in Canada (TCEC) limitations have been barriers to be eligible for the SR\&ED program enhanced rate. Firm10 believes that 2019 will be their last year to be eligible for the SR\&ED program enhanced rate due to the TCEC threshold. The company has been audited for SR\&ED program claims several times, but they have been successful each time. The audits involved software projects and mechanical engineering relating to robotics. These audits have had an impact on what their engineers would like to submit as a claim. After undergoing an audit, several engineers are reticent to claim their work as SR\&ED-eligible activities unless it is a certainty. Consequently, the finance group and R\&D management believe they are too conservative in their claims.

\subsubsection{Firm11}

Firm11 is a data analytics company with three primary business lines: executive decisionmaking support, managed data analytics services, and marketing services. The managed data analytics service is the most significant product line, and it is the product line in which most of the $R \& D$ is conducted.

The founder is the CEO of the company, and the company is structured around its product divisions. All the executives are full-time, except for the CFO, who is part-time. There are no identified strategies or values statements on the website.

The CFO indicated that there are no issues in obtaining the right talent; however, the number of people they can hire is limited due to financial constraints. The financial constraints also have an impact on the decision-making priorities and scope of R\&D projects. 
The competition also has a significant impact on the priorities of the company. The company evaluates what the competitors are offering to the marketplace. When developing their products for customers, privacy regulations influence their product offerings. Since most of their customers comprise mostly small to medium customers from the United States and the United Kingdom, the company indicates they must be cognizant of privacy regulations in these jurisdictions.

The company has applied for the SR\&ED program several times, and they use a SR\&ED consultant to assist. The CFO indicated that the SR\&ED program processes have forced the company to better document the activities that are eligible for the SR\&ED program, such as time sheets. The CEO, CTO, and CFO make the decision to apply for the SR\&ED program and which projects should be included. The SR\&ED projects generally comprise the development of new data analytic mechanisms and not necessarily due to customer demand. In effect, the company is trying to anticipate market demand.

The company has undergone audits for their SR\&ED program claims. Due to the lengthy discussions among the company, the SR\&ED consultants, and CRA, they often settle on what CRA indicates that it will reimburse rather than fight. The CFO indicates there is a significant language barrier between CRA and R\&D managers. She states, "if you don't say it the right way, or position it the right way, or demonstrate technical uncertainty, it kind of jeopardizes your claim." The CFO further states that the auditor does not always understand the business and makes assumptions based on their experience. She gives the example in which the auditor asked the R\&D department, "What challenges did you come up with? How long did it take you? 
And what was your process?" The in-house engineer stated, "I'm an engineer, I am just going to figure it out." Based on the engineer's response, a significant portion of the claim was denied. The CFO indicates that many of the engineers have difficulty articulating the trial and error process in a succinct way that conforms to the SR\&ED claim criteria.

The CFO has found that NRC ITAs often assist companies as they work with the engineers to create the grant application and employ the appropriate verbiage. She believes that this assistance is missing in the SR\&ED program. The CFO also believes that if there were templates available, such as time sheets, it would assist smaller firms in complying with the requirements.

\subsubsection{Firm12}

Firm12 is a SAAS company that assists firms to manage their supply chain data and ensure that they meet regulatory requirements. For example, to ship to the EU, companies must comply with the EU Registration, Evaluation, Authorisation, and Restriction of Chemicals (REACH) regulations; therefore, all chemicals sourced for manufacturing must meet these standards.

One of the two founders of Firm12 remains in the firm as a VP of growth. The other founder left the company six years ago to allow a new CEO to facilitate its growth strategy. Since then, the company grew from 25 to 350 employees and have expanded their product offerings. The vision and values statements are posted both in their facility and their website.

Resource constraints were identified as an issue for growth. In order to deal with this, Firm12 has sought venture capital and financing from the Business Development Bank of Canada (BDC) to facilitate their growth strategies. The company structured the investment in a manner not to 
have an impact on their CCPC status. The ever-changing regulatory landscape has been a boon, but it also has been challenging to obtain staff with the appropriate knowledge set. As a result, they have hired staff in the United States, European Union, and Malaysia that work remotely. All of the R\&D is intramural and done in Canada.

The comptroller stated that the competition faced is from the in-house resources within a firm. In effect, firms rely on their personnel to be cognizant of the regulations. In addition, the other competitors are firms that may specialize in a specific regulation rather than various regulations. For example, a firm may specialize in conflict minerals but not conflict minerals and RoHs. Given the firm's business model, the regulatory environment is an integral part of their business. The company needs to keep abreast of regulations throughout the world. Their customers are worldwide, and these customers are mid to large in scale that service markets globally.

$R \& D$ priorities are based on the product roadmap, which is a collaboration among the company, suppliers, and customers. The company has set up a product advisory board to determine how they can improve their current products. The R\&D department is split into maintenance and its new product development and improvements. The R\&D department uses planning software to manage their projects and calculate the time spent on projects.

Firm12 uses a SR\&ED consultant for the claim. The R\&D department completes the initial write-up, and the comptroller completes the costing for the projects. The comptroller states that the SR\&ED consultants are critical to the SR\&ED program claim, as they improve the language used and challenge the team on time spent and by whom. 


\subsubsection{Firm13a \& 13b}

Firm13a is a mobile gaming company. The company initially built games for Palm OS and has since evolved to providing games to several smart phone platforms. Firm $13 \mathrm{~b}$ is an alcoholic beverage manufacturer.

The person interviewed was a co-founder and CEO of Firm13a and is a co-founder and senior management of Firm13b. As a result, Firm13a and Firm13b are associated since there is a shared ownership structure. There are no identified strategies at Firm13a nor Firm13b.

Firm13a has identified values of collaboration and professionalism on their website. There are no values statements on the website of Firm13b.

Financial constraints were an ongoing issue with Firm13a. The founders would often take loans against the SR\&ED claims. Borrowing against a SR\&ED claim became an issue when one of the claims was delayed, and ultimately the claim amount was reduced. The resources to develop mobile gaming also became an issue. As technology changes, the existing resources no longer had the appropriate technical skills. The R\&D department made it difficult to "right-size" - it is difficult to retrain or reduce existing employees while hiring talent for new technologies. Since the ITC expenditure limit must be allocated among associated companies, and the lack of flexibility of the increasing or reducing the size of the R\&D, a decision was made a few years ago to outsource most of the R\&D to Vietnam.

Firm13b is not as well established as Firm13a, but the company also has financial constraints, which have an impact on investing in capital assets for brewing and distilling. Obtaining talent to work in the facility has not been an issue. 
Competition for both Firm13a and $13 \mathrm{~b}$ is intense and is dominated by large multi-nationals.

Both these companies try to focus on niche markets rather than the mass market. The regulatory environment does not have much of an impact on Firm13a. In contrast, Firm13b must comply with health regulations and provincial regulations regarding the production and distribution of alcohol.

The market for the Firm13a originally was the telephone companies in Canada, the United States, and Europe. The mobile game market has changed in that applications are now offered on stores by the phone or operating system manufacturers such as the Apple App Store. To distribute its product, Firm13b must sell the product via the provincial liquor board or directly through their online store.

Initially, when Firm13a conducted intramural R\&D, the R\&D department was divided by function. For example, some developers were focused on game development and others on game deployment to different phone applications. R\&D for Firm13b is conducted in-house, and this entity claims the full SR\&ED ITC expenditure limit. The R\&D department for Firm13b is considerably smaller, and it is focused on developing new manufacturing processes to develop innovative beverages and automation of the processes.

R\&D priorities are primarily set by market demand for both companies. The marketing and development groups try to determine what products will be of interest. As the two companies are not in direct contact with their customers, they conduct market research to determine trends. 
The processes at Firm13a are informal. Design is completed at their headquarters, and development requirements are then sent to Vietnam. The development process is described as using a sprint software development process in which prototypes are quickly developed for review by the design team. This process was consistent with the processes used when development was in Canada. The R\&D process for new beverages is much more systematic in Firm13b as they experiment with different flavours and its impact on appearance and taste. In contrast, the R\&D development process to automate manufacturing is similar to Firm $13 \mathrm{~b}$, as the CTO of Firm13a consults with the R\&D team at Firm13b.

Firm13a filed for the SR\&ED program and did not use a SR\&ED consultant to file, as one of their internal resources within Firm13a previously worked at CRA. Due to the lack of familiarity with filing SR\&ED program claims for manufacturing processes, Firm13b uses a SR\&ED consultant to assist in the claim.

\subsubsection{Firm14}

Firm14 is a software company that develops internet protocol television that allows communication service providers to offer digital solutions to their subscribers. Firm14 was purchased by a public company in the summer of 2019.

Even though a public company purchased Firm14, the company operates in a similar manner as when it was a CCPC. The company currently operates as a division of the public company. The CEO and the R\&D structure have remained in place. The R\&D manager feels that the culture and values have been retained regardless of the purchase. On Firm14's pre-acquisition site, the culture and values of the company were documented on their website. 
The R\&D manager could not directly comment on the financial constraints, but he did indicate that the SR\&ED tax incentives were an essential resource for R\&D development. In terms of R\&D talent, the manager did not find it challenging to obtain talented software developers.

The main competition faced by Firm14 is from large multi-national companies. Given their size, their customers are mostly smaller to mid-size telephone and cable providers outside of Canada. As some of their customers are in Europe and United Kingdom, they are required to comply with privacy regulations, including the EU GDPR.

Pre-acquisition, the R\&D department was divided into product lines. Resources were split on new product development and routine maintenance. Several systems were used to manage the R\&D department. Excel would be used to track time, but other systems would be used for testing and code documentation. The R\&D manager indicates that they use an Agile development process with two-week sprints.

Firm14 used a product roadmap to determine their R\&D projects. The roadmap was based on market analysis, and from input from their customers. The roadmap would be updated every two to three years. The CTO was responsible for determining what technology platforms they would use based on the product roadmap.

When they were a CCPC, the firm applied for the SR\&ED program on an annual basis. In his 13 years applying for the SR\&ED program, the R\&D manager indicated he does not remember being audited. The R\&D manager was responsible for completing the project descriptions for the SR\&ED program claim, including outlining the technical uncertainty. He also managed the 
time sheet process and allocating expenditures to the specific SR\&ED projects, but would hand off the financial calculations to the finance group. The R\&D manager emphasized that the language and projects had to be structured to meet SR\&ED requirements. In terms of language, he would try to group the projects into a theme. He was also cognizant that the CRA expects to see a defined beginning and end for a project. Consequently, he would try to complete projects within a one to two-year time frame. If the product features were not completed, he would open a new project to track the R\&D activities.

\subsubsection{Firm15}

Firm15 is a software company that assists transportation companies in automating functions such as dispatch, phone systems, mobile applications for customers, and back-office applications. A private company from Ireland purchased Firm15 in December 2019.

Financial constraints were a significant issue prior to being acquired by the Irish firm. The CEO indicated that the size of the R\&D department would vary depending on whether a SR\&ED program claims were successful and paid promptly. The company did not have issues engaging engineers and programmers.

The CEO has remained with the company post-acquisition, as the company is operating as a separate division. There is no identified values statement on the website. Since the 
acquisition, the overall strategy is now determined by the Irish firm. Prior to the acquisition, there was no identified strategy.

Initially, the CEO states there was little competition in their space. However, competition has become fierce with the entry of large multi-national firms. Consequently, the CEO indicates that customers are more driven by price than by quality. Firm15 is also affected by regulation. In Canada, transportation can be regulated by the city, the province, or federally. Regulation at different levels of government is common in other countries as well. Consequently, the products must satisfy the regulatory requirements for the region in which their customer operates. Their customer base is 70 percent international, and the customers are medium to large.

$R \& D$ is divided among product lines. Market demand primarily determines new development priorities. In effect, if they win a large contract, they will commence development custom for that client. However, the CEO indicates they continuously monitor their competition and develop comparable products to be able to compete. Due to the influence of the SR\&ED program, numerous processes were put in place to track the work of the engineers on development. Firm15 uses Agile software development processes and Jira as the system to track their R\&D development.

The company applied for the SR\&ED tax incentives for several years. Except for the initial claim, the company filed the SR\&ED program claim by themselves. The CEO indicated that the language used in the project description was critical. The feedback he received from the first consultant was, "we'll use all the right words to describe what you just told us." Subsequently, 
the company would have three internal resources review and modify the language of the claim. Since they are now foreign- owned, Firm15 is no longer eligible for the enhanced rate. As a result, they have no intention of applying in the future. The CEO states that the R\&D department is wary of not applying for the SR\&ED program, as the department is cognizant that SR\&ED program claims had an impact on the number of projects and resources assigned to new product development.

\subsubsection{Firm16}

Firm16 offers recovery systems for industrial and commercial drones. If a drone crashes, it may be destroyed or unable to be recovered. The company offers after-market technology that attaches a parachute system and location identifier to the drone. The long-term strategy is to partner with original equipment manufacturers, so their technology will be embedded rather than selling to end-users. The company's headquarters are in city in one province; however, most of its R\&D is conducted in another province.

In addition to an identified strategy of their product being integrated with the initial manufacture of drones, the company's website also affirms values of reliability, creativity, and customer relations.

The company was initially self-funded. Subsequently, they obtained grants and guaranteed loans. In addition to financial pressures, the company has difficulty in obtaining hardware engineering talent. The CEO indicated that recent graduates have the software skills but rarely have the hardware skills. The company trains recent graduates; however, this is timeconsuming and bears some risk. 
Initially, the CEO stated there was little competition; however, since 2018, competition has increased substantially as the use of drones has increased. Firm16 is affected by regulation. New regulations were released in 2018 regarding drone technology. As a result, they had to ensure their products met the regulations, and the new regulations delayed the release of new products. There are also regulations on flight zones for testing. These regulations are the main reasons why the company conducts development and testing in a rural area of another province.

The R\&D department is divided by product line, and it is further divided by hardware and software development. The CEO and the R\&D team developed a three-year product roadmap, and this roadmap sets the priorities for development. The processes are not as formal as the CEO would like them to be, but they track time for new product development through Microsoft Excel.

The company applied for the SR\&ED program twice and have used a SR\&ED consultant, as they did not find the process of filing the SR\&ED program claim was as straight forward as obtaining other government funding. Since the SR\&ED consultant indicated that the company might have difficulties in proving technical uncertainty for software development, the claims are limited to hardware development. The CEO decided to use an external consultant as he found that in his previous endeavours, the language used for the claim is very important. The CEO states that finding the right language is a "bit of an art." Using the wrong word or words can jeopardize the funding or the speed of the approval. He believes that if SMEs try to file the SR\&ED program claim themselves to reduce costs, it will be an obstacle or a barrier to secure funding. 
The CEO also stated that he thinks that CRA should have templates on their website to assist SMEs to document the R\&D processes that would support a SR\&ED program claim. He also suggests that companies should be able to file monthly reports to show their R\&D development progress and "tell a story" of their R\&D projects. He likens the current project description reporting as "cramming for an exam."

\subsubsection{Firm17}

Firm17 offers road analysis software that employs a user's smart phone to collect and submit the data. The software has two primary functions: to monitor the condition of existing roads or road construction progress. The company is very small, as it employs ten people.

The CEO is the founder of the company. Given its size, there is not a robust management structure. The CEO and the lead developer are the primary decision-makers. The CEO states that their strategy is to double licence revenue and to grow their consulting revenues. The website has no identified values on the website.

Before starting the company, the CEO was a civil engineer working on roads, and he created a business plan to develop the technology. Creating the company required some initial investment, and the CEO forwarded the business plan to government agencies. He was able to secure government funding, such as IRAP. The CEO indicated that they are not in a hurry to hire additional developers until they have increased their revenues.

The main competition in this industry is large engineering firms, such as Stantec. When asked if they are affected by regulation, the CEO indicated that the company is not affected by 
regulation. Their customers are primarily in Canada and consist of small to medium municipalities.

There is no formal R\&D department; however, most of the employees are civil engineers and software programmers. R\&D priorities are set at the beginning of the year with the CEO and the lead developer. The priorities are shaped by their customers using their platform and their feedback to improve the technology. The processes are informal. The lead developer documents software development using Google docs. They do not have established systems for development.

Firm17 applied for the SR\&ED program in 2014 for a few thousand dollars, and they were declined. The CEO indicated that the claim was reviewed and found the process to be adversarial. The company has no intention to apply for the SR\&ED program in the future, as he believes that the process is time-consuming, and the criteria of technical uncertainty is subjective. The CEO suggests that there should be a simplified version for very small companies that do not have substantial R\&D expenditures.

\subsection{Summary of external context}

As part of this study, the evaluation of the external pressures faced by the firms interviewed comprised a firm's competition, its regulatory environment, and its market.

\subsubsection{Competition}

The competitive environment varied for each firm; however, in most cases, the competition were large multi-nationals. The firms interviewed often perceived themselves as providing 
unique products or services that their larger competitors could not. For example, Firm3 indicated that larger competitors offer cybersecurity protection; however, they do not consider user behaviour and provide solutions to train employees on safe practices.

Consistent with absorptive capacity (Cohen \& Levinthal, 1990), some of the firms interviewed indicated that they continually monitor the competition. For example, Firm11 evaluates the data analytics solutions offered by their competitors. By scanning what the competition is offering and whether the market responds, Firm11 determines if they should expand their data analytic solutions.

For firms such as Firm7 and Firm9, the competition also is used as a barometer of the firm's innovative capabilities. Both Firm7 and Firm9 felt they were falling behind their competitors due to their inability to fully utilize the SR\&ED program. Consequently, these firms were looking for solutions to narrow the gap. This behaviour is consistent with the behavioural theory of the firm (Cyert \& March, 1963) in that their R\&D behaviour is driven by their management aspirations and risk tolerance. The CEOs of both firms aspire to be on the leading edge of innovation in their fields, and they have a higher risk tolerance. These aspirations are well captured by the CEO of Firm7, "So we're about five years ahead of the market in the way that we're doing it but being ahead is not always a good thing because it takes time for the consumer to catch up."

\subsubsection{Regulatory}

When discussing the impact of regulations, most firms indicated that compliance with regulations was embedded in their product design. As a result, the firms did not feel ongoing 
pressure from the regulatory environment. A number of firms, such as Firm9 and Firm10, have a compliance culture and have actively obtained certifications to demonstrate their compliance behaviour.

The regulatory environment was highly dependent on the industry. For example, for firms involved in information technology that included customer information, privacy regulations were most common. Table 4-1 outlines the regulations that had an impact on the firms interviewed. Within this table, privacy and environmental regulations were the two most common factors. A column that comprises miscellaneous regulations is labeled as "other". For example, the other column for Firm9 includes regulations for nuclear safety and controlled goods. The column named "not applicable" is used for interviewed firms that do not feel that the regulatory environment had an impact on their operations or strategy.

Some firms that indicated that they were not affected by regulations demonstrated actions that indicate to the contrary. For example, Firm13a indicated that they outsourced their R\&D to Vietnam due to the need to right-size. Firms in Canada can reduce their workforce according to their needs. However, due to provincial employment laws, the firms will need to pay severance or retrain employees with obsolete skills. 
Table 4-1 Summary of the regulatory environment

\begin{tabular}{|l|c|c|c|c|}
\hline & Privacy & Environment & Other & Not applicable \\
\hline Firm1 & & $\mathrm{x}$ & & $\mathrm{x}$ \\
\hline Firm2 & & & & $\mathrm{x}$ \\
\hline Firm3 & & & & \\
\hline Firm4 & $\mathrm{x}$ & & $\mathrm{x}$ & \\
\hline Firm5 & & & $\mathrm{x}$ & \\
\hline Firm6 & $\mathrm{x}$ & & $\mathrm{x}$ & \\
\hline Firm7 & & $\mathrm{x}$ & $\mathrm{x}$ & \\
\hline Firm8 & & $\mathrm{x}$ & $\mathrm{x}$ & \\
\hline Firm9 & & & $\mathrm{x}$ & \\
\hline Firm10 & $\mathrm{x}$ & & $\mathrm{x}$ & \\
\hline Firm11 & & & $\mathrm{x}$ & \\
\hline Firm12 & & & & \\
\hline Firm13a & & & & \\
\hline Firm13b & & & & \\
\hline Firm14 & & & & \\
\hline Firm15 & & & & \\
\hline Firm16 & & & & \\
\hline Firm17 & & & & \\
\hline
\end{tabular}

For a couple of the firms, the regulatory environment provided an advantage. For example,

Firm12 has built a business in which they assist their customers in complying with regulations within their supply chain. Firm 12 's competitors often specialize in one or two regulations, but not a broad set of regulations.

In a couple of instances, the interviewed firms indicated that the regulatory bodies actively audited their activities. Firm1 and Firm8 are two examples. In Firm1's case, the regulatory body may test the water and audit the methodology used. The CTO at Firm1 recounted the following encounter with a regulator in which "he couldn't get his head around our approach, because it seemed counterintuitive." Ultimately, the regulator and Firm1 resolved their issues, as the testing results were within the required parameters. 


\subsubsection{Market}

During the interviews, the key informants described their market by the size of their customers, the number, their customers' geographic locations. The size of the customer can be an indication of the degree of market power the customer may yield (Porter, 1979). For example, Firm3 indicated that their largest customer provided regular feedback on the product and new product features.

The product offering had an impact on the number of customers required to be viable. For example, firms such as Firm7 that offer subscription services require a greater number of customers to be viable. In contrast, a firm, such as Firm9, that produces bespoke products for customers require fewer customers to be sustainable. In general, consistent with Wong \& Aspinwall's (2004) discussion on SME characteristics, the majority of the interviewed firms were dependent on a smaller customer base.

Wong \& Aspinwall (2004) also indicated that SMEs had more frequent contact with their customers. Firm12 is an example of a firm that receives continual feedback on their application. This type of feedback was common among several firms, and in some cases, the customers were part of their advisory board or strategy development. Notable exceptions of frequent communication with customers are firms that are subscription-based or sold their products via distributors. For example, Firm13a and $4 \mathrm{~b}$ do not know who their end consumers are, as they distribute their products through online stores and the provincial liquor board, respectively. 
The majority of the firms interviewed served the Canadian market. Table 4-2 provides an illustration of the where the primary market for the firms is located.

Table 4-2 Summary of geographic location of customers of firms interviewed

\begin{tabular}{|l|c|c|c|}
\hline & Canadian & United States & $\begin{array}{c}\text { International } \\
\text { (other than U.S.) }\end{array}$ \\
\hline Firm1 & $\mathrm{x}$ & $\mathrm{x}$ & \\
\hline Firm2 & $\mathrm{x}$ & & $\mathrm{x}$ \\
\hline Firm3 & $\mathrm{x}$ & & $\mathrm{x}$ \\
\hline Firm4 & $\mathrm{x}$ & $\mathrm{x}$ & $\mathrm{x}$ \\
\hline Firm5 & & $\mathrm{x}$ & \\
\hline Firm6 & $\mathrm{x}$ & $\mathrm{x}$ & $\mathrm{x}$ \\
\hline Firm7 & $\mathrm{x}$ & $\mathrm{x}$ & $\mathrm{x}$ \\
\hline Firm8 & $\mathrm{x}$ & $\mathrm{x}$ & \\
\hline Firm9 & & $\mathrm{x}$ & \\
\hline Firm10 & & & $\mathrm{x}$ \\
\hline Firm11 & $\mathrm{x}$ & $\mathrm{x}$ \\
\hline Firm12 & $\mathrm{x}$ & $\mathrm{x}$ & \\
\hline Firm13a & $\mathrm{x}$ & & \\
\hline Firm13b & & & \\
\hline Firm14 & & & \\
\hline Firm15 & & & \\
\hline Firm16 & & & \\
\hline Firm17 & & & \\
\hline
\end{tabular}

A number of firms, such as Firm11, indicated that the Canadian market was not large enough to sustain operations and needed to market outside of Canada. Firms that sold outside Canada frequently had satellite sales offices in different countries. For example, Firm11 had a sales office in the United Kingdom.

\subsection{Summary of internal context}

This section describes the internal challenges and context of the firms interviewed based on their strategy, values, ownership and management, resources, and systems and processes. 


\subsubsection{Strategy}

From discussion with key informants, some firms had identified or intended strategies. For example, Firm 7 had a defined strategy to build an additional 30 channels. Other firms did not have an identified strategy, but an emergent strategy had developed based on their external and internal context. Firm8 is an example of a firm in which discussions with potential customers changed their product strategy. Initially, Firm8 was providing data for valuation for companies through reports. At one trade show, the firm received numerous queries about whether they had an application programming interface (API). Given this demand, the strategy of the company of providing reports to customers changed to providing online access to the data to a customer's computer terminal or online platform.

Using Miles \& Snow's (1978) four strategic typologies of firms, the firms interviewed are categorized in Table 4-3 as prospectors, defenders, analyzers, and reactors. Prospectors are firms that are innovative and growth oriented (Miles \& Snow, 1978). These firms are often risktakers as they seek new markets and develop new products or services. In contrast, defenders aim to maintain and protect their market share (Miles \& Snow, 1978). Their focus is on serving their existing customers. Similar to defenders, analyzers strive to maintain their market share; however, they have a moderate emphasis on innovation through either new products/services and internal efficiencies (Miles \& Snow, 1978). Finally, a reactor is a firm that does not have a clear strategy, but these firms react to their environment (Miles \& Snow, 1978). 
Table 4-3 Strategic typologies of firms interviewed

\begin{tabular}{|l|c|c|c|c|}
\hline & Prospectors & Defenders & Analyzers & Reactors \\
\hline Firm1 & $\mathrm{x}$ & & & \\
\hline Firm2 & $\mathrm{x}$ & & & \\
\hline Firm3 & $\mathrm{x}$ & $\mathrm{x}$ & & \\
\hline Firm4 & & $\mathrm{x}$ & & \\
\hline Firm5 & & & & \\
\hline Firm6 & $\mathrm{x}$ & & & \\
\hline Firm7 & & & & \\
\hline Firm8 & $\mathrm{x}$ & & & \\
\hline Firm9 & & & & \\
\hline Firm10 & & & $\mathrm{x}$ & \\
\hline Firm11 & & $\mathrm{x}$ & & \\
\hline Firm12 & & & & \\
\hline Firm13a & & $\mathrm{x}$ & & \\
\hline Firm13b & & & & \\
\hline Firm14 & & & & \\
\hline Firm15 & & & & \\
\hline Firm16 & & & & \\
\hline Firm17 & & & & \\
\hline
\end{tabular}

The firms in the sample provided a broad perspective on the strategy dimension. It should be noted that a majority of the interviewed firms can be categorized as prospectors. For example, Firm1 believes in taking perceived impossible projects to differentiate themselves from their competitors. The CTO states, "sometimes the competitive advantage is that no one's ever thought of doing this before." The prospector firms were focused on creating new products or services or improving existing products to appeal to a broader market. A number of the firms spoke of risk-taking and entrepreneurship, such as Firm2 and Firm7, as critical to their success.

Defender firms, such as Firm5 and Firm15, have established a reputation among their customers. Nevertheless, the competition is quite significant as large multi-nationals can offer a less costly product. Consequently, the defenders focus on product quality and a relationship 
with their customers. The firm's focus is developing improvements to its existing products, rather than creating new products or services.

Firm13a is a good example of an analyzer firm. R\&D was outsourced to allow the company to be more flexible and reduce costs. In addition, Firm13a evaluates market trends to determine new game development. Initially, Firm13a was more aggressive in product development and reaching new markets. As the mobile gaming market matured, the firm's focus changed to reducing costs and choosing development opportunities more tactically.

From the firms interviewed, reactors firms were younger firms. When asked about strategy, Firm6 and Firm17 indicated they were focused on obtaining additional customers for their products. The firms did not seem to have an identified strategy and seem to be reacting to the market rather than be proactive.

In addition to emergent rather than deliberate strategies, the firm's strategic orientation had an impact on R\&D decisions. Firms that were prospectors, defenders, analyzers, and reactors differed in their R\&D decision-making process. Prospectors were likely to undertake R\&D projects to increase their market share by offering new products or services. In many cases, these firms had several product lines. For example, Firm9 and Firm10 both had several product lines. By introducing new product lines, the firms were seeking to expand their market. In the case of Firm9, the customer base for automotive was not the same as their nuclear division. Different product lines with significantly different customer bases can be considered riskier than expanding into new products within an existing customer base. 
For firms with a defender strategic orientation, the focus is on retaining their market share. In these cases, the firms would often state that their R\&D projects were influenced by their market for improved features or products. Firm3, a firm with a defender strategic orientation, indicated that their largest client, a bank, would provide frequent feedback on system improvements. The firm viewed these suggestions as positive to not only retain their most important client, but also to provide value-add to their smaller customers as well. As a result, in contrast to prospectors, R\&D is focused on improving the existing product rather than introducing new product lines.

Analyzer firms evaluate the competition and the market conditions and derive their strategy accordingly. For example, Firm13a indicated that they monitor the mobile gaming trends before deciding on developing a new game. Firm11 stated that as data analytics is continually evolving, the company scrutinizes their competitor's data solutions. For both these firms, the R\&D projects selected are based on observations rather than direct feedback from customers.

Reactor firms did not have a specific decision-making process for determining whether to invest in developing new products or improve existing products. These firms would try to secure a contract or customer. Subsequently, the company would develop the project based on the customer's needs. For example, Firm6 focuses on soliciting cities and municipalities to utilize their data visualization solution, and correspondingly, develops the product according to customer requirements. 


\subsubsection{Values}

During the interview process, most of the interviewees could identify the values of the organization. For example, Firm2 indicated that a commitment to improving public safety was their core value. Many firms, such as Firm5 and Firm9, did have value statements outlined and posted within their organizations and websites.

Many of the firms interviewed included their commitment to human resources as one of their values. For example, Firm3's values have two human resource components: people and team. Other firms, such as Firm4 and Firm16, indicated that they invested in in-house training when they found talent with potential.

Consistent with Laforet \&Tann (2006), the values at the SMEs interviewed are often influenced by the owner. For example, Firm 1 indicated that the risk-taking and problem-solving values were derived by the organization's founders, and these values permeated throughout the organization. The values were often the reason cited as to why a company was founded. Firm6 was created as the CEO felt that cities were not using data to combat climate change and poverty when designing new developments.

Many owners feel strongly that they are making a difference in Canada and abroad. The CEO of Firm7 speaks of owner/entrepreneurs as "we're focused on building something that makes an impact and potentially could have scientific capability that would benefit whatever area that we're working in." 


\subsubsection{Ownership and management}

Most of the firms interviewed were owner-operated. However, age and size had an impact on the management structure. In general, the older and the larger the organization, the management structure was more established. Firm10 had a full executive team and R\&D management assigned per product line. Similarly, Firm9 has a CEO and a President for each of the product lines. In contrast, Firm8 did not have an established management infrastructure in place.

Consistent with Torres's (2004), the owner-operated firms had centralized decision-making. For example, Firm15 indicated that prior to the acquisition by the Irish firm, he was acting as CEO and acting CTO and decided upon the strategy and IT priorities. Most firms interviewed indicated that the strategy and R\&D priorities were determined by a small group of managers with little or no feedback from the rest of the company.

\subsubsection{Resources}

The industry of the firm had a substantial impact on the resources required. For example, firms that were in advanced manufacturing not only relied on human resources, but also required capital equipment as well. Firms whose primary line of business was information technology were highly reliant on talent with the appropriate technical skills.

A few firms, such as Firm16, indicated that sourcing high-quality talent was difficult. A number of firms, such as Firm5, would hire co-op students or recent graduates to be able to meet the need for talent. The VP indicated the reason they bring in co-op students is "we are big 
believers that everybody needs exposure and experience to really be a better developer in the future. We also see it as a great hiring tactic for our company."

Each firm interviewed indicated that financial resource constraints were a factor in growth and R\&D capability. As the CTO of Firm1 indicates, "We're always at capacity constraint. We never have enough time, or money, or people to do it right then, so we always have to choose."

A number of the firms discussed government incentives to alleviate resource constraints. A distinct preference was for government grants such as IRAP, in which money was provided up front based on a business plan and/or prototypes. Firm8 indicates, "so those programs really helped us get this off the ground, we wouldn't be here if it wasn't for those programs." The SR\&ED program was seen as an important program by most firms; however, because the SR\&ED tax incentives are a reimbursement after the R\&D funds are spent, it was not considered ideal. For example, the CEO of Firm4 states that firms "cannot include the potential refund as part of the budget planning process, since it is not guaranteed." Some firms, such as Firm7, Firm9, and Firm10, state that delays or reductions in SR\&ED program claims have had an impact on the R\&D expenditures in the year post-claim.

Due to resource constraints, some of the firms interviewed sought to obtain external funding through angel or venture capital or by acquisition. For example, Firm12 obtained funding from BDC and venture capital. Some CFOs, such as the CFO from Firm11, indicated that firms often would structure their financing from outside foreign investors to ensure that they did not lose their CCPC status. Other firms, such as Firm15, were more concerned with resolving the financial constraints than retaining their CCPC status. As a result, these firms sought to be 
acquired or obtain external funding, and their ability to obtain SR\&ED program funding was secondary.

\subsubsection{Systems and processes}

Consistent with Wong \& Aspinwall's (2004) description of SME characteristics, the interviewed firms' systems and processes were often simple and flexible that allowed for straight-forward communication flows. However, the systems and processes used were also dependent on the industry of the firm.

SMEs in software-based industries tended to use systems primarily for software code repositories; however, these were rarely linked to timesheets, costing, or other documentation. In addition, these systems required that programmers document their results and descriptions of the work completed. Several firms, such as Firm7 and Firm15, indicated that the benefit of using systems, such as Phabricator and Jira, for documentation of the software development and testing is only as good as the commitment of the software programmers to use the tool. In comparison, advanced manufacturing firms, such as Firm9 and Firm10, used ERP systems, such as SAS and Epicor, to track the manufacturing and R\&D processes.

Most firms identified using an Agile development process, in which there are sprints, and a prototype is developed at each sprint. For example, Firm5 stated by using Agile strategies, "we're not rebuilding the product every single time, we're enhancing and advancing the product" through the sprint process. Agile methodology was initially designed for small, teambased software-development projects, but the methodology is increasingly being employed in other settings (Annosi, Foss, \& Martini, 2020) 
As the Agile development process is iterative, many firms used systems to support testing of code or prototypes. For example, Firm3 indicated that the firm uses Microsoft Azure "to enable things like central code repository, creation of tasks, check-ins of tasks, pull requests and code validation, and then right up to pushing out to our production environment." Scrum meetings are also part of the iterative process. Scrum meetings are short, generally held standing up, in which project team members discuss any emerging issues and try to solve the issues through team feedback (Annosi, Martini, Brunetta, \& Marchegiani, 2020). Due to Agile's iterative nature, some firms found that the documentation of the development process is a challenge. Firm8 states, "developers don't want to document anything, they really don't. They just want to go code." 


\section{CHAPTER FIVE: ANALYSIS \& DISCUSSION}

This chapter outlines additional findings of this study through the lenses of the SME SR\&ED

program network, engage, manage, and the SR\&ED program. In addition, this chapter seeks to answer the research questions outlined in chapter one.

\subsection{The SME SR\&ED program network}

As the SR\&ED program is an R\&D tax incentive, the $R \& D$ expenditures and $R \& D$ development are undertaken prior to filing a program SR\&ED claim. The process to benefit from the SR\&ED tax incentives has a number of steps outlined in Figure 5-1.

Figure 5-1 The SME SR\&ED program major steps

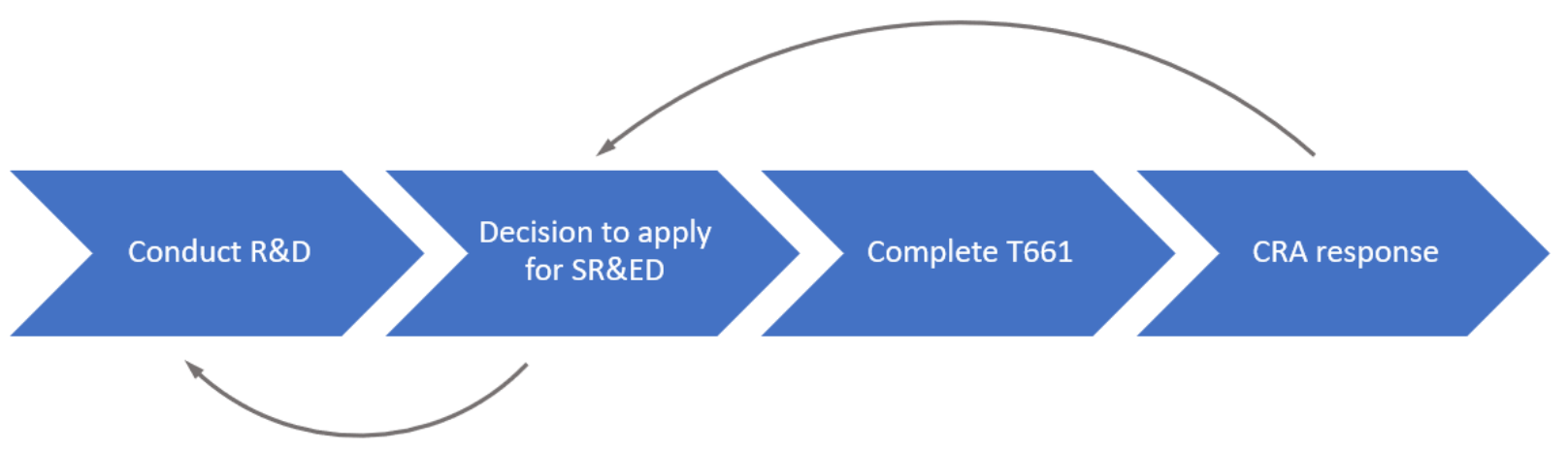

As the process indicates above, engineers and technical employees conduct R\&D work.

Subsequently, at fiscal year-end, the decision-makers within a firm decide whether to apply for the SR\&ED tax incentives for all or part of the intramural R\&D efforts. In general, the SR\&ED program claim is filed by the accounting and finance team. However, as the T661 requires a project description, the accounting and finance team interact with the R\&D team to describe 
the project(s). Once the claim is filed, the claim can be accepted by CRA without review, or the claim can be reviewed or audited.

The process is not necessarily linear. Based on the data obtained from the interviews, responses from CRA can have an impact on future R\&D activities and the decision to engage in SR\&ED. If a firm undergoes an audit or review, the decision to engage in SR\&ED is under more scrutiny within the firm. Some firms, such as Firm17, decide to conduct R\&D but will not engage in the SR\&ED program based on their experience during the audit process. Other firms decide to reduce their future SR\&ED program claims. Similarly, CCPCS may reflect on the type of R\&D conducted based the SR\&ED program claim requirements. Firms may decide to engage in R\&D projects that would meet the SR\&ED program requirements. These behaviours suggest that based on information received from CRA, firms engage in congenital learning and modify their future actions in regards to SR\&ED.

Although the process to apply for the SR\&ED program appears to be straight-forward, a number of key informants discuss the challenges associated with completing the T661 form. As a result, to assist in the completion of the form, the SME SR\&ED program network often involves external actors. Figure 5-2 outlines the relationships among the actors in this network. 
Figure 5-2 Relationships among actors in the SME SR\&ED program network

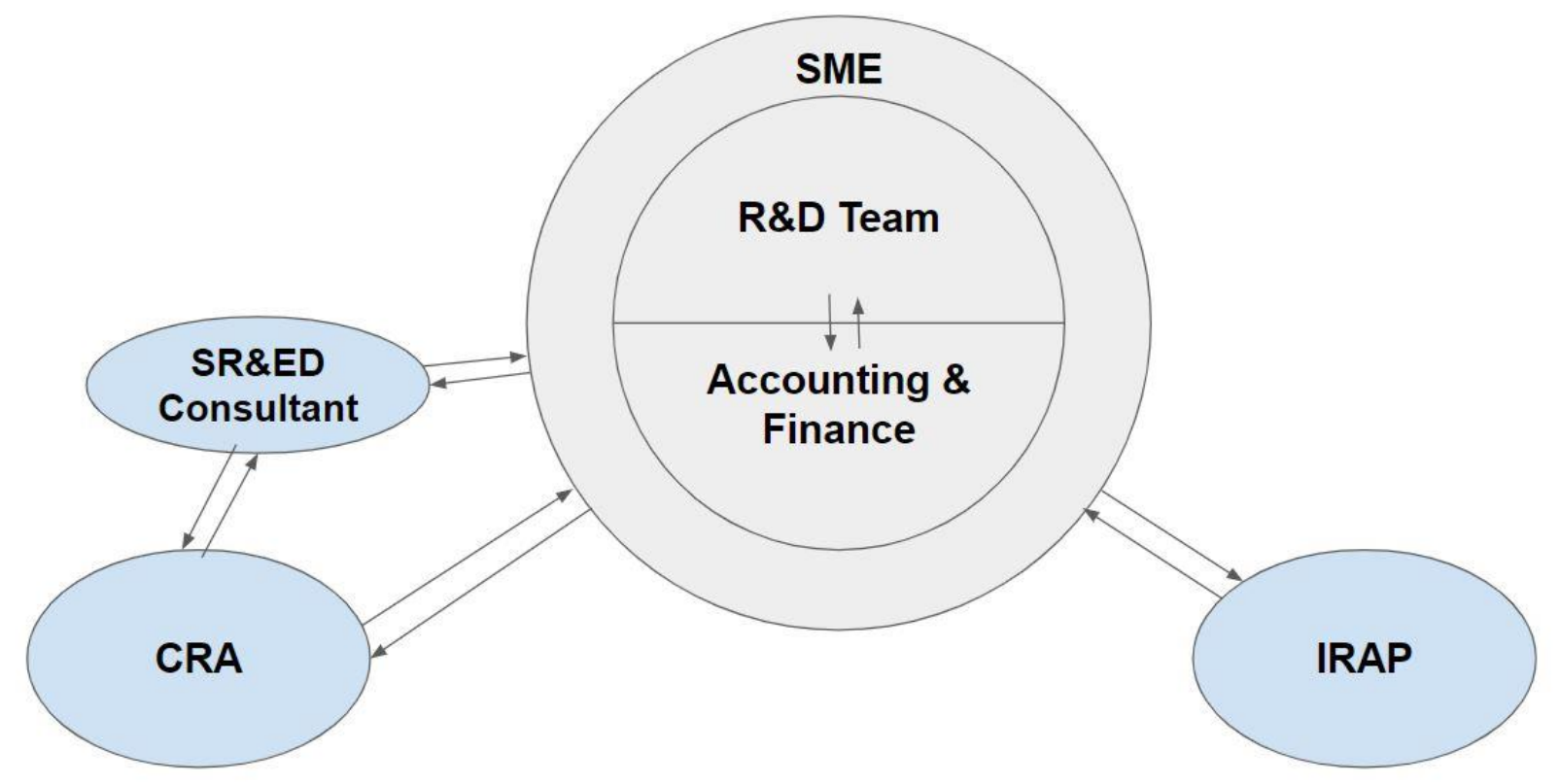

Due to the complexity of completing the T661 to ensure that it meets CRA requirements, many of the interviewed firms sought external assistance by either SR\&ED consultants or the CRA SR\&ED pre-claim services. Firms, such as Firm3 and Firm16, engaged SR\&ED consultants to assist them in determining whether a project would be eligible for the SR\&ED program. In Firm3's case, the consultants indicated that their claim would most likely not meet the technical uncertainty threshold, as it was software related. For Firm17, the SR\&ED consultant indicated that only the hardware R\&D expenditures should be submitted as eligible SR\&ED expenditures, as the "consultants are apprehensive on the software side and highlight the risks" of submitting a claim with software expenditures.

If all or part of the project was deemed eligible, the SR\&ED consultant often would assist in the discussions with the R\&D team and the accounting \& finance team to prepare the T661 form. Firm12 describes the typical process for SMEs as the finance team will work with the product 
team for the detailed tasks and costing, the SR\&ED consultant will conduct interviews with the product team to develop the technical description, and the finance team will forward the T661 for review to the SR\&ED consultant prior to submission. If there were an audit or a review, the SR\&ED consultant would often participate in the process.

As the cost associated with using SR\&ED consultants can exceed several thousand dollars, some firms, such as Firm7 and Firm13a, opted to use CRA's pre-claim consultations. Firm7 did not find the process helpful, as "it's supposed to be a three-week turnaround and we got a call [after] almost eight months, which means the project could not get started." Both Firm7 and Firm13a found that the pre-determination results were dependent on the reviewer.

Although IRAP is not part of the SR\&ED process, many key informants described a different process and experience with IRAP than the SR\&ED program. As IRAP is a grant facility to assist in R\&D, a number of firms used IRAP to help fund their R\&D. When the firms applied for IRAP, they provided a business plan or initial project proposal. Subsequently, the key informants were contacted by an NRC ITA. These advisors assisted the firms in finalizing their project proposal to submit for IRAP funding. Some firms indicated that the NRC ITA provided advice on applying for a SR\&ED claim. For example, Firm8 stated that their NRC ITA advised them to maintain documentation "in the following ways: make sure that it's from a research perspective, what's the thesis that you're trying to resolve, and what are the steps that you are taking."

A challenge that was identified by several interviewed firms regarding the completion of the T661 form is the differences in language among the participants of the SR\&ED process. The 
accounting and finance group identified a language barrier working with the R\&D team to develop a project description. In particular, the issue of whether a project met the CRA definition of technical uncertainty was a problematic area for a number of firms to navigate.

The language barriers found intra-firm and between the firm and CRA reviewers may be due to differences in socialization and jargon. All the key informants belonging to the finance and accounting group possessed professional credentials. Similarly, the key informants belonging to the technical group were engineers or had technical degrees.

\subsubsection{Intra-firm language barriers}

Within the firms interviewed, the accounting and finance team would work with the R\&D team to compile the T661 form. The accounting and finance employees would collect the financial data, including the current R\&D expenditures and the hours allocated to SR\&ED-eligible activities. This group was clear on the contents of the ITA regarding eligible SR\&ED program expenditures. In the interviews, the technical team was responsible for identifying whether an activity would be considered as a SR\&ED-eligible activity.

In a number of interviews, the key informants indicated that the R\&D team could easily differentiate between routine engineering and R\&D. However, the technical team often had difficulty with the specific CRA definition of technical uncertainty. The ITA definition of scientific research and experimental development is deliberately vague to avoid continually updating the ITA as technology advances (Hearn, Puterman, \& Tari, 2011). However, unlike some definitions of innovation (e.g., Damanpour, 1996), technical uncertainty does not necessarily mean creating something new. The Tax Court of Canada asserts that there needs to 
be evidence of technological risk in the pursuit of a technological advancement (i.e., to create something new) (Hearn et al., 2001). The R\&D manager at Firm10 indicated that it was very challenging for the engineers to articulate R\&D in words consistent with SR\&ED program criteria. She states, "they know that it's R\&D, but actually getting them to couch it in terms of, "What was your hypothesis?" and "What were the uncertainties, and the advancements?" She stated that they are very smart, but their writing skills required to describe SR\&ED projects in CRA required language are deficient. As an example of the struggle with the CRA forms, the R\&D manager of Firm14 indicated that on the T661 form, "there's a lot of overlap and so it took a bit of time to get, sort of understand the nuances of the differences between the three questions." (See Appendix A, lines 242, 244, and 246 for the three questions).

The intra-firm language barriers may be a result of the professionalization processes of accountants and engineers. In the context of the health professions, Hall (2005) outlines the professionalization process in which both the education and socialization of professions during their training period result in its members having similar values, problem-solving approaches, and language. Similarly, in Canada, accountants and engineers undergo professional education to be able to be accredited. Durocher, Bujaki, \& Brouard (2016) found that Millennials recruited by accounting firms develop their identity as an accountant through an internal organizational socialization process, while the accounting firms also adapt to the Millennials' values.

Comparably, through both the education and socialization processes, engineers develop their set of values and language. For example, engineering courses often teach problem-solving skills 
using idealized problems, fully defined parameters, and step-by-step procedures to efficiently solve the problems (Kumar \& Hsiao, 2007). In practice, although the problems are no longer idealized or there are clear parameters, engineers utilize their technical skills and scientific knowledge obtained through their education and experience to solve practical problems (Kumar \& Hsiao, 2007). However, the skills to communicate with other parts of the organization are often developed on the job (Kumar \& Hsiao, 2007). Consequently, the skills required to communicate or complete the project description of the T661 may not be fully developed.

\subsubsection{SR\&ED consultants}

A number of firms identified the need to use SR\&ED consultants to bridge the gap between the accounting and finance group, the technical group, and CRA. More importantly, the SR\&ED consultants understand the complexity of the SR\&ED program and the expectations of CRA. Firm12 states, "the [consulting] firm knows what CRA is looking for, and they know how technical to be. I think sometimes our product team will explain something, but they won't use enough technical terms, or it's not explained clearly enough."

The CFO of Firm11 indicates that smaller firms are at a disadvantage, as they are not often equipped to complete their own T661 form. However, "you're not going to pay an external consultant $[\ldots] 15$ to 20 thousand to do the interviews, to write the report for you and do the calculations [...] if you won't even get 10 thousand out of it, or 15 thousand. Right? So, a lot of times they just forego the decision, because it's a lot of work." 


\subsubsection{CRA versus IRAP}

In most cases, unless a firm underwent a review, an audit, or attended an information session, the only interface firms have with CRA for the SR\&ED program is the T661 form and the applicable sections of the ITA related to the SR\&ED program. A number of firms indicated that they found the verbiage vague. For example, the CFO of Firm11 indicated, "part of the challenge is knowing what's an eligible activity and what's not an eligible activity and making sure it's documented." Similarly, the CEO of Firm4 indicated that they have experience defining their R\&D within the IRAP framework; however, he believes there is a "gray zone" for software engineering that may make a successful SR\&ED claim more difficult to obtain.

In contrast, most firms indicated that their experience with the IRAP program was positive. They found that NRC ITAs gave them tools to succeed. The NRC ITAs wanted to better understand their business and offered advice on the R\&D process in terms of documentation. The CFO of Firm11 states, "it is the preferred program, it's just less painful. And the IRAP advisors that they have now, again, a lot of them have come from industry... they're way easier to deal with." In many cases, the key informants indicated that the NRC ITAs assisted them in their R\&D process and provided feedback as the firms provided R\&D progress reports. For example, the CEO of Firm3 indicated, "when we qualify for IRAP, that puts more structure around the R\&D project."

A number of firms compared the treatment they received from NRC ITAs with CRA's SR\&ED reviewers. The CEO of Firm17 indicated that the NRC ITA gave them feedback on their application to ensure it was a success; however, it seemed like the SR\&ED reviewer was "trying 
to poke holes in our story." Although a number of the CRA reviewers come from industry, a number of firms indicated that they felt that the reviewer was focused on the minutia. The CEO of Firm7 indicated, "they're are focusing very deep on the low level rather than focusing on the high level of the spirit of the research." For example, Firm7 was asked questions about why they were using certain languages and libraries in their programming.

It should be noted that the SR\&ED program process commences once a firm conducts R\&D, whereas a firm must apply for the IRAP program prior to conducting R\&D. Consequently, to better understand the motivation to apply for the SR\&ED program, it is necessary to identify the context in which a firm decides to engage in R\&D.

\subsection{Engaging in R\&D}

In this section, the decision to engage in R\&D and to apply for the SR\&ED program will be compared against the preliminary conceptual model to structure this analysis. Specifically, the external and internal context of the interviewed SMEs will be contrasted against the preliminary conceptual model identified in chapter two.

The decision to engage in R\&D can be considered a strategic decision (Slivko \& Theilen, 2014) as it involves a firm's commitment of resources and can change the scope of the firm. A firm can change its scope by developing new products or services or improvements to existing products/services. Subsequently, the firm decides whether to engage in intramural R\&D or source the development externally to achieve this change of scope. The firms interviewed indicated that these strategic decisions often involved multiple people, including the CEO, the finance team, the CTO or R\&D management, and marketing. In making these decisions, these 
individuals evaluate a number of factors in their external and internal context. Further, it appears the decision (or not) to engage in R\&D, and the type of R\&D, was influenced by the firm's product lifecycle.

\subsubsection{Influence of the external context}

As part of the semi-structured interviews, the SME key informants were asked about their external context. Specifically, the SMEs were asked about their competition, the regulatory environment, and their market. The key informants were asked if these factors had an impact on their decisions concerning R\&D and their decision to apply for the SR\&ED program. From the interview, the external factors acted as either a constraint or a driving force.

From the interviews with the SME key informants, the competitive environment could be seen as a driving force. A number of firms had evaluated the competition before forming the company and decided to engage in R\&D to offer products to address a need not being filled by the competition. For example, Firm 8 had analyzed several online financial data platforms and found that they were offering financial data and ratio analysis, but the competitors were not providing business valuation data. Based on this perceived gap, the founder created a software that analyzed publicly available financial data to create business valuations. Similarly, other SMEs chose to differentiate themselves from large multi-nationals by focusing their R\&D efforts on offering a niche product or providing customized solutions. As an example, Firm5 customizes their health records system depending on the client's needs and the infrastructure available in their region. In contrast, their large multi-national competitors provide a standard medical records system that does not always account for differences in regional infrastructure. 
Other firms, such as Firm2, were founded based on trying to find a solution to solve a specific problem, and initially, there was little competition for their products. For these firms, the initial $R \& D$ investment efforts were significant to be able to offer an innovative product that was not on the market. These SMEs often expressed their frustration in being the first to the market, and subsequently, shortly after launch, other firms offer a similar solution. For example, Firm2 indicated that a number of new competitors were offering a similar solution with increased capabilities, which Firm2 believed was not technically possible. This example of a knowledge spillover illustrates the risk of engaging in R\&D when a competitor can replicate the efforts for less time and cost (Lester, 2012; Michael \& Pierce, 2009).

Once their initial product/service was commercialized, some of the companies continued to monitor the competitors as part of their decision-making process for R\&D. For some firms, such as Firm7 and Firm9, monitoring the competition was a catalyst for innovation. These firms continually were concerned they were falling behind their multi-national competitors; thus, the firms felt the need to continue to innovate. This behaviour is consistent with the international technology transfer hypothesis (Coe \& Helpman, 1995), in which greater competition spurred companies to innovate.

Similar to the competitive environment, firms considered their regulatory environment before they engaged in R\&D. In other words, when designing and developing their product, the firms would ensure the compliance requirements were embedded in the product. For a number of companies, they had to consider regulations in several jurisdictions when making a decision. For example, firms, such as Firm7, need to comply with EU regulation on privacy before 
extending their services to countries in the EU. Effectively, the regulatory environment had a moderating effect on the design of the R\&D.

The regulatory environment was cited as a constraining factor due to evolving regulations. For example, for Firm16, the drone regulations had an impact on their R\&D development. As development was in progress, they had to redesign their product to meet the amended standards. Similarly, Firm12 continually needs to keep abreast of new regulations and any updates to existing regulation that may have an impact on their supply chain compliance solutions. Firm 12 has hired subject matter experts from different countries to support the R\&D department in making modifications to the product to comply with the evolving regulations.

Consistent with Wong \& Aspinwall's (2004) description of SME characteristics, most of the interviewed firms reported frequent communication with their customers. Accordingly, the firms would have contact with customers to obtain feedback on the products and services. As a result, the market was seen as a driving force. This feedback often influenced the decision to engage in R\&D projects and influenced their R\&D strategy. For example, Firm12 included some of its customers on its advisory board.

Some firms do not have direct contact with the end consumer. For example, Firm13a and Firm13b primarily sold their products through third-party channels. Although the feedback from the end consumer is limited to social media or product reviews, the market had an impact on their R\&D decisions. For Firm13b, new flavours or combinations for alcoholic beverages were based on monitoring social media and market trends. 
In summary, competition and the market were driving forces in the decision to engage in R\&D.

In contrast, the regulatory environment could be considered a constraining force depending on the industry. All three forces had an impact on the type of R\&D. The competitive forces could be a catalyst for either incremental changes or new product development. In contrast, the market would often push for incremental innovation rather than new products or services. Similarly, the regulatory environment often required enhancements to existing products or services.

\subsubsection{Influence of the internal context}

In addition to their external context, firms were queried on whether their strategies (or lack thereof), the values, the ownership and management structure, the resources, and the systems and processes influenced their R\&D strategy decisions. Both Christensen (1997) and Laforet \& Tann (2006) indicated that firms with an innovative strategic orientation and values, along with the supporting systems, processes, and resources, were more likely to engage in R\&D.

Only a few of the interviewed firms had explicitly stated strategies. Several firms had a technology or product roadmap; however, a roadmap can be seen as a tactic to implement a firm's strategy. In effect, a technology or product roadmap is a document to give direction to the R\&D department. As a result, product and technology roadmaps will be discussed in section 5.3 .

Given the lack of definite strategies for a number of the firms interviewed, it can be assumed that, as per Mintzberg \& Waters' (1985) definition, most of the interviewed SME's strategies were not deliberate, but rather emergent. Consistent with Mintzberg \& Waters' (1985) analysis 
of emergent strategies, it would appear that a series of organizational decisions resulted in a strategic direction. As an example, the original strategic direction changed trajectory for Firm8 based on feedback received at tradeshows. Subsequently, the firm made a number of tactical decisions, including creating a new programming language to distribute data to customers through an API.

Mintzberg \& Waters (1985) contend that firms with emergent strategies tend to be learning organizations. For example, Firm1 does not have a deliberate strategy. However, the strategy that has emerged is a product differentiation strategy. The CTO states, "Most of the things we work on are things that people haven't solved before, and that's I think where our niche is. We're too small and therefore probably too costly to compete with the big players in the area." The СТO also emphasized that the firm was driven by values of learning and problem-solving. This experiential organizational learning, consistent with Clarysse et al. (2009) and Rosenberg (1992), is expressed by the CTO's description of their learning process, "occasionally incredibly frustrating, and occasionally we just get it wrong" and "Oh, that was a bad idea. Learn another way not to do it." Consequently, the decision to engage in R\&D aligns with their problemsolving values and their strategy of differentiating themselves by taking on projects that appear impossible to solve.

In contrast to firms with emergent strategies, Mintzberg \& Waters' (1985) posited that firms with deliberate strategies were more likely to "focus on direction and control - getting things done" (Mintzberg \& Waters, 1985, p. 271). Firm7 is a good example of a firm with a deliberate strategy and a mindset of "getting things done." Their current platform includes over 15 
communication channels, including email, surveys, contact management, and social media. The decision to engage in $R \& D$ is primarily driven to increase the number of communication channels on their integrated platform. The "getting things done" mindset is also consistent with Wong \& Aspinwall (2004) in which the authors asserted that the values are resultsoriented.

The values of the firm also had an impact on the decision to engage in R\&D. For example, although Firm1 and Firm7 had different strategic orientations, both firms had values that reflected problem-solving and risk-taking. Firm1 indicates that the firm enjoys challenges and projects that seem impossible to solve. Similarly, Firm7 is seeking to be on the leading edge of integrating communication channels for their customers. Both of these firms engage in R\&D that aligns with their values.

The ownership and management structure had both a direct and indirect impact on R\&D decision making. Decision-making is often centralized among the owner and select individuals from management. Both R\&D project selection and resources allocated are determined by this group.

In addition, R\&D decisions were also affected indirectly by ownership and management, as the strategy and values often derive from this group. Once the ownership and management structure adopted a strategic vision of the firm, the firm's strategy would have an impact on the R\&D projects selected. Values are often a result of the owner's beliefs (Leonard-Barton, 1992; Wong \& Aspinwall, 2004). 
Firms were also queried on whether resources, systems, and processes had an impact on the R\&D decision-making process. Resources and systems and processes did not have a direct impact on the R\&D decisions, rather they are considered to be a constraining element. Figure 5-3 illustrates the relationships among ownership and management, strategy, values, resources, and systems and processes on R\&D decisions.

Figure 5-3 Relationships among internal context factors and R\&D strategic decisions

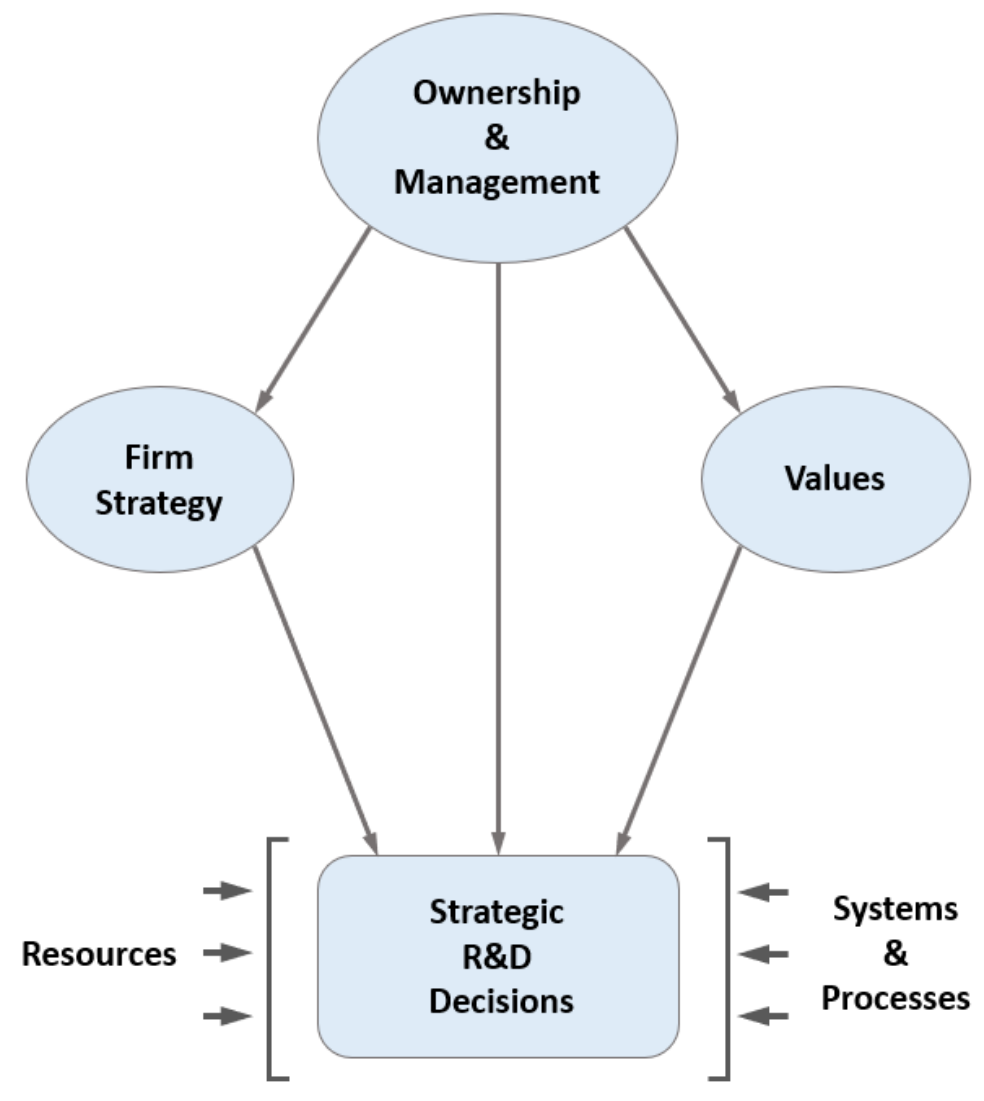

Physical and human resource requirements were dependent on the industry. Advanced manufacturing firms, such as Firm10 and Firm9, required substantial capital equipment. In contrast, technology firms had a reliance on human resources such as programmers and engineers. Availability of human resources was dependent on region and industry. For 
example, Firm7 indicated there were no issues in engaging talent due to the number of universities in their vicinity.

Financial resources had an impact on the number of projects undertaken and project selection. All firms interviewed indicated that the scope of their R\&D effort was constrained due to a lack of financial resources. As a result, they needed to rank projects or determine the magnitude of the project(s). A number of firms also indicated that priority is placed on projects that may be eligible for SR\&ED tax incentives.

Similar to resources, systems and processes was a constraining factor in R\&D decision making. Consistent with Salles (2006), a lack of integrated systems resulted in ownership and management making decisions with a higher level of ambiguity since the SMEs did not have access to all the data required. Firms, such as Firm10 and Firm9, indicated that an interactive system was required to allow management to ascertain costs and profits at the unit level. R\&D decisions were made based on data obtained from disparate systems, rather than a unifying system such as an enterprise resource planning system (ERP). The cost to implement an ERP or add more modules to an existing ERP was considered prohibitive. Consistent with Bloom et al. (2017), the implementation of structured management practices can be costly for SMEs.

\subsubsection{Product lifecycle}

Along with the internal and external context, a firm's product lifecycle has an impact on a firm's strategy (Hofer, 1975). Consequently, the product lifecycle may have an impact on the decision to engage in R\&D. Figure 5-4 illustrates the firm and its stage in the product lifecycle. Hofer (1975) outlined the corresponding R\&D strategy depending on a firm's product lifecycle. In the 
introduction phase, the firm's R\&D focus is often on engineering changes to fix any issues encountered in the market (Hofer, 1975). In the growth phase, the focus is on a successor product (Hofer, 1975). In the maturity and saturation phase, there is pressure to find efficiencies in the process and to develop major adaptations to start a new product cycle (Hofer, 1975). In the decline stages, the focus is to cease R\&D on existing products (Hofer 1975).

Figure 5-4 Interviewed firms and product lifecycle stage

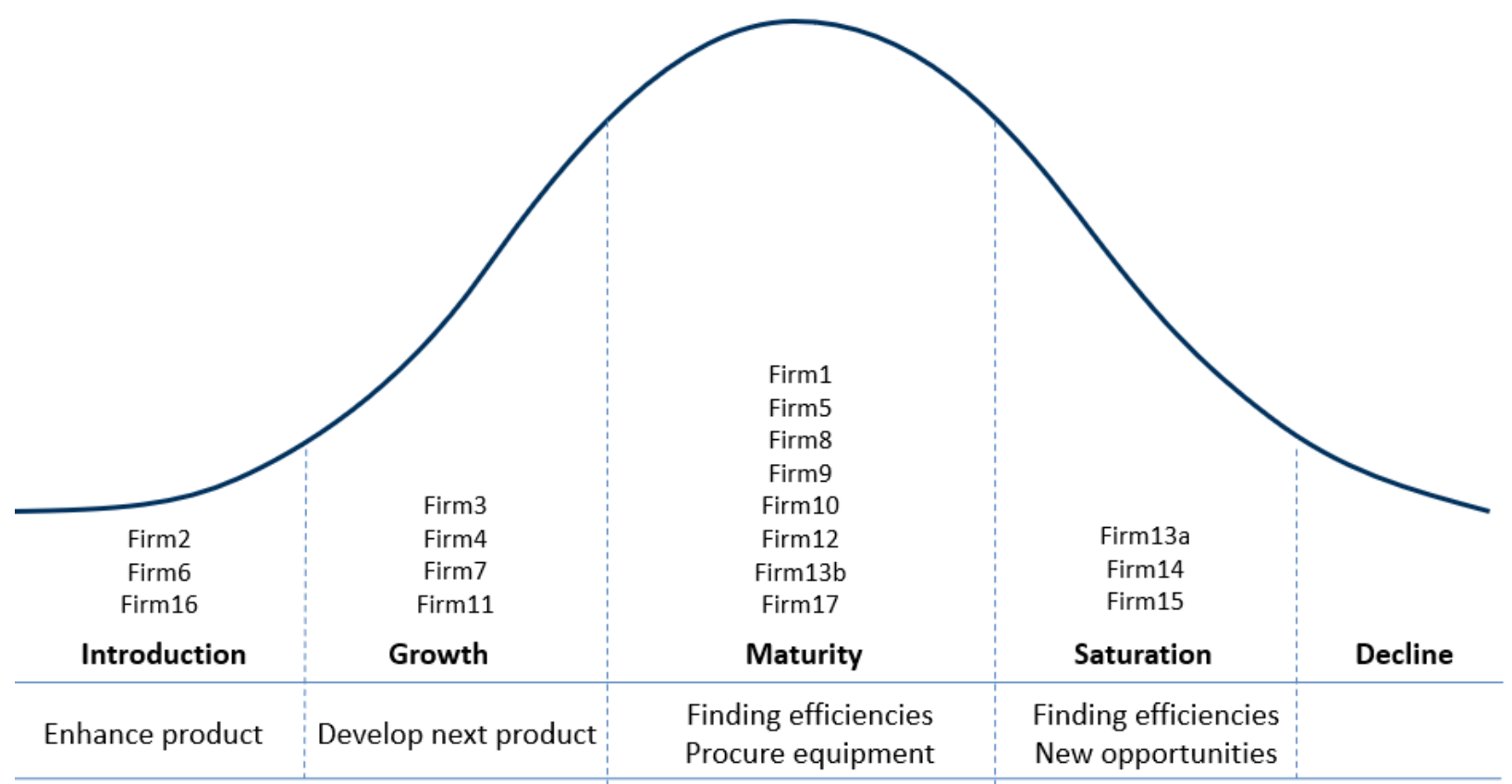

For firms, such as Firm2, with products in the introduction phase, the R\&D focus was to perfect the weapon detection product. For example, to improve the portability of their product to allow the detection device to be mounted on police cars or drones, Firm2 developed a version of their product that could be loaded on NVIDIA Xavier cards. By focusing their R\&D on this type of engineering improvement, they could expand their market of their product. 
For firms in the growth phase, such as Firm4, the focus was to engage in R\&D to develop a subsequent product. The augmented reality product currently supports industrial environments such as energy and defence; however, they decided to engage in R\&D to expand to increasingly challenging environments, such as low bandwidth, to expand their market.

For firms in the maturity phase, such as Firm9, there was a dual focus. Firstly, there was a focus on finding efficiencies in the R\&D process. The CEO of Firm9 indicated that "to remove all the waste in the company, waste caused by our own mismanagement typically, I have to invest into IT and infrastructure." Secondly, Firm9 invested in equipment, in collaboration with the University of Waterloo, to develop a new generation metal additive manufacturing process to create custom components at a lower-cost and higher quality, specifically targeting the aerospace and defence industries.

For firms interviewed that were in the saturation phase, such as Firm13a, there was a focus on finding efficiencies by outsourcing R\&D to Vietnam. Firm13a was also scanning the market for new opportunities for mobile games; however, the intensity of R\&D efforts had diminished from previous years.

Therefore, consistent with Hofer's (1975) contingency theory, a firm's decision to engage in $R \& D$ is dependent on the external and internal context, as well as the product lifecycle. However, the product lifecycle often had an impact on the type of R\&D that was conducted. Depending on the product lifecycle stage, a firm may choose to engage in R\&D to improve the existing product or commence development on a subsequent product. By elaborating on a 
portion of Figure 5-3, Figure 5-5 illustrates how the product lifecycle influences a firm's R\&D strategic decisions along with a firm strategy and its constraints.

Figure 5-5 Influence of internal context and product lifecycle on strategic R\&D decisions

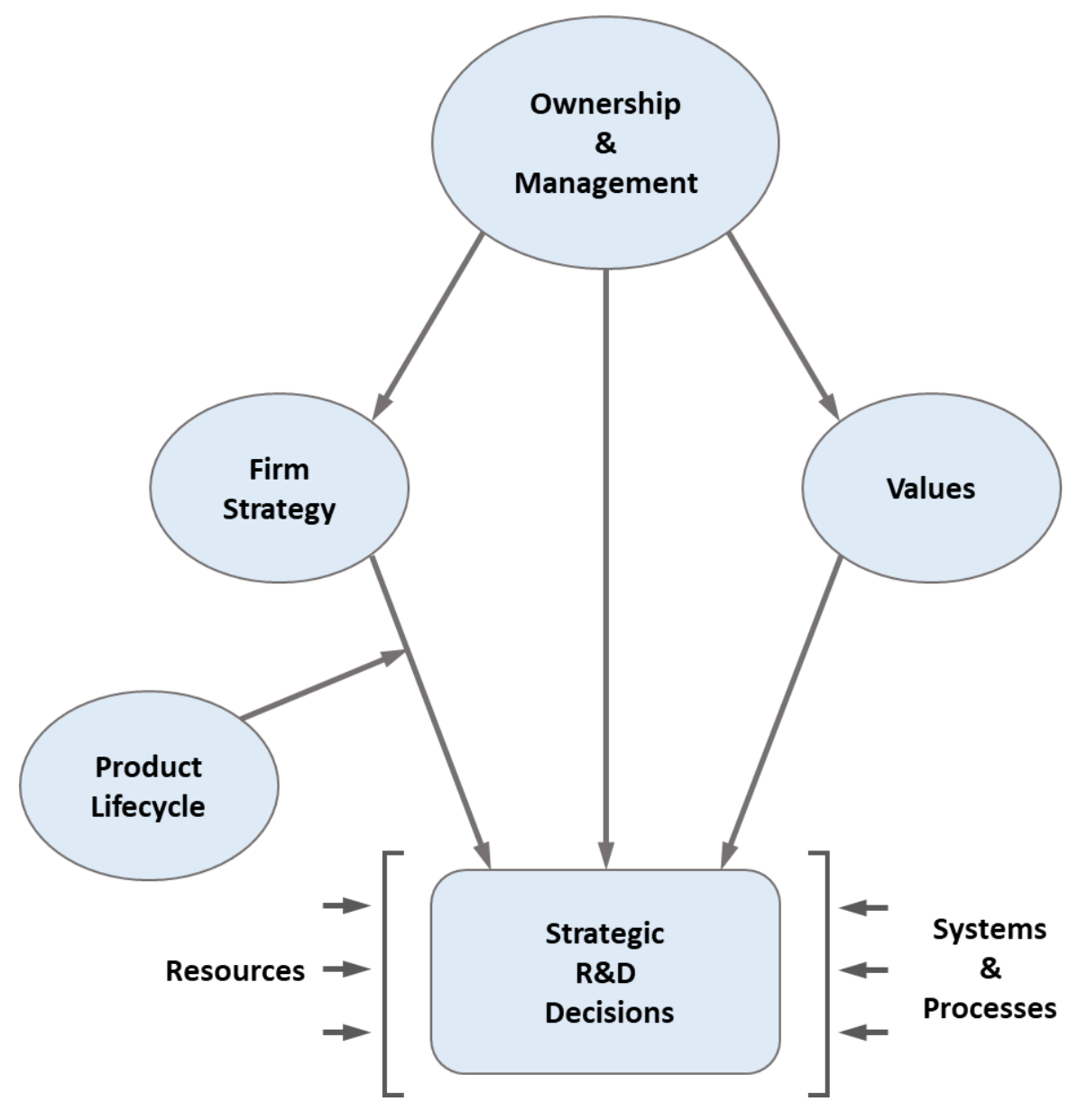

The product lifecycle also appeared to have an impact on the decision to restructure the firm. Of the interviewed firms, two firms (Firm6 \& 14) that were acquired were in the saturation product lifecycle stage. In both these cases, a large multi-national competitor had dominated and saturated the market with its product. As a result, both firms decided that business's acquisition was the best option as the firms indicated it was no longer economically feasible as a small CCPC to invest in R\&D to differentiate their product. In contrast, another firm in the 
process of being acquired, Firm2, which is in the introduction stage, was approached by a public company in the same field. The founders had agreed to the acquisition to resolve their financial constraint issues.

In summary, CCPCs decide to engage in R\&D based on the values and strategy derived by the owner and management. The product lifecycle influences the firm strategy to engage in R\&D either inadvertently or deliberately, while the R\&D strategy is affected by a CCPC's resources, systems, and processes constraints. Given the CCPC's internal context and product lifecycle, once a CCPC decides to engage in R\&D, the ensuing focus is the management of R\&D personnel and practices to achieve their R\&D strategy.

\subsection{R\&D Management Practices}

In this section, the R\&D management practices of the interviewed firms will be contrasted against the preliminary conceptual model. As part of the interview, key informants were asked about their R\&D management practices. Building on Winn \& Roome's (1993) definition of R\&D management as the management of the R\&D department, the development process, and priority setting, key informants discussed the R\&D department, its system and processes, and its priority-setting exercises.

In contrast to the decision to engage in $R \& D$, the management of R\&D can be considered a series of tactical and operational decisions as they do not immediately alter the scope of the firm (Shivakumar, 2014). To be able to achieve their R\&D goals, management makes decisions regarding the structure of the R\&D department, the allocation of resources for the systems and processes used to support the R\&D process, and how priorities are set. 


\subsubsection{R\&D department structure and composition}

The presence of a separate $R \& D$ department has an impact on how R\&D is managed. As Chandler (1962) indicated that structure follows strategy, the R\&D department structure can be seen as a tactical decision to implement the R\&D strategy. The R\&D department can be structured as a separate division, it can be embedded within operations, and it can further be divided by product lines or project.

Some of the firms interviewed, such as Firm7, had a separate R\&D department from its operations. The CEO of Firm7 describes the demarcation as if the R\&D department is operated as a separate company. In contrast, for some firms, such as Firm5, the R\&D department is part of the operations team. In effect, some employees may be dedicated to new development, others perform routine maintenance, or the personnel does a combination of both development and maintenance. If the R\&D division is separate, it can be assumed that the resources allocated (both physical and human) are dedicated to the R\&D department. In contrast, if $R \& D$ is part of operations, the allocation of the time, personnel, and resources must be prioritized.

For some firms, the R\&D was further segregated by product line. For example, Firm10 divided their R\&D and operations by product line. At the product line level, firms also made delineations between routine R\&D and SR\&ED-eligible activities by having personnel enter time codes associated with work associated with the SR\&ED-eligible activities. The head of the R\&D department often determined routine R\&D versus SR\&ED-eligible activities. In the situations in which firms needed to delineate between routine R\&D and SR\&ED-eligible activities, the head 
of the R\&D department evaluated whether the activities met the SR\&ED program criteria of technical uncertainty.

Other firms, such as Firm1 and Firm13a, divided their R\&D by project. Teams would be assigned to projects. Consequently, if the project was deemed an SR\&ED-eligible project, the project's time was allocated to SR\&ED expenditures. However, there were challenges identified with dividing R\&D by project. For example, Firm13a indicated that with R\&D divided by project, managing the resources and maintaining a cohesive culture was challenging. The CEO identified scenarios in which the project was over-budget or was not progressing well and the firm could not easily migrate the developers to other projects, resulting in layoffs of surplus employees.

As reported in Table 1-6, Wong \& Aspinwall (2004) indicated that SMEs have a simple and flexible structure. From the interviews, it was found that most firms had a relatively flat structure. In many cases, the CTO or CEO was directly responsible for the R\&D department. For example, at Firm1, all projects reported to the CTO. Other firms such as Firm9 and Firm10 had additional layers; however, the executive team was involved in R\&D decisions. Given the flexible structures and involvement of the management team in R\&D, the status differences within the SMEs appeared to be low.

Regardless of structure, R\&D management practices also include the attraction and retention of technical talent. The department's composition was reliant on the values of the firm, as well as the industry and geographic location. The CEO of Firm3 states, "the culture that we've created an organization where people feel empowered and welcomed and part of something greater, which is tied to our mission, has made it a lot easier than a lot of other companies to recruit." 
The organization's values are reflected in a firm's managerial systems, which include training and apprenticeship opportunities (Leonard-Barton, 1992). Firms, such as Firm4 and 5, felt that their focus on developing capabilities gave them a competitive advantage in recruitment. Some firms indicated that they had difficulty in finding the right talent to be able to innovate. Other firms indicated that training mitigates challenges in finding qualified technical talent. For example, Firm16 indicated that finding qualified resources for hardware was a challenge. Consequently, the firm trained high potential software graduates to build their hardware design skills. The willingness to train new graduates was a common refrain from firms whose values included human resources.

In addition to a commitment to developing capabilities, the low status difference due to a relatively flat structure may assist in both recruitment and retention (Huang \& Lin, 2006). For example, Firm5 indicated that newer graduates appreciated that the structure of R\&D allowed them to "become part of the team. When they go into large companies, they get stuck in Quality Assurance."

From the interviews, it also appears that the composition of the R\&D department is dependent on the industry. For software firms, the R\&D department often were mostly composed of software programmers. In advanced manufacturing firms, the R\&D department had a significant number of engineers. A number of the interviewed firms, such as Firm3 and Firm7, indicated the proximity to a university was also a factor in the recruitment and composition of the R\&D team. 


\subsubsection{R\&D systems and processes}

Similar to the decision on how to structure the R\&D department, the systems and processes to support R\&D can be considered a tactical decision as they are bound by the strategic decision

to engage in $R \& D$, require a level of commitment, but there is no change in scope. As with the reporting structure, the firm's values influence the technical systems, which include the systems and processes used in a firm (Christensen, 1997; Leonard-Barton, 1992). In addition, the structure of the R\&D department, resource constraints, and the regulatory environment had an impact on the systems and processes used for R\&D purposes.

In Leonard-Barton's (1992) framework, the firm's values are embedded in the technical systems, as they are used in the codification of knowledge. In effect, the values influence the development, documentation, and sharing of knowledge. For example, SMEs whose values reference team, such as Firm3, would be expected to utilize systems and processes that allow for collaboration. Indeed, Firm3 indicated that the R\&D department used Microsoft Teams to collaborate among R\&D team members.

Similarly, firms with values of learning would be expected to use systems and processes that encourage learning. Building on Simon's (1995) discussion on levers of control, interactive control systems can enable learning and firm performance. Therefore, firms that value learning in the $R \& D$ process are more likely to choose interactive control systems that promote learning and collaboration. When asked to describe their R\&D process, several firms, such as Firm5, indicated they use Agile methodology. In order to successfully execute Agile methodology, a firm should be learning organization that is flexible and able to adapt to resolve emerging 
challenges in R\&D (Annosi et al., 2020). The Agile process results in knowledge creation and accumulation through both experiential and vicarious learning among team members (Annosi et al., 2020).

Agile seems to be well-suited as an enabling interactive control system for SMEs with a flexible and flat structure. Annosi et al. (2020) indicate that larger firms may not be well-suited to Agile. This methodology requires reduced role differentiation, increased cross-functional knowledge, and frequent communication with end users (Annosi et al., 2020). These optimal conditions for Agile methodology are consistent with Wong \& Aspinwall's (2004) characteristics of SMEs, including frequent communication with customers and low specialization.

Although Agile may promote innovation and learning in SMEs, Agile methodology may exacerbate issues with documentation of the R\&D process and knowledge accumulated. In their study of Agile methodologies, Annosi et al. (2020) found that codification of knowledge was more difficult due to Agile's informal processes. Consequently, Agile methodology may be more consistent with Eisenhardt \& Martin's (2000) concept of simple rules in which the development team is provided basic guidelines and priorities. Eisenhardt \& Martin (2000) asserted that simple rules are appropriate for rapidly changing or volatile environments. Similarly, firms often elect to utilize Agile methodology to allow for flexibility in a dynamic and complex environment (Annosi et al., 2020).

From discussions with firms that used Agile, the degree of structure of R\&D practices were dependent on the composition of the technical team. Consistent with Bloom et al. (2017), the R\&D management practices were often influenced by the level of skill and education of the 
workforce. Firms, such as Firm1 and Firm7, with a considerable number of engineers, had more structured R\&D practices than those with fewer engineers. For example, even though Firm1 used Agile methodology, the engineers would document the problem, set up experiments, produce a prototype, and document the results.

In addition to a firm's values, the structure of the R\&D department also had an impact on the technical systems. When a team member works in both operations and R\&D, the systems to support each function differ. SMEs indicated that when R\&D was integrated with operations, the firm needed systems to track the time allocated to R\&D. Many firms used time sheets to track their R\&D efforts. However, Firm10 indicated that they believed that the R\&D department was conservative in their estimates in tracking time that could be applied to the SR\&ED program since this system relied on R\&D resources to identify the time spent. In contrast, a company such as Firm1, is better able to track most of the effort as the R\&D department was divided by project. If the project was deemed to be eligible for the SR\&ED program, the systems could track the work specifically to that project.

The choice of systems to support R\&D processes was affected by financial constraints. Due to financial constraints, several smaller firms used simple systems to manage their R\&D department. For example, some firms, such as Firm16, indicated that they used Microsoft Excel to monitor their projects. Consequently, firms such as Firm11 and 12 indicated that pulling data for a SR\&ED claim was an onerous process.

Larger SMEs with more access to capital, such as Firm10, had more sophisticated systems such as SAS. Being able to link to other systems for costing purposes and to be able to obtain greater 
efficiencies was a frustration among a number of the key informants that were part of the finance group. Firm 9 and Firm10 believed that larger firms had an advantage due to the ability to fund more sophisticated systems. Both firms indicated that even though they believed that more integrated systems were required to better understand the operations and costs associated with R\&D, the additional cost was difficult to justify.

From an external environment perspective, as asserted by Bloom et al. (2017), the regulatory environment had an impact on R\&D management practice. Firms, such as Firm7 and Firm10, with certifications would ensure that their development processes met the requirements. Firm7 ensured that its development met security and privacy requirements. Firm 9 ensured that the manufacturing and R\&D processes met safety protocols and nuclear safety requirements. As these firms were subject to audit, the R\&D processes and operational activities were well documented.

\subsubsection{R\&D priority setting}

From discussions with the SMEs, the decision to develop new versus improve existing products/services appeared to be a more complicated decision than the decision to engage in R\&D. Firms often would need to prioritize operations, routine R\&D, and R\&D that could be considered as SR\&ED-eligible activities. The firms interviewed indicated that resource constraints and the external environment influenced their priority setting exercises. To be able to add structure to the R\&D priority setting, several firms indicated they used a product or technology roadmap. 
A product or technology roadmap can be considered to be a tactic to achieve the firm's strategy. As management practice, a roadmap can provide structure to an organization's work and can facilitate improved performance in SMEs (Nisar, Kumar, \& Prabhakar, 2018). Some firms, such as Firm2, emphasized that they did not deviate from the product roadmap when deciding upon R\&D projects. Other firms, such as Firm3, used the roadmap as a guideline to outline projects that would be an enhancement of the central platform.

The definition of priority setting differed depending on the R\&D structure. For firms without a separate R\&D department, R\&D personnel are specifically allocated to new development or routine maintenance and engineering based on the priorities. In some firms, such as Firm5, the $R \& D$ personnel may work part of the day on routine maintenance and engineering, and the other part of the day on new development. In contrast, for firms with a separate R\&D department, such as Firm9, the priority setting involves allocating resources to the existing projects based on its ranking of importance.

All firms indicated that financial resources were a constraining factor in priority setting. Financial constraints had an impact on the number of R\&D employees, access to talent with the appropriate skill set, and required equipment. Due to these constraints, firms often needed to select which R\&D projects to undertake.

Most often, financial constraints had an impact on the number of R\&D personnel employed at a firm. For example, Firm7 indicated that due to reduced or rejected SR\&ED program refunds, they were not able to hire 10 to 20 R\&D employees to work on SR\&ED-eligible projects. In addition, financial constraints have an impact on attracting the right talent. Firm4 indicated 
that virtual reality developers are generally located in Silicon Valley and Vancouver, and they have not been able to engage talent from these areas. Consequently, firms such as Firm4 must devote resources in training to develop the capabilities.

Consistent with Winn \& Roome (1993) and Bloom et al. (2017), the external environment had an impact on R\&D management practice of priority setting. The interviewed firms indicated that both the competition and the market had an impact on the setting of priorities. These two elements had both an impact on balancing operations and R\&D and ranking R\&D projects.

The competitive environment can be considered to be a driver based on its influence on R\&D priorities. A number of firms, such as Firm11, scanned the competitive environment for opportunities. This behaviour is consistent with the acquisition and assimilation dimensions of potential absorptive capacity (Zahra \& George, 2002), in which the firms would scan the external environment for opportunities and assimilate the knowledge within their firm. For example, Firm11 indicated that if they find their competitors offer a unique data analytic solution, the firm will invest resources to better understand the competitor's product. If Firm11 believes it is a viable marketable product, the firm would add the solution to their roster of R\&D projects.

In contrast to the competitive environment, the market can be seen as primarily as a constraining force. When SMES were asked how they set their priorities, several firms, indicated that the market had a sizeable influence on their priorities. Customers would often ask for enhancements for existing products and services. In some cases, routine development and engineering took precedence over new development. The influence of customer feedback 
was particularly evident if there was at least one large customer. Firm3 and Firm8 both indicated that their primary customer would request enhancements be added to their R\&D project schedule.

Other firms, such as Firm4 and Firm9, indicated they include customer feedback in product enhancements but acknowledge that the market does not always know what they want. The CEO of Firm4 states, "if you just do market feedback, you only end up doing a small incremental improvement instead of chasing the big picture. So, got to be a mix of both." In effect, the market may constrain more robust R\&D or new product development projects in favour of improvements to existing products.

In summary, how CCPCs manage their R\&D practices reflects their internal context, with the competitive environment and the market act as driving forces. In contrast, the regulatory environment may act as a constraining force. For firms who chose to decide to engage in the SR\&ED program, features of the SR\&ED program also can be a factor in how CCPCS manage their R\&D practices.

\subsection{SR\&ED program}

When asked why the firms applied for the SR\&ED program, all firms indicated their motivation was due to financial constraints. For firms, such as Firm9 and Firm10, the SR\&ED program claim reduced their taxable liability. Many other firms were dependent on the refundability provisions for cash flow purposes. In effect, the refund would fund the following year's R\&D efforts. 
The SR\&ED program criteria and eligibility rules had an impact on the decision to engage in the SR\&ED program. Firms, such as Firm3, did not apply for the SR\&ED program due to concerns about meeting the technical uncertainty criteria. Other firms, such as Firm13a and Firm15, no longer applied for the program due to eligibility rules. The eligibility rules for the enhanced rate for CCPCs and the requirements to share expenditure limits with associated companies had an unexpected impact as well.

The SR\&ED program also had an impact on R\&D management and R\&D practices. In effect, the SR\&ED program had an impact on the R\&D processes, the management of these processes, and R\&D priorities. The Association of International Certified Professional Accountants (AICPA) outlines 12 principles of good tax policy, including neutrality. Neutrality is defined as "minimizing the effect of the tax law on a taxpayer's decisions as to how to carry out a particular transaction or whether to engage in a transaction is important" (AICPA, 2007, p. 3). Consequently, the importance of the SR\&ED program and its impact appear to be in contradiction with the neutrality principal of good tax policy. In addition, SR\&ED program reviews and audits had a lasting impact on a firm's R\&D behaviour, and at times, had a negative impact on individual team members.

\subsubsection{Financial constraints}

The decision to engage in the SR\&ED program differed from the decision to engage in R\&D activities. Strategy, values, and the firm's product lifecycle influenced the decision to engage; however, SMEs indicated they applied for the SR\&ED program due to financial constraints. The motivation to apply for the SR\&ED program due to resource constraints is consistent with neo- 
classical economic theory. Under this theory, participants utilize tax incentives to reduce the cost of capital to invest in R\&D. Therefore, participating firms are expected to engage in R\&D or increase their R\&D spending as a result. Consequently, this theory believes that firms will not engage in R\&D unless it is certain that the investment will yield a marginal return.

However, from the interviews, in many cases, the R\&D decision was made prior to the decision to engage in the SR\&ED program and without the certainty of the ability to obtain the SR\&ED tax incentives.

Although firms indicated that they applied for the SR\&ED tax incentives due to financial constraints, some firms indicated that they did not rely on the SR\&ED program to fund their R\&D. As the R\&D expenditures needed to be incurred before firms could apply for the SR\&ED tax incentives, firms chose to fund R\&D based on available cash flow. Some firms indicated that they did not rely on the SR\&ED program to fund their R\&D, as the SR\&ED claim is not guaranteed. However, many firms, such as Firm7 and Firm13a, did indicate that funds received from the SR\&ED program would have an impact on the R\&D planning for the following year. The CEO of Firm7 stated the rejection of his claim, "has reduced the talent pool. We're not training these individuals and we're not conducting R\&D work and then we're now two years, three years behind because we're not upping our game in the R\&D spectrum within our organization."

Given some of the challenges, some firms, such as Firm4 and Firm9, indicated that they weighed applying for the SR\&ED program against the effort required to apply and obtaining funds elsewhere. The CFO of Firm9 indicated to the CEO, the SR\&ED program "is so much 
headache. You have to comply to the government requirements. It's going to slow you down. It's going to give us a lot of paperwork, and everybody hates it." The CEO of Firm4 also indicated that in the first year of operations, they did not apply for SR\&ED tax incentives due to the effort required compared to the potential reimbursement.

A couple of the firms, such as Firm9 and Firm10, indicated that SR\&ED tax incentives made the difference between profitability or a loss. In addition, with the removal of capital expenditures from eligible SR\&ED expenditures, both firms indicated that they needed to find efficiencies elsewhere in the organization to ensure profitability. Customers can also pressure firms to reduce prices based on a reduction of expenditures due to the SR\&ED tax incentives. For example, Firm9 indicated that two large multi-national customers requested a reduction in price for new development based on the assumption that Firm9 would apply for the SR\&ED program.

\subsubsection{Technical uncertainty}

The criteria for technical uncertainty were a significant cause for discussion among key informants. While most firms stated they understood the need for criteria to designate an activity as eligible for the SR\&ED program, many firms believed that the SR\&ED program had not evolved to reflect the changing nature of R\&D. The CEO of Firm7 states, "digitalization is something that's just very odd, and it's taken a while for the government of Canada, specifically the SR\&ED offices, to consider this new revolution."

Firms that were involved in software programming perceived there was a bias against SR\&ED claims for software. These firms indicated that they were being told by SR\&ED consultants that 
unless they were creating a new language, their software would not meet the technical uncertainty threshold. For example, Firm3 decided not to apply for the SR\&ED program due to their SR\&ED consultant's feedback about their software development. Firm4 describes software engineering as a "gray zone." For firms with a hardware and software component, such as Firm16, they did file for SR\&ED claims for the software development based on advice from their SR\&ED consultants.

The concerns about software development and its interpretation as a SR\&ED-eligible activity appears to be well established. In 1997, CRA issued information circular 97-1 Scientific Research and Experimental Development - Administrative Guidelines for Software Development. This now obsolete information circular provided guidance on meeting the threshold of technical uncertainty and examples of eligible and non-eligible software development projects. Currently, there is no information circular available for guidance on software development eligibility for the SR\&ED program on the CRA website.

\subsubsection{Association rules}

Firm13a and $13 \mathrm{~b}$ are in a unique situation in comparison with the other interviewed firms. The two companies were associated due to an entrepreneur investing in both companies. In this case, the investor was active and owned over 50 percent of both firms. Based on ITA $127(10.21)$, the expenditure limit must be allocated among the associated corporations. However, as demonstrated in this case, the association rules may have a detrimental impact on R\&D in Canada. 
It should be noted that the two companies each operate as a separate entity and are in nonrelated industries. Firm13a is a mobile gaming company, whereas Firm13b is a beverage manufacturer. The R\&D was moved offshore for three reasons. Firstly, as an associated company, Firm13a was absorbing most of the R\&D expenditures. Secondly, as the mobile gaming industry matured, the SR\&ED claims came under increasing scrutiny for technical uncertainty. As a result, Firm13a would claim a portion of eligible expenditures that could have been used for Firm13b, only to have portions of the claim reduced. Due to the increased challenges with the SR\&ED claims and the need to hire/downsize depending on projects, the R\&D was sent offshore to Vietnam. Given that the intent of the SR\&ED program is to encourage innovation in Canada, it can be assumed that one of the goals is to promote R\&D employment in Canada. However, the association rules have a negative impact on R\&D employment in Canada.

\subsubsection{SR\&ED program threshold limits}

Firms that were interviewed that were larger in size (over 100 employees) found that the SR\&ED program encouraged CCPCs to remain small. Initially, the threshold limits of taxable income of $\$ 500,000$ was an issue for Firm9 and Firm10. The executive team at both organizations indicated that they knew companies that purposely stayed within the $\$ 500,000$ taxable income to ensure that the company would still be eligible for the reduced rate.

These two companies also felt that the TCEC limit had an impact on investment in Canada. Firms would not want to exceed these limits to ensure that they stayed within the thresholds. 
Firm10 indicated their frustration in not being able to take advantage of the enhanced rate for 2020 due to the continued investment in Canada.

The executives in these firms felt that the SR\&ED program encouraged companies to stay small in Canada. If firms grew and exceeded the TCEC limit, the firms would lose the enhanced rate for no perceived increased benefit. The executives also indicated that they know other firms that sought to be purchased by a foreign investor to be able to expand their R\&D capabilities.

\subsubsection{R\&D practices}

Most of the firms interviewed indicated that the SR\&ED program had an impact on their R\&D processes and priority setting exercises. These changes are consistent with behavioural additionality theory, in which firm's behaviour changes based on receipt of R\&D tax incentives (Clarysse et al., 2009).

Many firms indicated that the SR\&ED requirements for supporting documentation were a catalyst for improving their processes. For example, the CEO of Firm8 states that based on the advice from their NRC ITA, they create very detailed spreadsheets with categories and the time spent. In addition, the lead developer creates an annual report of the R\&D conducted throughout the year. The CEO indicates that this approach, as well as assistance from their SR\&ED consultant, makes the process seamless to apply for the SR\&ED program.

Some firms, such as Firm2, indicated that processes might have an impact on the success of SR\&ED claims. The CEO of Firm2 felt that since Agile methodology focuses on building prototypes after each sprint, CRA may believe that there was little technical uncertainty if firms 
were able to develop prototypes quickly. In addition, Agile methodology may have an impact on documentation requirements for SR\&ED claims. For example, in Agile, scrum meetings often replace formal project meetings (Annosi et al., 2020). Consequently, there may not be the same commitment to taking notes and documenting decisions made within meetings.

The SR\&ED program also has an impact on R\&D priorities. Most firms indicated that due to financial constraints, they prioritized projects that would be applicable for SR\&ED claims. This priority setting behaviour is consistent with neoclassical economic theory in which firms will make R\&D investment decisions based on selecting projects that should reduce their marginal cost of R\&D.

\subsubsection{Reviews and audits of SR\&ED claims}

A common refrain among interviewed firms is the impact of a review and audit of the SR\&ED claim. The key informants highlighted two main issues. Firstly, the audit was highly dependent on the reviewer, and the audit had an impact on future behaviour within the R\&D team.

A number of key informants indicated that they felt that the reviewer made or broke the process. For example, Firm4 indicated that some of the reviewers may have industry experience, but it is often outdated. The reviewers were no longer in touch with the requirements in the industry. Other firms discussed getting in disagreements regarding their development methods or use of programming language. For example, Firm7 was advised that, "you shouldn't be using Microsoft SQL. You should be using JavaScript." 
The impact of a reduced or rejected claim not only had an impact on the following year's R\&D.

Firms, such as Firm5 and Firm7, indicated that it had an impact on their long-term innovation strategy and the consumption of resources to file notices of objection. The CEO of Firm7 states that a rejection of the claim "has a cascading effect in the long term for the company. And then the other resources that we have to allocate to filing objections."

Some firms were able to see a silver lining from a rejection or audit. Firm5 indicated that one of the reasons they encountered difficulties in their claim is the lack of formal documentation. Considerable R\&D design work was completed in developing countries in which they used blackboards. Images of the work had not been captured, which resulted in difficulties in documenting the work. Post-audit, Firm5 indicated they implemented more robust documentation retention practices.

Another frequent discussion in the interviews revolved around the impact a SR\&ED review or audit had on future claims. Firm10 indicated that engineers tended to err on the side of caution and indicate that their development would not meet the technical uncertainty test. The CFO and R\&D management team believed that they were leaving money on the table due to the engineers' reticence. Similarly, due to Firm5's experience of escalating the SR\&ED claim to court, the founders had little appetite to submit another claim.

\subsection{Proposed conceptual model}

This section aims to discuss an updated proposed conceptual model of R\&D engagement and R\&D management practices based on the study's findings. In contrast to the preliminary conceptual model (Figure 2-3), the updated model is a bifurcation of the concepts of the 
decision to engage in R\&D and the management of R\&D practices. The theoretical basis of the preliminary conceptual model included Hofer's (1975) contingency framework. Although the product lifecycle features prominently in Hofer's (1975) framework, this element was not included in the preliminary conceptual model. The proposed conceptual model (Figure 5-6) not only includes the product lifecycle, but it also outlines the elements that the interviewed firms indicated had an impact on their decision to engage in R\&D and their R\&D management practices.

The proposed conceptual model builds upon Figure 5-5. The top part of the model outlines the elements that influence R\&D strategic decisions. The owner and management determine the values and firm strategy. These factors, in conjunction with the product lifecycle, are integral to the decision to engage in $R \& D$ and the R\&D strategy.

From discussions with key informants, R\&D management practices include managing R\&D employees, priority setting, and managing the development process to ensure that it achieves the firm's goals and timelines. R\&D management practices can be considered a tactic to achieve the R\&D strategic decisions that resulted from the ownership and management, values, firm strategy, and product lifecycle. As result, the management practices are primarily a manifestation of the internal context, including the constraining factors. In effect, these factors had an impact on the type of R\&D conducted, the structure of the R\&D department, and how R\&D decisions are made. 
Figure 5-6 Proposed conceptual model on R\&D engagement and management

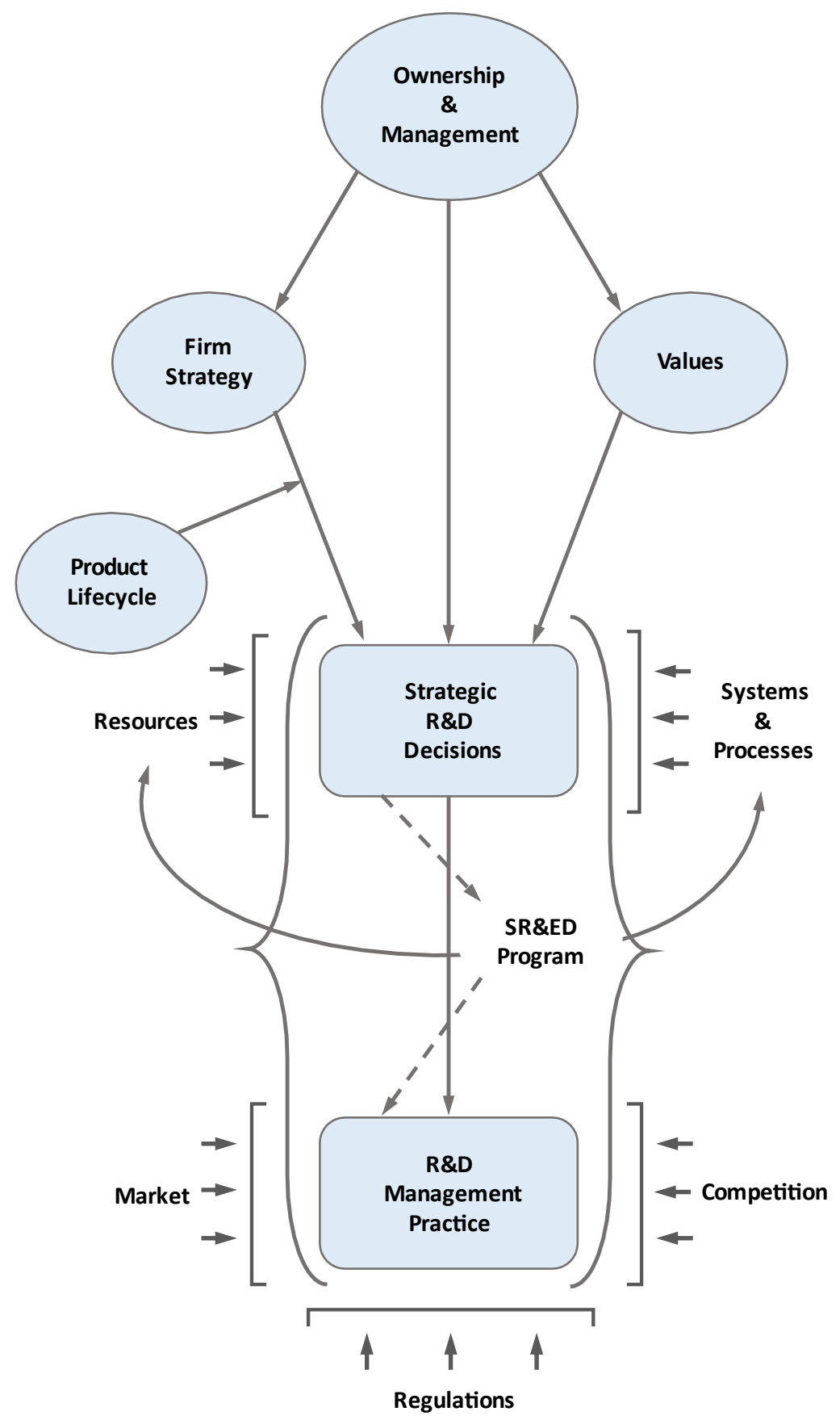


The constraining factors on the decision to engage in R\&D (resources and systems and processes) also had an impact on R\&D management practice. For example, the systems and processes support the R\&D practices of knowledge creation, codification, and dissemination. Without adequate systems, manual processes were required for documenting time worked and the results of project.

In addition to the internal context and constraining factors, this study also found firms engaged in congenital learning, as the external environment influenced R\&D management practice. Specifically, the competition and the market were seen as driving forces. For example, the competition and the market had an impact on R\&D priority setting and the scope of the R\&D projects. In contrast, the regulatory environment was seen as a constraining force. For example, to be able to enter the EU market, firms would need to modify their products to ensure compliance with EU regulations.

In addition to the external factors in Figure 5-6, the SR\&ED program is also included as a factor in influencing a firm's R\&D management practices. Of the interviewed firms, most firms indicated that the SR\&ED program had an impact on their organization. Due to resource constraints, the SR\&ED program influenced a firm's priority-setting exercises. However, the SR\&ED program had a positive impact on requiring firms to improve their knowledge codification processes. In effect, due SR\&ED program requirements, firms utilized their congenital learning capabilities to modify their R\&D practices.

Figure 5-6 also includes a feedback loop between the SR\&ED program and a CCPC's resources and systems and processes. If a CCPC receives a reimbursement, the SR\&ED program has a 
positive impact on the available funds for the subsequent year's R\&D efforts. Some firms, such as Firm7 indicated the SR\&ED program funds assisted in hiring additional R\&D personnel to work on future SR\&ED projects. The SR\&ED program also has an influence on the systems and processes to be used on future SR\&ED projects. To be able to collect data on R\&D projects to submit as a SR\&ED program claim, some firms implemented time sheet and processes to document the development process. For example, Firm 8 indicated that the firm implemented documentation processes such as an annual review report to codify their efforts throughout the year. 


\section{CHAPTER SIX: CONCLUSION}

Chapter six provides an overview of the findings of this thesis, the contributions, the implications, limitations, suggestions for future research directions, and concluding remarks.

\subsection{Overview of the findings}

This thesis sought to better understand how small CCPCs decide to engage in R\&D and how they manage their R\&D practices in the context of the SR\&ED program. Prior research in R\&D tax incentives focuses on R\&D additionality behaviour and crowding-out behaviour. Overall, prior research found that for firms that did receive $R \& D$ tax incentives, the firms engaged in additionality behaviour, in that they increased their R\&D expenditures. However, the previous literature did not examine how firms decided to engage in R\&D and how they managed their R\&D practices. Further, the literature did not examine how firms decide to apply for tax incentives and if these tax incentives had an impact on their R\&D management practices. By obtaining the experiences of CCPCs involved with the SR\&ED program, and analyzing the findings via contingency theory and organizational learning theory lenses, this study addresses the research gap in better understanding the motivation to apply for tax incentives and the impact of these incentives on R\&D management practice for SMEs.

This chapter proceeds by first examining how small CCPCs decide to engage in R\&D, why some CCPCs engage in the SR\&ED program and others do not, and if the SR\&ED program influences the decision to engage in R\&D. Subsequently, a discussion ensues on how small CCPCs manage their R\&D practices, the scope of small CCPCs' R\&D activities, and the R\&D projects, priorities, 
and processes in small CCPCs. Finally, the section evaluates how the SR\&ED program influences the decision to engage in R\&D activities and the management of R\&D activities.

\subsubsection{The decision to engage in $R \& D$}

Based on the interviews with key information in small CCPCs, the decision to engage in R\&D was made by the firm's ownership and management after consideration of the external and internal context. The decision to engage in R\&D is consistent with contingency theory (Hofer, 1975) in that ownership and management evaluated several factors before deciding to engage in R\&D. However, the contingency factors took on roles as a driving, moderating, or constraining force.

From an external context perspective, the competitive and market environments can be considered driving forces to engage in $R \& D$. The regulatory environment can also influence the decision to engage; however, it was not a catalyst to engage in R\&D. As the example of drone technology illustrates, an evolving regulatory environment can also be a constraining factor in engaging in R\&D.

The internal context also had an impact on the decision to engage in R\&D. The ownership and management of small CCPCs influenced both the strategy and the values of the firms. The values and the strategy are driving forces in the decision to engage in R\&D. As the values of the firm influenced the strategy, the two elements were aligned. Depending on the strategy, the decision to engage in R\&D may be based on a product differentiation strategy or a market or product development strategy. 
There were two constraining factors that influenced the decision to engage in R\&D. Firstly, resource constraints had the most significant impact. All firms indicated that resource constraints restricted their R\&D efforts. If the firm did not receive external funding, such as from IRAP, the R\&D was reliant on operating cash flows. Financial constraints had an impact on procuring the necessary equipment and the number and quality of technical employees that could be employed to conduct R\&D. In addition, systems and processes were a constraining factor in the decision to engage in R\&D.

Upon analysis of the sample CCPCs and the stages of their product lifecycles, it was also found that the stage of product lifecycle influenced firm strategy and the decision to engage in R\&D. Consistent with Hofer (1975), the decision to engage and the type of R\&D differed depending on if the firm was in the introduction, growth, maturity, saturation, or decline product lifecycle stage.

Based on the interviews, firms that engage in $R \& D$ are more likely to have an internal context with entrepreneurial values and a strategic orientation to develop new products and services or improve existing products and services. These values and strategic orientation are consistent with firm characteristics outlined by Christensen (1997) and Laforet \& Tann (2006). It should be noted that the strategic orientation is influenced by the product lifecycle, the competitive environment, and the market. For example, a highly competitive market may signal that the product lifecycle is at the saturation stage, and the customers have considerable power. Firms facing these conditions may be driven to engage in R\&D to develop a major adaption to their existing products or services. Christensen 
(1997) and Laforet \& Tann (2006) also indicated that innovative firms required supporting systems, processes, and resources to support their innovative aspirations. Due to resource constraints, having adequate systems and resources was a challenge for many small CCPCs. Consequently, a number of these firms relied on SR\&ED tax incentives to defray the cost of R\&D.

The decision to engage in the SR\&ED program differed from the decision to engage in R\&D. The decision to engage in the SR\&ED program was driven by resource constraints. The primary reasons to no longer engage in the SR\&ED program were due to previous experience of a SR\&ED application (e.g., Firm5 \& Firm17) and concerns about meeting the technical threshold (e.g., Firm4) for SR\&ED eligibility. Firms that no longer met the CCPC requirements also did not feel compelled to engage in the SR\&ED program due to the time and effort required to complete the T661 form for a perceived reduced benefit. From an organizational learning perspective, these behaviours are consistent with experiential learning. In effect, firms modified their behaviour based on negative experiences with the SR\&ED program.

\subsubsection{R\&D management}

The study found that R\&D management practices are influenced by both the internal environment and the external environment. Specifically, R\&D management practices reflect a firm's internal characteristics, but the external context also influences these practices.

$R \& D$ management practice includes the management of R\&D employees and R\&D practices. R\&D practices include knowledge creation, codification, and dissemination (Leonard-Barton, 
1992). These practices are a result of the R\&D department structure, values of the firm, and the supporting systems and processes. These findings are consistent with Leonard-Barton's (1992) core capability framework, in which the managerial and technical systems comprise the firm structure, systems, and processes. At the centre of the framework lies the values of a firm.

The values of the firm determined how knowledge was accumulated. Firms with values reflecting human resources and learning had managerial systems that included training to build capabilities. Development processes, such as Agile methodology, allowed for the flexibility and ability to learn from others through scrum meetings and interactions with the team.

Consequently, Agile methodologies seem to support learning-by-doing (Rosenberg, 1982) and experiential learning.

The structure of the department also had an impact on systems and processes. If the R\&D team was part of operations, the systems to track tasks associated with R\&D or SR\&ED-eligible activities needed to be in place. Due to financial constraints, most firms had simple technical systems, such as Excel, or online systems such as Jira. Without adequate supportive systems, several processes were manual. For example, timesheets frequently needed to be manually entered by the employees and compiled manually by the R\&D manager or finance group. In addition, without more robust or integrative systems, costing and data analysis were more difficult and time-consuming.

Consistent with Winn \& Roome's (1993) model of R\&D management practice, the external context, specifically, economic (market and financial resources) and political (regulatory), had an impact on the scope of small CCPCs' R\&D activities. Most of the CCPCs were in frequent 
contact with their customers. Consequently, the customers would frequently request modifications to the existing products or services. This pressure on the scope was more acute if there was one dominant customer. The firms that did not have direct contact with their endusers engaged in congenital learning by monitoring the market for trends. From an economic perspective, due to financial constraints, small CCPCs are limited in the scope and number of projects that they can conduct at one time. As well, some firms were not able to engage additional or appropriate talent for R\&D projects.

In addition to economic forces, regulations would often modify the scope of the projects. For example, a number of firms had to ensure that their products complied with privacy regulations or environmental regulations.

Similar to scanning the market for trends, consistent with Cohen \& Levinthal's (1990) absorptive capacity (i.e., congenital learning), some firms would scan the competitive environment for new opportunities. Consequently, the scope of R\&D would reflect the new information that was acquired and included in their scope of R\&D activities.

Given the pressures on increasing the scope and number of projects, firms were required to set priorities to determine which projects are undertaken. The priority-setting exercise was dependent on firm structure. If there was a dedicated R\&D department, the projects were ranked by level of importance. In contrast, if R\&D were embedded within operations, resources would need to be allocated against R\&D projects and operations. Many of the firms used a product or technology roadmap as a tactic to ensure that their firm strategy and values were reflected in their priorities. Despite these tactics, the CCPCs indicated that the elements 
that applied pressure on the scope also had an impact on the priority setting. In addition, due to financial constraints, and consistent with Clarysse et al.'s (2009) discussion of R\&D behavioural additionality, the SR\&ED program influenced project selection.

\subsubsection{The influence of the SR\&ED program}

The decision to engage in R\&D activities was not directly affected by the SR\&ED program. The decision to engage in R\&D was primarily due to a firm's internal and external context, including resource constraints. However, a firm's resource constraints were responsible for the decision to engage in the SR\&ED program. Consequently, the SR\&ED program had an impact on the reliance on external parties, R\&D firm strategy, and R\&D practices. Finally, the impact of a SR\&ED audit or review seems to have persistent repercussions within a firm.

As the T661 form requires a combination of financial data and project description, the SR\&ED program highlights intra-firm language barriers to comply with the CRA's expected language. Given this language barrier, most firms utilized an external SR\&ED consultant to assist with the SR\&ED application or obtain advice on whether their R\&D projects met the technical

uncertainty threshold. Given the fees associated with engaging an external SR\&ED consultant, the need to obtain assistance at an additional cost applies additional financial pressures for firms. Consequently, if the eligible R\&D expenditures are not significant, firms often choose to forego applying for the SR\&ED program.

The specific threshold and the association rules also had an impact on firm strategy. Consistent with Clarysse et al. (2009), the program's structure seems to modify firm's behaviour to take 
advantage of the tax incentives. In order to be eligible for the enhanced rate, firms are incented to remain under this threshold rather than grow. The intent of the program appears to be to incent small CCPCs to engage in R\&D activities. However, the decision to engage in R\&D seems to be separate from the decision to engage in the SR\&ED program. As a result, the threshold limits may be encouraging CCPCs to remain small.

The association rules also seem to have an unintended consequence. A number of the CEOs interviewed indicated that they were serial entrepreneurs in that they have founded more than one company. In one instance, partly due to the association rules and the requirement to share the expenditure limit, one of the firms decided to outsource the R\&D outside of Canada. Once again, the spirit of the program is to encourage innovation in Canada; however, the association rules seem to have the opposite effect.

Consistent with inter-organizational learning, R\&D management practices also were influenced by the SR\&ED program. Firstly, on a positive note, the requirements of the program require diligent knowledge codification. Firms are required to keep documentation on the identification of the problem, the design, the hypothesis, and the results. In order to ensure there was sufficient supporting documentation, CCPCs implemented more rigorous systems and processes to capture and collect data.

In addition to documentation retention, the SR\&ED program had an impact on the priority setting exercises of a firm. Due to resource constraints, R\&D projects that were deemed to be SR\&ED-eligible activities were given higher priority than projects that may not meet the technical uncertainty threshold. Consequently, firms may undertake riskier projects to meet 
the technical uncertainty threshold. Alternatively, projects that align with the firm's strategy, the market trends, or competitive pressures may not be selected in favour of SR\&ED-eligible projects.

Finally, given the small sample size, the number of firms that had undergone a review or audit was surprising. In some cases, the audit was for expenditures less than $\$ 10,000$. Most firms found the experience to be adversarial. As a result, some firms chose not to apply for the SR\&ED program for future projects. More commonly, the firm felt that the R\&D team were conservative in their estimates of SR\&ED-eligible expenditures to avoid another audit or review.

\subsection{Contributions}

This section discusses the contributions of this thesis to theory, practice, and policy. This study contributes through both the methodology and the insights obtained from the analysis. Specifically, this study provides insights on how small CCPCs engage in R\&D, how they manage their R\&D activities, and the impact of the SR\&ED program on firm behaviour.

Firstly, the methodology employed by the thesis contributes to the extant literature in R\&D tax incentives. This thesis contributes to the literature by employing an exploratory research lens to understand SME'S R\&D behaviour in the context of the SR\&ED program. By utilizing a qualitative research approach with semi-structured interviews, the study provided a voice to small CCPCs and captured their experience with both R\&D and the SR\&ED program. Further, since the extant literature often used public data for analysis, SMEs were often not included as a unit of analysis. The contribution of this thesis is rooted in the generation of insights based on the unique firm-level interview data of small CCPCs. 
In addition to the methodology, the previous literature on R\&D tax incentives does not evaluate the decision-making process and management of R\&D as separate concepts. The R\&D tax incentive literature evaluated whether there was additionality or crowding-out, based on empirical data obtained from governmental sources or surveys. In effect, the analysis was limited to measuring firms' behaviour or performance once they received the R\&D tax incentives. There has been comparatively little analysis evaluating the influence of firm characteristics and the external environment on how firms engage in R\&D tax incentive programs and how they manage their R\&D practices. By approaching the decision to engage in $R \& D$ and the management of $R \& D$ as an interconnected system, this thesis broadens our understanding of the influence of R\&D tax incentives on the R\&D behaviour of CCPCs.

By using a qualitative approach, and considering the R\&D engagement decision and management as separate concepts, this study generated a number of insights. Firstly, from the interview data, systems, and processes were seen as a constraining factor, as SMEs could not easily access the data to make R\&D strategic decisions. From an R\&D management practice perspective, the market and competition were deemed drivers of R\&D management practice, and the regulatory environment was a constraining factor. Finally, the SR\&ED program had an impact on R\&D management practice and R\&D behaviour within a firm.

Based on the insights garnered from the study, the proposed conceptual framework (Figure 56) contributes to the existing literature on SME'S R\&D behaviour, as it integrates numerous dimensions internal and external to SMEs. Within the proposed conceptual framework, the internal factors are integral in deciding to engage in R\&D. Ownership and management both 
influenced the strategy and the values of a firm. In turn, due to a SME's centralized decision making, the firm's ownership and management, along with their values, influenced the R\&D strategic decisions. In addition, the firm's strategy and the firm's stage in the product lifecycle influenced the decision to engage in R\&D, and the type of R\&D conducted.

Consequently, this study's proposed conceptual framework contributes to theory by extending Hofer's (1975) contingency theory, in which a firm's internal characteristics, external environment, and product lifecycle have an impact on the choice of strategy. Hofer's (1975) 54 factors did not include a firm's values or learning capabilities. Although the external environment influences the decision to engage in R\&D, how a firm reacts to the external environment and the product lifecycle depends on a firm's ownership and management. Effectively, the firm's ownership and management determine the strategy and the values that influence the R\&D strategic decisions. In turn, the values of the firm have an impact on the learning capabilities within a firm.

This study's proposed conceptual framework also considered the decision to engage in the SR\&ED program. In contrast to the decision to engage in $R \& D$, the decision to engage in the SR\&ED program was based on resource constraints. Although this element of the framework is consistent with neoclassical economic theory used in the extant literature, in which firms seek to reduce the marginal cost of R\&D expenditures, inter-firm learning is engaged via a feedback loop between the receipt or rejection of SR\&ED program funding and a firm's future R\&D and its systems and processes. It should be noted that the R\&D input additionality effects are reflected in the following year's R\&D efforts. As R\&D expenditures for small CCPCs needed to 
be incurred prior to filing a SR\&ED program claim, most R\&D was funded through internal cash flow. As a result, firms generally increase their R\&D activity in the following year after receiving the SR\&ED program reimbursement. Similarly, a review or audit often resulted in firms reducing their future SR\&ED program claims, discontinuing applications for the SR\&ED program, or improving their existing systems and processes to document their R\&D efforts. As a result, this study contributes to the research of Clarysse et al. (2009) by highlighting the lagged effects of R\&D tax incentives and extending the scope of behavioural additionality within a firm due to R\&D tax incentives.

Further extension of behaviourial additionality due to $R \& D$ tax incentives are derived from the insights obtained on the unintended consequences of the SR\&ED program. Firstly, the program thresholds for the enhanced rate and refundability of unused tax credits appeared to incent firms to remain small. Secondly, the program's association rules contribute to R\&D behavioural additionality in SMEs, as serial entrepreneurs balance the R\&D expenditures among their associated companies to ensure that they remain within the R\&D expenditure threshold. As Firm13a illustrates, the association rules may incent firms to outsource R\&D development offshore.

Finally, this study contributes to the R\&D tax incentive literature by underscoring the intraorganizational and inter-firm language barriers that can occur when submitting and defending $R \& D$ tax incentive claims. There is little discussion on the challenges of meeting the R\&D tax incentive program requirements. Nor does the literature delve into the intra-firm language barriers between the accounting department and R\&D management. These challenges may 
shed some light on the scope of $R \& D$ projects and the R\&D intensity of firms that apply for R\&D tax incentives.

In management practice, a firm's strategic decisions influence the implementation of R\&D decisions. The strategic decisions are influenced by both firm characteristics and a firm's external context. By understanding the firm's operating context and its influence on R\&D management practices, this thesis provides insights to firms that wish to engage in R\&D and the SR\&ED program.

As a result, this study contributes to practice by providing factors that firms should consider before engaging in R\&D. Firstly, firms should evaluate their external environment and stage of their product lifecycle. Most of the firms interviewed had completed a scan of the external environment; however, there seemed to be little evaluation of the product lifecycle. From an internal perspective, financial resources, systems, and processes were deemed constraining factors and should be considered before engaging in R\&D.

In addition, this study contributes to practice by highlighting challenges that SMEs may encounter if they apply for the SR\&ED program. This thesis highlighted a potential language barrier, issues with technical uncertainty, and systems and processes that may have an impact on a SR\&ED claim. Both the language barrier and the technical uncertainty criteria were reasons identified for employing a SR\&ED consultant. SR\&ED consultants can be costly, especially for firms that are ramping up their R\&D efforts. 
Although the decision to engage in the SR\&ED program was driven by financial constraints, the systems and processes have an impact on the success of a SR\&ED program claim. Without adequate systems and processes in place, there are additional challenges in gathering and retaining data and making informed decisions. Consequently, small CCPCs should consider the adequacy of their systems and processes before deciding to engage in the SR\&ED program.

From a policy perspective, as illustrated by the evolution of Canadian government R\&D tax incentives, the program has maintained enhanced rates and expanded the definition of a small CCPC. It can be assumed that, due to the differentiation between ITC rates and refundability, the Canadian government would like to encourage R\&D activities in small CCPCs. However, this study found that the TCEC threshold incentivizes some firms to stay small. Similarly, the association rules resulted in a change of R\&D strategy from domestic intramural R\&D to international extramural R\&D. Based on this finding, a review should be conducted of the impact of the TCEC threshold limits and the association rules. For example, it is unclear why the TCEC is limited to $\$ 10$ million, and the SR\&ED expenditure limit for the enhanced rate is $\$ 3$ million.

In comparison to NRC ITAs, the key informants indicated that the SR\&ED reviewers were not considered helpful, as they did not provide any guidance to the taxpayers to assist in their claim. A program review should be considered to determine if that perceived bias is accurate and if the current definitions accurately reflect $R \& D$ efforts within the information technology industry. For example, the CRA information circular regarding software development guidelines for the SR\&ED program is no longer available on the CRA website. By updating the document, 
small CCPCs in the software development sector may be better able to ascertain whether their R\&D meets the technical uncertainty threshold without employing SR\&ED consultants. Similarly, CRA publishes the Financial Claim Review Manual - Review Procedures for Financial Reviewers (Canada Revenue Agency, 2012) that outlines CRA's guiding principles such as respect, cooperation, and professionalism in respect to the SR\&ED program; however, given the evolution of the program since 2012, further updates may be warranted.

\subsection{Implications}

This study has a number of research, management practice, and public policy implications.

Table 6-1 provides a summary of the implications of this study. From a research perspective, the insights obtained from the firm-level data can assist in research in the R\&D decision-making process for SMEs and the impact of R\&D tax incentives on SME R\&D behaviour. The insights gained on the factors that influence the R\&D decision-making process and the challenges associated with obtaining SR\&ED program funding can assist SMEs' management practice. Finally, at a policy level, the data obtained from the interviews can assist policymakers in making improvements to the SR\&ED program.

Firstly, insight into the factors associated with the R\&D decision making in SMEs can extend the use of Hofer's (1975) contingency model for R\&D research. By using the proposed conceptual model, researchers can test the impact of values and learning capabilities, specifically in SMEs, on the decision to engage in R\&D. 
Table 6-1 Summary of the study's implications on research, practice, and policy

\begin{tabular}{|c|c|c|c|}
\hline \multirow{2}{*}{ Insights } & \multicolumn{3}{|c|}{ Implications } \\
\hline & Research & Practice & Policy \\
\hline $\begin{array}{l}\text { Factors associated } \\
\text { with R\&D decision- } \\
\text { making in SMEs }\end{array}$ & $\begin{array}{l}\text { Operationalize } \\
\text { Hofer's (1975) } \\
\text { contingency theory }\end{array}$ & $\begin{array}{l}\text { Utilize tools to } \\
\text { understand the internal } \\
\text { and external context }\end{array}$ & $\begin{array}{l}\text { Consider the } \\
\text { internal and } \\
\text { external factors } \\
\text { influencing the } \\
\text { R\&D decision- } \\
\text { making in SMEs }\end{array}$ \\
\hline Constraining factors & $\begin{array}{l}\text { Test the impact of } \\
\text { systems and } \\
\text { processes on the } \\
\text { decision to engage in } \\
\text { R\&D }\end{array}$ & $\begin{array}{c}\text { Evaluate the efficacy of } \\
\text { the systems and } \\
\text { processes before } \\
\text { engaging in R\&D }\end{array}$ & $\begin{array}{l}\text { Consider } \\
\text { implementing } \\
\text { program to assist } \\
\text { firms to upgrade } \\
\text { their systems }\end{array}$ \\
\hline $\begin{array}{l}\text { Lack of clarity of } \\
\text { technical uncertainty } \\
\text { \& language barrier }\end{array}$ & $\begin{array}{l}\text { Test understanding } \\
\text { of technical } \\
\text { uncertainty of R\&D } \\
\text { management team } \\
\text { \& impact of } \\
\text { socialization }\end{array}$ & $\begin{array}{c}\text { Consider engaging } \\
\text { external assistance or } \\
\text { utilizing CRA } \\
\text { information sessions } \\
\text { and pre-determination } \\
\text { services }\end{array}$ & $\begin{array}{c}\text { Creating increased } \\
\text { outreach to assist } \\
\text { small CCPCs }\end{array}$ \\
\hline $\begin{array}{l}\text { R\&D tax incentives } \\
\text { influence on SME } \\
\text { R\&D management } \\
\text { practices }\end{array}$ & $\begin{array}{l}\text { Build upon measures } \\
\text { established by } \\
\text { Clarysse et al. (2009) } \\
\text { for behavioural } \\
\text { additionality and } \\
\text { R\&D tax incentives }\end{array}$ & $\begin{array}{c}\text { Be mindful of impact of } \\
\text { using online } \\
\text { development tools } \\
\text { when applying for the } \\
\text { SR\&ED program. }\end{array}$ & $\begin{array}{l}\text { Evaluate policy to } \\
\text { ensure that it is } \\
\text { meeting the } \\
\text { objectives of } \\
\text { increasing } \\
\text { innovation }\end{array}$ \\
\hline $\begin{array}{c}\text { Unintended } \\
\text { consequences of the } \\
\text { SR\&ED program }\end{array}$ & $\begin{array}{c}\text { Test if the thresholds } \\
\text { have an impact on } \\
\text { the growth of the } \\
\text { company \& if } \\
\text { association rules } \\
\text { reduce intramural } \\
\text { R\&D }\end{array}$ & $\begin{array}{l}\text { Understand the impact } \\
\text { ownership of multiple } \\
\text { firms may have on } \\
\text { SR\&ED program claims. }\end{array}$ & $\begin{array}{l}\text { Review the } \\
\text { association rules } \\
\text { and TCEC } \\
\text { thresholds to } \\
\text { ensure that they } \\
\text { remain relevant }\end{array}$ \\
\hline $\begin{array}{l}\text { Impact of an audit or } \\
\text { review on a firm }\end{array}$ & $\begin{array}{l}\text { Test if post-audit or } \\
\text { review behaviour } \\
\text { results in reduced } \\
\text { SR\&ED program } \\
\text { claims }\end{array}$ & $\begin{array}{c}\text { Consider the impact of } \\
\text { an audit or review on } \\
\text { personnel }\end{array}$ & $\begin{array}{l}\text { Review role of } \\
\text { auditor/reviewer } \\
\text { and consider a } \\
\text { streamlined } \\
\text { process for smaller } \\
\text { CCPCs }\end{array}$ \\
\hline
\end{tabular}

From a management practice perspective, a better understanding of the factors associated with engaging in R\&D may assist firms to make better strategic R\&D decisions. Tools, such as a 
Strength, Weaknesses, Opportunities, and Threats (SWOT) analysis, may assist firms to better understand their stage of the product lifecycle, the regulatory environment, the market conditions, and their competition. Further, an analysis of their internal capabilities through tools, such as a knowledge matrix, may assist in determining if they have appropriate conditions in place or if they need to make modifications.

From a policy perspective, a better understanding of the factors that influence a CCPC's decision to engage in R\&D can assist in the development of any updates to the SR\&ED program. For example, firms in the introduction phase will focus their R\&D strategy on improving their existing product and services. In contrast, firms with products in the saturation stage will make $R \& D$ decisions to create a new product or service.

The constraining factors of resources, systems, and processes on the decision to engage in R\&D have implications at a research, practice, and policy level. Utilizing contingency theory, future researchers can test the impact of systems and processes on a SME's decision to engage in R\&D. Given the asymmetry of information available to SMEs to make an informed decision in comparison to larger firms, the impact of systems and resources may be more acute for SMEs.

With a better understanding of the constraining factors, before firms engage in the SR\&ED program, firms should also evaluate their R\&D systems and processes. Due to the documentation requirements for the SR\&ED program, firms should ensure that they document their hypotheses, the development process, and the results of testing. Firms that use informal processes, such as Agile methodology, should consider implementing documentation procedures as part of their operational routines. 
From a policy perspective, this study found that systems and processes were a constraining factor to engage in R\&D. Although capital expenditure deductions and ITCs are no longer part of the program, some consideration should be made to assist firms in implementing systems that can streamline knowledge accumulation, codification, and dissemination. In addition to assistance in implementing systems to support the decision-making and R\&D processes, a number of key informants indicated that CRA should provide templates for taxpayers. For example, a timesheet template and project description templates would be helpful for smaller CCPCs.

The findings of technical uncertainty and the resulting inter- and intra-organizational language barriers have several implications for research. Researchers can test R\&D management on their understanding of what standard meets technical uncertainty and SR\&ED eligible activities. These tests may provide insight into the specific challenges that firms encounter when differentiating between R\&D and SR\&ED-eligible activities. Further research can be conducted on the impact of socialization of both the R\&D and accounting departments to determine the impact on the scope of R\&D tax incentive claims.

Given that firms that decide to engage in the SR\&ED program may encounter challenges with inter- and intra-organizational language barriers and technical uncertainty, small CCPCs may be compelled to engage a SR\&ED consultant to assist the SR\&ED program claim. In order to better understand the language of the SR\&ED program and the concept of technical uncertainty, CRA does hold information sessions to assist claimants. These information sessions are free and may assist SMEs to better understand the requirements of the SR\&ED program. The CRA website 
also includes a SR\&ED Self-Assessment and Learning Tool, designed to assist firms in learning about the program requirements (Canada Revenue Agency, 2016).

From a policy perspective, there is an opportunity for CRA to reach out to small CCPCs to advise them of these services and provide a consultative role similar to NRC ITAs. While there is a guide to assist in completing the T661 form, completing the form resulted in the reliance on external consultants for assistance. Several key informants indicated that CRA should improve their pre-claim support services. For example, some key informants recommended that CCPCs could opt to send in progress reports, similar to those sent to the IRAP program. With these interim reports, CRA can review the reports and provide feedback on whether the R\&D meets the technical uncertainty criteria or whether firms need to provide additional information for CRA to make a ruling.

The influence of R\&D tax incentives on SME R\&D management practices can be further evaluated using the conceptual model. Expanding upon Clarysse et al.'s (2009) study, a researcher can apply absorptive capacity in addition to organization learning theories to evaluate $R \& D$ additionality behaviour as a consequence of engaging in $R \& D$ tax incentive programs. Specifically, R\&D tax incentives influence SME behaviour by the type of R\&D conducted, the prioritization of R\&D projects, and R\&D knowledge codification processes.

The findings of R\&D tax incentive influence on R\&D management practices also have implications in practice and policy. In practice, current R\&D development methodologies and systems may have a negative impact on future SR\&ED claims. Firms should be cognizant that using online tools may make a review or audit challenging. The SR\&ED program's influence on 
knowledge codification practices should be considered in a policy review of the SR\&ED program. Given the changes in R\&D development, consideration by CRA should be given to other documentation practices using online tools like Microsoft Teams and development practices such as Agile. Discussion of technological challenges and hypotheses may no longer occur in formal meetings and may be conducted primarily online.

Similar to the findings of R\&D tax incentives' impact on R\&D management practice, the insight gained regarding the unintended consequences of the SR\&ED program can extend the R\&D behavioural additionality literature. Additional measures to assess the impact of differing rates and thresholds due to the size of firms and rules of association can assist in better understanding the impact of $R \& D$ incentives on $R \& D$ intensity within firms.

In practice, serial entrepreneurs should understand the impact of controlling ownership of multiple firms. By having controlling ownership of more than one innovative company, the associated companies will be required to share the R\&D expenditure limit. Given the intent of the program is to encourage innovation, a review by CRA of the association rules and TCEC thresholds in this context to ensure that they are relevant would be warranted.

In terms of the impact of audit on R\&D behaviour in firms, there is an opportunity to test postaudit input or output additionality behaviour. For example, if an audit results in a reduced claim, is the increase in additionality behaviour commensurate with a similar size claim that had not undergone an audit? In other words, does the assumption of increased input and output additionality behaviour upon receipt of an R\&D tax incentive only apply if the claim does not undergo rigorous review? 
From a practice perspective, firms should consider the impact of an audit or review on personnel. From the interview data, R\&D management became more conservative in their assignment of R\&D activities as SR\&ED-eligible activities following an audit or review. Other firms decided to cease applying for the SR\&ED program due to the adversarial process. Engaging external parties, such as a SR\&ED consultant, to assist with the audit may mitigate the impact on a firm.

Given the number of audits, reviews, and appeals to notices of objection within this small sample, further consideration by CRA should be given to the process. Some key informant's suggestions were a review of a CCPCS R\&D program to ensure that it meets the criteria and provides a rapid approval process for firms that choose to undergo the review. Others suggested setting up a grace period and threshold limit for automatic approval. For example, for firms that are less than three years old with R\&D expenditures less than $\$ 10,000$, automatic approval would be granted with proof of R\&D expenditures. Alternatively, a bifurcation of the role of a SR\&ED reviewer should be considered. The audit role is still necessary to ensure fairness in the implementation of the program; however, an additional role within CRA could be created for SR\&ED consultation purposes.

\subsection{Limitations}

Although this study comprised a cross-section of SMEs to better understand why small CCPCS engage in the SR\&ED program and how they manage their SR\&ED practices, there are some limitations in the research. Consequently, these limitations should be taken into consideration when interpreting the findings. 
Firstly, there are limitations due to the sample. Most of the interviewed SMEs were from two provinces. Firms from provinces not represented in the sample may provide more robust findings. For example, firms from two provinces perceived that the SR\&ED reviewers in their region were more restrictive than those in other regions. In addition, the sample had a high concentration of technology-related companies - either as a product or as professional services. Firms from biotechnology, pharmaceutical, and resource industries such as mining or oil and gas exploration may also bring additional nuances to the challenges of small CCPCs.

Another limitation is the lack of clarity from some key informants regarding their R\&D practices. The lack of clarity was particularly acute when the discussions were with key informants from the accounting and finance groups. These individuals could only provide high-level information regarding the systems and processes used in the R\&D department. For example, Firm12 could not indicate the development methodology used by the R\&D group. However, the crosssection of key informants allowed the researcher to uncover issues such as the language barrier.

From a methodological perspective, the key informants' biases and perceptions may have influenced the responses in their semi-structured interviews. For example, when asked about strategy, most indicated that they had a strategy. However, a number of the key informants referenced their product or technology roadmap as their strategy, rather than their tactic. In order to mitigate this issue, the researcher reviewed each firm's website and news releases to obtain further information on their strategy, values, and management structure. 


\subsection{Future research}

While the research provided insight on why small CCPCs engage in R\&D and how they manage their R\&D activities in the context of the SR\&ED program, further research can evaluate the relative impact of each factor on decisions. For example, do values have a greater impact than the available resources within a firm on the decision to engage in R\&D?

This study focused on the federal R\&D tax incentive program. Many Canadian provinces offer R\&D tax incentives that differ from the federal program (Crisan \& McKenzie, 2017). Future research can review the impact of the provincial tax incentives for R\&D in SMEs. For example, do differences in programs among provinces result in a firm choosing to establish itself in more favourable jurisdictions?

The program criteria, technical uncertainty, and enhanced rate thresholds were recurring themes throughout the study. Further research would be warranted on the differing definitions of $R \& D$, the different program criteria, and regulations among different countries. It would be of interest of whether Canada's program is an outlier, and as a result, whether the impact of these elements on R\&D behaviour would be specific to Canada.

The study also found there was a more favourable impression of the IRAP program than the SR\&ED program. Future research can compare the factors with the decision to engage in IRAP with the SR\&ED program, its influence on R\&D management practice, and its R\&D outcomes. Similarly, future research can evaluate government policy for R\&D intervention's impact on the decision to engage in $R \& D$ and its influence on R\&D management. In this study, two of the 
companies were acquired by a foreign entity. Future research can evaluate the impact of foreign direct investment regulations and the loss of CCPC status on R\&D activities in SMEs.

Given the prominent role of SR\&ED consultants as part of the SR\&ED program claim process, further research should be considered to delve into the SR\&ED program ecosystem, the role of SR\&ED consultants, and their advice provided to taxpayers. Other participants in the ecosystem, such as SR\&ED reviewers, could also be interviewed to better understand their perceived role in the SR\&ED ecosystem and any improvements to the program they may suggest.

In the extant $R \& D$ research, public data is often gleaned to evaluate the efficacy of R\&D tax incentives. Researchers are able to measure the differences in R\&D expenditures ex-ante and ex-post receipt of the tax incentives. Public firms are often compelled to report their R\&D expenditures and their treatment of government grants. However, CCPCs' financial information is not readily available, and their financial statements may not delineate R\&D expenditures. Future research that includes an examination of SME financial statements may be able to shed light on the impact of R\&D tax incentives and the treatment of these incentives in their financial statements.

Another potential area for future research is the impact the association rules had on reducing intramural R\&D in Canada. One can assume that association rules are in place as an antiavoidance measure. Further research would be warranted to determine if the practice of sharing the SR\&ED expenditure among companies in unrelated industries is commonplace. 
Given the small sample of firms included in this research, the number of notices of objection and lawsuits filed seems disproportionately high. Further research is suggested in the area of reviews, audits, and rejections of SR\&ED claims. Not only does there seem to be a significant number of these instances within this sample, but there also appears to be a persistent negative impact on future SR\&ED claims.

Given the language barrier between firms and CRA and the perceived adversarial role that CRA SR\&ED reviewers take, further research can include semi-structured interviews of CRA SR\&ED personnel about their role. It would be interesting to determine if the directives from management differ from the stated objectives of the program. Alternatively, whether the socialization or professional background of the SR\&ED reviewers is a factor in their conduct in reviews and audits.

A number of firms, such as Firm7, discussed the ease of recruitment for SR\&ED eligible projects due to their proximity to universities. Other key informants spoke of collaborative efforts with research departments from universities in their area as part of their SR\&ED-eligible activities. For example, Firm9 discussed the collaboration with a university regarding enhancements in advanced manufacturing. Further research into the impact of SR\&ED program claims due to the proximity and collaboration of universities and research centres should be considered.

\subsection{Concluding remarks}

As the SR\&ED program is one of the most extensive government programs to assist businesses, it is important to understand why firms choose to engage in the SR\&ED program. The extant research had concentrated on the efficacy of R\&D tax incentives on R\&D input and output 
additionality behaviour. However, little research was conducted on the motivation to conduct R\&D and to apply for these tax incentives. In addition, the structure of these programs may have an impact on the R\&D behaviour of firms.

By using firm-level data, a number of insights were garnered from the interviews. Firms that engage in R\&D are more likely to have an internal context with values and a strategic orientation to develop new products and services or improve existing products and services. The type and scope of the R\&D activities are influenced by the external context, product lifecycle, and resource constraints.

In contrast to the decision to engage in R\&D, the decision to engage in the SR\&ED program is based solely on resource constraints. However, the SR\&ED program does influence the R\&D management practices of firms. Knowledge codification practices tend to be enhanced due to the SR\&ED program requirements; however, firms are more likely to modify their scope and priority setting exercises to ensure that R\&D projects selected will meet the SR\&ED program criteria.

Some unintended consequences of the SR\&ED program also emerged from the study. Firstly, the program's complexity highlighted the intra-firm language barriers that often necessitated using a third party to assist with the application. Secondly, the review and audit process had persistent adverse outcomes on the firm's R\&D activities. Finally, the threshold and association rules of the SR\&ED program resulted in firms outsourcing their R\&D or curtailing their growth plans. To mitigate the negative outcomes of the SR\&ED program rules, this thesis offers practical policy suggestions that should be considered. 


\section{REFERENCES}

Acs, Z. J., \& Audretsch, D. B. (1990). Innovation and Small Firms. Cambridge: MIT press.

Acs, Z. J., Audretsch, D. B., \& Feldman, M. P. (1994). R\&D Spillovers and Innovative Activity. Managerial and Decision Economics, 15(2), 131-138.

Annosi, M.C., Foss, N. \& Martini, A. (2020). When Agile Harms Learning and Innovation: (And What Can be Done About It). California Management Review, 63(1), 61-80.

Annosi, M.C., Martini, A., Brunetta, F., \& Marchegiani, L. (2020). Learning in Agile Setting: A Multilevel Research Study on the Evolution of Organizational Routines. Journal of Business Research, 110 (March), 554-566.

Agrawal, A., Rosell, C., \& Simcoe, T. (2014). Do Tax Credits Affect R\&D Expendtures by Small Firms? Evidence form Canada. National Bureau of Economic Research Working Paper Series, 20615(2014), 1-45.

Agrawal, A., Rosell, C., \& Simcoe, T. (2020). Tax Credits and Small Firm R\&D Spending. American Economic Journal: Economic Policy, 12(2), 1-21.

Arora, A., Belenzon, S., \& Sheer, L. (2017). Back to Basics: Why do Firms Invest in Research? National Bureau of Economic Research Working Paper Series, No.23187(2017), 1-24.

Aragón-Sánchez, A., \& Sánchez-Marín, G. (2005). Strategic Orientation, Management Characteristics, and Performance: A Study of Spanish SMEs. Journal of Small Business Management, 43(3), 287-308.

Association of International Professional Accountants. (2017). Tax Policy Concept 1: Guiding Principles of Good Tax Policy: A Framework for Evaluating Tax Proposals. Retrieved from: https://www.aicpa.org/advocacy/tax/downloadabledocuments/tax-policy-conceptstatement-no-1-global.pdf

Audretsch, D., \& Feldman, M. P. (1996a). R\&D Spillovers and the Geography of Innovation and Production. The American Economic Review, 86(3), 630-640.

Audretsch, D., \& Feldman, M. P. (1996b). Company-Scientist Locational Links: The Case of Biotechnology. The American Economic Review, 86(3), 641-652.

Autio, E., Kanninen, S., \& Gustafsson, R. (2008). First- and Second-Order Additionality and Learning Outcomes in Collaborative R\&D Programs. Research Policy, 37(1), 59-76.

Baghana, R., \& Mohnen, P. (2009). Effectiveness of R\&D Tax Incentives in Small and Large Enterprises in Québec. Small Business Economics, 33(1), 91-107.

Benbasat, I., Goldstein, D., \& Mead, M. (1987). The Case Research Strategy in Studies of Information Systems. MIS Quarterly, 11 (September), 369-386. 
Berger, P. G. (1993). Explicit and Implicit Tax Effects of the R\&D Tax Credit. Journal of Accounting Research, 31(2), 131-171.

Bernard, H. R., \& Ryan, G. W. (2010). Analyzing Qualitative Data: Systemic Approaches. Thousand Oaks: Sage Publications.

Bernstein, J. I. (1986). The Effect of Direct and Indirect Tax Incentives on Canadian Industrial R\&D Expenditures. Canadian Public Policy, 12(3), 438-448.

Bérubé, C., \& Mohnen, P. (2009). Are Firms That Received R\&D Subsidies More Innovative? Canadian Journal of Economics, 42(1), 206-225.

Bhagat, S., \& Welch, I. (1995). Corporate Research \& Development Investments: International Comparisons. Journal of Accounting and Economics, 19(2-3), 443-470.

Billings, A., Glazunov, S., \& Houston, M. (2001). The Role of Taxes in Corporate Research and Development Spending. R\&D Management, 31(4), 465-477.

Bishop, S., Eck, K., Pringle, E., \& Robinson, K. (2018). EY's Guide to Scientific Research \& Experimental Development (3rd ed.). Toronto: Ernst \& Young Electronic Publishing Services.

Bloom, N., Brynjolfsson, E., Foster, L., Jarmin, R. S., Patnaik, M., Saporta-Eksten, I., \& Van Reenen, J. . (2017). What Drives Differences in Management? Retrieved from http://www.nber.org/papers/w23300

Bloom, N., Griffith, R., \& Van Reenen, J. (2002). Do R\&D Tax Credits Work? Evidence from a Panel of Countries 1979-1997. Journal of Public Economics, 85(1), 1-31.

Bloom, N., Van Reenen, J., \& Williams, H. (2019). A Toolkit of Policies to Promote Innovation. Journal of Economic Perspectives, 33 (3), 163-184

Bloom, N., \& Van Reenen, J. (2007). Measuring and Explaining Management Practices across Firms and Countries. The Quarterly Journal of Economics, 122(4), 1351-1408.

Bösenberg, S., \& Egger, P. (2017). R\&D Tax Incentives and the Emergence and Trade of Ideas. Economic Policy, 32(89), 39-80.

Bound, J., Cummins, C., Griliches, Z., \& Jaffe, A. (1984). Who Does R\&D and Who Patents? In Z. Griliches (Ed.), R\&D, Patents, and Productivity ( $1^{\text {st }}$ ed., pp. 21-54). Chicago: The University of Chicago Press.

Branstetter, L. (2006). Is Foreign Direct Investment a Channel of Knowledge Spillovers? Evidence from Japan's FDI in the United States. Journal of International Economics, 68(2), 325-344.

Braun, V., \& Clarke, V. (2006). Using Thematic Analysis in Psychology. Qualitative Research in Psychology, 3(1), 77-101. 
Brown, J. R., Martinsson, G., \& Petersen, B. C. (2012). Do Financing Constraints Matter for R\&D? European Economic Review, 56(8), 1512-1529.

Brown, J. R., Martinsson, G., \& Petersen, B. C. (2017). What Promotes R\&D? Comparative Evidence from around the World. Research Policy, 46(2), 447-462.

Bryman, A., Bell, E., Mills, A. J., \& Yue, A. R. (2011). Business Research Methods (Canadian Ed.). Don Mills: Oxford University Press.

Burrell, G., \& Morgan, G. (1979). Sociological Paradigms and Organizational Analysis. London: Heinemann.

Busom, I. (2000). An Empirical Evaluation of The Effects of R\&D Subsidies. Economics of Innovation and New Technology, 9(2), 111-148.

Busom, I., Corchuelo, B., \& Martínez-Ros, E. (2014). Tax Incentives... or Subsidies for Business R\&D? Small Business Economics, 43(3), 571-596.

Busom, I., Corchuelo, B., \& Martínez-Ros, E. (2017). Participation Inertia in R\&D Tax Incentive and Subsidy Programs. Small Business Economics, 48(1), 153-177.

Canada Revenue Agency (1997). Scientific Research and Experimental Development Administrative Guidelines for Software Development. Retrieved from http://www.scitax.com/pdf/OBSOLETE_CRA.Pub.97-

1_SRED.Admin.Guidelines.for.Software.Development_Feb-1997.pdf

Canada Revenue Agency. (2012). Financial Claim Review Manual - Review Procedures for Financial Reviewers. SR\&ED Program. Retrieved from https://www.canada.ca/en/revenue-agency/services/scientific-research-experimentaldevelopment-tax-incentive-program/financial-claim-review-manual-review-proceduresfinancial-reviewers-6.html

Canada Revenue Agency. (2015a). Eligibility of Work for SR\&ED Investment Tax Credits Policy. Retrieved from https://www.canada.ca/en/revenue-agency/services/scientific-researchexperimental-development-tax-incentive-program/eligibility-work-investment-taxcredits.html

Canada Revenue Agency. (2015b). T4408: Scientific Research and Experimental Development (SR\&ED) Expenditures Claim: Guide to Form T661. Ottawa: Canada Revenue Agency.

Canada Revenue Agency. (2015c). T661: Scientific Research and Experimental Development (SR\&ED) Expenditures Claim. Ottawa: Canada Revenue Agency.

Canada Revenue Agency (2016, May 18). SR\&ED Self-Assessment and Learning Tool. Retrieved from https://www.canada.ca/en/revenue-agency/services/scientific-researchexperimental-development-tax-incentive-program/self-assessment-learning-tool.html

Cappelen, Å., Raknerud, A., \& Rybalka, M. (2011). The Effects of R\&D Tax Credits on Patenting 
and Innovations. Research Policy, 41(2), 334-345.

Casadesus-Masanell, R., \& Ricart, J. E. (2010). From Strategy to Business Models and onto Tactics. Long Range Planning, 43(2-3), 195-215.

Castellacci, F., \& Lie, C. M. (2015). Do the Effects of R\&D Tax Credits Vary Across Industries? A Meta-Regression Analysis. Research Policy, 44(4), 819-832.

Chan, L. K. C., Lakonishok, J., \& Sougiannis, T. (2001). The Stock Market Valuation of Research and Development Expenditures. Journal of Finance, 56(6), 2431-2456.

Chandler, A. (1962). Strategy and Structure. Cambridge: The MIT Press.

Charmaz, K. (2014). Constructing Grounded Theory (2nd ed.). Thousand Oaks: Sage Publications.

Chesbrough, H. W. (2003). Open Innovation: The New Imperative for Creating and Profiting from Technology. Boston: Harvard Business School Press.

Chesbrough, H. W. \& Crowther, A. K. (2006). Beyond High Tech: Early Adopters of Open Innovation in other Industries, R\&D Management, 36(3), 229-236

Christensen, C. A. (1997). The Innovator's Dilemma: The Revolutionary Book That Will Change the Way You Do Business. New York City: Harper Collins.

Chuluun, T., Prevost, A., \& Upadhyay, A. (2017). Firm Network Structure and Innovation. Journal of Corporate Finance, 44(C), 193-214.

Ciftci, M., \& Darrough, M. (2016). Does the Riskiness of R\&D Outweigh Its Benefits? The Perspective of US Private Lenders. Journal of Business Finance and Accounting, 43(5-6), 654-692.

Clarysse, B., Wright, M., \& Mustar, P. (2009). Behavioural Additionality of R\&D Subsidies: A Learning Perspective. Research Policy, 38(10), 1517-1533.

Cocolakis-Wormstall, M. (2018). Labour Shortage in Canada: Here to Stay. Retrieved from https://www.bdc.ca/en/documents/analysis_research/labourshortage.pdf?utm_campaign=Labour-Shortage-Study-2018--download-EN\&utm_medium=email\&utm_source=Eloqua

Coe, D. T., \& Helpman, E. (1995). International R\&D Spillovers. European Economic Review, 39(5), 859-887.

Cohen, W., \& Levin, R. (1989). Innovation and Market Structure. In R. Schmalensee \& R. D. Willig (Eds.), The Handbook of Industrial Organization (2nd ed., pp. 1059-1107). New York City: Elsevier Science.

Cohen, W. M., \& Levinthal, D. A. (1990). Absorptive Capacity: A New Perspective on Learning and Innovation. Administrative Science Quarterly, 35(1), 128-152. 
Coombs, R. (1996). Core Competencies and the Strategic Management of R\&D. R\&D Management, 26(4), 345-355.

Crespi, G., Giuliodori, D., Giuliodori, R., \& Rodriguez, A. (2016). The Effectiveness of Tax Incentives for R\&D+i in Developing Countries: The Case of Argentina. Research Policy, 45(10), 2023-2035.

Creswell, J. W. (1994). Research Design: Qualitative \& Quantitative Approaches. Thousand Oaks: Sage Publications.

Creswell, J. W. (2013). Qualitative Inquiry \& Research Design: Choosing Among Five Approaches (3rd ed.). Thousand Oaks: Sage Publications.

Creswell, J. W. (2014). Research Design: Qualitative, Quantitative, and Mixed Methods Approaches ( $4^{\text {th }}$ ed.). Thousand Oaks.

Crisan, D., \& McKenzie, K. J. (2017). Finances of the Nation, Tax Subsidies for R\&D in Canada, 1981-2016. Canadian Tax Journal, 65(4), 951-981.

Crotty, M. (1998). The Foundation of Social Research: Meaning and Perspective in the Research Process. Thou: Sage Publications.

Cuervo-Cazurra, A., \& Un, C. A. (2010). Why Some Firms Never Invest in Formal R\&D. Strategic Management Journal, 31(7), 759-779.

Cyert, R. M., \& March, J. G. (1963). A Behavioral Theory of the Firm (1 $1^{\text {st }}$ ed.). New Jersey, USA: Prentice-Hall, Inc.

Czarnitzki, D., \& Delanote, J. (2015). R\&D Policies for Young SMEs: Input and Output Effects. Small Business Economics, 45(3), 465-485.

Czarnitzki, D., Hanel, P., \& Rosa, J. M. (2010). Evaluating the Impact of R\&D Tax Credits on Innovation: A Microeconometric Study on Canadian Firms. Research Policy, 40(2), 217229.

Czarnitzki, D., \& Hottenrott, H. (2011). R\&D Investment and Financing Constraints of Small and Medium-Sized Firms. Small Business Economics, 36(1), 65-83.

Dahlby, B. (2005). A Framework for Evaluating Provincial R\&D Tax Subsidies. Canadian Public Policy/Analyse de Politique. 31(1), 45-58.

Damanpour, F. (1996). Organizational Complexity and Innovation: Developing and Testing Multiple Contingency Models. Management Science, 42(5), 693-716.

David, P. A., Hall, B. H., \& Toole, A. A. (2000). Is public R\&D a Complement or Substitute for Private R\&D? A Review of the Econometric Evidence. Research Policy, 29(4-5), 497-529.

Denzin, N. K., \& Lincoln, Y. S. (2012). Introduction: The Discipline and Practice of Qualitative 
Research. In N. K. Denzin \& Y. S. Lincoln (Eds.), Collecting and Interpreting Qualitative Materials (4th ed., p. 656). Thousand Oaks: Sage Publishing.

Department of Finance. (1983). Budget in Brief, 1983. Retrieved July 23, 2019 from https://www.budget.gc.ca/pdfarch/1983-brf-eng.pdf

Department of Finance. (1985). Budget Papers, 1985 . Retrieved July 23, 2019 from https://www.budget.gc.ca/pdfarch/1985-pap-eng.pdf

Department of Finance. (1992). Budget Papers, 1992. Retrieved July 23, 2019 from https://www.budget.gc.ca/pdfarch/1992-pap-eng.pdf

Department of Finance. (2012a). Budget Plan, 2012. Retrieved July 23, 2019 from https://budget.gc.ca/2012/plan/pdf/Plan2012-eng.pdf

Department of Finance. (2012b). Consultation Regarding the Impact of Contingency Fees on the Effectiveness of the Scientific Research and Experimental Development Tax Incentive Program. Retrieved July 23, 2019, from https://www.fin.gc.ca/activty/consult/sred-rsdeeng.asp

Dechezleprêtre, A., Einiö, E., Martin, R., Nguyen, K. T., \& Van Reenen, J. (2016). Do Fiscal Incentives Increase Innovation? An RD Design for R\&D. National Bureau of Economic Research Working Paper Series, No. 22405 (2016), 1-35

Dougherty, D. (1992). Interpretive Barriers to Successful Product Innovation in Large Firms. Organization Science, 3(2), 179-202.

Dosi, G.; \& Nelson, R. R. (2010). Technical Change and Industrial Dynamics as Evolutionary Processes. In B. H. Hall \& N. Rosenberg (Eds.), Handbook of the Economics of Innovation, Volume 1 (1st ed., pp. 51-127). New York City: Elsevier BV.

Durocher, S., Bujaki, M., \& Brouard, F. (2016). Attracting Millennials: Legitimacy Management and Bottom-up Socialization Processes within Accounting Firms. Critical Perspectives on Accounting, 39, 1-24.

Eberhart, A. C., Maxwell, W. F., \& Siddique, A. R. (2004). An Examination of Long-Term Abnormal Stock Returns and Operating Performance Following R\&D Increases. Journal of Finance, 59(2), 623-650.

Eisenhardt, K. M., \& Martin, J. A. (2000). Dynamic Capabilities: What are They? Strategic Management Journal, 21(10-11), 1105-1121.

Eisenhardt, K. M. (1989). Building Theories from Case Study Research. Academy of Management Review, 14(4), 532-550.

Fagerberg, J., Srholec, M., \& Verspagen, B. (2010). Innovation and Economic Development. In B. H. Hall \& N. Rosenberg (Eds.), Handbook of the Economics of Innovation, Volume 2 (1st ed., 
pp. 731-1331). New York City: Elsevier B.V.

Farr, C. (2017). One of Google's Most Embarrasing Flops is Turning into a Real Business. Retrieved June 28, 2017, from https://www.cnbc.com/2017/04/11/google-glassbecoming-surprise-success.html

Federal Economic Development Agency for Southern Ontario (n.d.) Southern Ontario Fund for Investment in Innovation. Retrieved from: https://www.sofii.ca/en/

Fereday, J., \& Muir-Cochrane, E. (2006). Demonstrating Rigor Using Thematic Analysis: A Hybrid Approach of Inductive and Deductive Coding and Theme Development. International Journal of Qualitative Methods, 5(1), 80-92.

Fiegenbaum, A., \& Karnani, A. (1991). Output Flexibility-A Competitive Advantage for Small Firms. Strategic Management Journal, 12(2), 101-114.

Fontana, A., \& Frey, J. A. (2008). The Interview: From Neutral Stance to Political Involvement. In N. K. Denzin \& Y. S. Lincoln (Eds.), Collecting and Intrepreting Qualitative Materials (3rd ed., pp. 115-159). Thousand Oaks: Sage Publications.

Fontana, R., Geuna, A., \& Matt, M. (2006). Factors Affecting University-Industry R\&D Projects: The Importance of Searching, Screening and Signalling. Research Policy, 35(2), 309-323.

Freel, M. S. (2000). Do Small Innovating Firms Outperform Non-Innovators? Small Business Economics, 14(3), 195-210.

Freel, M.S. (2007). Are Small Innovators Credit Rationed? Small Business Economics, 28(1), 2335.

Gibbert, M., Ruigrok, W., \& Wicki, B. (2008). What Passes for a Rigourous Case Study? Strategic Management Journal, 29(13), 1465-1474.

Gibcus, P., Vermeulen, P. A. M., \& de Jong, J. P. J. (2006). Strategic Decision-Making in Small Firms: Towards a Taxonomy of Entrepreneurial Decision-Makers. Scientific Analysis of Entrepreneurship and SMEs. January 2006, 1-30.

Gibcus, P., Vermeulen, P. A. M., \& de Jong, J. P. J. (2009). Strategic Decision Making in Small Firms: a Taxonomy of Small Business Owners. International Journal of Entrepreneurship and Small Business, 7(1), 74-91.

Goldkuhl, G. (2012). Pragmatism vs Interpretivism in Qualitative Information Systems Research. European Journal of Information Systems, 21(2), 135-146.

González, X., \& Pazó, C. (2008). Do Public Subsidies Stimulate Private R\&D Spending? Research Policy, 37(3), 371-389.

Government of Canada. (2019). Budget 2019. Ottawa. Retrieved from https://www.budget.gc.ca/2019/home-accueil-en.html 
Grant, R. M. (1996). Prospering in Dynamically-Competitive Environments : Organizational Capability as Knowledge Integration. Organization Science, 7(May), 375-387.

Greve, H. R. (2003). A Behavioral Theory of R\&D Expenditures and Innovations : Evidence from Shipbuilding. Academy of Management Journal, 46(6), 685-702.

Guest, G., Bunce, A., \& Johnson, L. (2006). How Many Interviews are Enough? An Experiment with Data Saturation and Variability. Field Methods, 18(1), 59-82.

Guest, G., MacQueen, K., \& Namey, E. (2014). Introduction to Applied Thematic Analysis. Applied Thematic Analysis. Thousand Oaks: Sage Publications.

Hall, B. H. (2002). The Financing of Research and Development. Oxford Review of Economic Policy, 18(1), 35-51.

Hall, B. H., Jaffe, A., \& Trajtenberg, M. (2005). Market Value of Patent Citations. Rand Journal of Economics, 36(1), 16-38.

Hall, B. H. \& Lerner, J. (2010). The Financing of R\&D and Innovation. In B. H. Hall \& N. Rosenberg (Eds.), Handbook of the Economics of Innovation, Volume 2 (1st ed., pp. 609-639). New York City: Elsevier B.V.

Hall, B. H., \& Van Reenen, J. (2000). How Effective are Fiscal Incentives for R\&D? A New Review of the Evidence. Research Policy, 29(2000), 449-469.

Hall, P. (2005). Interprofessional Teamwork: Professional Cultures as Barriers. Journal of Interprofessional Care, 19(Supp1), 188-196.

Hardcopf, R., Gonçalves, P., Linderman, K., \& Bendoly, E. (2017). Short-Term Bias and Strategic Misalignment in Operational Solutions: Perceptions, Tendencies, and Traps. European Journal of Operational Research, 258(3), 1004-1021.

Harris, R., Li, Q. C., \& Trainor, M. (2009). Is a Higher Rate of R\&D Tax Credit a Panacea for Low Levels of R\&D in Disadvantaged Regions? Research Policy, 38(1), 192-205.

Hearn, D. R., Puterman, J. A., \& Tari, A. C. (2011). Jentel: Short and Sweet Guidance on SR\&ED Eligibility. Canadian Tax Journal, 59(4), 816-821.

Helfat, C. E., \& Peteraf, M. A. (2003). The Dynamic Resource-Based View: Capability Lifecycles. Strategic Management Journal, 24(10 Special Issue), 997-1010.

Henderson, R. M., \& Clark, K. B. (1990). Architectural Innovation: The Reconfiguration of Existing Product Technologies and the Failure of Established Firms. Administrative Science Quarterly, 35(1), 9-30.

Hofer, C. W. (1975). Toward a Contingency Theory of Business Strategy Toward a Contingency 
Theory of Business Strategy. Academy of Management Journal, 18(4), 784-810.

Hsu, F. M., Horng, D. J., \& Hsueh, C. C. (2009). The Effect of Government-Sponsored R\&D Programmes on Additionality in Recipient Firms in Taiwan. Technovation, 29(3), 204-217.

Huang, E. Y., \& Lin, S. (2006). How R\&D Management Practice affects Innovation Performance. Industrial Management \& Data Systems, 106(7), 966-996.

Inkpen, A., \& Choudhury, N. (1995). The Seeking of Strategy Where It Is Not: Towards a Theory of Strategy Absence. Strategic Management Journal, 16(4), 313-323.

Iqbal, M. (1995). R \& D Tax Incentive Comparisons: Canadian and US Large Manufacturing Industries. Canadian Tax Journal, 43(1), 120-133

Jou, J., \& Lee, T. (2001). R\&D Investment Decision and Optimal Subsidy. R\&D Management, 31(2), 137-148.

Julien, P. A. (1993). Small Businesses as a Research Subject: Some Reflections on Knowledge of Small Businesses and its Effects on Economic Theory. Small Business Economics, 5(2), 157166.

Khan, A.M., \& Manopichetwattana, V. (1989). Innovative and Noninnovative Small Firms: Types and Characteristics. Management Science, 35(5), 515-643.

Kitch, E. W. (1977). The Nature and Function of the Patent System. Journal of Law and Economics, 20(2), 265-290.

Klassen, K., Pittman, J. A., \& Reed, M. P. (2004). A Cross-national Comparison of R \& D Expenditure Decisions: Tax Incentives and Financial Constraints. Contemporary Accounting Research, 21(3), 681-685.

Klein, H. K., \& Myers, M. D. (1999). A Set of Principles for Conducting and Evaluating Interpretive Field Studies in Information Systems. MIS Quarterly, 23(1), 67-94.

Kobayashi, Y. (2014). Effect of R\&D tax Credits for SMEs in Japan: A Microeconometric Analysis Focused on Liquidity Constraints. Small Business Economics, 42(2), 311-327.

Koga, T. (2003). Firm Size and R\&D Tax Incentives. Technovation, 23(7), 643-648.

Kogut, B; \& Zander, U. (1992). Knowledge of the Firm , Combinative Capabilities, and the Replication of Technology. Organization Science, 3(3), 383-397.

Kumar, S. \& Hsiao, J. K. (2007). Engineers Learn "Soft Skills the Hard Way": Planting a Seed of Leadership in Engineering Classes. Leadership and Management in Engineering, 7(1), 1823.

Lach, S. (2002). Do R\&D Subsidies Stimulate or Displace Private R\&D? Evidence from Israel. 
Journal of Industrial Economics, 50(4), 369-390.

Laforet, S., \& Tann, J. (2006). Innovative Characteristics of Small Manufacturing Firms. Journal of Small Business and Enterprise Development, 13(3), 363-380.

Laursen, K., \& Salter, A. (2006). Open for Innovation: The Role of Openness in Explaining Innovation Performance Among U.K. Manufacturing Firms. Strategic Management Journal, 27(2), 131-150.

Lentile, D., \& Maresse, J. (2009). A Policy to Boost R\&D: Does the R\&D Tax Credit Work? EIB Papers, 14(1), 145-169.

Leonard-Barton, D. (1992). Core Capabilities and Core Rigidities: A Paradox in Managing New Product Development. Strategic Management Journal, 13(1), 111-125.

Lester, J. (2012). Benefit-Cost Analysis of R \& D Support Programs. Canadian Tax Journal, 60(4), 793-836.

Lev, B. (2001). Intangibles. Washington, D.C.: The Brookings Institution.

Lincoln, Y. S., Lynham, S. A., \& Guba, E. G. (2017). Paradigmatic Controversies, Contradictions, and Emerging Confluences, Revisted. In N. K. Denzin \& Y. S. Lincoln (Eds.), The Sage Handbook of Qualitative Research (5th ed., pp. 97-108). Thousand Oaks: Sage Publications.

Lokshin, B., \& Mohnen, P. (2013). Do R\&D Tax Incentives Lead to Higher Wages for R\&D workers? Evidence from the Netherlands. Research Policy, 42(3), 823-830.

Lukka, K. (1990). Ontology and Accounting: The Concept of Profit. Critical Perspectives on Accounting, 1(3), 239-261.

Luthans, F., \& Stewart, T. I. (1977). A General Contingency Theory of Management. Academy of Management Review, 2(2), 181-195.

Mahmood, I. P., \& Rufin, C. (2005). Governments Dilemma: The Role of Government in Imitation and Innovation. Academy of Management Review, 30(2), 338-360.

Mamuneas, T. P., \& Nadiri, M. I. (1996). Public R\&D Policies and Cost Behavior of the US Manufacturing Industries. Journal of Public Economics, 63(1), 57-81.

Mansfield, E. (1984). R\&D and Innovation: Some Empirical Findings. In Z. Griliches (Ed.), R\&D, Patents, and Productivity (1st ed., pp. 127-148). Chicago: University of Chicago Press.

Mansfield, E. (1986). The R \& D Tax Credit and Other Technology Policy Issues. The American Economic Review, 76(2), 190-194.

Mansfield, E., \& Switzer, L. (1985a). How Effective Are Canada's Direct Tax Incentives for R\&D? Canadian Public Policy / Analyse de Politiques, 11(2), 241-246. 
Mansfield, E., \& Switzer, L. (1985b). The Effects of R\&D Tax Credits and Allowances in Canada. Research Policy, 14(2), 97-107.

March, J. G., \& Simon, H. A. (1958). Organizations. New York: John Wiley \& Sons, Inc.

Marino, M., Lhuillery, S., Parrotta, P., \& Sala, D. (2016). Additionality or Crowding-out? An Overall Evaluation of Public R\&D Subsidy on Private R\&D Expenditure. Research Policy, 45(9), 1715-1730.

Martínez-Noya, A. \& Narula, R. (2018). What More Can We Learn from R\&D Alliances? A Review and Research Agenda. Business Research Quarterly, 21, 195-212.

Martínez-Román, J. A., \& Romero, I. (2017). Determinants of Innovativeness in SMEs: Disentangling Core Innovation and Technology Adoption Capabilities. Review of Managerial Science, 11(3), 543-569.

McKenzie, K. J., \& Sershun, N. (2010). Taxation and R\&D: An Investigation of the Push and Pull Effects. Canadian Public Policy, 36(3), 307-324.

Michael, S. C., \& Pearce, J. A. (2009). The Need for Innovation as a Rationale for Government Involvement in Entrepreneurship. Entrepreneurship and Regional Development, 21(3), 285-302.

Miles, R., \& Snow, C. (1978). Organizational Strategy, Structure and Process. New York: McGraw-Hill.

Minniti, A., \& Venturini, F. (2017). The Long-run Growth Effects of R\&D Policy. Research Policy, 46(1), 316-326.

Mintzberg, H., \& Waters, J. A. (1985). Of Strategies, Deliberate and Emergent. Strategic Management Journal, 6(3), 257-272.

Murray, K. J. (1995). Scientific Research and Experimental Development : A Program in Crisis? Canadian Tax Journal, 43(5), 1265-1286.

Myers, M. D. (2009). Qualitative Research in Business Management (1st ed.). London: Sage Publications.

National Research Council (2019). NRC Funding to Hire Young Graduates. Retrieved from https://nrc.canada.ca/en/support-technology-innovation/nrc-irap-funding-hire-younggraduates

Nelson, R. R. (1962). The Rate and Direction of Inventive Activity: Economic and Social Factors. Princeton University Press.

Nelson, R. R., \& Winter, S. J. (1982). An Evolutionary Theory of Economic Change. Cambridge: The Belknap Press of Harvard University Press 
Nisar, T., Kumar, N., \& Prabhakar, G. (2018). Effects of Best Management Practices on the Performance and Productivity of Small Firms. Production, Planning \& Control, 30(10-12) 919-934.

Nonaka, I. (1994). A Dynamic Theory of Organizational Knowledge Creation. Organization Science, 5(1), 14-37.

OECD. (2002). Frascati Manual 2002: Proposed Standard Practice for Surveys on Research and Experimental Development. Paris: OECD Publishing.

Oriani, R., \& Sobrero, M. (2008). Uncertainty and the Market Valuation of R\&D within a Real Options Logic. Strategic Management Journal, 29(4), 343-361.

Orlikowski, W. J., \& Baroudi, J. J. (1991). Studying Information Techology in Organizations: Research Approaches and Assumptions. Information Systems Research, 2(1), 1-28.

Ortega-Argilés, R., Vivarelli, M., \& Voigt, P. (2009). R\&D in SMEs: A Paradox? Small Business Economics, 33(1), 3-11.

Otley, D. (2016). The Contingency Theory of Management Accounting and Control: 1980-2014. Management Accounting Research, 31, 45-62.

Otley, D. T. (1980). The Contingency Theory of Management Accounting: Achievement and Prognosis. Accounting, Organizations and Society, 5(4), 413-428.

Pandit, S., Wasley, C. E., \& Zach, T. (2011). The Effect of Research and Development (R\&D) Inputs and Outputs on the Relation between the Uncertainty of Future Operating Performance and R\&D Expenditures. Journal of Accounting, Auditing \& Finance, 26(1), 121-144.

Parsons, M., \& Phillips, N. (2007). An Evaluation of the Federal Tax Credit for Scientific Research and Experimental Development. Retrieved from http://www.fin.gc.ca/pub/pdfs/wp200708e.pdf

Pavitt, K. (1984). Sectoral Patterns of Technical Change: Towards a Taxonomy and a Theory. Research Policy, 13(6), 343-373.

Pelham, A. M. (2000). Market orientation and other potential influences on performance in small and medium-sized manufacturing firms. Journal of Small Business Management, 38(1), 48-67.

Porter, M. E. (1979). How Competitive Forces Shape Strategy. Harvard Business Review, 57(2), 137-145.

Prahalad, C. K., \& Hamel, G. (1990). The Core Competence of a Corporation. Harvard Business Review, May-June Issue, 79-91.

Radas, S., Ani, I.-D., Tafro, A., \& Wagner, V. (2015). The Effects of Public Support Schemes on 
Small and Medium Enterprises. Technovation, 38, 15-30.

Rao, N. (2016). Do Tax Credits Stimulate R\&D Spending? The Effect of the R\&D Tax Credit in its First Decade. Journal of Public Economics, 140(August), 1-12.

Raymond, L., \& St-Pierre, J. (2010). Strategic Capabilities for Product Innovation in SMEs: A Gestalts Perspective. The International Journal of Entrepreneurship and Innovation, 11(3), 209-220.

Reitzes, J. D. (1991). The Impact of Quotas and Tariffs on Strategic R\&D Behavior. International Economic Review, 32(4), 985-1007.

Rogers, E. M. (2003). Diffusion of Innovations (5th ed.). New York: Free Press, A Division of Simon \& Schuster, Inc.

Romer, P. M. (1990). Endogenous Technological Change. Journal of Political Economy, 98(5), 71-102.

Romer, P. M. (2000). Should the Government Subsidize Supply or Demand in the Market for Scientists and Engineers? National Bureau of Economic Research Working Paper Series, No. 7723(2000), 221-252.

Romijn, H., \& Albaladejo, M. (2002). Determinants of Innovation Capability in Small Electronics and Software Firms in Southeast England. Research Policy, 31(7), 1053-1067.

Rosenberg, N. (1982). Inside the Black Box: Technology and Economics (First ed.). Cambridge: Press Syndicate of the University of Cambridge.

Russo, B. (2004). A Cost-Benefit Analysis of R\&D Tax Incentives. Canadian Journal of Economics, 37(2), 313-335.

Sakakura, S., \& Kobayashi, M. (1991). R\&D Management in Japanese Research Institutes. Research Policy, 20(6), 531-558.

Salles, M. (2006). Decision Making in SMEs and Information Requirements for Competitive Intelligence. Production Planning and Control, 17(3), 229-237.

Saunders, M., Lewis, P., \& Thornhill, A. (2012). Research Methods for Business Students (6th ed.). New York: Pearson Education Limited.

Schumpeter, J. A. (1934). The Theory of Economic Development. Cambridge: Harvard University Press.

Sharma, A., Adhikary, A., \& Borah, S. B. (2020). Covid-19's Impact on Supply Chain Decisions: Strategic Insights from NASDAQ 100 firms using Twitter Data. Journal of Business Research, 117(September Special Issue), 443-449.

Shivakumar, R. (2014). How to Tell Which Decisions are Strategic. California Management 
Review, 56(3), 78-97.

Simon, H. A. (1955). A Behavioral Model of Rational Choice. Quarterly Journal of Economics, 69(1), 99-118.

Simons, R. (1995). Levers of Control: How Managers Use Innovative Control Systems to Drive Strategic Renewal. Cambridge: Harvard Business School Press.

Singleton, R. A., \& Straits, B. C. (2010). Approaches to Social Research (5th Ed.). New York: Oxford University Press.

Slivko, O., \& Theilen, B. (2014). Innovation or Imitation? The Effect of Spillovers and Competitive Pressure on Firms' R\&D Strategy Choice. Journal of Economics, 112(3), 253282.

Smith, K. (2005). Measuring Innovation. In J. Fagerberg, D. C. Mowery, \& R. R. Nelson (Eds.), The Oxford Handbook of Innovation (pp. 148-177). Oxford: Oxford University Press.

Snow, C. C., \& Hambrick, D. C. (1980). Measuring Organizational Strategies: Some Theoretical and Methodological Problems. Academy of Management Review, 5(4), 527-538.

Statistics Canada. (2016). Key Small Business Statistics - June 2016. Ottawa: Statistics Canada

Statistics Canada. (2019a). Key Small Business Statistics 2019. Ottawa: Statistics Canada. Retrieved from https://www.ic.gc.ca/eic/site/061.nsf/eng/h_03090.html\#point2-1

Statistics Canada. (2019b). 2018 Annual Survey of Research and Development in Canadian Industry. Ottawa: Statistics Canada

Teece, D.J., Pisano, G., \& Shuen, A. (1997). Dynamic Capabilities and Strategic Management, Strategic Management Journal, 18(7), 509-533

Teece, D. J. (2007). Explicating Dynamic Capabilities: The Nature and Microfoundations of (Sustainable) Enterprise Performance. Strategic Management Journal, 28(13), 1319-1350.

Teece, D. J. (2010a). Business Models, Business Strategy and Innovation. Long Range Planning, 43(2-3), 172-194.

Teece, D. J. (2010b). Technological Innovation and the Theory of the Firm: The Role of Enterprise-Level Knowledge, Complementaries, and (Dynamic) Capabilities. In B. H. Hall \& N. Rosenberg (Eds.), Handbook of the Economics of Innovation, Volume 1 (1st ed., pp. 680-724). New York: Elsevier B.V.

Teirlinck, P., \& Spithoven, A. (2013). Formal R\&D Management and Strategic Decision Making in Small Firms in Knowledge-Intensive Business Services. R\&D Management, 43(1), 37-51.

Tessier, S., \& Otley, D. (2012). A Conceptual Development of Simons' Levers of Control Framework. Management Accounting Research, 23(3), 171-185. 
Tidd, J., \& Pavitt, K. (2011). Managing Innovation: Integrating Technological, Market And Organizational Change. (5th ed.). Sussex: Wiley-Blackwell.

Torres, O. (2004). The SME Concept of Pierre-André Julien: An Analysis in Terms of Proximity. Piccola Impresa/Small Business, 2, 1-12. Retrieved from http://www.oliviertorres.net/travaux/pdf/TORRESINGL.pdf

Treasury Board of Canada Secretariat. (1995). Guide on Financial Arrangements and Funding Options.

Tsai, K. H. (2005). R\&D Productivity and Firm Size: A Nonlinear Examination. Technovation, 25(7), 795-803.

van de Vrande, V., de Jong, J. P. J., Vanhaverbeke, W., \& de Rochemont, M. (2009). Open Innovation in SMEs: Trends, Motives and Management Challenges. Technovation, 29(6-7), 423-437. 1

Viner, E. (2016). Guide to the Taxation of R\&D Expenses (16th-3rd ed.). Toronto: Thomson Reuters.

Wang, E. C. (2010). Determinants of R\&D Investment: The Extreme-Bounds-Analysis Approach Applied to 26 OECD Countries. Research Policy, 39(1), 103-116.

Wang, Y., \& Zhao, J. (2014). Hedge Funds and Corporate Innovation. Financial Management, 44(2), 353-385.

Warda, J. (2002). Measuring the Value of R\&D Tax Treatment in OECD Countries. Science Technology Industry-STI Review, 27, 185-211.

Welsh, J. \& White, J. (1981). A Small Business is Not a Little Big Business. Harvard Business Review, 59(4), 18-27.

Winn, S. F., \& Roome, N. J. (1993). R\&D Management Responses to the Environment: Current Theory and Implications to Practice and Research. R\&D Management, 23(2), 147-160.

Wong, K. Y., \& Aspinwall, E. (2004). Characterizing Knowledge Management in the Small Business Environment. Journal of Knowledge Management, 8(3), 44-61.

Yang, C. H., Huang, C. H., \& Hou, T. C. T. (2012). Tax Incentives and R\&D Activity: Firm-level Evidence from Taiwan. Research Policy, 41(9), 1578-1588.

Yin, R. K. (2014). Case Study Research: Design and Methods (5th ed.). Thousand Oaks: Sage Publications.

Zahra, S. A., \& George, G. (2002). Absorptive Capacity : A Review, Reconceptualization, and Extension. The Academy of Management Review, 27(2), 185-203.

Zajac, E. J., \& Bazerman, M. H. (1991). Blind Spots in Industry and Competitor Analysis: 
Implications of Interfirm (Mis)Perceptions for Strategic Decisions. Academy of Management Review, 16(1), 37-56.

Zollo, M. \& Winter, S., (2002). Deliberate Learning and the Evolution of Dynamic Capabilities, Organization Science, 13(3), 339-351 


\section{APPENDIX A - T661}

1- Canada Ferenue Agence du newenu

Protected B when completed

Code 1501

Scientific Research and Experimental Development (SR\&ED) Expenditures Claim

Use this form:

- to provide technical information on your SR\&ED projects;

- to calculate your SR\&ED expenditures; and

- to calculate your qualified SR\&ED expenditures for investment tax credits (ITC).

To claim an ITC, use either:

- Schedule T2SCH31, Investment Tax Credit - Corporations, or

- Form T2038(IND), Investment Tax Credit(Individuals).

The information requested in this form and documents supporting your expenditures and project information (Part 2) are prescribed information.

Your SR\&ED claim must be filed within 12 months of the filing due date of your income tax return.

To help you fill out this form, use the T4088, Guide to Form T661, which is available on our Web site: www.cra.gc.ca/sred.

\section{Part 1 - General information}

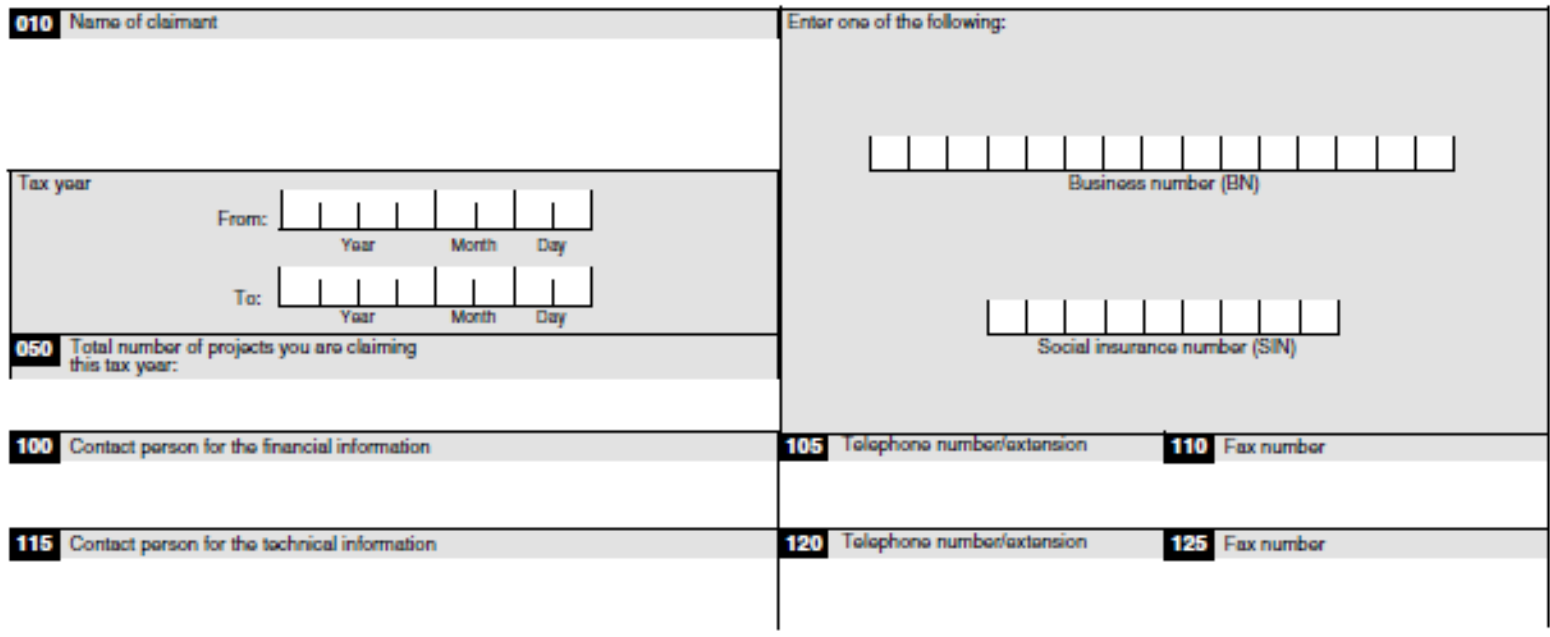

\begin{tabular}{|c|c|c|c|c|}
\hline \multicolumn{5}{|c|}{ If you arewerod no to line 151, comploto lines 153,156 and 157.} \\
\hline 153 & Namos of the parthars & \begin{tabular}{|l|l|l|}
156 & $\%$ \\
\end{tabular} & $\mathrm{BN}$ or SiN & \\
\hline \multicolumn{5}{|l|}{1} \\
\hline \multicolumn{5}{|l|}{2} \\
\hline \multicolumn{5}{|l|}{3} \\
\hline \multicolumn{5}{|l|}{4} \\
\hline 5 & & & & \\
\hline
\end{tabular}


Part 2 - Project information

200 Projoct tiflo (and idantification codo if applicablo)

202

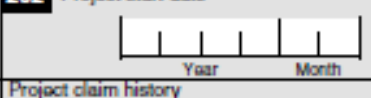

204 Complotion or oxpoctod completion dato

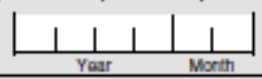

206 Fiold of sciance or tochnology oodo (Soo guido for list of oodes)
20

218 If you answerod yea to line 218, comploto lines 220 and 221 .

220

Names of tho businessos

$210{ }^{1} \square$ First claim for the projpet

1

2

3

Section B - Project descriptions

242 What sciantific or tachnological uncartaintias did you attlampt to oweroome? (Maximum 350 words)

244 What work did you perturn in the tax year to ovecoome the sciontific or lochnological uncortaintios doscribod in line 2427

(Summarizo tho systamatio invastigation or saarch) (Mavimum 700 words)

246 What scientific or tochnological advancomonts dd you achiavo or attompt to achiava as a rosult of tho work doscribod in lino 244 ? (Maximum 350 words) 
Protected B when completed

Part 2 - Project information (continued)

CRA internal form identifier 060 Code 1501

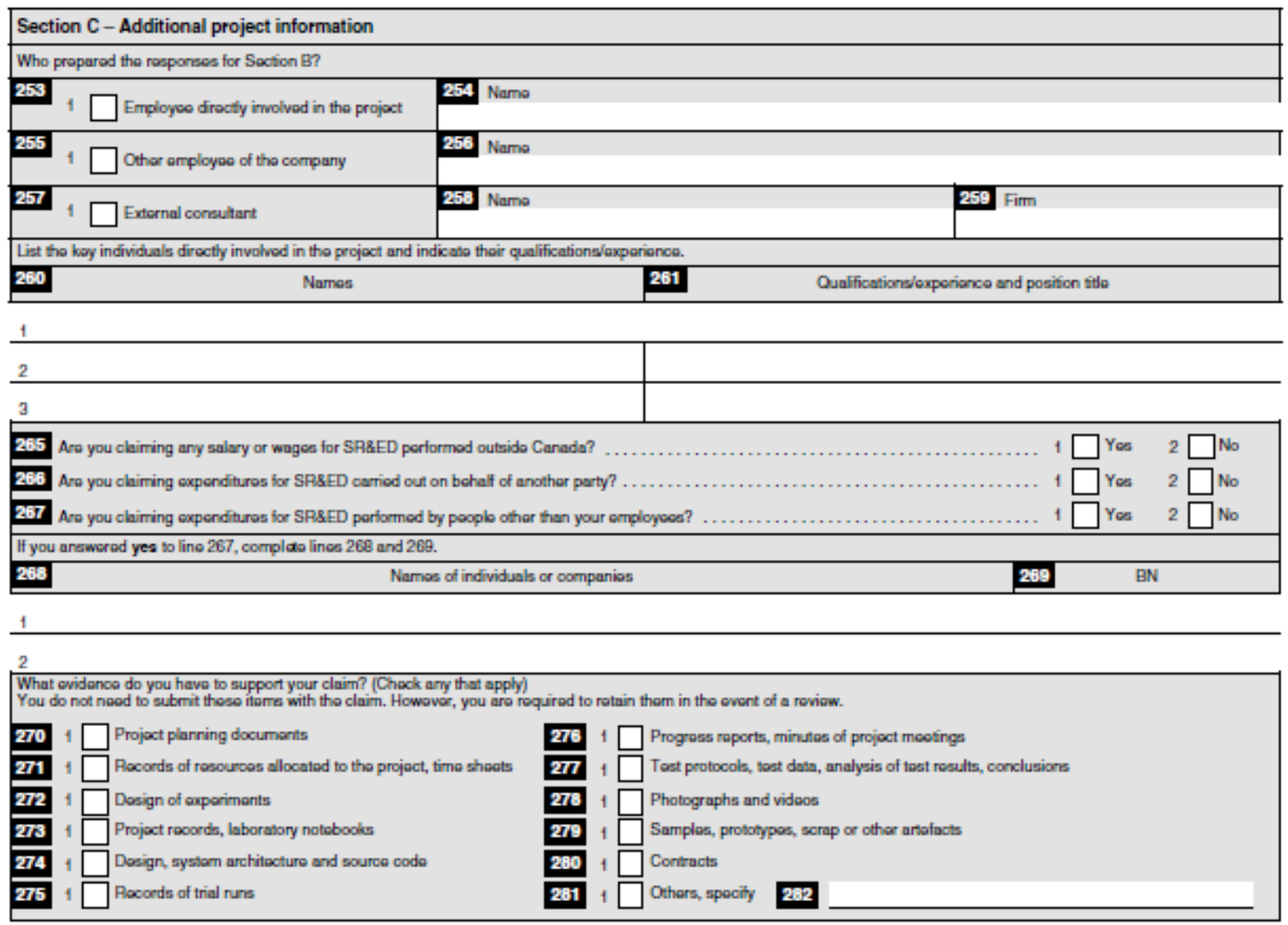


APPENDIX B - LITERATURE REVIEW TABLE

\begin{tabular}{|c|c|c|c|}
\hline Author & Theory & $\begin{array}{l}\text { Research } \\
\text { approach }\end{array}$ & $\begin{array}{l}\text { Data collection } \\
\text { methods }\end{array}$ \\
\hline $\begin{array}{l}\text { Mansfield \& Switzer (1985a } \\
\text { and b) }\end{array}$ & $\begin{array}{l}\text { Neoclassical - } \\
\text { incrementality ratio }\end{array}$ & Quantitative & Survey \\
\hline Mansfield (1986) & $\begin{array}{l}\text { Neoclassical - } \\
\text { incrementality ratio }\end{array}$ & Quantitative & Survey \\
\hline Bernstein (1986) & $\begin{array}{l}\text { Neoclassical -effective } \\
\text { interest rate }\end{array}$ & Quantitative & Analytical \\
\hline Berger (1993) & $\begin{array}{l}\text { Neoclassical - } \\
\text { incrementality ratio }\end{array}$ & Quantitative & $\begin{array}{l}\text { Econometric- } \\
\text { event study }\end{array}$ \\
\hline Bhagat \& Welch (1995) & Q theory & Quantitative & $\begin{array}{l}\text { Econometric - } \\
\text { panel data }\end{array}$ \\
\hline Mamuneas \& Nadiri (1996) & $\begin{array}{l}\text { Neoclassical - } \\
\text { incrementality ratio }\end{array}$ & Quantitative & $\begin{array}{l}\text { Econometric- } \\
\text { panel data }\end{array}$ \\
\hline David, Hall, \& Toole (2000) & $\begin{array}{l}\text { Neoclassical - user } \\
\text { cost elasticity }\end{array}$ & Quantitative & Literature review \\
\hline Hall \& Van Reenan (2000) & $\begin{array}{l}\text { Neoclassical - } \\
\text { incrementality ratio } \\
\text { and user-cost elasticity }\end{array}$ & Quantitative & $\begin{array}{l}\text { Literature review - } \\
\text { meta-analysis }\end{array}$ \\
\hline $\begin{array}{l}\text { Billings, Glazunov, \& Houston } \\
\text { (2001) }\end{array}$ & $\begin{array}{l}\text { Neoclassical - } \\
\text { incrementality ratio } \\
\text { and user-cost elasticity }\end{array}$ & Quantitative & $\begin{array}{l}\text { Econometric - } \\
\text { panel data }\end{array}$ \\
\hline Jou \& Lee (2001) & $\begin{array}{l}\text { Neoclassical - user } \\
\text { cost elasticity }\end{array}$ & Quantitative & Analytical \\
\hline $\begin{array}{l}\text { Bloom, Griffith, \& Van } \\
\text { Reenan (2002) }\end{array}$ & $\begin{array}{l}\text { Neoclassical - user } \\
\text { cost elasticity }\end{array}$ & Quantitative & $\begin{array}{l}\text { Econometric- } \\
\text { panel data }\end{array}$ \\
\hline Lach (2002) & $\begin{array}{l}\text { Neoclassical - } \\
\text { incrementality ratio }\end{array}$ & Quantitative & Survey \\
\hline Warda (2002) & $\begin{array}{l}\text { Neoclassical - effective } \\
\text { interest rate }\end{array}$ & Quantitative & $\begin{array}{l}\text { Analytical and } \\
\text { archival }\end{array}$ \\
\hline Greve (2003) & $\begin{array}{l}\text { Behavioural Theory of } \\
\text { the Firm }\end{array}$ & Quantitative & $\begin{array}{l}\text { Empirical and } \\
\text { archival }\end{array}$ \\
\hline Koga (2003) & $\begin{array}{l}\text { Neoclassical - user } \\
\text { cost elasticity }\end{array}$ & Quantitative & $\begin{array}{l}\text { Econometric- } \\
\text { panel data }\end{array}$ \\
\hline $\begin{array}{l}\text { Klassen, Pittman, \& Reed } \\
\text { (2004) }\end{array}$ & $\begin{array}{l}\text { Neoclassical - } \\
\text { incrementality ratio }\end{array}$ & Quantitative & $\begin{array}{l}\text { Econometric - } \\
\text { panel data }\end{array}$ \\
\hline Russo (2004) & $\begin{array}{l}\text { Neoclassical - } \\
\text { economic growth } \\
\text { theory }\end{array}$ & Quantitative & Analytical \\
\hline Gonzalez \& Pazo (2008) & $\begin{array}{l}\text { Neoclassical - } \\
\text { incrementality ratio }\end{array}$ & Quantitative & $\begin{array}{l}\text { Econometric - } \\
\text { panel data }\end{array}$ \\
\hline
\end{tabular}




\begin{tabular}{|c|c|c|c|}
\hline Author & Theory & $\begin{array}{l}\text { Research } \\
\text { approach }\end{array}$ & $\begin{array}{l}\text { Data collection } \\
\text { methods }\end{array}$ \\
\hline Baghana \& Mohnen (2009) & $\begin{array}{l}\text { Neoclassical - user } \\
\text { cost elasticity }\end{array}$ & Quantitative & Survey and archival \\
\hline Berube \&Mohnen (2009) & $\begin{array}{l}\text { Neoclassical - user } \\
\text { cost elasticity }\end{array}$ & Quantitative & Survey \\
\hline $\begin{array}{l}\text { Clarysse, Wright, \& Mustar } \\
\text { (2009) }\end{array}$ & Organizational learning & Quantitative & Survey \\
\hline Harris, Li, \&Trainor (2009) & $\begin{array}{l}\text { Neoclassical - user } \\
\text { cost elasticity and } \\
\text { absorptive capacity }\end{array}$ & Quantitative & $\begin{array}{l}\text { Econometric - } \\
\text { panel data }\end{array}$ \\
\hline $\begin{array}{l}\text { Cznaritzki, Hanel, \& Rosa } \\
(2010)\end{array}$ & $\begin{array}{l}\text { Neoclassical - user } \\
\text { cost elasticity }\end{array}$ & Quantitative & Survey \\
\hline $\begin{array}{l}\text { Capellan, Raknerud, \& } \\
\text { Rybalka (2011) }\end{array}$ & $\begin{array}{l}\text { Neoclassical - } \\
\text { incrementality ratio }\end{array}$ & Quantitative & Survey \\
\hline Lester (2012) & $\begin{array}{l}\text { Neoclassical - user } \\
\text { cost elasticity }\end{array}$ & Quantitative & Survey \\
\hline Yang, Huang, \& Hou (2012) & $\begin{array}{l}\text { Neoclassical - } \\
\text { incrementality ratio }\end{array}$ & Quantitative & $\begin{array}{l}\text { Econometric - } \\
\text { panel data }\end{array}$ \\
\hline Lokshin\& Mohnen (2013) & $\begin{array}{l}\text { Neoclassical - user } \\
\text { cost elasticity }\end{array}$ & Quantitative & $\begin{array}{l}\text { Econometric - } \\
\text { panel data }\end{array}$ \\
\hline $\begin{array}{l}\text { Busom, Corchelo, \& } \\
\text { Martinez-Ros (2014) }\end{array}$ & $\begin{array}{l}\text { Neoclassical - user } \\
\text { cost elasticity }\end{array}$ & Quantitative & $\begin{array}{l}\text { Econometric - } \\
\text { panel data }\end{array}$ \\
\hline Kobayashi (2014) & $\begin{array}{l}\text { Neoclassical - } \\
\text { incrementality ratio }\end{array}$ & Quantitative & Survey \\
\hline Castellacci \& Lie (2015) & $\begin{array}{l}\text { Neoclassical - } \\
\text { incrementality ratio } \\
\text { and user-cost elasticity }\end{array}$ & Quantitative & $\begin{array}{l}\text { Literature review - } \\
\text { meta-analysis }\end{array}$ \\
\hline Czarnitzki \& Delanote (2015) & $\begin{array}{l}\text { Neoclassical - } \\
\text { incrementality ratio }\end{array}$ & Quantitative & Survey and archival \\
\hline $\begin{array}{l}\text { Radas, Ani, Tafro, \& Wagner } \\
\text { (2015) }\end{array}$ & $\begin{array}{l}\text { Neoclassical - } \\
\text { incrementality ratio } \\
\text { and Absorptive } \\
\text { capacity }\end{array}$ & Quantitative & Survey \\
\hline $\begin{array}{l}\text { Crespi, Giuliodori, Giuliodori, } \\
\text { \& Roberto (2016) }\end{array}$ & $\begin{array}{l}\text { Neoclassical - user } \\
\text { cost elasticity }\end{array}$ & Quantitative & Survey \& panel data \\
\hline $\begin{array}{l}\text { Marino, Lhuillery, Parotta, \& } \\
\text { Sala (2016) }\end{array}$ & $\begin{array}{l}\text { Neoclassical - } \\
\text { incrementality ratio }\end{array}$ & Quantitative & $\begin{array}{l}\text { Econometric - } \\
\text { panel data }\end{array}$ \\
\hline Rao (2016) & $\begin{array}{l}\text { Neoclassical - user } \\
\text { cost elasticity }\end{array}$ & Quantitative & $\begin{array}{l}\text { Econometric - } \\
\text { panel data }\end{array}$ \\
\hline
\end{tabular}




\begin{tabular}{|c|c|c|c|}
\hline Author & Theory & $\begin{array}{l}\text { Research } \\
\text { approach }\end{array}$ & $\begin{array}{l}\text { Data collection } \\
\text { methods }\end{array}$ \\
\hline $\begin{array}{l}\text { Bodas Freitas, Castacelli, } \\
\text { Fontana, Malerba, \& Vezzuli } \\
\text { (2017) }\end{array}$ & $\begin{array}{l}\text { Neoclassical - } \\
\text { incrementality ratio } \\
\text { and R\&D orientation } \\
\text { (Pavitt, 1984) }\end{array}$ & Quantitative & $\begin{array}{l}\text { Econometric - } \\
\text { panel data }\end{array}$ \\
\hline Bösenberg \& Egger (2017) & $\begin{array}{l}\text { Neoclassical - effective } \\
\text { interest rate }\end{array}$ & Quantitative & $\begin{array}{l}\text { Econometric - } \\
\text { panel data }\end{array}$ \\
\hline $\begin{array}{l}\text { Busom, Corchelo, \& } \\
\text { Martinez-Ros (2017) }\end{array}$ & $\begin{array}{l}\text { Neoclassical - } \\
\text { incrementality ratio }\end{array}$ & Quantitative & Survey \& panel data \\
\hline $\begin{array}{l}\text { Brown, Martinsson, \& } \\
\text { Peterson (2017) }\end{array}$ & $\begin{array}{l}\text { Neoclassical - user } \\
\text { cost elasticity }\end{array}$ & Quantitative & $\begin{array}{l}\text { Econometric - } \\
\text { panel data }\end{array}$ \\
\hline Crisan \& Mackenzie (2017) & $\begin{array}{l}\text { Neoclassical - effective } \\
\text { interest rate }\end{array}$ & Quantitative & $\begin{array}{l}\text { Analytical and } \\
\text { archival }\end{array}$ \\
\hline Minnitti \& Venturini (2017) & $\begin{array}{l}\text { Neoclassical - } \\
\text { economic growth } \\
\text { theory }\end{array}$ & Quantitative & $\begin{array}{l}\text { Econometric- } \\
\text { panel data }\end{array}$ \\
\hline $\begin{array}{l}\text { Agrawal, Rosell, \& Simcoe } \\
(2020)\end{array}$ & $\begin{array}{l}\text { Neoclassical - user } \\
\text { cost elasticity }\end{array}$ & Quantitative & $\begin{array}{l}\text { Econometric- } \\
\text { panel data }\end{array}$ \\
\hline
\end{tabular}




\section{APPENDIX C - SR\&ED DEDUCTIONS USING TRADITIONAL OR PROXY METHOD}

Under the traditional method, a claimant includes all the SR\&ED-related direct and overhead expenditures incurred during the year (ITA 37 and Income Tax Regulation (ITR) 2900). In contrast, the proxy method involves calculating an amount based on $55 \%$ of direct labour in lieu of overhead and other expenditures called the prescribed proxy amount (PPA). It should be noted that the PPA does not form part of the SR\&ED expenditure pool under ITA 37(1), but the PPA is included in the computation of qualified expenditures under 127(9).

\begin{tabular}{|l|l|l|}
\hline Expenditure & Traditional Method & Proxy Method \\
\hline Labour & $\begin{array}{l}\text { Labour that includes } \\
\text { undertaking, supervising, } \\
\text { and supporting SR\&ED- } \\
\text { eligible activities as per ITA } \\
\text { 37(8)(a)(ii)(A)(II) } \\
\text { ITR 2900(2)(b) }\end{array}$ & $\begin{array}{l}\text { Only labour that is directly } \\
\text { engaged in SR\&ED-eligible } \\
\text { activities as per ITA } \\
\text { 37(8)(a)(ii)(B)(IV) }\end{array}$ \\
\hline $\begin{array}{l}\text { Materials that are consumed or } \\
\text { transformed }\end{array}$ & $\begin{array}{l}\text { ITA 37(8)(a)(ii)(A)(II) } \\
\text { ITR 2900(2)(a) }\end{array}$ & ITA 37(8)(a)(ii)(B)(V) \\
\hline $\begin{array}{l}\text { Subcontracts for SR\&ED work } \\
\text { performed on behalf of claimant }\end{array}$ & $\begin{array}{l}\text { Can be claimed as current } \\
\text { expenditures that are all or } \\
\text { substantially all attributable } \\
\text { to SR\&ED activities per ITA } \\
\text { 37(8)(a)(ii)(A)(II) }\end{array}$ & ITA 37(8)(a)(ii)(B)(II) \\
\hline $\begin{array}{l}\text { Other current expenditures } \\
\text { Directly attributable to SR\&ED- } \\
\text { eligible activities }\end{array}$ & $\begin{array}{l}\text { Expenditures that are } \\
\text { directly related and } \\
\text { incremental } \\
\text { ITA 37(8)(a)(ii)(A)(II) } \\
\text { ITR 2900(2) and (3) }\end{array}$ & Not applicable \\
\hline Third party payments & ITA 37(1)(a)(i.1)-(iii) & ITA 37(1)(a)(i.1)-(iii) \\
\hline $\begin{array}{l}\text { Current expenditures all or } \\
\text { substantially all attributable to } \\
\text { SR\&ED-eligible activities }\end{array}$ & ITA 37(8)(a)(ii)(A)(I) & Not applicable \\
\hline
\end{tabular}

adapted from Bishop, Eck, Pringle \& Robinson, 2018

Under the traditional method, the cost of salaries or wages for employees who directly undertake, supervise, or support SR\&ED activities are eligible. In addition, labour or other 
expenditures that are all or substantially all attributable to SR\&ED activities may be deducted. In contrast, under the proxy method, the PPA replaces the overhead and other current expenditures that would be included under the traditional method. As a result, the traditional method is broader than the proxy method. Expenditures that are not eligible under the proxy method remain deductible as ordinary business expenses. 


\section{APPENDIX D - INTERVIEW GUIDE}

\section{A. Preamble}

- Introduction

- Presentation of study

- Discussion and obtain signature for informed consent

\section{B. Decision to engage in R\&D}

1. Does your firm engage in Research \& Development (R\&D)? Why or why not?

2. What is your decision-making process when making the decision?

3. What internal considerations did your firm make when making the decision?

a. Discuss resources, and systems and processes.

b. Discuss values, strategy, ownership, and management

4. What external considerations did the firm make when making the decision?

a. Discuss the competition

b. Discuss the market

c. Discuss the regulatory environment

5. Were there any other factors that your firm considered in the decision-making process?

6. Have you applied for Scientific Research and Experimental Development (SR\&ED) program?

a. Why or why not the SR\&ED program?

7. How did the firm make the decision to apply for the SR\&ED program?

a. Who was involved?

b. When the SR\&ED program details enter in the decision?

c. SR\&ED program important in the decision? How?

\section{Management of R\&D activities}

8. How do you manage R\&D?

9. Who is responsible for R\&D in the organization?

10.Does your firm have an R\&D department?

a. How many people are assigned to the R\&D department? Role of R\&D department? Role of individuals in R\&D activities? Full time vs part-time employees? Other responsibilities in addition to R\&D?

b. External support or internal?

11.Can you briefly describe your R\&D systems and processes?

12. How has your firm's experience with SR\&ED had an impact on your firm?

a. Its systems and processes? 
b. Scope of the projects that are eligible for SR\&ED determined?

c. Priorities set for projects that are eligible for SR\&ED?

d. Documentation to support activities and practices (in addition to T661)

13. Would you be willing to share your firm's T661 form?

\section{Wrap-up}

14.Do you have any questions or comments you would like to make? Is there anything we missed?

15. Wrap-up the interview and thank the participant for taking part in the interview. 


\section{APPENDIX E - LIST OF ECONOMIC DEVELOPMENT ORGANIZATIONS}

\section{List of Economic Development Organizations}

\begin{tabular}{|l|l|l|}
\hline Organization & Region & Website \\
\hline Invest Ottawa & Ottawa & investment.ocri.ca \\
\hline Communitech & Waterloo & communitech.ca \\
\hline Haltech & GTA - Halton, Oshawa, Milton & haltech.ca \\
\hline Innovate B.C. & British Columbia & innovatebc.ca \\
\hline Innovation Guelph & Guelph & innovationguelph.ca \\
\hline Innovate Niagara & Niagara & innovateniagara.com \\
\hline Launch Lab & Kingston & launchlab.ca \\
\hline MaRs & Toronto & marsdd.com \\
\hline $\begin{array}{l}\text { New Brunswick Innovation } \\
\text { Foundation }\end{array}$ & New Brunswick & nbif.ca \\
\hline Nova Scotia Business Inc. & Nova Scotia & \\
\hline RIC centre & Mississauga & novascotiabusiness.com \\
\hline Techalliance & London & riccentre.ca \\
\hline
\end{tabular}




\section{APPENDIX F - SAMPLE LETTER OF REQUEST FOR ASSISTANCE FROM EDOS}

\section{Carleton \\ U N I V E R S I T Y}

Canada's Capital University

Title: Scientific Research \& Experimental Development (SR\&ED) engagement and management by small Canadian-Controlled Private Corporations (CCPCs)

Date of ethics clearance: 11 July 2019

Ethics Clearance for the Collection of Data Expires: 31 July 2020

(Insert date)

Dear Sir or Madam,

My name is Lucille Perreault and I am a PhD student in the Sprott School of Business at Carleton University. I am working on a research project under the supervision of Professor Francois Brouard, DBA, FCPA, FCA.

I am writing to you today to request your assistance in a study on the Scientific Research \& Experimental Development (SR\&ED) tax incentives and small CanadianControlled Private Corporations (CCPCs). This study aims to better understand how CCPCs engage in Research and Development (R\&D) and SR\&ED and how they manage their SR\&ED practices.

I am seeking to interview small to medium firms that engage in R\&D (or not) and discuss their experience. Similarly, if any firms that engage in R\&D have not chosen to apply for the SR\&ED incentives, I would be interested in their motivations.

Given your organization's exposure to innovative firms in <insert region here>, I am requesting your assistance in providing some interested candidates for the study. It is my belief with a better understanding of the motivation and experiences of small to medium firms in Canada, the SR\&ED experience and program can be enhanced to better assist Canadian firms to develop innovation.

This study involves a 60-minute interview that will take place in a mutually convenient, safe location. With the participant's consent, interviews will be audiorecorded.

All research data, including audio-recordings and any notes will be password protected. Any hard copies of data (including any handwritten notes or USB keys) 
will be kept in a locked cabinet at Carleton University. Research data will only be accessible by the researcher and the research supervisor.

This project was reviewed and cleared by the Carleton University Research Ethics Board - A (\#111141). If you have any ethical concerns with the study, please contact Carleton University Research Ethics Board by phone at 613-520-2600 [ext. 2517] or by email at ethics@carleton.ca.

If you would like to assist in this research project, or have any questions, please contact me at lucille.perreault@carleton.ca.

Sincerely,

(Insert signature)

Lucille Perreault, MBA, CPA, CMA 


\section{Carleton \\ U N I V E R S I T Y}

Canada's Capital University

Title: Scientific Research \& Experimental Development (SR\&ED) engagement and management by small Canadian-Controlled Private Corporations (CCPCs)

Date of ethics clearance: 11 July 2019

Ethics Clearance for the Collection of Data Expires: 31 July 2020

(Insert date)

Dear Sir or Madam,

My name is Lucille Perreault and I am a PhD student in the Sprott School of Business at Carleton University. I am working on a research project under the supervision of Professor Francois Brouard, DBA, FCPA, FCA.

I am writing to you today to request your assistance in a study on the Scientific Research \& Experimental Development (SR\&ED) tax incentives and small CanadianControlled Private Corporations (CCPCs). This study aims to better understand how CCPCs engage in Research and Development (R\&D) and SR\&ED and how they manage their SR\&ED practices.

I am seeking your collaboration to identify employees in your firm who are involved in the decision to engage (or not) in R\&D and those who manage R\&D. Similarly, if your firm engages in R\&D but has chosen not to apply for the SR\&ED incentives, I would be interested your firm's motivations. It is my belief with a better understanding of the motivation and experiences of small to medium firms in Canada, the SR\&ED experience and program can be enhanced to better assist Canadian firms to develop innovation.

This study involves a 60-minute interview that will take place in a mutually convenient, safe location. With the participant's consent, interviews will be audiorecorded. We are also asking for your collaboration to share information on ongoing R\&D projects and the T661 SR\&ED application to assist in our research study. As this project will ask you about your firm's financials and R\&D projects, there may be some economic risks. While this risk is expected to be minimal, I will take precautions to protect the identity of the firm. This will be done by applying a pseudonym for all responses and allowing you to request that certain responses not 
be included in the final project.

All research data, including audio-recordings and any notes will be password protected. Any hard copies of data (including any handwritten notes or USB keys) will be kept in a locked cabinet at Carleton University. Research data will only be accessible by the researcher and the research supervisor.

This project was reviewed and cleared by the Carleton University Research Ethics Board - A (\#111141). If you have any ethical concerns with the study, please contact Carleton University Research Ethics Board by phone at 613-520-2600 [ext. 2517] or by email at ethics@carleton.ca.

If you would like to assist in this research project, or have any questions, please contact me at lucille.perreault@carleton.ca.

Sincerely,

(Insert signature)

Lucille Perreault, MBA, CPA, CMA 


\section{APPENDIX H - SAMPLE LETTER OF INVITATION TO KEY INFORMANT}

\section{Carleton}

U N I V E R S I T Y

Canada's Capital University

Title: Scientific Research \& Experimental Development (SR\&ED) engagement and management by small Canadian Controlled Private Corporations (CCPCs)

Date of ethics clearance: 11 July 2019

Ethics Clearance for the Collection of Data Expires: 31 July 2020

(Insert date)

Dear Sir or Madam,

My name is Lucille Perreault and I am a PhD student in the Sprott School of Business at Carleton University. I am working on a research project under the supervision of Professor Francois Brouard, DBA, FCPA, FCA.

I am writing to you today to invite you to participate in a study on the Scientific Research \& Experimental Development (SR\&ED) tax incentives and small CanadianControlled Private Corporations (CCPCs). This study aims to better understand how CCPCs engage in SR\&ED and how they manage their SR\&ED practices.

This study involves one 60-minute interview that will take place in a mutually convenient, safe location. With your consent, interviews will be audio-recorded.

As this project will ask you about your firm's financials and R\&D projects, there may be some economic risks. While this risk is expected to be minimal, I will take precautions to protect the identity of the firm. This will be done by applying a pseudonym for all responses and allowing you to request that certain responses not be included in the final project.

You have the right to end your participation in the study at any time, for any reason, up until two weeks after the interview. You can withdraw by phoning or emailing the researcher or the research supervisor. If you withdraw from the study, all information you have provided will be destroyed.

All research data, including audio-recordings and any notes will be encrypted. Any hard copies of data (including any handwritten notes or USB keys) will be kept in a locked cabinet at Carleton University. Research data will only be accessible by the researcher and the research supervisor. 
This project was reviewed and cleared by the Carleton University Research Ethics Board - A (\#111141). If you have any ethical concerns with the study, please contact Carleton University Research Ethics Board by phone at 613-520-2600 [ext. 2517] or by email at ethics@carleton.ca.

If you would like to participate in this research project, or have any questions, please contact me at lucille.perreault@carleton.ca.

Sincerely,

(Insert signature)

Lucille Perreault, MBA, CPA, CMA 


\section{APPENDIX I - SAMPLE CONSENT FORM FIRMS}

\section{Carleton}

U N I V E R S I T Y

Canada's Capital University

Title: SR\&ED engagement and management by small Canadian Controlled Private Corporations (CCPCs)

Date of ethics clearance: 11 July 2019

Ethics Clearance for the Collection of Data Expires: 31 July 2020

Firm, chooses to participate in a study on the Scientific Research \& Experimental Development (SR\&ED) program. This study aims better understand how CCPCs engage in SR\&ED and how they manage their SR\&ED practices.

The researcher for this study is Lucille Perreault in the Sprott School of Business. She is working under the supervision of Professor Francois Brouard in the Sprott School of Business.

This study involves 60-minute interviews with employees or management identified by your firm. With your firm's and participant's permission, these interviews will be audio-recorded. Once the recording has been transcribed, the audio-recording will be destroyed.

As this project will ask you about your firm's financials and R\&D projects. As a result, there may be some competitive risks. While this risk is expected to be minimal, I will take precautions to protect the identity of the firm. This will be done by applying a pseudonym for all responses and allowing you to request that certain responses not be included in the final project.

You have the right to end your firm's participation in the study at any time, for any reason, up until 2 weeks after the interview/s. You can withdraw by phoning or emailing the researcher or the research supervisor. If your firm chooses to withdraw from the study, all information you have provided will be destroyed.

All research data, including audio-recordings and any notes will be password protected. Any hard copies of data (including any handwritten notes or USB keys) will be kept in a locked cabinet at Carleton University. Research data will only be accessible by the researcher and the research supervisor. 
Once the project is completed, all research data will be kept for five years and potentially used for other research projects on this same topic. At the end of five years, all research data will be securely destroyed. (Electronic data will be erased and hard copies will be shredded.)

If you would like a copy of the summary of the research findings, you are invited to contact the researcher to request an electronic copy which will be provided to you.

This project was reviewed and cleared by the Carleton University Research Ethics Board - A (\#111141). If you have any ethical concerns with the study, please contact Carleton University Research Ethics Board by phone at 613-520-2600 [ext. 2517] or by email at ethics@carleton.ca.

Researcher contact information:

Lucille Perreault, MBA, CPA, CMA

Sprott School of Business

Carleton University

Tel: $\quad 613$ 983-5822

Email: lucille.perreault@carleton.ca

\section{Supervisor contact information:}

Francois Brouard, DBA, FCPA, FCA

Sprott School of Business

Carleton University

Tel: (613) 520-2600, ext. 2213

Email: francois.brouard@carleton.ca

Do you agree to be audio-recorded:

Yes No

Would you like a copy of the summary of the research findings:

Yes No

Would your firm be willing to share their T661 SR\&ED expenditure claim form: Yes No

Signature of <insert title>

Date

Date 


\section{APPENDIX J - SAMPLE CONSENT FORM INDIVIDUALS}

\section{Carleton}

U N I V E R S I T Y

Canada's Capital University

Title: SR\&ED engagement and management by small Canadian Controlled Private Corporations (CCPCs)

Date of ethics clearance: 11 July 2019

Ethics Clearance for the Collection of Data Expires: 31 July 2020

I choose to participate in a study on the Scientific Research \& Experimental Development (SR\&ED) program. This study aims better understand how CCPCs engage in SR\&ED and how they manage their SR\&ED practices.

The researcher for this study is Lucille Perreault in the Sprott School of Business. She is working under the supervision of Professor Francois Brouard in the Sprott School of Business.

This study involves one 60-minute interview. With your consent, interviews will be audio-recorded. Once the recording has been transcribed, the audio-recording will be destroyed.

As this project will ask you about your firm's financials and R\&D projects. As a result, there may be some competitive risks. While this risk is expected to be minimal, I will take precautions to protect the identity of the firm. This will be done by applying a pseudonym for all responses and allowing you to request that certain responses not be included in the final project.

You have the right to end your participation in the study at any time, for any reason, up until 2 weeks after the interview. You can withdraw by phoning or emailing the researcher or the research supervisor. If you withdraw from the study, all information you have provided will be destroyed.

All research data, including audio-recordings and any notes will be password protected. Any hard copies of data (including any handwritten notes or USB keys) will be kept in a locked cabinet at Carleton University. Research data will only be accessible by the researcher and the research supervisor. 
Once the project is completed, all research data will be kept for five years and potentially used for other research projects on this same topic. At the end of five years, all research data will be securely destroyed. (Electronic data will be erased and hard copies will be shredded.)

If you would like a copy of the summary of the research findings, you are invited to contact the researcher to request an electronic copy which will be provided to you.

This project was reviewed and cleared by the Carleton University Research Ethics Board - A (\#111141). If you have any ethical concerns with the study, please contact Carleton University Research Ethics Board by phone at 613-520-2600 [ext. 2517] or by email at ethics@carleton.ca.

Researcher contact information:

Lucille Perreault, MBA, CPA, CMA

Sprott School of Business

Carleton University

Tel: $\quad 613$ 983-5822

Email: lucille.perreault@carleton.ca

\section{Supervisor contact information:}

Francois Brouard, DBA, FCPA, FCA

Sprott School of Business

Carleton University

Tel: (613) 520-2600, ext. 2213

Email: francois.brouard@carleton.ca

Do you agree to be audio-recorded:

Yes

No

Would you like a copy of the summary of the research findings:

Yes

No

Signature of participant

Date

Lucille Perreault

Date 